Florida International University

FIU Digital Commons

\title{
Indigenous Water Governance in the Anthropocene: Non- Conventional Hydrosocial Relations Among the Wayuu of the Guajira Peninsula in Northern Colombia
}

\author{
David A. Robles
}

Florida International University, drobl016@fiu.edu

Follow this and additional works at: https://digitalcommons.fiu.edu/etd

Part of the Social and Cultural Anthropology Commons

\section{Recommended Citation}

Robles, David A., "Indigenous Water Governance in the Anthropocene: Non-Conventional Hydrosocial Relations Among the Wayuu of the Guajira Peninsula in Northern Colombia" (2020). FIU Electronic Theses and Dissertations. 4416.

https://digitalcommons.fiu.edu/etd/4416

This work is brought to you for free and open access by the University Graduate School at FIU Digital Commons. It has been accepted for inclusion in FIU Electronic Theses and Dissertations by an authorized administrator of FIU Digital Commons. For more information, please contact dcc@fiu.edu. 


\section{FLORIDA INTERNATIONAL UNIVERSITY}

Miami, Florida

INDIGENOUS WATER GOVERNANCE IN THE ANTHROPOCENE: NONCONVENTIONAL HYDROSOCIAL RELATIONS AMONG THE WAYUU OF THE GUAJIRA PENINSULA IN NORTHERN COLOMBIA

A dissertation submitted in partial fulfillment of the requirements for the degree of DOCTOR OF PHILOSOPHY in

GLOBAL AND SOCIOCULTURAL STUDIES

by

David Robles 
To: Dean John F. Stack, Jr.

Steven J. Green School of International and Public Affairs

This dissertation, written by David Robles, and entitled Indigenous Water Governance in the Anthropocene: Non-Conventional Hydrosocial Relations Among the Wayuu of the Guajira Peninsula in Northern Colombia, having been approved in respect to style and intellectual content, is referred to you for judgment.

We have read this dissertation and recommend that it be approved.

$\begin{array}{r}\hline \text { Elizabeth Anderson } \\ \hline \text { Kevin Grove } \\ \hline \text { Dennis Wiedman } \\ \hline \text { Juliet Erazo, Major Professor }\end{array}$

Date of Defense: March 23, 2020

The dissertation of David Robles is approved.

Dean John F. Stack, Jr. Steven J. Green School of International and Public Affairs

Andrés G. Gil

Vice President for Research and Economic Development and Dean of the University Graduate School

Florida International University, 2020 


\section{DEDICATION}

I dedicate this dissertation to my parents, Orlando and Mary, for always believing in me and for their unwavering support. I look up to you both and I hope I make you proud as much as you make me proud.

And to my wife Edith, son Shane, and daughter Leilani, I have learned so much

from you about life, love and about being a kid at heart. I hope I inspire you as much as you inspire me. 


\section{ACKNOWLEDGMENTS}

Firstly, I would like to acknowledge the Wayuu people for inspiring me to explore their intimate relationship with water. I thank the Wayuu inhabitants of Mayapo, Cardón, Irraipa and members of several other communities on the Guajira Peninsula that took the time to share with me their knowledge, concerns and hopes about water and life. I hope my dissertation contributes to the positive recognition of the Wayuu society's relationship with this vital liquid.

I want to recognize the work of my field assistants, co-workers and Wayuu translators in La Guajira, Colombia: Jasai Pérez, Nelvis Ipuana, Arnoldo Pimienta, Aida Kuast, Erika Muñoz, Clemencia Pushaina, Elidys Herrera and Margelis Illidge. Without them, information gathering would have been impossible. I appreciate the cooperation of the Cerrejón Foundation for Progress of La Guajira for allowing me to use information from the project "Design of a Sustainability Strategy for Five Water Supply Systems in the Wayuu Communities of La Gran Vía, Kaiwa, Kaleruwou, Jotomana and Utaykalamana in the Colombian Upper Guajira." I want to recognize the passion and work ethic of the project manager Orlando Scoppetta and the project coordinator Mildred Nájera. The project introduced me to the complexity of water interventions in Wayuu territory and motivated me to deepen my understanding of the topic through doctoral research.

Thank you to Dr. Alexis Carabalí and Dr. Martha Ligia Castellanos of the SemiArid Territories of the Caribbean Research Group of the University of La Guajira. I appreciate their continued support and for giving me the opportunity to work with them on the Colciencias project "Guidelines for the Coastal and Marine Territorial Ordering in 
the Province of La Guajira based on its Cultural Diversity." This experience allowed me to visit several distant Wayuu communities that add breadth to my dissertation research.

A special thank you to my committee members, Dr. Juliet Erazo, Dr. Elizabeth Anderson, Dr. Kevin Grove and Dr. Dennis Wiedman. I have learned a great deal about being a dedicated, well-rounded scholar through your teaching, advising, writing and professionalism. I especially want to thank my adviser, Dr. Juliet Erazo, for her mentorship during my time at FIU and for the time and effort she dedicated to improving my dissertation. I feel lucky to have had her as my adviser and to have been part of such a dynamic department and a great cohort.

Much of my dissertation writing was done in my aunt's apartment overlooking the central plaza in Riohacha, Colombia. Day after day, the tranquility of her home, her encouragement and endless supply of coffee and fruit truly made dissertation writing enjoyable. Gracias, Tía Pau! I also broadened my professional skills by entering the wonderful world of map making. Thank you to Sheyla Santana at the FIU GIS Center and fellow grad students Melissa Bernardo, Karina Livingston and Adrian Cetina for helping me out. Finally, I want to acknowledge those who funded my doctoral studies, conference trips, dissertation fieldwork and dissertation writing: Florida International University's UGS Graduate Assitantship, the FIU Doctoral Year Fellowship, the Steven J. Green School of International and Public Affairs, the Global and Sociocultural Studies Department, the Graduate \& Professional Student Committee and the Tinker Foundation.

Thank you to all for giving me the opportunity to expand my knowledge and appreciation of the Wayuu world. 


\begin{abstract}
OF THE DISSERTATION
INDIGENOUS WATER GOVERNANCE IN THE ANTHROPOCENE: NONCONVENTIONAL HYDROSOCIAL RELATIONS AMONG THE WAYUU OF THE GUAJIRA PENINSULA IN NORTHERN COLOMBIA
\end{abstract}

\author{
by
}

David Robles

Florida International University, 2020

Miami, Florida

Professor Juliet Erazo, Major Professor

The dissertation problematizes the supremacy of a global water management regime while discerning and defending local Wayuu hydrosocial relations. The Wayuu relationship with water-considered non-conventional, unsanitary or insecure according to hegemonic Western standards - can also be characterized positively as alternative, resilient, sustainable, adaptive and exceptional. Contemporary water governance presents challenges yet also opportunities for the Wayuu and other Indigenous peoples to (re)assert and (re)establish contextualized and culturally specific practices, traditions and ways of knowing that have been historically silenced by conventional water management.

The Wayuu territory, located on the semi-arid Guajira Peninsula in northern Colombia, is widely considered a region suffering from chronic food and water insecurity, aggravated by climate change and exacerbated by widespread corruption and political instability. In response, a conventional approach presumes that the Wayuu are in urgent need of assistance and the solution to the water problem lies in installing waterworks; instructing the Wayuu in acceptable water, sanitation and hygiene behaviors; and 
instilling good water governance practices. I argue that this common discourse is a representation of reality that uses epistemological assumptions, vested authority, rhetoric and specialized terminology to present a dominant —yet deceptive and partial—depiction of Wayuu-water relations.

While some resource management experts are confident that integration is possible between Indigenous and Western knowledge systems, critical social scientists from political ecology and ontological anthropology find bridging initiatives problematic. While political ecology emphasizes the politics and contested nature of water accessibility between different social actors, ontological anthropology underscores the deep ontological divide that impedes mutual understanding and integration of water knowledge systems. Informed by the debates in these fields, I use ethnographic evidence from over 80 Wayuu communities, including survey data, mapping, semi-structured interviews, participant observation and discourse analysis, to explore the (in)commensurability between "non-conventional" Wayuu hydrosocial relations and the dominant conventional water management regime. The dissertation research found that a generalized pattern of failed or faulty water development projects throughout Wayuu territory meant to increase water security often produce water insecurity and increased vulnerability, further exacerbating the precarity caused by anthropogenic climatic change. 


\section{INTRODUCTION - THE (IM)POSSIBILITY OF BRIDGING WESTERN AND}

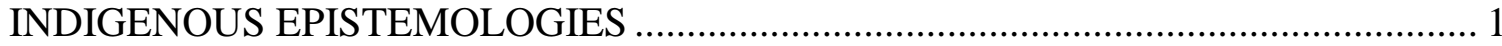

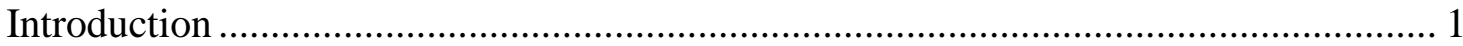

Scrutinizing universality and the right to be different............................................. 7

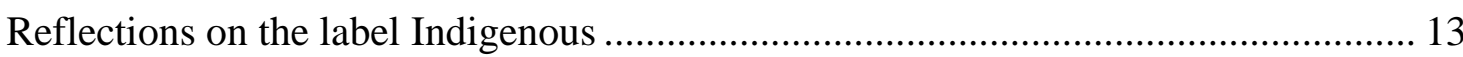

Critical social theory from the Global South ................................................................ 19

Legibility and commensurability of Indigenous knowledges and cultures ................... 22

Political ecology and environmental management power struggles ............................. 25

Relational ontology and the incommensurability of alterity ....................................... 29

Critiquing the conventional approach of Western science and management................. 38

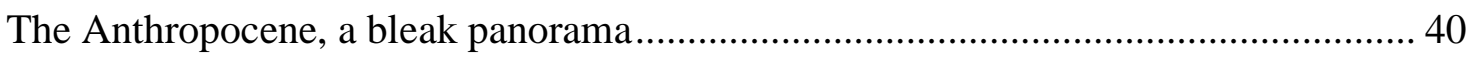

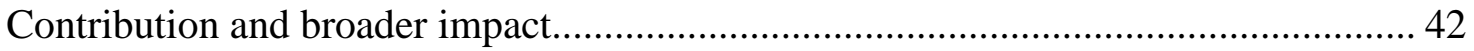

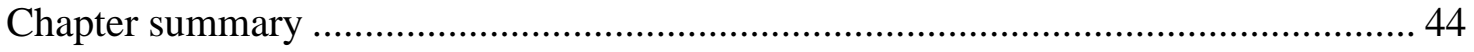

II. PERSONAL EPISTEME, METHODS AND THEORETICAL BIAS ....................... 48

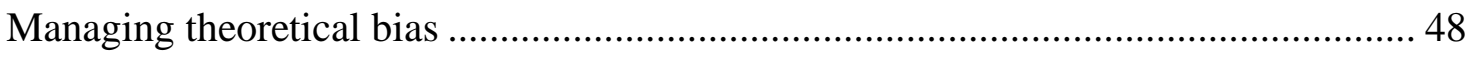

Methodology, Phase I: Antecedents ....................................................................... 53

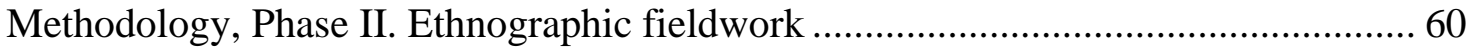

Methodology, Phase III. Ethnographic and ethnohistoric data analysis ....................... 74

III. THE WAYUU PEOPLING OF THE GUAJIRA PENINSULA …………………...... 76

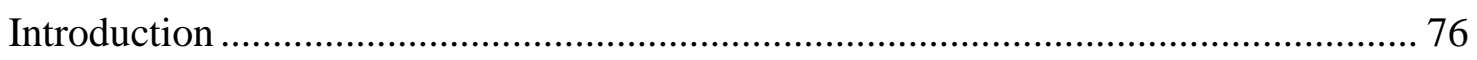

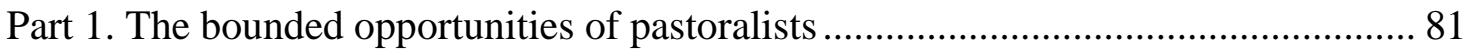

The Kuria of northern Tanzania …………........................................................... 87

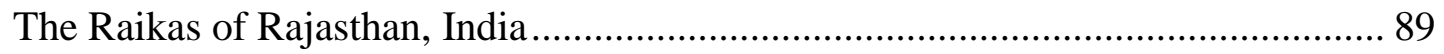

The Diné pastoralists of the American Southwest.................................................... 95

Part 2. The Rise of the pastoralist Wayuu ................................................................. 99

Scholarly work on the Wayuu ................................................................................. 99

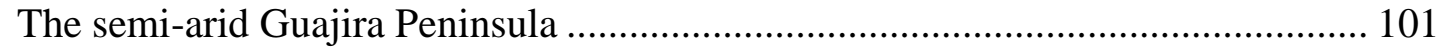




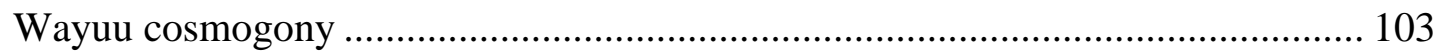

The pre-Hispanic past of the Guajira Peninsula ..................................................... 104

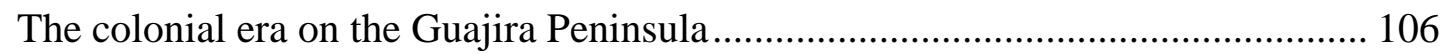

Mayapo, an example of Wayuu modernity ………………………………….... 112

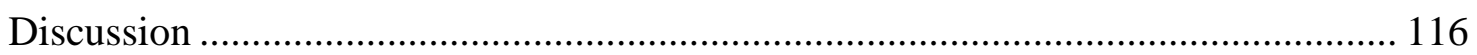

IV. THE CONVERGENCE OF MULTIPLE SCALES OF WATER GOVERNANCE

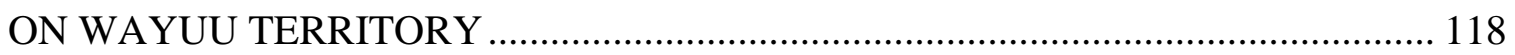

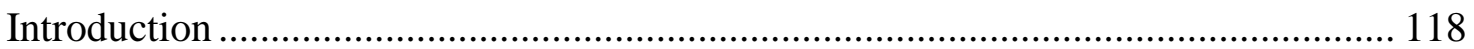

Global water governance............................................................................... 123

National water governance........................................................................ 128

Provincial water governance ……….............................................................. 130

Private sector and NGO water governance ………….......................................... 132

Community-level Wayuu water governance …………......................................... 135

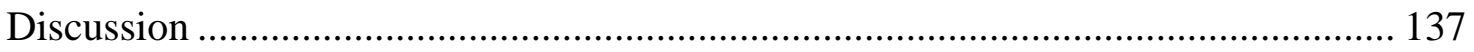

V. WAYUU WATER KNOWLEDGE AND HYDROSOCIAL RELATIONS ............. 139

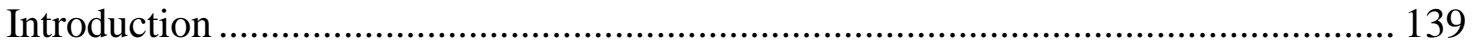

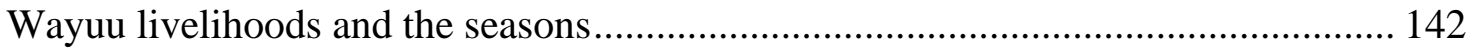

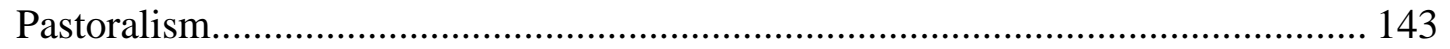

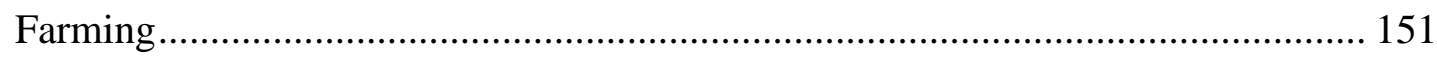

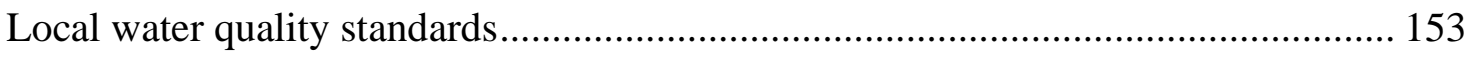

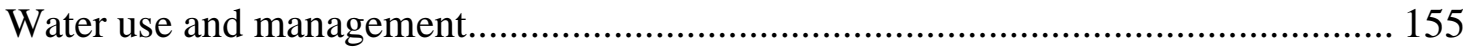

Seasonality of water sources in Irraipa and Cardón.................................................. 158

Water gathering in Cardón and Irraipa................................................................ 164

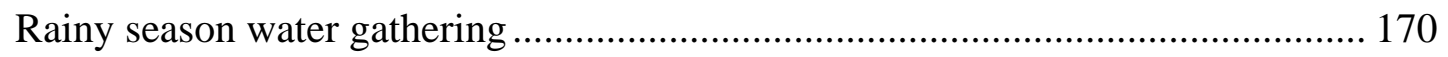

Dry season water gathering ............................................................................... 174

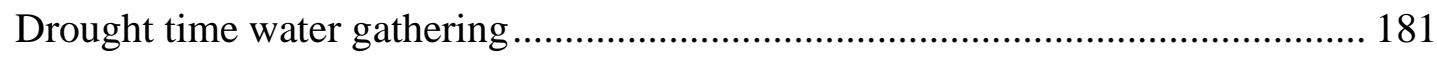

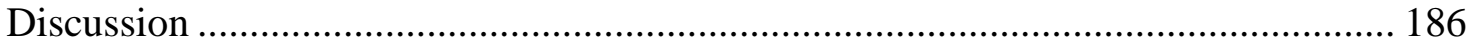

A conventional interpretation of Wayuu-water relations........................................ 186

A political ecology interpretation of Wayuu-water relations ................................... 194

A relational ontology interpretation of Wayuu-water relations ................................ 197 


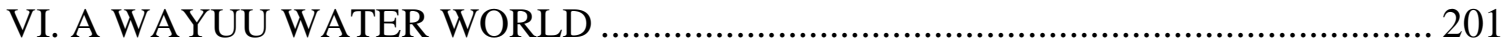

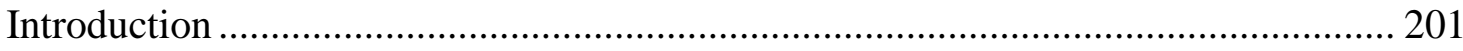

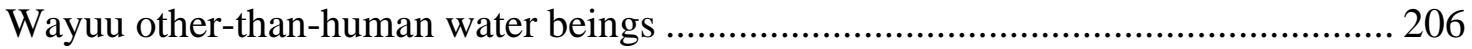

Perrin's ethnographic data and analysis from the 1970s ............................................. 207

Paz Ipuana's ethnographic data from the 1970s......................................................... 209

Contemporary Wayuu conceptions of Pulowi and Juyá in Mayapo ........................... 212

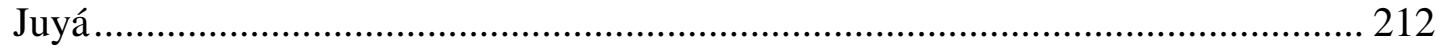

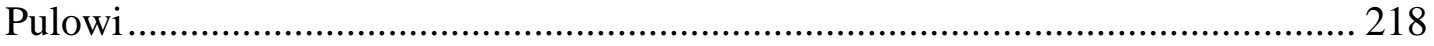

An Interview with Ocari Pushaina, the outsü (shaman) of Mayapo........................ 220

An interview with Malena, the Pulowi of the pond.................................................. 223

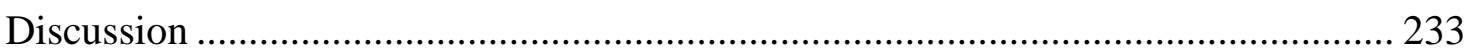

VII. FAILED WATER INTERVENTIONS AND WHITE ELEPHANTS ON

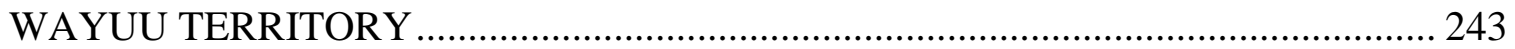

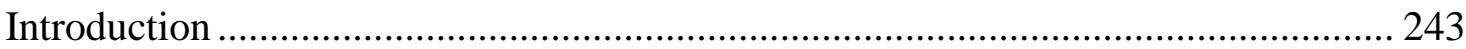

Why water security is water insecurity and vice versa ............................................ 244

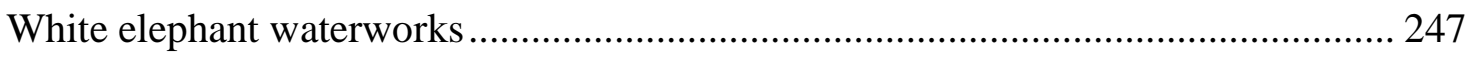

Six examples of failed or faulty waterworks ......................................................... 250

Mayapo's malfunctional water supply system .......................................................... 257

The technical non-feasibility of provisioning the Upper Guajira with purified water 269

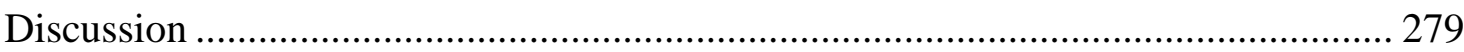

VIII. CONCLUSION - INDIGENOUS WATER GOVERNANCE IN THE

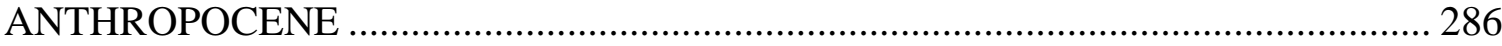

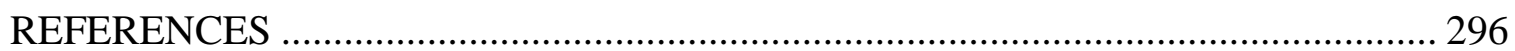

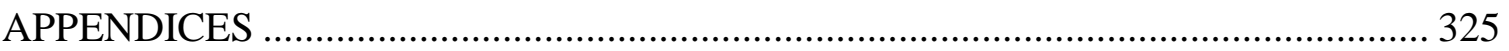

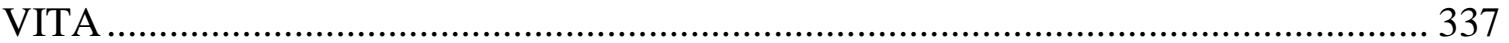




\section{LIST OF FIGURES}

FIGURE

PAGES

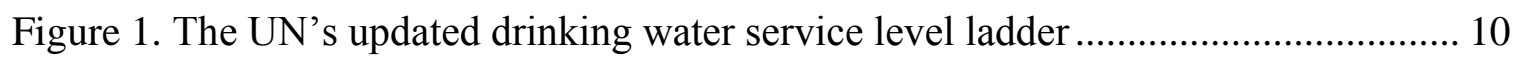

Figure 2. Word cloud with the most frequent words used by Wayuu interviewees ......... 66

Figure 3. Ms. Olga Rodríguez (left) who kindly received Margelis (right) and me........ 71

Figure 4. Mr. Ipuana, the traditional authority and his wife Mrs. Epieyu, Mayapo’s

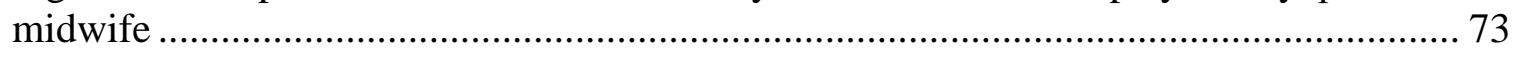

Figure 5. Mother, Zoila, and son, Samuel. A member of the Epieyu Clan is born. ......... 73

Figure 6. Water governance and its four ranges .............................................. 120

Figure 7. Two water governance moments, actors and places in Wayuu territory......... 122

Figure 8. Human and livestock populations in Irraipa, Cardón and Mayapo ................. 144

Figure 9. Estimated human and livestock water use in the three study areas ................ 150

Figure 10. Herder watering his sheep in the community of Pasadena ......................... 157

Figure 11. Wayuu modes of transporting water.................................................... 169

Figure 12. Fencing and troughs around the Irraipa Reservoir (August 2015) ............... 179

Figure 13. Ocari Pushaina, the outsü of Mayapo ................................................. 221

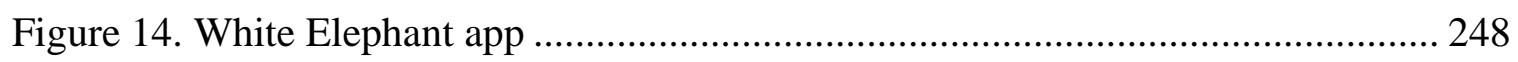

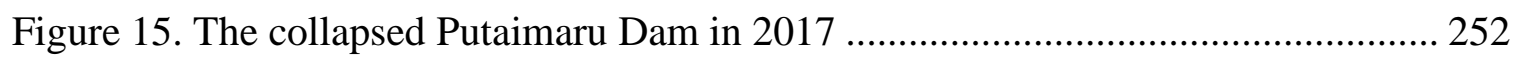

Figure 16. Punta Espada's damaged solar powered drilled well (May 2018) ............... 254

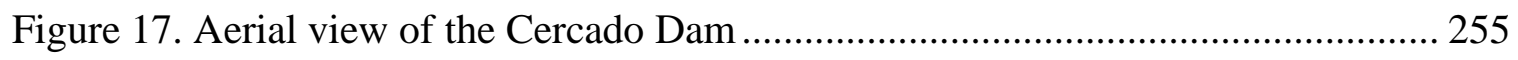

Figure 18. Mayapo's inoperative (left) and operative (right) elevated water tanks....... 257

Figure 19. Mr. López unearthing his unused water meter ....................................... 258

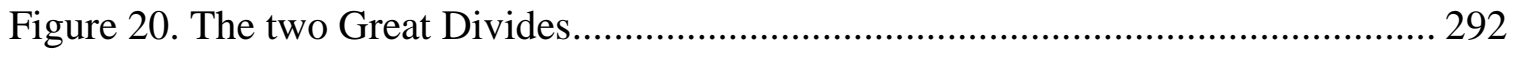




\section{LIST OF MAPS}

MAPS

PAGES

Map 1. La Guajira Peninsula with fieldwork sites......................................................... 62

Map 2. The Guajira Peninsula, the northernmost point of South America..................... 106

Map 3. Daily water gathering trips in Cardón during the rainy season ........................... 171

Map 4. Daily water gathering trips in Irraipa during the rainy season .......................... 173

Map 5. Daily water gathering trips in Cardón during the dry season ............................ 176

Map 6. Daily water gathering trips in Irraipa during the dry season .............................. 177

Map 7. Daily water gathering trips in Cardón during times of drought ......................... 183

Map 8. Daily water gathering trips in Irraipa during times of drought........................... 184

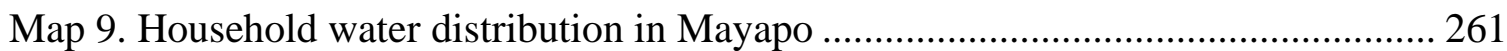




\section{LIST OF ABBREVIATIONS AND ACRONYMS}

DANE Dirección Nacional de Estadística (National Statistics Agency, Colombia)

DPS Departamento de Prosperidad Social (Department of Social Prosperity, Colombia)

IPCC Intergovernmental Panel on Climate Change

IWRM Integrated Water Resources Management

MCD modernity/coloniality/decoloniality

SDG Sustainable Development Goal

TEK Traditional Ecological Knowledge

USAID United States Agency for International Development

UNDP United Nations Development Program

WFP World Food Program

WHO World Health Organization 


\section{LIST OF COMMON WORDS USED IN WAYUUNAIKI AND SPANISH WITH THEIR ENGLISH TRANSLATION}

$\begin{array}{ll}\text { Alijuna } & \begin{array}{l}\text { Common translation: Non-Wayuu, non-Indigenous. Less common } \\ \text { translation: "People who cause pain." Pronounced ah-li-hoo-na }\end{array} \\ \text { Asheyu } & \text { Wayuu shaman's helping spirit. Pronounced ah-sheh-yu } \\ \text { Cardón } & \text { Wayuu village district where fieldwork was conducted } \\ \text { Chirrinchi } & \text { Distilled liquor using hardened sugar cane molasses } \\ \text { Irraipa } & \text { Wayuu village district where fieldwork was conducted } \\ \text { Juyá } & \quad \text { Rain. Supreme rain being. A male other-than-human person. Year. } \\ \text { Mayapo } & \text { Wayuu village district where fieldwork was conducted } \\ \text { Outsü } & \text { Wayuu shaman (feminine form) } \\ \text { Pulowi } & \text { Water being, a female other-than-human person } \\ \text { Yanama } & \text { Collective work }\end{array}$




\section{INTRODUCTION - THE (IM)POSSIBILITY OF BRIDGING WESTERN AND INDIGENOUS EPISTEMOLOGIES}

The native people who inhabit the Guajira, the Wayuu, live in conditions so precarious that their very name has become a kind of shorthand in Colombia for extreme poverty... Gnawing hunger and thirst never leave the Wayuu.

The Washington Post, August 7, 2017

Representations of the racialized Other, however "accurate" or "inaccurate" they may be, however "undistorted" or "exaggerated and oversimplified" they may be, however much they may erase or suppress or fabricate, are always social facts in themselves"

The Past is Not Dead (Pred, 2004, 4)

Introduction

Most Colombian alijuna (non-Wayuu) experts and laymen agree that the situation of the Guajira Peninsula in northern Colombia is one of chronic food and water insecurity, exacerbated by persistent droughts, widespread corruption and political instability in the region. In 2017, the Colombian Constitutional Court's Ruling T-302 affirmed the state of affairs in the province of La Guajira was unconstitutional due to the mass and systematic violation of the fundamental rights of Wayuu boys and girls, specifically their interrelated rights to food, water and health (Corte Constitucional 2017). Over the last ten years the prolonged droughts and deaths of Wayuu children have received increased media coverage, prompting numerous international humanitarian agencies, NGOs and government agencies to converge on the peninsula to provide aid and devise solutions to the perceived precarious living conditions of the Indigenous ${ }^{1}$ inhabitants of this territory.

\footnotetext{
${ }^{1}$ Throughout the dissertation I capitalize the term Indigenous when referring to the native peoples of a land, who are also known as First Nation, Native American, Indian or Aboriginal. I adopt this usage as a sign of respect to Indigenous peoples and to distinguish it from the more general definition of indigenous by
} 
The Wayuu territory has become a site of competing interests and perspectives on how to best provide and manage water for this pastoralist society. Each Wayuu community targeted for assistance in the form of water services, infrastructure and expertise engages with these powerful external entities with a certain amount of trepidation, following a fraught history of water development and other negative encounters between the Wayuu and alijuna (non-Wayuu) in the near and distant past. Case in point, the Wayuu scholar Rafael Mercado translates the term alijuna as "people who cause pain" - a widely known meaning of the term among the Wayuu, but not among the non-Wayuu — that encapsulates the collective sentiment among this Indigenous group of a long history of oppression and marginalization by the dominant non-Indigenous populace (Mercado Epieyu 2017, 24).

The portrayals of the Wayuu and the local water situation have been one-sided by news, development and academic sources, for the most part depicting a negative situation threatening the existence of the Wayuu society. As the first epigraph shows, the Wayuu are often described in the media as victims of state abandonment and political corruption, poor, uneducated, underdeveloped, undernourished, unruly and politically unorganized. To simplify a complex situation, the general consensus among non-Wayuu (and some of the Wayuu individuals who have taken on the role of representing the Wayuu) is that 1) there is a current food and water crisis in the Wayuu territory; 2) the Wayuu are in urgent need of assistance; and 3) the solution to the water problem lies in installing waterworks; instructing the Wayuu in acceptable water, sanitation and hygiene (WASH) behaviors;

\footnotetext{
Webster's Dictionary: "produced, growing, living, or occurring natively or naturally in a particular region
} or environment." 
and instilling good governance practices. As I will demonstrate, this common discourse is a representation of reality that uses epistemological assumptions, vested authority, rhetoric and specialized terminology to present a dominant—albeit deceptive and partial—depiction of Wayuu hydrosocial relations. By using the term hydrosocial relations, I align my research with political ecologists of water, Jamie Linton and Jessica Budds who "seek to transcend the dualistic categories of 'water' and 'society', and employ a relational-dialectic approach to demonstrate how instances of water become produced and how produced water reconfigures social relations" $(2014,171)$.

Throughout the dissertation, I will scrutinize the above truth claims to the "food and water crisis in Wayuu territory" by placing three approaches in conversation with each other: a conventional scientific approach, a political ecology approach and a relational ontology approach. Each approach has its merits and limitations, of which I also hope to convey with the intention of reducing my theoretical bias and putting into practice what Santos has termed the ecology of knowledges. He warns, "to learn certain forms of knowledge may lead to forgetting others, and ultimately, becoming ignorant of them" (Santos 2011,36). My intention is not to romanticize the Wayuu way of life or argue that the Wayuu people have overcome the political, environmental or economic adversities present in the region. Rather, I wish to portray a people whose relationship with water-considered non-conventional, unsanitary or insecure according to Western hegemonic standards — can also be characterized positively as alternative, resilient, sustainable, adaptive and exceptional.

Therefore, I adopt a cultural relativist stance that rejects the universality of dominant modes of knowing and interacting with water. Cultural relativism is an 
anthropological concept developed in the early $20^{\text {th }}$ century by Franz Boas - considered the founding father of American anthropology — and popularized by his students Margaret Mead, Ruth Benedict and Melville Herskovits (Brown 2008, 364). Brown identifies three categories of cultural relativism: methodological, cognitive and moral relativism. I applied the three types of relativism while conducting fieldwork and documenting my findings. Using methodological relativism, I intentionally suppressed passing judgment on the beliefs and practices I witnessed and recorded. During my ethnographic writing and analysis, I uphold the axiom of cognitive relativism that "members of different societies live in different and incommensurable knowledge worlds" (ibid, 367). This axiom explicitly links the tenets of relational ontology within anthropology's much older concept of cultural relativism. Finally, I apply moral relativism by insisting that, "each people's values are sui generis and self-validating, requiring that outsiders assess them by that group's own standard rather than by a universal one" (ibid).

The Guajira Peninsula, the northernmost region of Colombia and of South America, is the ancestral territory of the Wayuu people, who number approximately 380,460 in Colombia and 413,437 in Venezuela (DANE 2019; INE 2011). The Wayuu provide a lesser known example of a tribal society that has flourished in a place where high temperatures and low rainfall produce an arid terrain with conditions that can be conventionally characterized as water insecure, even inhospitable. From a cultural ecology approach — which arose in the mid- $20^{\text {th }}$ century from the work of anthropologist Julian Steward - the term adaptation was used to describe how entire cultures adapted to environments, as expressed through their subsistence practices, technology, 
environmental knowledge, and family organization (Tucker 2013, 144). Consequently, the Wayuu people's cultural and biological adaptation over hundreds of years to the biophysical conditions of the arid peninsula ascribes them authoritative status on how to survive and thrive in this dry environment. Therefore, we must question when experts from other regions, principally urban dwellers from Colombia's Andean region or the Global North ${ }^{2}$, come to La Guajira with the intention of assisting and teaching a traditionally desert-dwelling people how to be more resilient in their desert environment. In a hypothetical egalitarian world, one could envision these same Western experts flocking to Wayuu territory not to impart training and resources but to receive guidance from the Wayuu on matters relating to water rights, water conservation, water spirituality, water knowledge and a wide range of traditions and practices that the Wayuu maintain and that maintain the Wayuu.

The water scarce Guajira Peninsula compels the Wayuu to center their attention on water management. However, Wayuu knowledge of rain, for instance, goes well beyond its meteorological attributes and its causal relationship with plants, animals and water sources. The meaning of rain for the Wayuu contains more than the standard definition of it and differs from a Western city-dweller's understanding of rain, who may not associate it with survival, abundance or misfortune. Emotionally, for the Euro-North American urbanite, rain may not fill his or her thoughts and emotions with worries, joy,

\footnotetext{
${ }^{2}$ I consider the Global North synonymous to First World, the West and developed countries while Global South is synonymous to Third World, underdeveloped, developing or less developed countries. I agree with Santos' definition of the Global South as "the social classes and groups that have systematically suffered the unjust inequalities and discriminations caused by capitalism and colonialism. The Global South is therefore not a geographic concept, even though the vast majority of these populations live in counties in the Southern Hemisphere" $(2011,35)$.
} 
anger, longing or other sentiments as it does with a Wayuu individual. Rain is linked with various Wayuu spheres of life including the arts (song, dance, stories), cosmology, social organization, masculinity, values, emotions, the afterlife, the passing of time- juyá, the word for rain, also signifies year - as well as most of their subsistence practices. In this sense, the often-heard term "water is life" among the Wayuu and other Indigenous peoples encapsulates an entire worldview in three words but its profoundness rests on the meaning ascribed to each word by the listener.

This dissertation examines the convergences and divergences between Western conventional water representations and those derived from "non-conventional" Wayuuwater relations. Using relational ontology and political ecology, I seek to identify the limits of Wayuu autonomy and agency in maintaining their local or "traditional" water relations and where external political forces, structural violence and inequality become determining factors in the availability of water. These perspectives are employed without disregarding Western climate science and water resources management (conventional approaches). Information from these areas of expertise are essential to better understand the causes and effects of the "natural" forces affecting water availability on Wayuu territory.

It is also necessary to question the validity of alarmist and cynical statements that describe the Wayuu society and livelihood as precarious or pitiful, such as the first epigraph and converting these representations of the "other" into "social facts" as noted in the second epigraph. I dispute these sweeping, denigrating generalizations by using empirical evidence from over 80 Wayuu communities and theoretical arguments from the critical social sciences. The marked absence in the media and gray literature of any 
positive reflections on Wayuu-water relations, ecological knowledge, adaptive strategies and belief/knowledge systems contrasts with the academic and humanistic literature where these more appreciative stances abound.

By questioning the dominant modernist discourse, my stance may seem antithetical to the advancement of the human right to water, specifically the UN's $6^{\text {th }}$ Sustainable Development Goal (SDG), to ensure availability and sustainable management of water and sanitation for all. In order to contest a seemingly unquestionable human right, I employ political ecology and relational ontology to disrupt the paradigmatic pursual of universal human rights based on Western scientific and moral standards that delegitimize the multiplicity of culturally specific standards. The true challenge of my argument will be to distinguish and analyze to what extent local practices are intrinsic to Wayuu culture and society as opposed to those practices that are a reaction to or consequence of impositions and marginalization because of unequal power relations, both interethnic and intraethnic.

Scrutinizing universality and the right to be different

Currently, there is greater public and institutional acceptance of cultural diversity. Contemporary Indigenous peoples in Colombia and globally have gained ground in territorial rights and self-determination, notably in various national constitutions, international conventions, UN declarations and other national and international doctrines and legislation. Indigenous peoples' overwhelming contribution to humanity's cultural and linguistic diversity, as well as a growing understanding of the correlation between Indigenous territories and biodiversity, have been scientifically documented (Maiero and Shen 2004; Gorenflo et al. 2012) and promoted by governing bodies (for example, 
UNESCO's Local and Indigenous Knowledge Systems (LINKS) Programme and the Man and the Biosphere (MAB) Programme).

The United Nation's 2008 Declaration on the Rights of Indigenous Peoples affirms, "Indigenous peoples are equal to all other peoples, while recognizing the right of all peoples to be different, to consider themselves different, and to be respected as such (United Nations 2008, 1; italics added). So too, the UNESCO Universal Declaration on Cultural Diversity states, "as a source of exchange, innovation and creativity, cultural diversity is as necessary for humankind as biodiversity is for nature" (UNESCO 2001, 4). In Colombia, Article 7 of the constitution asserts, "the State recognizes and protects the ethnic and cultural diversity of the Colombian nation" (República de Colombia 1991, 3). If a defining characteristic of Indigenous peoples is to be different and that difference is to be protected, then when is it acceptable to be different and when is difference, or alterity, to be frowned upon, eradicated and replaced by sameness or universality? Who decides? If UN statements such as the ones above are to be taken seriously, then there is a contradiction between the UN declarations and the UN Sustainable Development Goals (SDGs). The latter are measured using international and national indicators and targets that are not always congruent with Indigenous livelihoods, cultures, cosmologies and values.

For example, the first Sustainable Development Goal, to end poverty in all its forms everywhere, relies on targets measuring extreme poverty by income (\$1.25/person/day), private property ownership, access to basic services, microfinance, and other nationally defined indicators of poverty (UN.org). These impose international 
or national standards that invisibilize localized non-cash economies, collective property ownership, alternatives to basic services, nonfinancial household maintenance strategies and local classifications of poverty, respectively.

In Colombia, poverty is measured using two methods, a monetary poverty index and a multidimensional poverty index that includes five dimensions: 1) educational conditions, 2) children and youth, 3) work, 4) health, and 5) housing and public services (Angulo 2011; DNP 2017). Again, indicators more attuned to Western, urban livelihoods and standards are employed that superimpose the poverty label on Indigenous societies who may not consider themselves as poor for not meeting the criteria established by the state. Consequently, multidimensional poverty index indicators-years of schooling, illiteracy, access to childcare, child labor, access to Western healthcare, absence of an onsite water source, absence of toilets, type of floors and walls of the residence, and number of individuals sharing a room—determine whether a Colombian family is living in poverty or not. Therefore, any Indigenous practices or modes of living that do not meet the criteria established by the state are measured and categorized according to the poverty indexes.

As for water rights, in 2010 the United Nations explicitly recognized the human right to water and sanitation through Resolution 64/292, and included in the 2015 Sustainable Development Goals the goal to ensure availability and sustainable management of water and sanitation for all, which similarly legitimizes certain hydrosocial relations while delegitimizing others. The first indicator for SDG \#6 is the proportion of the population using safely managed drinking water services and the second the proportion of the population using safely managed sanitation services, including a 
hand-washing facility with soap and water. The following chart by the Joint Monitoring Programme (JMP) between UNICEF and the World Health Organization (WHO) shows the five levels of drinking water services and their definitions (Figure 1) (United Nations 2018, 37). The figure clearly shows what are desired, acceptable and unacceptable behaviors, water sources and values associated with water management (ibid). In this sense, at the bottom of the water service ladder are ponds and dug wells, the two most important sources of drinking water for the Wayuu in the areas of Irraipa and Cardón where my fieldwork was conducted. Regarding sanitation services, the Wayuu practice of open defecation is also on the lowest rung of the sanitation service ladder (not shown here), indicating a lack of adequate sanitation services and practices according to Western standards.

\begin{tabular}{l|l}
\multicolumn{1}{c|}{ SERVICE LEVEL } & \multicolumn{1}{c}{ DEFINITION } \\
SAFELY MANAGED & $\begin{array}{l}\text { Drinking water from an improved water source that is located on premises, available when needed and } \\
\text { free from faecal and priority chemical contamination }\end{array}$ \\
\hline BASIC & $\begin{array}{l}\text { Drinking water from an improved source, provided collection time is not more than } 30 \text { minutes for a } \\
\text { round trip, including queuing }\end{array}$ \\
\hline LIMITED & $\begin{array}{l}\text { Drinking water from an improved source for which collection time exceeds } 30 \text { minutes for a round } \\
\text { trip, including queuing }\end{array}$ \\
\hline UNIMPROVED & $\begin{array}{l}\text { Drinking water from an unprotected dug well or unprotected spring } \\
\text { SURFACE WATER }\end{array}$ \\
\hline Note: Improved sources include: piped water, boreholes or tubewells, protected dug wells, protected springs, rainwater, and packaged or delivered water. \\
\hline Source: WHO and UNICEF (2017a).
\end{tabular}

Figure 1. The UN's updated drinking water service level ladder Source: Sustainable Development Goal 6: Synthesis Report on Water and Sanitation (United Nations 2018, 37)

The category safely managed at the top rung of the ladder is a new addition to the service levels, added to monitor the current SDGs (2015-2030); from 2000 to 2015 the term improved water was the highest level of the ladder to monitor the Millennium 
Development Goals (MDGs) (Joint Monitoring Programme 2015, 35). Interestingly, packaged and delivered water went from being unimproved water sources in 2012 (Joint Monitoring Programme 2012, 6) to improved water sources in 2017 (Joint Monitoring Programme 2017,8). This significant change shows the shifting nature of Western water standards and the possible lobbying pressure by the private water sector on the governing institutions' standardization processes. Clearly, the private sector stands to benefit from international and national policy and regulations including bottled water and delivered water-commodified water products - as improved, rather than unimproved, water sources.

With these global water standards and Wayuu water and sanitation practices in mind, the following questions arise: are Wayuu hydrosocial relations commensurable with the top rung of the global standards? How much of the Wayuu identity is tied to their water practices that are discouraged by Western water experts? Hypothetically, if each SDG—no poverty, zero hunger, good health and wellbeing, quality education, gender equality, clean water and sanitation, affordable and clean energy, decent work and economic growth, among others - is met by the Wayuu, would they still be Wayuu? Each target met would imply a step away from what makes the Wayuu, and many other Indigenous groups, different, and one step closer towards a Western ideal. In this light, the SDGs become a hegemonic assimilation apparatus operating on a global scale. A Foucauldian genealogy of the SDGs would reveal that each goal contains values, assumptions, expectations, attitudes, and emotions stemming from a particular culture and worldview that became dominant and universal. 
Notwithstanding, each Indigenous society develops culturally specific notions of poverty, prosperity, progress, happiness, security, scarcity, risk, rights and quality of life different from any Western definition of the terms. Should these local definitions be recognized and protected as much as the intangible heritages safeguarded by UNESCO? Do all or should any Western standards apply to Indigenous peoples? The discourse expounded by those in power who celebrate and protect cultural diversity is based on a popular definition of culture that includes arts, crafts, language, song, music, dance, religion, food, among other appealing and emblematic elements. This narrow definition of culture is only a small aspect of E.B. Tylor's classic anthropological definition of culture as "that complex whole which includes knowledge, belief, art, law, morals, custom, and any other capabilities and habits acquired by man as a member of society" (Tylor 1871,1 ) or a contemporary definition that includes "socially transmitted, often symbolic, information that shapes human behavior and that regulates human society so that people can successfully maintain themselves and reproduce." (Bodley 2011, 568). If culture is made up of all the material and non-material elements that are learned, shared, symbolic, patterned and integrated in a society, then cultural diversity would include a plethora of local values, standards, concepts, practice and relations. In this sense, taken for granted universals such as the UN's human rights and the Sustainable Development Goals are also social constructions grounded in, and a reflection of, a very recent place and time in human history.

Despite this current mission to promote and conserve certain aspects of cultural diversity, the $19^{\text {th }}$ century mission to civilize has far from disappeared. Past ideologies and prejudices of race and culture such as the stages of unilineal cultural evolution, the 
Malthusian dilemma and the tragedy of the commons are reinterpreted across space and time, a pattern analyzed in Pred's The Past is Not Dead (2004), where he reveals that racism surfaces under different guises throughout history. As evidenced in the second epigraph of this introduction, Pred argues that current racial representations trace a permanent connection between the present and the past, forming a continuous thread of a racialized representation that is reworked and reinterpreted but never forgotten nor abandoned (ibid, 4). Regarding Indigenous peoples, labels and descriptors such as savage, barbaric, wild, uncivilized, fierce, backward and Indian become more infrequent yet are replaced by politically correct terms such as vulnerable, poor, marginalized, ethnic, traditional and Indigenous.

\section{Reflections on the label Indigenous}

Prior to presenting the theoretical approaches I use in the dissertation, I want to highlight some of the problems inherent in the Indigenous/non-Indigenous binary when discussing dominant and subordinate discourses. In the case of the Americas, with 500 years of shared history, what it means to be Indigenous and non-Indigenous has changed dramatically. Since colonization, interactions between Indigenous and non-Indigenous populations in Latin America has produced a wide spectrum of assimilation, ranging from complete integration to near complete isolation. The abrupt disappearance of some Indigenous societies through genocide as well as the gradual transformation into peasants has occurred in Colombia and throughout the Americas.

Understudied and underappreciated has been the adoption of various aspects of Pre-Columbian and contemporary Indigenous cultures by the dominant societies. Indigenous contributions to regional and national identities are evidenced in culinary 
practices and ingredients, religious syncretism, native linguistic terminology and artistic expressions, to name a few. Latin American countries promote their Indigenous cultures for tourism and national identity yet this public display of acceptance of the Indigenous obscures the power-laden disparities in culture, race, ethnicity, territory, identity and language that have produced and perpetuated the notion of Indigenous peoples as inferior to the dominant whites and mixed/mestizo/mestiço populations. In the English, Spanish and Portuguese-speaking nations of the Americas, the derogatory racial terms indian/indio/indiano and their superlative antonyms white/blanco/branco, capture the underlying racial relations masked by the more neutral term, Indigenous. Each Indigenous group has its own pre-colonial, colonial and post-colonial history that both unites and distinguishes it from other Indigenous groups and from the dominant societies with whom they coexist. South American Indigenous peoples from Patagonia, the Andes, Circum-Caribbean, the Amazon Basin, as well as other lowland regions (Steward 1963) have developed a variety of livelihoods adapted to their local environments such as small-scale farming, hunting, gathering, fishing and herding, while also participating in local and regional market economies, and beyond.

Underlying misconceptions, held by some, of Indigenous peoples as "noble savages" who live in harmony with the environment, are contrasting ideas held by some others who see them as ignorant or inefficient land managers whose relationship with the land is based on unscientific, hence backward, knowledge (Nadasdy 2005). The current prejudices towards Indigenous peoples in environmental land management harken back to the theory of unilinear cultural evolution, promoted by late $19^{\text {th }}$ century anthropologists E.B. Tylor, Herbert Spencer and Lewis H. Morgan. This now debunked theory deemed 
that all human societies progress or improve in a unilineal manner through three stages of human culture: evolving first through initial stages of savagery, then escalating through lower and upper stages of barbarism until reaching the pinnacle of cultural progress, known as civilization (Kottak 2015, 51). These (white) cultural evolutionists argued that while white European and North American cultures had achieved civilization, all nonEuro-North American and Indigenous societies were slowly progressing or stagnated in the first two stages. Assisting these contemporary, yet anachronic, cultures to progress out of the past and into modern civilization became the justification and "noble" side of the imperialist agenda, also known as the white man's burden (ibid, 284).

In the Americas, the uneven historical relations between natives and non-natives remain intact and the civilizing mission has far from ended. Since World War II, development initiatives by the Global North (aka First World, Developed countries) in the Global South (aka Third World, underdeveloped, developing or less developed countries) have been considered within decolonization literature as a continuation of the prior era of European and American colonialism by dictating the meaning and direction of progress, understood as economic progress and material prosperity (Escobar 1995; Mignolo 2000; Santos 2018). Indigenous peoples have been negatively impacted by the forces of modernity that promote progress, beginning with colonialism, evangelization, the rise of capitalism, conventional resource management and neoliberal governance, all of which have brought about land usurpation, forced displacement, assimilation, land degradation, pollution and commodification of natural resources, to list a few of the consequences of modernity. Assimilation and globalization forces continue to threaten Indigenous peoples, many of whom face an uncertain future (Maybury Lewis 2002). 
Compounding the somber situation are the negative impacts of climate change that affect disadvantaged and vulnerable groups such as Indigenous peoples disproportionately (IPCC 2018, 9).

However, Indigenous peoples are not only survivors of colonialism or victims of oppression. Latin Americanist scholars have written extensively on Indigenous peoples' relations with Latin American nation-states, highlighting the positive results of their participation in identity politics, territorial struggles and their continued distinctiveness despite sustained pressure to assimilate (Sherzer and Urban 1991; Turner 1995; de la Cadena 2000; Warren 2001; Rappaport 2005; García Hierro and Surrallés 2005; Mallon 2005; Becker 2011; Erazo 2013; Cepek, 2018). For example, the Indigenous movement and subsequent constitutional reforms within Colombia and several Latin American nations are viewed as positive measures towards increased Indigenous rights and political participation (Assies, Haar, and Hoekema 2000; Jackson and Warren 2002; Rappaport 2005; Sherzer and Urban 1991; Becker 2011).

Abstract and generalizing terms such as Western and Indigenous imply a spurious homogeneity within each and a clear distinction between them. However, it is misleading to speak of a single Western intellectual tradition, as it is to speak of a unified Indigenous tradition. In doing so, one strips the cultural and ontological diversity found within these groupings of humankind, relapsing into a simplified us/them dichotomy so prevalent in scholarly and non-scholarly literature, past and present. Within the Western intellectual tradition, heterogeneity is found between orthodox and heterodox positions, giving rise to debates, new disciplines, alternate discourses and in rare cases, paradigm shifts (Kuhn 
1970). Despite the heterogeneity, citing Mayr (1997) and Cordova (2007), Pierotti notes

that,

Western European attitudes toward nature come from the same European philosophical roots - Descartes, Bacon, Locke, and the Enlightenment (N. Smith 1984, 1996; Coates 1998). These traditions assume that humans are autonomous from, as well as in control of, the natural world. As described in the writings of philosophers ranging from Aristotle and Descartes to Kant, humans are considered to be creatures apart from the rest of life $(2010,208)$.

For Pierotti, a major difference of how Indigenous societies view nature is ontological:

for them, humans are connected to the natural world, form part of it, neither existing independent of each other (2010, Chapter 7).

While Pierotti's statements contrasting Western and Indigenous views on nature may be valid, it is important to keep in mind the tremendous heterogeneity among Indigenous peoples whose generalization was initiated by Christopher Columbus when he used the term Indian to incorrectly label the peoples he came in contact with in the Americas in the late $15^{\text {th }}$ century. While Native American, American Indian and First Nations are terms now widely used in North America, Aboriginal or Aborigine in Australia and tribal peoples in India, the most widely used term is Indigenous peoples.

The term Indigenous was proposed in 1974 by Indigenous representatives of various nations, led by the National Indian Brotherhood of British Columbia, which then formed the World Council of Indigenous Peoples with a secretariat in Canada who maintained a consultative role with the United Nations and the International Labor Organization (ILO) (Laenui, Burgess, and TCP 1990). For them, Indigenous peoples were those "living in countries which have a population composed of differing ethnic or racial groups who are descendants of the earliest populations living in the area and who 
do not as a group control the national government of the countries within which they live" (World Council of Indigenous Peoples 1974). In 1982, the United Nations established the Working Group on Indigenous Populations, then in 2000 created the Permanent Forum on Indigenous Issues and in 2007 adopted the Declaration on the Rights of Indigenous Peoples.

While still regarding the self-determination and distinct colonial history faced by each group (Smith 2012), since the 1970s, a collective voice for all colonized peoples has led to increased participation in the international and national political arenas through the combined efforts of Indigenous peoples from all over the world, governments, nongovernmental organizations, the UN and the ILO. Because of the great diversity found among Indigenous peoples, misrepresentation and erasure of identity comes with the label "Indigenous" as opposed to their own group-specific name. On the other hand, Indigenous peoples understand that when participating in the politics of pan-indigeneity and Indigenous rights the term Indigenous is useful for fostering international solidarity and amplifying their collective voice. Nevertheless, Kovach (2009) insists that those who currently control the production of knowledge within and beyond academia, should use methods and theories that acknowledge the diversity and complexity of Indigenous peoples and avoid simplifying generalizations that mask rather than reveal the unlimited potentialities and capacities of the human race. For this reason, throughout the dissertation I limit the use of the term Indigenous when referring to the Wayuu, in order to minimize generalization and maintain their group-specific identity. 


\section{Critical social theory from the Global South}

Boaventura de Sousa Santos offers two premises that are fundamental to his epistemologies of the South theoretical framework and encapsulate the complexity of the world as well as optimism in an uncertain future. The first premise states that our understanding of the world is much broader than the Western understanding of the world, and the second proclaims that the diversity in the world is infinite (Santos 2011, 35). So, for Santos, alternatives exist, but what is needed is an alternative way of thinking about the alternatives. In the epistemologies of the South, latent alternatives and possible futures can disrupt the current epistemological and ontological hegemony of the Western world that suppresses traditional, Indigenous and local ways of understanding and being. To better critique the hegemonic processes at work, he proposes a sociology of absences that identifies the forces, institutions and actors that actively create non-existence by only allowing to exist: 1) a Western scientific epistemology, 2) a singular understanding of linear time associated with progress, 3) the naturalization of a hierarchical social classification ideology, 4) the universal and the global as the dominant scales and 5) the unquestioned objective of economic growth based on capitalist productivity (30-32).

Ample evidence of failed development projects, the growing awareness of ethical standards in research and a global increase in appreciation of Indigenous cultures shows a need to move away from paternalistic relations between the dominant and marginalized societies, and with the environment. In order to surmount the epistemological imbalance that heavily favors Western science, Santos proposes an ecology of knowledges and intercultural translation. The ecology of knowledges does not aim to discredit Western science but rather lend credibility to non-scientific knowledge, redirect scientific 
knowledge production toward counter-hegemonic objectives and promote the interdependence of dominant and marginalized knowledge traditions (36). For Santos, all knowledge is incomplete, and ignorance is a part of knowledge acquisition. In other words, by knowing something we are ignoring something else. The ecology of knowledges requires us to question the value of what we learn and be mindful of what we may forget or ignore. Western scientific knowledge is in a privileged position and is the predominant epistemology in intercultural exchanges. Santos proposes intercultural translation as the means of bridging the divide and establishing a horizontal relationship between dominant and subordinate epistemologies. Intercultural translation consists of creating reciprocal intelligibility between lived and possible experiences of radically different human cultures (37). How this can be done or if it is possible has been the subject of debate within anthropology since the discipline's inception amidst a colonial context in the late $19^{\text {th }}$ century and continues to be a pressing topic in the present day. Escobar's modernity/coloniality/decoloniality (MCD) framework (2008, Chapter Four) complements Santos' epistemologies of the South to further understand how hegemony is enacted. For Escobar, modernity is a homogenizing endeavor, displacing and replacing "relational worlds and ontologies" that challenge the unrestrained development and neoliberal use of nature's resources without considering how territory, humans, non-humans and sentient beings are all bound together (ibid). The modernity/coloniality/decoloniality framework argues that modernity began with the conquest of America; colonialism and capitalism are constitutive of modernity; modernity should be explained through a world perspective rather than something particular to Europe; modernity rests on the subordination of knowledge and other 
cultures; and, eurocentrism as a knowledge form claims universality based on world hegemony (ibid, 167-168).

Prior to Santos and Escobar, Fals Borda (2002) critiqued the Euro-North American dominion of knowledge, noting that Latin America was providing sophisticated and critical intellectual and methodological contributions, including Hughes Galeano's Open Veins of Latin America (1971), Cardoso and Faletto's Dependency and Development in Latin America (1979), Freire's Pedagogy of the Oppressed (1970) and Fals Borda's Participatory Action Research (1973) to name a few. Without spurning the critical studies put forth in the Global North, he asks "Why should we continue giving flowers to dubious idols, uncritically cite obsolete writers, or elevate as masters colleagues whose thinking is an echo of, or developed from, our own analyses, an echo at times amplified by the resonance of hegemonic apparatuses" (Fals Borda 2002, 180).

If we visualize the production of knowledge in Spanish-speaking Latin America as a hierarchy with Euro-North American knowledge at the top followed by Hispanic intellectual production, there are (at least) three more subjugated levels relating to Indigenous peoples in the Americas that are rarely considered. Indigenous ambassadors and intellectuals form another group of knowledge producers but are not given the same importance as their Hispanic counterparts in Latin America. These people are often bilingual speakers who are indoctrinated in the ways of the Hispanic society and represent the Indigenous group regionally, nationally or internationally. Less visible are the local Indigenous leaders who live within the communities, often monolingual or with little fluency of the official European language and dissociated from the Hispanic culture. This group includes the elders, healers, clan leaders or those with other types of expertise 
and specialized knowledge. At the bottom of the hierarchy are the vast and heterogeneous Indigenous populaces, young and old, who do not lead nor represent their people yet are the current sources and repositories of each Indigenous society's wealth of practical knowledge. Through daily routines and oral history, the ordinary members of Indigenous communities are the silent educators and knowledge bearers who understand and navigate the social and natural milieus of their territory using tacit and explicit knowledge systems. Cultural transmission is greatest at this level, producing and reproducing the group specific culture as well as micro cultures at the familial and community scales.

\section{Legibility and commensurability of Indigenous knowledges and cultures}

Protests in the $21^{\text {st }}$ century led by Andean farmers in the Bolivian highlands, Amazonian peoples in Brazil, and Native Americans in North Dakota, are examples of the persistence of marked differences in understandings and governance of water between Indigenous peoples and the nation-states that encompass them. Yet it has also been a time of increased appreciation of Indigenous knowledge systems and greater appropriation of constitutional and customary rights by Indigenous peoples in Colombia and worldwide. Social movements for the right to water in Bolivia, Uruguay and Argentina in the early 2000s have led to constitutional reforms proclaiming water a human right (Motta Vargas 2010). Consequently, contemporary water governance presents a clear opportunity for the Wayuu and other Indigenous peoples and pastoralists to (re)assert and (re)establish contextualized and culturally specific practices, traditions, beliefs (knowledge) and aspirations that have been historically silenced by conventional water management. 
However, the intensification of water, food and health interventions in Wayuu territory over the last ten years to real or perceived food and water scarcity has not resolved the gross disparities between urban and rural water, sanitation and hygiene conditions. Yet these interventions have reduced the agency and capacity of the Wayuu beneficiaries to analyze, define and propose solutions to their water needs internally. The following questions then arise: first, which "traditional" water practices, technologies and values should be maintained, and which should be replaced by "modern" ones? Second, who decides? And third, are those local water practices commensurable with the introduced waterworks? I explore possible answers to these questions from a relational ontology and political ecology perspective based on research among the Wayuu in La Guajira, Colombia.

To give a Colombian example that points out the discrepancy or hypocrisy evidenced when those in power disregard the voice of the marginalized, I cite Danilo Villafañe Torres, an Arhuaco Indigenous leader of the Sierra Nevada de Santa Marta mountain range in northern Colombia. During a panel on the post-conflict situation in Colombia after over 50 years of civil war, he stated, "Those who practiced war [the Colombian government and the Revolutionary Armed Forces of Colombia (FARC)] now speak to us about peace. It's a strange phenomenon. Those of us who have lived in peace are not involved in the peace process" (ICCB 2017). A similar story can be told with the Wayuu or any other Indigenous group when addressing human-induced climate change. Those who created the problem — industrial, capitalist societies - are now the ones in charge of coming up with solutions, while non-industrial societies who are not responsible for global warming are not seriously considered as sustainability experts. 
As Western science reveals humanity's destructive power over nature, our increasing vulnerability to nature and our lack of understanding of 'socio-nature', (Dalby 2009; Chandler 2014; Evans and Reid 2014), Indigenous peoples have reasserted their identity as spiritual, knowledgeable and ethical custodians of a complex world (Wildcat 2009). For decades, social scientists, environmental scientists and resilience scholars have agreed that the complexity and interrelation of ecological systems and social systems have been poorly addressed by conventional environmental management, which should now be understood and analyzed as socio-ecological systems (SES), complex adaptive systems (CAS) (Berkes, Colding, and Folke 2003; Folke 2016; Folke et al. 2007) or using a biocultural diversity approach (Elands et al. 2019; Nemoga 2016; Caillon et al. 2017).

The mounting evidence of the negative environmental impacts of the conventional, command-and-control approach to resource management and the benefits of incorporating Indigenous land management approaches, have led to various strategies including co-management, adaptive management, ecosystems-based management, sustainable development, resource security and resilience planning. In the process, Indigenous expertise on the environment has been sought out and operationalized into the dominant management paradigm under the term traditional ecological knowledge (TEK). The ascension of Indigenous knowledge and management practices has the potential to redirect Western environmental management towards the current objective of environmental sustainability based on resilient socioecological systems. However, critical scholars consider the incorporation of Indigenous knowledge as another means of suppressing Indigenous alterity through bureaucratic standardization that makes the 
incommensurable commensurable or "legible" (Scott 1998; Povinelli 2001; Nadasdy 2003).

TEK proponents emphasize the holistic understanding and positive relationship Indigenous peoples have with their environment, as presented by numerous studies that demonstrate how TEK strengthens ecological and community resilience (Berkes, Colding, and Folke 2000; Sillitoe 2007; Lertzman 2010; Pierotti 2010; Berkes 2012; Gomez and Sawyer 2012; Grossman and Parker 2012; Cochran et al. 2013; Eira et al. 2013; Simmons 2013; Chief et al. 2014; Anderson et al. 2019). While these authors are confident that bridging or integration is possible between Indigenous knowledges and traditional Western science, some critical social theorists, including environmental anthropologists (Nadasdy 2007; West 2006; Lansing 1991), political ecologists (Kosek 2006; Neumann 2005; Robbins 1998), ontologists (Povinelli 2001; de la Cadena 2010; Blaser 2009) and resilience thinkers (Evans and Reid 2014, 29) find bridging initiatives problematic for various reasons that can be grouped into two broad interrelated categories, power struggles surrounding environmental management - the hallmark of a political ecology approach — and the incommensurability between Western and Indigenous societies, a fundamental topic within ontological anthropology.

Political ecology and environmental management power struggles

Research in political ecology looks at the politics behind resource management, and provides a strong critique of the homogenizing developmentalist vision that silences local beliefs and relationships with nature (Sneddon 2013; Neumann 2005). Political ecologists have critiqued the accusations towards the rural poor as the culprits of environmental degradation. According to this perspective, focusing critiques on the 
marginalized shifts the focus away from how colonial histories, state institutions and a dominant capitalist paradigm have produced their marginalization and consequently, environmental degradation (Neumann 2005). For instance, Robbins' degradation and marginalization thesis considers how "otherwise environmentally innocuous production systems undergo transition to overexploitation of natural resources on which they depend as a response to state development intervention and/or increasing integration in regional and global markets” (2012, 21). This theory counters Hardin's (1968) apolitical theory which predicted that self-interested livestock herders in pursuit of personal economic gain would increase their livestock production until the common pastures were degraded to the point of tragedy. Applying Robbins' (2012) theory of degradation to pastoralism, this livelihood can be viewed historically as a well-adapted subsistence strategy that has become increasingly damaging to the environment because of land dispossession that reduces the extensive grazing areas pastoralists have access to, yet need, for this activity to be sustainable.

Pastoralists are Indigenous peoples who maintain a distinct livelihood to that of the dominant society that encompasses them and share common elements with other Indigenous peoples. These include adaptability, traditional knowledge, common property resource management and subsistence livelihoods, but also unequal relations with the state, loss of land, loss of autonomy and overall marginalization. Many pastoralists today, such as the Wayuu, lead a marginalized, rural, mobile livelihood that contrasts with sedentary, urban societies where wealth is concentrated and policy and legislation are enacted. In the Global South, pastoralists have been encompassed by nations characterized as poor and underdeveloped due to their colonial histories and weak 
governments that seek out or are obligated to acquiesce to European and North American markets, aid and expertise (Escobar 1995; Wallerstein 2004). Pastoralists' mobility and adaptive capacity are bounded by economic and political institutions of nation-states that prioritize a host of competing economic activities including agriculture, ranching, industry, mining, conservation, tourism and hydropower that have historically negatively affected herding societies (discussed further in Chapter 3) (Fratkin 1997).

If Santos $(2011,35-39)$ proposes an ecology of knowledges and intercultural translation to legitimize marginalized knowledge, political ecology research underscores the prevalence of power inequalities and hegemonic apparatuses that must first be surmounted. Power inequality within national and global economic systems is evidenced when business interests take precedence over cultural or environmental interests. Global environmental management, as a hegemonic apparatus, operates within a capitalist paradigm where social inequality is embedded. This socio-environmental management paradigm was intensified in developing countries after World War II through the Washington Consensus and development interventions that have proven to exacerbate impoverishment rather than bring progress and prosperity (Escobar 2012, viii).

Asymmetrical relations between Indigenous peoples and government agencies limit the possibilities of successful integration of Indigenous perspectives in comanagement and other nature-society relations. Paul Nadasdy describes the nature of engagement between the Kluane First Nations peoples and the Canadian governmentwhether through lands claims, environmental impact assessments or resource comanagement - the Kluane were forced to participate using Western values, language, timeframes, administrative bureaucracy and Western understandings of TEK (Nadasdy 
1999; 2002; 2003). For Nadasdy (1999), in order to make Indigenous knowledge compatible, a distillation process into the dominant framework is carried out by those in power, who decide what is "traditional", "ecological" and "knowledge" and this process serves to further concentrate power in administrative centers rather than transfer power to the Indigenous groups. Chapter 6 further analyzes the problems of TEK integration.

Many scholars have documented the highly contested nature of relations between nation-states and Indigenous groups, noting the top-down implementation of measures and the environmental destructiveness of modernist government interventions, while highlighting countermeasures Indigenous groups, and factions within these, implement to diminish external control and strengthen their individual and collective agencies (Conklin and Graham 1995; Cepek 2011; Nadasdy 2003; Perreault 2008; Erazo 2013; Hodgson 2011). In some cases, Western environmental management is adopted by Indigenous groups or individuals in leadership roles, whose understanding of the environment is altered by dominant institutional regimes, described by Arun Agrawal (2005) as environmentality. This concept examines "the extent to which varying levels of involvement in institutional regimes of environmental regulation facilitate new ways of understanding the environment... in which technologies of self and power are involved in the creation of new subjects concerned about the environment" (Ibid, 161). Contesting the concept of environmentality, Michael Cepek (2011) presents a case from the Ecuadorian Amazon, arguing “although the ECP's [Environmental Conservation Program] scientific conservation program is a regulatory regime par excellence, it does not succeed in remaking the beliefs, desires, values, and identities of Cofán participants" (ibid, 502). Still others have documented the long history of failed attempts by 
governmental and non-governmental institutions to communicate and implement their agendas with Indigenous peoples, who opposed the interventions or were unable to adopt them because of serious problems related to administration, politics, economics, or the incommensurability with local livelihoods, discussed in the following section (Scott 1998; Ferguson 1990; Mosse 2005; Nadasdy 2003).

The examples of power struggles surrounding environmental and water management among Indigenous peoples mentioned above has informed my research of the overt and hegemonic mechanisms that stifle Indigenous peoples' agency over land and water governance and that prohibit the consolidation of alternative ways of managing the environment. I apply this approach to water governance among the Wayuu by highlighting the interrelatedness of the global, national and local socio-political contexts, ruled by powerful businesses, global water mandates and various governing institutions (discussed in Chapter 4). My contribution to the literature entails exploring the limits of the political ecology approach by including a relational ontology approach to analyze Wayuu water use and management. This latter approach questions if and how a second major obstacle to the ecology of knowledges and intercultural translation can be surmounted by considering the incommensurability or incompatibility between radically different cultures.

\section{Relational ontology and the incommensurability of alterity}

Even before the ontological turn, anthropologists studying failed development projects often noted the huge cultural divides between those who design and implement projects and those who are the intended beneficiaries. For example, in The Anti-Politics Machine, Ferguson (1990) analyzed rural development in Lesotho and how it confronted, 
among other things, the incomprehensible relationships that the Sesotho pastoralists held with their cattle. He concluded,

whatever interests may be at work, and whatever [the institutions] may think they are doing, they can only operate through a complex set of social and cultural structures so deeply embedded and so ill-perceived that the outcome may be only a baroque and unrecognizable transformation of the original intention (Ferguson 1990, 17).

The plethora of institutions involved, and their unremitting failures led Ferguson to point out that the complexity and illegibility of rural life cannot be modified towards desired ends by simply introducing a development project. Furthermore, he noted that governments represent multiple and often competing interests; rather than alleviating the plight of the rural poor, the interests of other, more powerful stakeholders are forwarded (ibid, 14). This line of critical research has also distinguished the work of political ecology, described in the previous section.

Based on past and present cross-cultural encounters in Latin America and other regions, there is a growing debate that has (re)surfaced within anthropology and beyond centering on radical alterity and the incommensurability of worldviews between societies, known as the ontological turn (Blaser 2010; Escobar 2016; Viveiros de Castro 2004; de la Cadena 2015; Povinelli 2001). Santos (2011), Escobar (2015), Mignolo (2000) and other proponents of the "ontological turn" argue that modernity’s One World World (OWW) forecloses complex ontologies from expressing possible alternatives to understanding and being in the world (Green 2013). As a precept of ontological anthropology, incommensurability is based on the idea that an undistorted interpretation or translation is impossible between linguistic and social worlds that are radically different (Povinelli 2001). Ontological anthropology's engagement with subaltern epistemologies questions 
prevalent assumptions of the nature/culture divide found in anthropology and in Western science in general. Relational ontology has encouraged scholars to go beyond the dominant dualistic paradigm by focusing on the deep relationships between humans and other-than-humans. This body of literature includes multinaturalist perspectivism (Viveiros de Castro 2004; Latour 2011), political ontology (de la Cadena 2015; Blaser 2010; Green 2013; Escobar 2008; Mignolo 2000; Santos 2018) and posthumanism (Kohn 2013; Haraway 2008; Povinelli 2016) that emphasize the place, role and relationships of animate and inanimate nonhuman beings within Indigenous and local communities.

Ontologists argue that Indigenous cultures, epistemologies (how we know what we know) and ontologies (the nature of being or existence) are so radically different from their Western counterparts that these are incommensurable. Furthermore, development is based on Western technology and expertise that differs from Indigenous understandings of ecological processes. For Escobar, the incommensurability between Western and Indigenous worlds lies in the very nature of the relationships between humans and nonhumans. Firstly, relational ontology argues that everything exists in the world through an infinite number of reality-producing practices and relations; nothing is a discrete, selfcontained being that preexists these relationships that constitute it. Secondly, all relationships are social, meaning that the subject/object binary commonly used when speaking of natural and supernatural beings does not apply (Escobar 2015). These two premises have political implications in that nonhuman or other-than-human entitiesincluding inanimate earth beings such as lakes, mountains and rain—are imbued with life and agency as sentient beings (de la Cadena 2015). For ontologists, reality is not defined 
solely by empirical science or logic, nor can sentient beings be explained away simply as cultural beliefs. For de la Cadena, the summoning of sacred landscapes towards political ends is an alternative discourse to the dominant Western, scientific view of nature.

Although native Andean cultures have maintained intimate relationships with nature since Pre-Columbian times, there is now greater possibility to insert them into politics to reinforce their rights.

For Viveiros de Castro (2004), translation across worlds can result in (un)controlled equivocation that identifies apparent cultural synonyms to be equivocal homonyms, resulting in the misunderstanding of the intent of the original language within the new one, producing incongruent conceptual visions. An early example of this equivocation, as told by Viveiros, is the way $16^{\text {th }}$ century Spanish conquistadors and Amerindians doubted and tested each other's humanity; the former through inquisitional torturing of the natives and the latter by drowning captured Spanish soldiers (ibid, 8). The Spaniards knew Amerindians had a human body but questioned whether they had a soul, while the natives assumed the Spaniards had a soul but questioned whether they had a human body. "Translation becomes an operation of differentiation—a production of difference - that connects the two discourses to the precise extent to which they are not saying the same thing, in so far as they point to discordant exteriorities beyond the equivocal homonyms between them" (Ibid, 20). In the above example, both groups used similar tactics to understand each other but were motivated to do so by completely divergent ontologies.

"Uncontrolled equivocation" results when attempts at communication between different worlds fall apart (de la Cadena 2015; Blaser 2009; Viveiros de Castro 2004). 
Conklin and Graham (1995) documented a tentative bridging and subsequent rupture between Western and Indigenous societies. In what the authors called the "shifting middle ground," these distinct groups came to a compromise based on assumptions each group had of the other and misunderstandings of the other group's motives, interests and perceptions (ibid). The native Amazonians entered the relationship viewing environmentalists as foreign allies in their mission to maintain or gain territorial control of economic development initiatives. The environmentalists, backed by scientific evidence from ethnobiology and with preconceived notions of the positive relationship between Indigenous knowledge and biodiversity (Blount and Gragson 1999; Posey 1999), also sought out an alliance with the native Amazonians. A shift from preservation to sustainable use in environmental science led Western scientists to seek out Indigenous peoples based on the stereotype of native peoples as natural conservationists, or “ecological noble savages" (Krech 1999; Nadasdy 2005). Nadasdy (2005) noted that Euro-North American notions that conflate environmentalism and Indigenous livelihoods are problematic since they do not consider real Native Americans' relationships with nature but rather an ideal, static concept that is impossible to live up to. What seemed a common interest between the Amazonians and the environmentalists turned out to be only superficial. Indigenous self-determination and territorial governance diverged from the environmentalists' sustainability agenda and biodiversity preservation (Conklin and Graham 1995).

Mario Blaser (2010) provides an ethnographic example of Viveiros de Castro's concept of controlled equivocation by describing how the failed sustainable hunting program, co-managed by the Paraguayan government and the Yshiro Indigenous 
federation, was due to ontological differences in their understandings of sustainability. Blaser's concept of political ontology incorporates the power-laden negotiation, interaction and conflict that takes places when diverging ontologies emerge and struggle to endure (ibid). The sustainable hunting program became a site of contention between two opposing ontologies. The Yshiro hunters' and fishers' understanding of conservation and sustainability was based on a network of reciprocal relationships that included all of the entities that exist in the yrmo (territory, world, cosmos), especially between humans and between humans and the supernatural bahluts (original specimens) who gift their abos, (animals, emanations) and provide other services to the Yshiro people (Blaser 2009). For the Yshiro, sustainability would be achieved by ensuring widespread reciprocity within their territory, giving little importance to the concerns of the scientists who stressed the need to maintain the quotas of animals hunted, adhere to the hunting seasons, and take into consideration the proper size or age of the targeted animals. Likewise, the scientists and biologists were less concerned about the reciprocal relations of the Yshiro, so long as they did not contradict their notion of sustainability. Here, the Yshiro's multinaturalist ontology struggled to emerge in the face of the opposing multiculturalist ontology put forth by the Western scientists.

In Governing Indigenous Territories, we see how both power inequalities and cultural incompatibility are evidenced within the Indigenous Rukullakta Cooperative in the Upper Napo Amazonian region of Ecuador (Erazo 2013). Rukullakta's residents have attempted to gain autonomy and strengthen their Kichwa traditions by organizing themselves formally as an Indigenous territory. In order to do so, they have had to cater to both nationalist and environmentalist notions of governance, shifts that bring the group 
closer to Western notions of progress, conservation and development. The cooperative's decision to change their legal designation from an agricultural cooperative to an Indigenous territory and the alliance they forged with environmental organizations were both strategies to gain access to sources of income and employment. Yet their new legal status also reinforced their indigeneity and proclaimed their sovereignty amidst a changing world around them. Erazo observed that strategies to gain access to sources of income and employment through alliances with conservation and environmentalist organizations were paralleled by acts of civil disobedience such as "government through distance" (7), their inconformity with the UN`s Reducing Emissions from Deforestation and Forest Degradation (REDD) Programme, and the continuation of local land tenure practices, all of which were seen by their environmentalist allies as destructive.

The various encounters between Indigenous and non-Indigenous peoples mentioned in this section show the difficulty in bridging cultural differences. These authors and many others have documented the abyss that still separates many Indigenous cultures from the culture of Western development and the attempts at bridge-building between them. Informed by the literature cited above, my research questions the commensurability between Western scientific water understandings and Wayuu-water relations. I will assume a Wayuu ontological world exists and operates on a temporal and spatial scale unique to the Wayuu society. This Wayuu world cannot be explained by nor confined to any current Western measurement of wellbeing (i.e. SDGs or Colombia's multidimensional poverty index) or scientific theory of adaptation (i.e. socioecological system, resiliency). 
However, I will not assume that the Wayuu world is impermeable to the natural and social surroundings beyond its fuzzy borders. This is evident when considering the impact the Venezuelan economic crisis has had on the Wayuu people. If 100 years ago thousands of Wayuu migrated to the Venezuelan city of Maracaibo and its surrounding areas in search of work, currently thousands are returning to Colombia fleeing from the economic instability in the neighboring country. This wave of returnees has strained social relations as they attempt to reclaim the lands they left behind and has placed added pressure on the natural resources of the territory (Carabali et al. 2019; Casey 2019). Therefore, a contribution of my research to ontological anthropology will be to examine the soundness of its postulates by placing it in conversation with both conventional science and political ecology in the context of the Wayuu territory on the Guajira Peninsula.

While I lay a heavier critique upon the conventional, hegemonic approach, I do not adopt the perspectives of political ecology and ontological anthropology uncritically. Ontological anthropology, which brings a fresh perspective to the study of difference, has been critiqued from within the discipline as reifying rather than dislodging the boundary between modern and non-modern societies. Furthermore, by dismissing the nature/culture binary, ontologists also ignore the real, ongoing and consequential purification of those terms in everyday life (Bessire and Bond 2014). Erazo and Jarrett also point out that focusing on the "ontological dimensions... tends to over-emphasize alterity and frame out ever-changing sociopolitical and economic realities facing contemporary Indigenous Amazonian peoples" (Erazo and Jarrett 2017, 147). 
What has been identified as a weakness of relational ontology has traditionally been political ecology's forte. A focus on power, hegemony and inequality among different actors and social groups within this approach provides nuanced insights to the often-ignored effects of power relations within and between societies and nature. Political ecology, however, has been critiqued for producing research that relates to the environment but focuses on "“politics' without 'ecology", describing "political contests over natural resources" with less attention to the environmental changes occurring (Vayda and Walters 1999, 168). Likewise, political ecology's emphasis on power relations has tended to deemphasize non-conventional relations and hermeneutics (ontological anthropology's strength).

I also hope to contribute to the growing literature of the political ecology of water (Swyngedouw 2004; Bakker 2012b; Goldin, Jacqueline, Harris, and Sneddon 2013; Goldman 2007; Sultana 2013; Budds and Sultana 2013; Anand 2017; Boelens 2014; Baker 2013) by questioning the deterministic nature of power inequality in the unequal access to water. Political ecologists of water rarely question the standards and statistics offered by the Western water experts. Moreover, they use these standards and statistics as a means to support their argument that a violation of the right to water has occurred, and then proceed to describe the political forces that restrict marginalized groups from accessing the same resources of more dominant stakeholders. This dissertation does not assume the objectives, standards and values surrounding water rights are universal. Nor does it accept the validity of the statistics coming from areas where I conducted ethnographic research because the "facts" presented by the donor agency are far removed from my findings. 
This brief summary of the critiques laid upon these two approaches shows that bias is prevalent in any and all theories in academic or scientific research. Therefore, by placing two critical social science perspectives and one mainstream perspective in conversation with each other to theorize the "water problem" on the Guajira Peninsula and the Wayuu relationship with water, I can better identify lacunae and distortions and put forth a more balanced analysis and a holistic understanding of water governance in Wayuu territory.

\section{Critiquing the conventional approach of Western science and management}

Conventional Western science is the self-proclaimed superior Euro-North American model of progress, modernity and universality that claims legitimacy on the way humanity must understand reality and what it must strive for (Escobar 2008). Within natural resource management, the conventional approach has been labeled by resilience scholars Holling and Meffe (1996) as "command-and-control" wherein,

a problem is perceived and a solution for its control is developed and implemented. The expectation is that the solution is direct, appropriate, feasible, and effective over most relevant spatial and temporal scales... The command-andcontrol approach implicitly assumes that the problem is well-bounded, clearly defined, relatively simple, and generally linear with respect to cause and effect (cited in Grove 2018, 69).

In the realm of conventional water management, the plurality of hydrosocial relations worldwide are made invisible by what Linton (2010) describes as the hegemony of modern water. He defines modern water as,

the dominant, or natural, way of knowing and relating to water, originating in western Europe and North America, and operating on a global scale by the later part of the twentieth century... [characterized by] its intellectual abstraction, scientific specification, material containment, and alienation from society and 
from the rest of non-human nature... an objective, homogenous, ahistorical entity devoid of cultural content (ibid:14, 19).

Western science has championed the idea of water as a measurable unit (a molecule of $\mathrm{H}_{2} \mathrm{O}$ ) and an element that travels through, and is temporarily held in various forms within, the hydrologic cycle (Linton 2010). With modern water consolidated as a resource, nation-states employ engineering as the apparatus to appropriate water from nature and from weaker societies whose claims to it become mute objections suppressed by techno-politics and hegemony (Bakker 2012b). Modern water becomes an object of contestation, producing uneven waterscapes across the globe (Chen and others 2013; Budds and Sultana 2013). Competing interests, growing populations, greater water demand and a diminishing resource characterize contemporary water governance (Swyngedouw 2004; Bakker 2007; Goldin, Harris, and Sneddon 2013; Sneddon 2013; Goldman 2007).

Droughts in the conventional sense, for example, have been narrowly thought of as a hydrologic phenomenon, a deficit in the amount of precipitation within a given time period in relation to a long-term average, which requires engineering and hydrologic solutions (Baker 2013, 27). Waterworks such as aqueducts, sewer systems, treatment plants, dams and channels have historically tamed water's unruly characteristics. The advances in water management as well as in the fields of Western medicine and health are laudable, but in many cases, they are modern solutions to modern problems and rife with inequity - they are accessible depending on where you live and who you are. This same modernity model has produced a global human society dependent on fossil fuels 
and prone to overconsume in ways that are unsustainable and threatening to the existence of our own and many other nonhuman species (Robbins 2014).

\section{The Anthropocene, a bleak panorama}

Labeled by some as the Anthropocene, our current epoch has witnessed the human-generated disruption of the planetary system, by which "the sheer scale of human activities means that we are living in increasingly artificial circumstances in a biosphere that we are changing" (Dalby 2009, 11). However, this phrase conceals as much as it reveals about humanity's current dilemma. It is not the scale of all human activities but specifically those related to industry, deforestation, neoliberal capitalism, mass consumption and population growth that are taking its toll on our planet. Dalby's use of the pronoun "we" is also misleading. It can be understood as all of humanity or as a human grouping of which he identifies with. I believe it is the latter because prior to this statement he notes the irony of our current situation, where "the social and political systems that have supposedly rendered at least the relatively affluent urban dwellers in the 'Northern' states secure have been based on the use of fossil fuels, which are now disrupting the environment that gave rise to urban civilization in the first place" (Ibid, 3).

Michael Mann's hockey stick model of climate change shows how the Northern Hemisphere's temperature maintained itself with relatively minor fluctuations at around 0.3 degrees Celsius below a mean global temperature of $13.6^{\circ} \mathrm{C}(1850-1870)$ for nine hundred years (1000-1900 A.D.), then around 1900 the temperature began an upward spike that has now risen $1.0^{\circ} \mathrm{C}$ from preindustrial temperatures (Mann 2012, 16) and is rising at a rate of $0.2^{\circ} \mathrm{C}$ per decade (IPCC 2018, 4). In the $21^{\text {st }}$ century, this abrupt shift in the global climate pattern has brought awareness and alarm to most national and 
international governing bodies to the rapidly deteriorating state of the planetary system (from a human perspective) as well as the limited time we have to slow down or reverse this downward spiral to a self-inflicted extinction.

While interest in climate change has intensified in the current century, climate science is not a new field. The greenhouse effect was discovered in 1824 and by 1896 Swedish chemist Svante Arrhenius stated that human-produced $\mathrm{CO}_{2}$ emissions were affecting the climate (Sample 2005). By the mid- $19^{\text {th }}$ century the Industrial Revolution was well underway in Britain and the U.S. and the unprecedented smog and noxious vapors prompted Britain to pass the first legislation to control industrial pollution (Alkali Act 1863). A publication by the U.S. Agriculture Department in 1941 foreshadows this country's official skepticism in climate change in the Trump era by dismissing the effects of carbon dioxide in the atmosphere, stating, "No probable increase in atmospheric carbon dioxide could materially either affect the amount of insolation reaching the surface or the amount of terrestrial radiation lost to space" (United States Dept of Agriculture 1941, 94). Nevertheless, the relatively sudden change in the earth's climate to a pattern of global warming has by and large been unanimously considered humaninduced by the international scientific community (IPCC 2014), primarily because of industrialization, urbanization, population growth, mass-production and consumerism at a global scale (Dalby 2009; Mann 2012). The Anthropocene is also marked by, "the rapid deforestation of the last few centuries, loss of many species, reduction in fish populations, conversion of huge areas to asphalt-covered cities, mining, farming, damming rivers, and numerous other activities... all happening at the same time" (Dalby 2009, 5). 
If the "urban civilization" that Dalby speaks of produced climate change and the problems associated with it, then which human societies are not in this category and what makes them different? Societies have been in perpetual contact with neighboring and distant societies through trade, war, migrations and intermarriage. Global demography has changed drastically with the spread and dominance of "urban civilization" beginning with the rise of Mesopotamian cities 5,000 years ago to the present where over half of the human population now resides in urban centers.

This urbanization of the world notwithstanding, Indigenous, nomadic, pastoralist, foraging, farming and other rural societies still maintain livelihoods that are in stark contrast to urbanity, the dominant mode of living now prevalent in nation-states across the globe. Bodley (2011) provides examples from three world regions of these types of societies, Native Amazonians, Australian Aborigines and East African cattle peoples, whose cultures highly contrast with one another yet share characteristics of tribal societies. Unlike contemporary urbanity, tribal societies have small-scale, domestically focused economies, rely on local resources and ecosystems, produce simple material technologies, maintain egalitarian social systems and live in relatively small, rural settlements with low population numbers. Among these small societies repose innumerable and invaluable sources of local alternatives and alternative ways of thinking about both planetary and localized problems related to the effects of global warming.

\section{Contribution and broader impact}

My intention in this dissertation is to identify and deflate the omnipotence of the global hegemonic water sector while discerning and defending the local or "nonconventional" Wayuu-water relations. If greater water availability and waterworks 
sustainability are to improve on the Guajira Peninsula - not in the conventional unilinear sense linked to progress, development or modernization, but in a nonlinear and contextualized sense - then greater attention must be given to local, subjugated knowledges and practices. The dissertation uses ethnographic and ethnohistorical data to provide a critical perspective of water governance, water security and conventional water management on Wayuu territory. To do so, I bring into conversation perspectives from conventional environmental management, political ecology and relational ontology.

This theoretical intermingling is useful because when the three approaches are considered side by side, a more comprehensive, unbiased view of the overall situation can be obtained. It is also important to identify and learn from the mistakes and failures of water management as it is to learn from what has succeeded, why it succeeded and who benefitted from its success. This is especially important in the province of La Guajira where various factors converge that add to its overall vulnerability. According to government statistics: it has the largest Indigenous population of Colombia (20\% of the country's total Indigenous population) (DANE 2019, 19); only 4\% of the province's rural population has access to potable water, the lowest in the country (Ministerio de Vivienda 2018, 3); La Guajira Province has the second highest level of extreme poverty (48\% of the province's population) (El Tiempo December 20, 2018); and it is the most vulnerable to desertification in Colombia (90\% of land degradation) (IDEAM 2017, 29).

In 2017 the Constitutional Court ruling T-302 found the state of affairs in La Guajira unconstitutional in three areas: healthcare, food security and water services. In response, in October of 2018 the National Government, through its Ministry of Housing, City and Territory and Vice Ministry of Water and Basic Sanitation, began the most 
ambitious program to provide clean water for the province of La Guajira and for the Wayuu, known as Guajira Azul (Blue Guajira). The program is ambitious in terms of the money invested (approximately \$54 million USD for the Upper Guajira interventions), community participation (4,000 workshops on sanitation education, 19 community organizations strengthened, 57,000 household visits) and water service coverage $(120,000$ direct beneficiaries). Guajira Azul aims to expand the availability of potable water in the rural area of the Upper Guajira, from $4 \%$ to $70 \%$ in four years and to $100 \%$ in eight years, to meet the needs of a sizeable and growing Wayuu population with an increasing water demand (Ministerio de Vivienda 2018). The planned interventions include wastewater treatment facilities, water management plans, 42 drilled wells and 19 public fountains, as well as the community workshops mentioned above.

On February 1, 2020 at the Summit of Mayors of La Guajira, the Vice Minister of Water and Basic Sanitation, José Luis Acero, reaffirmed the national government's commitment to the Guajira Azul program. "We've come with enthusiasm to continue working with Guajira Azul, the most important intervention a National Government has made in the province... This will require all the support and political will of the leaders" (Redacción La Guajira Hoy.com 2020). While it is indispensable that the local representatives back the program for the allotted financial resources to be executed properly, it is just as important to understand the various pitfalls and possibilities of water interventions on Wayuu territory presented in this dissertation.

\section{Chapter summary}

The following chapter, Personal Episteme, Methods and Theoretical Bias, describes the methodological instruments and research design, organized into three 
phases: antecedents, ethnographic fieldwork and ethnographic and ethnohistoric data analysis. Here, I reflexively consider the epistemology of scientific writing and its influence on my dissertation, keeping in mind the theoretical bias inherent in all scientific research. I provide the reasons the study was carried out among the Wayuu on the topic of water, as well as the areas of study, a description of the mixed methods used and the data analysis instrument I employed.

The third chapter, The Wayuu Peopling of the Guajira Peninsula, is organized into two parts. The first uses a political ecology approach to provide a global assessment of pastoralism, including the challenges faced by pastoralists and the "bounded opportunities" they have for greater control of their territory and water sources. I provide examples of three pastoralist groups from three different world regions to show the effects of global and national processes and relations on local pastoralist societies. Through a political ecology perspective, the Raika of Rajasthan, India, the Diné (Navajo) of the American Southwest and the Kuria of East Africa reinforce the unequal relations between pastoralists, the state and other populations they interact and compete with for local resources. These examples will help situate the Wayuu within world pastoralism and provide insights into how global processes are reproduced locally. The second part of the chapter provides a biophysical description of the Guajira Peninsula and a historic overview of the Wayuu people. The chapter describes their interaction with other societies in the region, ranging from other Indigenous groups, African slaves, various European powers and other alijuna inhabitants. The chapter ends by introducing Mayapo, a Wayuu community that has shifted from a "traditional" mode of living to a "modern" 
one, and whose problems, water and otherwise, become more complex as it transforms from a rural to an urban settlement.

The fourth chapter, The Convergence of Multiple Scales of Water Governance on Wауии Territory, identifies various scales of water governance that coexist on the Guajira Peninsula, including global, national, provincial, private sector and community scales. To better understand the contested nature of water governance, this chapter uses a political ecology approach to explore how formalized global and national water management priorities have impacted traditional water relations. This chapter also analyzes the global water management framework known as Integrated Water Resources Management (IWRM) and hegemonic concepts such as water security and water scarcity.

The fifth chapter, Wayuu Water Knowledge and Hydrosocial Relations, uses ethnographic data to describe the traditional water relations of the Wayuu inhabitants of two areas in the Upper Guajira, Irraipa and Cardón. The chapter describes the seasonality of water sources and the relationship between pastoralism and farming with the seasonal cycle. Qualitative and quantitative data from the two areas are presented and analyzed to describe the relationship the Wayuu have with the various water sources. Seasonal maps of the two areas illustrate the distances covered to gather water and provide an instrument to determine if Wayuu water service standards are compatible with those developed by the World Health Organization, the UN, the World Bank and other global governing institutions. The chapter also identifies and describes local water quality standards, water management strategies and water governance mechanisms.

In Chapter Six, A Wayиu Water World, I explore a Wayuu ontological world where other-than-human persons such as Juyá (pronounced hoo-yah) and Pulowi play an 
important role in Wayuu-water relations. I present extensive transcriptions from interviews with Mayapo's outsü (shaman) and her asheyu (helping spirit) supported by other primary and secondary data to make visible the undervalued spiritual meaning of water for the Wayuu. The chapter ends by using critical social theory to discuss the obstacles of incorporating holistic, spiritual, non-scientific and non-empirical Indigenous knowledge, into a conventional resource management framework

The seventh chapter, Failed Water Interventions and White Elephants on Wayuu Territory, presents several cases of white elephants (failed water interventions) across the Wayuu territory. Here, I argue that the obstacles for bridging the divide between Indigenous and Western ontologies - power inequalities and cultural incompatibilityare the same impediments to the sustainability of the introduced waterworks. The chapter focuses on two projects to provide water for the Wayuu that resulted as white elephants: an aqueduct in the community of Mayapo, and reservoir-based water supply systems built in several Wayuu communities in the Upper Guajira.

The conclusion, Indigenous Water Governance in the Anthropocene, develops the idea of the Wayuu territory as a microcosm of the world in the Anthropocene. As a semiarid region with an extensive coastline and bordering Venezuela, the Guajira Peninsula encapsulates several interrelated problems that reflect current events occurring at the global scale. These include climate change, sea level rise, increasing drought conditions, desertification, population growth, political instability, mass immigration, corruption and increasing consumption. Under these circumstances, the complexity of water governance on Wayuu territory presents challenges but also a source of alternatives to the toxic relationship that now dominates between humanity and mother nature. 


\section{PERSONAL EPISTEME, METHODS AND THEORETICAL BIAS}

The present doubts about objectivity and the status of scientific knowledge followed a period of relative confidence and certainty, in which science was predominantly seen as the steady accretion of objective knowledge through the unproblematic medium of observation or "experience".

Method in Social Science (Sayer 1992, 45)

\section{Managing theoretical bias}

In Method in Social Science, Sayer states, "Our knowledge of the world is fallible and theory-laden... The conditions and social relations of the production of knowledge influence its content” $(1992,4)$. Proponents of STS (Science and Technology Studies) and feminist research have revealed Western science to be historically situated, socially constructed, male dominated and interest-driven (Kuhn 1970; Haraway 1989; Latour 1993; Sayer 1992). Its ascent to preeminence came at the expense of the multiple "belief systems" - described by Foucault as subjugated knowledges — of Western and nonWestern peoples that were systematically discredited for not meeting the criteria established by the scientific method (Foucault and Gordon 1980) (described further in Chapter 6). One key concept in this dissertation is epistemology, how we know what we know, arguing that small societies such as the Wayuu have local, contextualized epistemologies that are considered illegitimate by practitioners of Western science. In this chapter I reflect on the epistemological tradition I follow, the methods I use and the theoretical bias inherent in my research.

The academic discipline of anthropology stems from Western social science, albeit heavily influenced by its sustained interest in non-Western cultures as the object of study. Epistemologically, the discipline relies on an established intellectual paradigm, 
Western theories and methods, some of which I employ. As can be assumed after reading the introduction, I am also a believer in Western climate science. As the evidence of climate science mounts against the culprits of global warming, namely capitalist institutions such as oil, gas, coal and agro-industrial companies, as well as unsustainable consumption habits of an increasing human population, the findings have the potential to disrupt neoliberal capitalism and the fossil fuel industry's global hegemony. However, the limited progress in decreasing global carbon emissions despite the acknowledged urgency highlights the power of capitalist enterprises whose stakeholders have managed to keep scientific facts from garnering credibility and inciting the collective will to reverse the destructive forces producing global warming. In this sense, climate science and non-Western epistemologies face formidable opponents who have, up to now, been able to maintain the status quo of modernity. As indicated in Santos' ecology of knowledges, "forging the credibility of non-scientific knowledge does not suppose discrediting scientific knowledge. It simply implies its counter-hegemonic use" (2011, 36).

This does not mean that my belief in climate change and climate science goes unquestioned. My training as a qualitative researcher has instilled in me an almost instinctive suspicion of quantitative data. The use of mixed methods in my research has produced qualitative and quantitative data that I myself gathered ethnographically, can identify and describe their sources, and explain the epistemic strengths and weaknesses of the findings. Among the quantitative data gathered are human and livestock populations in the study areas, distances and time to water sources during different seasons, water consumption estimates per person and water source inventories. 
Through source analysis, the study of a document's validity (Barber and Berdan 1998), I have encountered quantitative data on Wayuu water use presented by the Colombian government and international humanitarian and lending agencies that are not congruent with my findings. Without citations or reference to the provenance of their data, I question these results and rationalize their divergence from my findings as a manipulation, exaggeration or falsification of the data to defend or synchronize with the dominant modernist paradigm of progress. After scrutiny of the "development" discourse by the World Bank report on Lesotho, Ferguson notes,

the mistakes and errors are always of a particular kind, and they almost invariably tend in predictable directions. The statistics are wrong, but always wrong in the same way; the conceptions are fanciful, but it is always the same fantasy... the picture of Lesotho as a species of a well-known genus, the genus "Less Developed Country" (1990, 55).

The institutions that produce this type of misleading information (propaganda) are abusing their privileged status as governing bodies whose findings may go unquestioned and ultimately provide the national and global statistics that are presented by the United Nation's Sustainable Development Goal (SDG) indicators and possibly those of the Intergovernmental Panel on Climate Change (IPCC). The increased importance of "factchecking" the communications of the executive branch of the current U.S. government underscores the declining trust of the "facts" released by institutions of power. Likewise, the current U.S. president has responded to the negative publicity he has received by mainstream media by repeatedly referring to it as "fake news." This use of (dis)information as a tool of persuasion by politicians and the free press reveals how personal and collective interests corrupt the professionalism and ethical conduct within reputable institutions, and science is not the exception. 
My academic and professional careers in cultural anthropology, imbued with the canons and the current tendencies of the discipline, have influenced my theoretical and methodological criteria. Using political ecology and ontological anthropology as my theoretical frameworks, my perspective of the situation encountered during fieldwork and interpretation of the gathered information is "fallible and theory-laden." Therefore, conflicting epistemologies, ontologies and ethics relating to water are addressed by recurring to my own interpretation of "the facts," a priority within postmodern anthropology. Within the social sciences, postmodernity is characterized by a shift from orthodoxy to heterodoxy, from singular narratives to pluralism, from reason to a critique of reason and from positivism to infinite semiosis (Fardon 1992, 25). I acknowledge, as I hope the reader will also, that the content of this dissertation is a product of, and limited by, multiple lenses that produce bias (theoretical, cultural, gender, ethnic, spiritual, ethical, linguistic and experiential). Recognizing this inherent subjectivity, I nevertheless strive to present valid and reliable information by using established anthropological research methods, detailed in the following section.

A focus on practice over discourse is emphasized in the dissertation because 1) my limited understanding of Wayuunaiki, the language spoken by the Wayuu, hindered a deeper discourse and linguistic analysis of the gathered information and 2) as Blaser argues, citing Latour and Law, “ontologies do not precede mundane practices, but rather are shaped through the practices and interactions of both human and nonhumans" (2010, 3). Graham and Penny further the proposition that indigeneity is enacted and "may best be understood in terms of contextually situated processes of being and becoming" (2014, 15). A classic example of routine and ritual activities generating an ontological world was 
the ceremonial exchange of necklaces and bracelets by the Trobrianders, known as Kula, that was accompanied by the trade and barter of ordinary items. Furthermore, as Povinelli states, "These other unperceived activities carried out in plain sight carry out the routine of creating the subjects who then take these routes and worlds as the best and most natural condition of the world" $(2011,7)$.

Therefore, my interpretation of Wayuu ontology is based more on their waterrelated routines, traditions, rituals and management practices, than on stated references to their belief or knowledge systems. This also implies that knowledge, for the most part communicated through language, is part of a larger web of meaning-making that is manifested by and manifests ontology and epistemology. Consequently, my theoretical assumptions guide my argument that Wayuu-water relations, sustained by Wayuu individuals, collectives and the entire society, form a legitimate livelihood, a cultural expression intrinsically special and a possible alternative to future tendencies.

Additionally, when given voice, this Wayuu alternative ontology becomes a counter-hegemonic manifestation critiquing "modern" Western societies' unsustainable water practices. Primacy is given to the silenced voices and overlooked governance practices of the water users, as opposed to the Wayuu leadership or non-Wayuu water and development agencies. As mentioned above, my description of Wayuu-water relations is ultimately an outsider's (etic) perspective founded on current critical social science theories of human-nature relations, coupled with my understanding and explanation of what I experienced, heard and read while spending time with the Wayuu.

In the following section, I reflexively consider the methodological instruments and research design, organized into three phases: antecedents, ethnographic fieldwork 
and ethnographic writing. Ethnography is both a methodology and a message. The ethnographic method involves gathering qualitative information, spending extended periods in the field and carrying out various research activities including participant observation, interviewing and surveying. The ethnographic message is what ethnographers produce after organizing, interpreting, analyzing and presenting their findings (Van Maanen 2011).

\section{Methodology, Phase I: Antecedents}

For nearly 13 years I have been engaged in work and study with the Wayuu. My Master's thesis, submitted in 2008, presented an ethnographic account of marketing by Wayuu women in the capital city of Riohacha, La Guajira, describing their role as cultural representatives and the challenges of maintaining and redefining their identities as Wayuu and women in an urban setting. This research informed my decision to move to La Guajira and serve the region as a professional anthropologist in development projects, cultural consultancy and higher education.

My initial motivation to academically study the Wayuu's relationship with water began in 2012 when I carried out two socio-cultural assessments in Wayuu territory on Wayuu-water relations while working as an anthropologist for the Cerrejón Foundation for Water in La Guajira (now the Cerrejón Foundation for Progress of La Guajira). The project's goal was to design and implement a sustainability plan for four reservoir-based water supply systems in the rural area of the municipality of Uribia, in Wayuu territory. Along with a Wayuu assistant, I conducted ethnographic fieldwork in two of these rural areas, in the village districts (corregimiento) of Cardón and Irraipa. I spent a total of 2⿺辶⿸ months in the two areas visiting 60 communities, conducting semi-structured and 
unstructured interviews, household surveys, participant observation, water source assessments, workshops, social cartography and georeferencing points of interest. ${ }^{3}$

As I describe in Chapter 7, the construction of the water supply systems and the sustainability project did not go as planned. The large amount of information gathered on the water sources in Wayuu territory and the way the Wayuu understand, use and manage water was organized into reports and delivered to the local government where it was shelved and forgotten. Pondering the disappointing result, I asked myself who, what, when, where, why and how things went wrong. These questions led me to write this dissertation.

Prior visits to Wayuu territory and interaction with members of this Indigenous group throughout my life had also brought me closer to the Wayuu people and broadened my understanding of their culture, territory, idiosyncrasies, concerns and aspirations. By describing my own non-academic social ties with the Wayuu, I am essentially describing common forms of social relationships between Wayuu and alijuna, both within the city of Riohacha and in Wayuu territory. These relationships include, but are not limited to, intercultural marriages, the Catholic bond known as compadrazgo, the informal adoption of a Wayuu youth by an alijuna family, the door-to-door commerce performed by Wayuu women known as marchantas and the transformation of peripheral Wayuu communities into city neighborhoods.

My father is from Riohacha, and while neither he, nor my paternal grandparents, are Wayuu, we have Wayuu family through intercultural marriages, as do many alijuna

\footnotetext{
${ }^{3}$ Fieldwork in Cardón was carried out between March 5 and May 5, 2012; in Irraipa, fieldwork was done between August 6 and September 20, 2012.
} 
residents of Riohacha. My uncle Juvenal Robles, who is my father's half-brother, spent his entire adult life in the Wayuu coastal salt mining town of Manaure, learned the native language and over the course of his lifetime had 17 children with seven Wayuu women. My Uncle Juvenal's interethnic relationships with several Wayuu women also serve to explain two important and opposing elements in the Wayuu society, the historic and ongoing mestizaje (miscegenation, inter-racial unions resulting in mixed race offspring as well as assimilation to the dominant society) that has occurred in La Guajira and the simultaneous maintenance or increase of the Wayuu ethnic stock and identity.

The Wayuu practice polygyny, the form of marriage that allows a man to have multiple wives. For the Wayuu man, having multiple wives is a sign of his affluence because he and his maternal family must have enough wealth to give the bride price to the bride's family. Therefore, while most Wayuu men only have one wife, it is not uncommon for some to have more than one. For Wayuu women, sharing a husband with other cowives is not a cause for shame, jealousy or resentment. To better understand why, it is necessary to clarify that the Wayuu are a matrilineal society, whose members trace their ancestral lineage through their maternal family. The Wayuu have three terms for family, apüshi, оирауи and аsanua (Goulet 1978, 300). The more important term in regard to social organization and solidarity is the apüshi, a person's maternal family of the same clan (e'iruku). The apüshi includes the woman (ego), her mother, siblings, sister's children, own children, daughters' children, among other who share the maternal lineage (Ibid). In this sense of the term for family, the man of the household, who is ego's husband and father of her children is, by definition, not part of the apüshi (maternal family) because he is not of the same matriline. Any children born of the union are not of 
his clan or apüshi. Oupayu refers to ego's husband and his matrilineal family, while asanua are ego's husband's children from another woman, his brother's children and his sister's son's children (Ibid). Consequently, a relationship between a Wayuu woman and a husband who has other wives should be understood not by any Western or patrilineal conception of the general term family (nor nuclear or extended family) but by local kinship terms and their implications.

Children are ascribed membership to the clan of their mother; likewise, the offspring of an alijuna man and a Wayuu woman is Wayuu because he/she receives the "flesh" (e'iruku) of the clan (in Wayuunaiki, the same term is used for flesh and clan). For the Wayuu, the flesh is considered the more important substance in the creation of the fetus, contributed during conception and gestation by the mother, while the father contributes the blood, asha, of less importance (Ibid, 23). Furthermore, most polygamous marriages are matrilocal; the wives maintain their premarital residence and are responsible for raising the children. Therefore, both biologically (according to Wayuu genetics) and culturally, most children conceived between an alijuna man and a Wayuu woman are Wayuu. This type of kinship system served the Wayuu society to increase rather than decrease its population during the colonial and Republican eras when Hispanic men had children with Indigenous women, a pattern pervasive throughout Latin America, as well as contemporary interethnic unions, as in the case of my Uncle Juvenal and my own marriage.

In 2013 I married a Wayuu woman from Riohacha of the Ipuana Clan with whom I have two children. My wife, Edith, is a monolingual Spanish-speaker who was born and raised in the Ranchería neighborhood of the city. I have learned a lot from my wife and 
her family about another dimension of the Wayuu society, the growing number of urbanized Wayuu. This population includes those Wayuu who have migrated out of the small, rural communities to live in the city; those whose community was engulfed by Riohacha or other urban centers, transforming it into a peripheral neighborhood as the urban areas expanded, such as the communities of Edith's parents; or those who have never lived in a rural community and consider the city their home, such as my wife and her siblings. Urbanized Wayuu are the most susceptible to assimilation forces and voluntarily or involuntarily make daily and lifetime decisions to maintain, abandon or adapt Wayuu culture and traditions.

The Wayuu anthropologist Weildler Guerra Curvelo, son of a Wayuu woman of the Uliana Clan and a mestizo man of Colombia's Andean region, is an example of how an urbanized Wayuu has represented with dedication and honor both the Wayuu and alijuna Guajiros, regionally, nationally and internationally. Guerra wrote a book on the Wayuu normative system titled The Dispute and the Word: Law in Wayuu society (2002), which contributed to the recognition of this institution and the figure of the mediator (pütchipu) by UNESCO as an Intangible World Cultural Heritage in $2010 .{ }^{4}$ He was also designated governor of La Guajira in 2017 by then President Santos, was accepted into the Colombian Academy of History in 2013, received his PhD in anthropology in 2019 in

\footnotetext{
${ }^{4}$ Guerra is a prolific writer whose books include El Poblamiento del Territorio (The Peopling of the Territory) (2007), Un Mirada Histórica y Etnográfica a la Cuenca del Río Ranchería (An Historic and Ethnographic Look at the Rancheria River Basin) (2013), El Mar Cimarron (The Wild Sea) (2015) and his PhD dissertation titled Ontología Wayuu: Categorización, Identificación y Relaciones de los Seres en la Sociedad Indígena de la Península de La Guajira, Colombia (Wayuu Ontology: Categorization, Identification and Relationships of Beings in the Indigenous Society of the Guajira Peninsula, Colombia) (2019). He also writes regularly in the regional newspaper, El Heraldo and national newspaper El Espectador, among others.
} 
the highest ranked university of Colombia, Los Andes, and this same year, became part of the Mission of the Learned - a select group of intellectuals who determine the country's vision for science, technology and innovation. Other Wayuu writers such as Estercilía Simanca, Vicenta Sioci and Miguel Angel Lopez (aka Vito Apüshana) have gained national and international acclaim by describing both the uniqueness of the Wayuu culture and the injustices this Indigenous society has historically faced. These urbanized Wayuu spokespersons and the whole of Wayuu city-dwellers expand what it means to be Wayuu in various and novel ways.

Another widespread practice among the more affluent Riohachan residents that has linked the alijuna and Wayuu societies is the informal adoption of a Wayuu boy or girl, sometimes as young as six or seven years old, to help care for an elderly or young member of the family and carry out household chores. It is understood that the child or adolescent will live with the family and carry out the tasks required of her or him. In exchange, he or she will receive food, boarding, education and all other necessities such as clothing, school supplies, medical treatment, personal hygiene products, among others. These Wayuu youth maintain ties with their families who live in the countryside, often visiting them on the weekends or receiving visits from them. The Wayuu parents see these arrangements as a means to distance their child from poverty, gain security, stability and the opportunity for a better education and future employment. Strong bonds are created between these Wayuu youth and the families for whom they work, often becoming like another member of the family. In the early 1990s, my Aunt Paulina brought in an adolescent Wayuu girl to help care for my grandmother. Her name was Dolores and she was diligent, respectful and patient. After a few years she found another 
job, got married and had children. My aunt and Dolores maintained contact over the years and now, almost 30 years later, Dolores is once again helping take care of my aunt parttime.

Over the last ten years I have formed relationships with three other Wayuu families through compadrazgo or becoming a godparent through the baptism of a child. This religious ceremony forms lasting social relationships between the godparents and child, as well as between parents and godparents. Often, the Wayuu will seek out an alijuna to become their child's godparent in order to strengthen their ties to that person and to the alijuna society. The godparent may be called upon to help the godchild throughout his or her lifetime, whether it be school-related, job-related or in times of sickness or financial difficulties.

Lastly, my understanding of the Wayuu was, and continues to be, shaped by the many encounters with them in order to purchase the products they sell in the city. Commerce is perhaps the earliest activity that bound the Wayuu and the alijuna since their initial encounter over 500 years ago. The marchantas, or the ambulatory Wayuu street vendors, embody the ties that link the urban alijuna society with the rural Wayuu society. Guerra notes that,

in Riohacha, the Wayuu marchantas are indissolubly bound to the mornings. For more than four centuries they have arrived with the punctuality of the sun to the Creole homes purveying them with food and human warmth... Each one of these itinerant women appears to have her own circuit in the city, a tacit intercultural contract that ties her community with certain streets and homes. (Guerra Curvelo 2007)

Among the products sold are sun-dried shrimp used to make Riohacha's signature dish, shrimp rice, as well as curdled milk and local varieties of beans, squash, 
watermelon, plum, cherry, cantaloupe and other farm and wild food products. In the past, Wayuu women supplied the city's residences with lump charcoal and firewood for cooking. These products are still available, yet much less prevalent since the introduction of the gas stove in the mid-1900s (first, using propane tanks, then, by piping). Likewise, water delivery was another centuries-old service done by Wayuu men that gradually became unnecessary with the introduction of water trucks and the construction of Riohacha's first aqueduct in 1923. Wayuu men known as barrileros (barrelers) delivered water from the nearby Ranchería River, which they gathered and hauled in barrels to the residences of Riohacha (Guerra Curvelo 2013, 71).

\section{Methodology, Phase II. Ethnographic fieldwork}

The ethnographic fieldwork phase consisted of my entry, presence and departure from the fieldsites. This phase began when I initiated preliminary fieldwork in La Guajira from May to August 2015 and a second visit from June to August 2016 (IRB \#103430, Appendix 3a, both funded by the Tinker Foundation). The base site for my research was Riohacha, the capital of La Guajira province. Most of the Wayuu territory is in this province and the city contains the principal public and private water sector institutions, universities and libraries. During the two initial visits, totaling six months of fieldwork, I carried out the following research activities:

- Literature review of archival and secondary documents of the Wayuu and waterrelated issues in La Guajira in departmental historical archives, libraries and public and private water sector institutions.

- Identification of water and development agencies and government programs operating in Wayuu territory. 
- Semi-structured interviews with personnel of public and private water sector institutions in the city of Riohacha.

- Fieldwork in 19 communities throughout the rural area of the Guajira Peninsula that included informal, unstructured and semi-structured interviews, participant observation and water source assessments.

Informed by prior coursework, theoretical and topical literature reviews, discussion with my committee members and preliminary fieldwork, I formulated a research proposal with clear objectives targeting two specific fieldsites, three sets of actors, three grassroots initiatives along with a feasible timeline and accepted methods. What I thought was a well-formulated proposal turned out to be untenable when two of the grassroots initiatives looked legitimate on paper but had failed to materialize. The third initiative seemed promising, but communicative, logistic and accessibility problems impeded an ethnographic study of it. While my research plans began to fall apart, other opportunities presented themselves. I ultimately narrowed my study to one set of actors, the water users, in one community to do long-term fieldwork, Mayapo, supplemented by short-term fieldwork in 23 other Wayuu communities. The formal grassroots water governance initiatives were replaced with a broad range of individual and collective informal water-related practices that provided the foundation to the theoretical and ethnographic findings in this dissertation.

Between June 2017 and December 2018, I conducted the majority of my dissertation research (IRB \#105382, Appendix 3b, 3c) and worked as a researcher at the University of La Guajira on a research project carried out by the interdisciplinary research group Semi-arid Territories of the Caribbean (funded by Colciencas, Colombia's administrative department of science, technology and innovation, project 
\#114574859311). This project consisted of gathering primary cultural and biophysical information from communities along the coastal zone of the Department of La Guajira with a focus on its cultural diversity in order to provide guidelines to the institutions and communities on territorial ordering. Territorial ordering in Colombia is an instrument used by the state to "exercise control over the territory and also, to encourage a certain development model” (Hernández Peña 2010, 99). The university project aimed to bolster the understanding of culturally contextualized self-regulation practices by the local inhabitants of the natural resources on their territory, identifying the similarities and differences with those implemented by the state (Carabali et al. 2019). The studies complemented each other; my dissertation research provided ethnographic insights for the university project, and the latter gave me access to over 15 communities across the Wayuu territory under the auspices of the university research group (see Map 1).

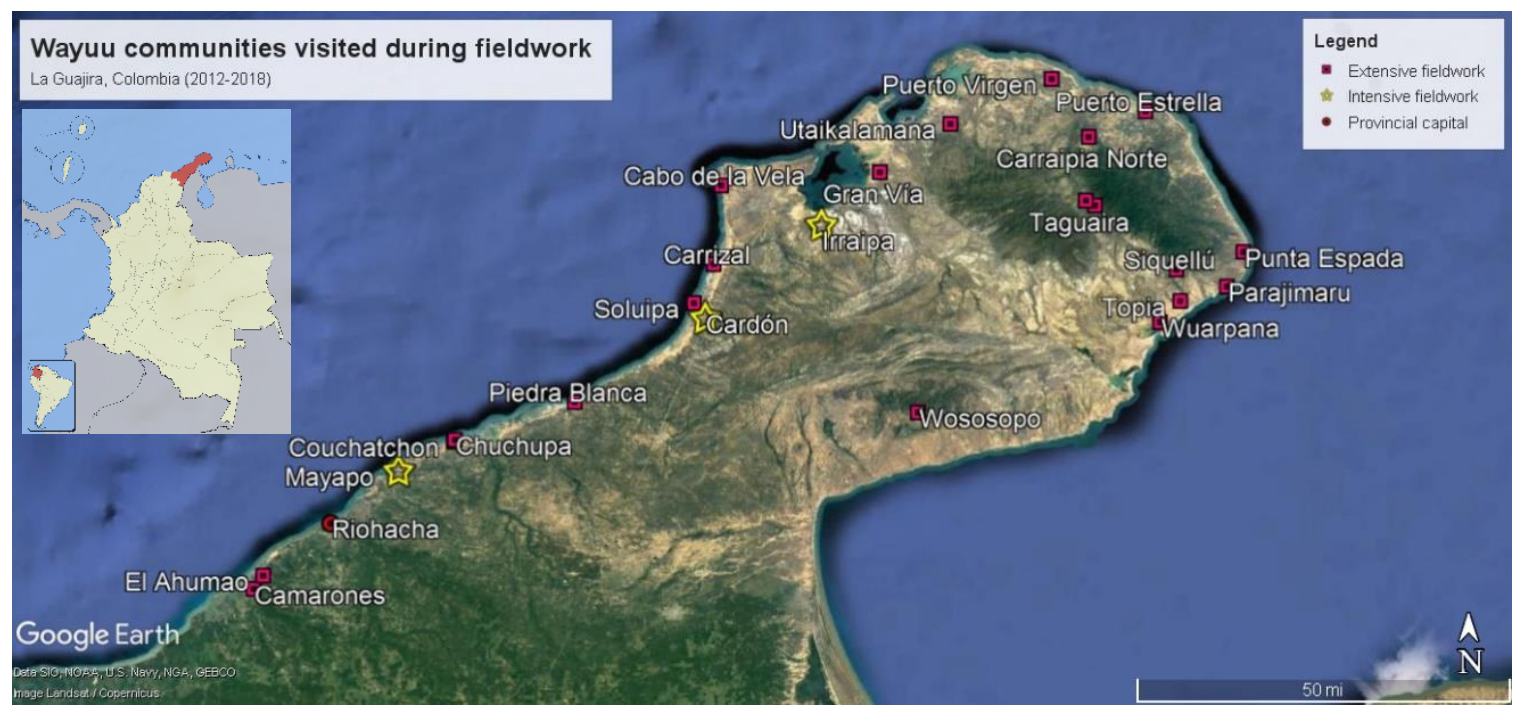

Map 1. La Guajira Peninsula with fieldwork sites

The funding and support received from the grants and the university project were essential since many of the communities visited were not easily accessible and 
transportation to the rural areas of the peninsula was costly. Approximately 50 miles northeast from the city of Riohacha, the paved road ends and only $4 \times 4$ vehicles driven by experienced drivers can transit the unpaved roads and countless trails in order to reach the small, dispersed Wayuu communities.

For this reason, these trips are not only arduous but also expensive. Furthermore, the accompaniment of a native-speaking Wayuu, preferably from the community visited, is recommended because of the language barrier and for safety reasons. Non-Wayuu travelling through Wayuu territory without a tribal member are not assured the same assistance or protection from assaults or other crimes by other Wayuu as one who is. This is because, for the Wayuu, their law supersedes national law. Any act that is considered an offense to a Wayuu member becomes the concern of the offended party's matrilineal family (apüshi), to be resolved through economic compensation, which, if it goes unfulfilled, may lead to armed conflict between the two apüshis (Guerra Curvelo 2002). Through the several outings to Wayuu territory, I became acquainted with various Wayuu students, professionals and local leaders who served as guides, interpreters and coresearchers. ${ }^{5}$ I want to highlight the importance the labor of these Wayuu individuals, especially my research assistant in the community of Mayapo, Margelis Illidge.

Margelis, now a professional social worker, at the time was a student in her last year of college. She had worked with me in the Colciencias project a few months prior,

\footnotetext{
${ }^{5}$ In 2012, the fieldwork I carried out for the Cerrejón Foundation for Progress of La Guajira in 27 communities in Cardón, was completed with the accompaniment of Jasai Pérez and in the 34 communities of Irraipa, Nelvis Ipuana and Arnoldo Pimienta were my Wayuu interpreters and co-researchers. The Wayuu guides, interpreters and co-researchers that accompanied me to the 23 short-term fieldwork sites between 2015-2018 were: Aida Kuast, Erika Muñoz, Clemencia Pushaina, Elydis Herrera and Margelis Illidge.
} 
translating, transcribing documents, applying surveys and interviews. She was also a member of Mayapo who had moved out of the community over 10 years ago but had maintained contact with her family and friends there. As a native speaker of both Wayuunaiki and Spanish, she effortlessly switched between the two languages. Her witty, humorous personality and gentle demeanor, as well as her ample knowledge of the community's residents and history, gave her greater rapport and confidence with those she interacted with. She would introduce me to the interviewees as profesor David since I had worked in the local university and added that I was married to a Wayuu woman from the Ipuana Clan. My status as a professor lent credence to the study and my affinal ties to the Wayuu added a level of familiarity and assurance, especially to those of the same clan, such as the traditional authority of Mayapo, Erasmo Ipuana.

Our work in the community was also facilitated because Margelis' father was a well-known and respected member of the community. Halfway through the fieldwork she half-joking, half serious (I wasn't always sure which when she made these type of remarks) said that she owed lots of people favors in the community for having given me their time and answered my questions. While I did compensate each interviewee with a small care package of food items and on occasions small amounts of money, in her mind this did not exempt her of returning the favor in the near or distant future. As with all meaningful relationships, reciprocity is fundamental among the Wayuu, as evidenced in collective work, bride price contributions, compensation of offenses, food distribution at funeral gatherings, transhumance practices, hospitality norms and many other quotidian encounters of gifting and counter-gifting. 
The Colciencias research project at the University of La Guajira gave me the opportunity to visit, and revisit, over 15 Wayuu communities over a four-month period (August-November 2017). In each community I coordinated a social team that carried out social cartography, participatory workshops, individual interviews and surveys that addressed issues relating to their history, territory, culture, resource use, current problems and future expectations. I was able to inquire specifically about their water sources, water issues, local and external solutions, if any, and the effectiveness of these. In each community I inspected its water sources and registered their current state and related information. Through this extensive, rather than intensive, fieldwork across the Wayuu territory, I was able to gain a more general understanding of the complexity of water provisioning among the Wayuu, the centrality of water in their subsistence livelihoods and the various ways they secure water daily and throughout the year. The word cloud in Figure 2 shows the 25 most frequent words used by the members interviewed in the 15 Wayuu communities visited, the largest words being the most frequent. The top ten words in descending order are water, fishing, animals, sea, Wayuu, rain, work, problem, fish, goats. At a glance, these words highlight two of the main activities practiced (primarily by men) in Wayuu territory, fishing and herding, and the importance of rain and water in their lives. With the information from this component of my fieldwork, I also made comparisons between communities, areas within the Wayuu territory and between different types of water sources, technology and infrastructure. 


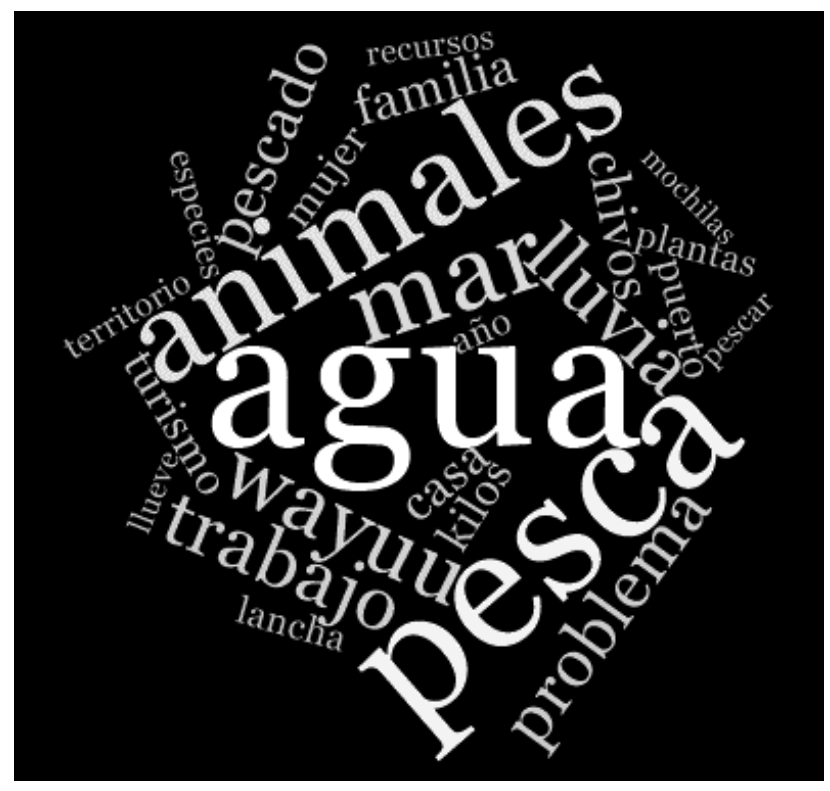

Figure 2. Word cloud with the most frequent words used by Wayuu interviewees

In August 2018 I met with the local authority of Mayapo, Erasmo Ipuana, to explain the objectives of my study and request permission to carry out long-term fieldwork in the community. Mr. Ipuana, in his 80 s and a direct descendant of the founding clan, is one of the community's elders and is highly respected and esteemed by the entire community. Notwithstanding his advanced age, from the first conversation with him and subsequent ones throughout my time in Mayapo, it was clear that this man had a vast understanding of the territory, the people, the history of the community and of Wayuu culture in general. Besides being the community's representative, he was also a pütchipu (local moral authority, mediator, orator), who has been called upon numerous times to resolve conflicts between families within and beyond the community. While his eyesight had begun to diminish, his voice was still strong and clear when he spoke, revealing his authority, leadership and oratory skills through decades of serving the community as the alaüla (maternal uncle, authority figure) and pütchipu. 
With Margelis as our interpreter, Mr. Ipuana described Mayapo’s water situation, how it was in the past and how it had changed, as had the community. Central to his concerns was the water treatment plant installed in 2013 that was meant to provide clean water to all the residents of Mayapo and another small community near Mayapo. Unfortunately, when the elevated storage tank with the capacity to serve the entire community was filled for the first time, copious amounts of water seeped out its bottom, wasting it and threatening the nearby houses if it eventually collapsed. An older, smaller water tank next to the damaged one (that also seeped water, but not as much) was adapted to the new water system but only provided water for one hour per day for roughly a third of the population. For several years now, the residents have had to deal with this situation that has divided the community into those with access and those without. Mr. Ipuana expressed sorrow for those who did not receive clean water to their homes. He also voiced his frustration for the false hopes raised by the municipal government representatives and aspiring politicians who promise solutions to the water problem in Mayapo but do not fulfill those promises. Mr. Ipuana also revealed signs of resignation and impotence to the fact that the waterworks may never be repaired, after insisting with the government and the water service provider for several years to no avail (Mayapo's water problem is explained further in Chapter 7).

After explaining the water situation in Mayapo, Mr. Ipuana gave me permission to do the study and talk with him further on another occasion. This initial visit was important because for the Wayuu, informed consent begins with the representative of the community prior to visiting any of the residences. Each interview would be carried out in the preferred language of the interviewee, Wayuunaiki or Spanish. If it was Wayuunaiki, 
Margelis would interpret, and if it was Spanish, I would ask the questions directly to the participant. Out of a sample size of 60 households, 25 were done in Spanish. All the participants were Wayuu except for two Afro-Colombian men who had married women from the community. Besides these two participants and one Venezuelan Wayuu, the other 22 who were interviewed in Spanish also spoke Wayuunaiki as their native language. Each interview was conducted at the participant's residence, usually under the sunroof where guests are customarily received. At the beginning of each interview, Margelis or I would explain the study, who we were, state that we had met with the traditional authority and proceed to request their verbal informed consent and permission to record the conversation and take photographs of the water piping, water containers, corrals and crop fields. A digital recorder and a notebook were used during each interview, as well as a GPS to record the coordinates of the residence. Each interview was later transcribed (and translated to Spanish, if necessary) and coded during the ethnographic writing phase using NVivo qualitative coding software, described in the next section.

The quantitative information gathered during the interviews included: occupation, gender, age, clan affiliation, family size, livestock ownership, water consumption practices, water sources used and water expenses. The qualitative included: past and present water use and management, local perspectives of the current water situation, thoughts on the relationship between the Wayuu with non-Wayuu companies or agencies, descriptions of economic and domestic water use activities and discussion on traditions, practices and beliefs relating to water. 
During fieldwork and with the help of Margelis in her role as a local informant, we determined that the sample must include households from the different sectors of the town, covering all types of water accessibility and include members of each of the clans residing within the community. Another factor influencing water access was the increased demand on the local water supply by Venezuelan migrants. ${ }^{6}$ Therefore, I chose to include four Venezuelan households from different sectors of the community in the sample. A total of 60 semi-structured household interviews were conducted out of 306 households in the community (19.6\% of total).

Forty of the household interviews were with women (67\%). All the interviewees except for two alijuna and one mestizo (mixed race) Wayuu claimed membership to one of nine Wayuu clans; members of the Epinayu and Epieyu Clans were the most interviewed (30\% and 16\% respectively). As for livelihoods and household economic activities, $47 \%$ of the households sampled owned livestock, $28 \%$ practiced seasonal farming, 13 out of 20 of the men interviewed were fishermen or worked in the fishing cooperative (65\%), and $78 \%$ of the women interviewees claimed weaving as their primary or secondary occupation.

Besides the semi-structured interviews described above, informal and unstructured interviews, participant observation and georeferencing were carried out at various locations and moments in the community between August and December 2018. Among those interviewed were farmers, herders, local leaders, fishermen, shamans (f.

\footnotetext{
${ }^{6}$ With the economic crisis in Venezuela producing mass migration to Colombia, the department of La Guajira receives a significant number of migrants for sharing an extensive border with the neighboring country. Mayapo, despite its limited options for work, has received nearly 100 Venezuelans according to estimates by the village inspector.
} 
outsü, m. outshi), herbalists, midwives, Venezuelan migrants, mediators (pütchipu), the village inspector, the traditional authority, the community council president, restaurant owners, weavers, elders, homemakers, teachers, construction workers and one nonhuman person (see Chapter 6). Visits, walks and conversations with residents took place in and around Mayapo's crop fields, beach sector, fisher's cooperative, ponds, cemetery, schools, surrounding pastures and nearby communities.

The ethnographic study in Mayapo culminated in early December 2018, amid a grieving community due to the loss of one of its dearest members and leader, Olga Rodriguez of the Epinayu Clan. Ms. Rodriguez served the community as its first health promoter and lobbied for the construction of the community's health clinic in the 1980s. She was deeply concerned for the health and wellbeing of the inhabitants, most of whom were her family and neighbors. Unfortunately, her own health deteriorated while she was in her 60s and she departed this world on November 30, 2018, leaving a void in her family and community but also a legacy never to be forgotten.

My final visit to the community coincided with the fourth day of her mourning. For the Wayuu, a death of a family member is a time of gathering, paying respects and accompanying those closest to the departed. The Wayuu receive funeral guests at the cemetery where each family has its sunroof and a makeshift kitchen next to the graveyard. It is also common for family and friends to spend a few days after the burial at the cemetery or residence of the deceased's family. Food and alcohol are usually abundant, provided by the hosts who also give meat and livestock to the guests from the stock of the late owner. Those sacrificed animals are thought to reunite with their owners 
in Jepira, the afterlife, so that they will have their livestock and therefore not go through hardship (Perrin, Michel 1993).

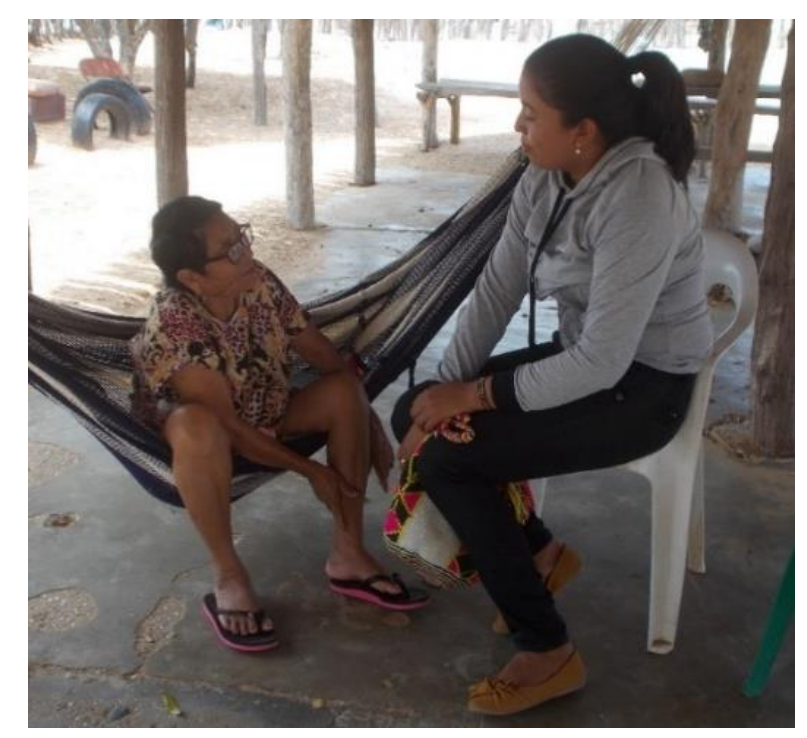

Figure 3. Ms. Olga Rodríguez (left) who kindly received Margelis (right) and me Source: Photograph taken by author.

On that day dozens of people were gathered at Ms. Rodriguez' house. I gave my condolences to her family and remembered how she described the Mayapo of her youth and the construction of Mayapo's first pond by General Rojas Pinilla, Colombia's president in the 1950s, lamenting, "We are very grateful to Mr. Rojas. When he died it brought us sorrow due to the appreciation we have for him" (See Figure 3). She also talked about the difficulties Mayapo has faced and is facing as it grows and transforms into a town. Mayapo's growing economy and improved utilities have not benefitted all members of the community equally, causing internal disputes and factioning that did not exist in the past. Among the topics she shared with me, she transmitted a feeling of nostalgia for the days gone by of Mayapo when life was difficult but simpler and 
relationships more intimate. Today, the community is grappling with the entrapments of modernity.

Margelis found a place in the shade for me and my three-year-old son Shane, who I'd brought with me, and then she returned with two plates of grilled goat meat, cooked manioc and uujot, a refreshing corn-based drink. As I conversed with Margelis' father, I looked around and saw women in the open air kitchen preparing food, guests eating, drinking, resting and telling stories under the sunroof, a group of men gathered around a large barrel filling used plastic soft drink bottles with chirrinchi, a locally produced liquor, and kids playing or idly watching or listening to the grown-ups.

The traditional authority was not present so Margelis, Shane and I walked to his house and found him resting in his hammock. I wanted to let him know that my study in the community had concluded and express my gratitude for his willingness to elucidate me on various occasions about Mayapo and grant me access to the rest of the community. I explained a few generalities of the time I had spent in the community, the number of households I visited, the various interviews I conducted and concluded that the information I gathered would be documented in a book that I (ambitiously) hoped would help improve the water situation in Mayapo and the Wayuu territory. I wished the best for him, his family and the community and gave him a photograph I had taken during a prior conversation with him (Figure 4). He thanked me for the picture and for taking the time to inform him that my study was over, noting it was considerate and respectful on my behalf. 


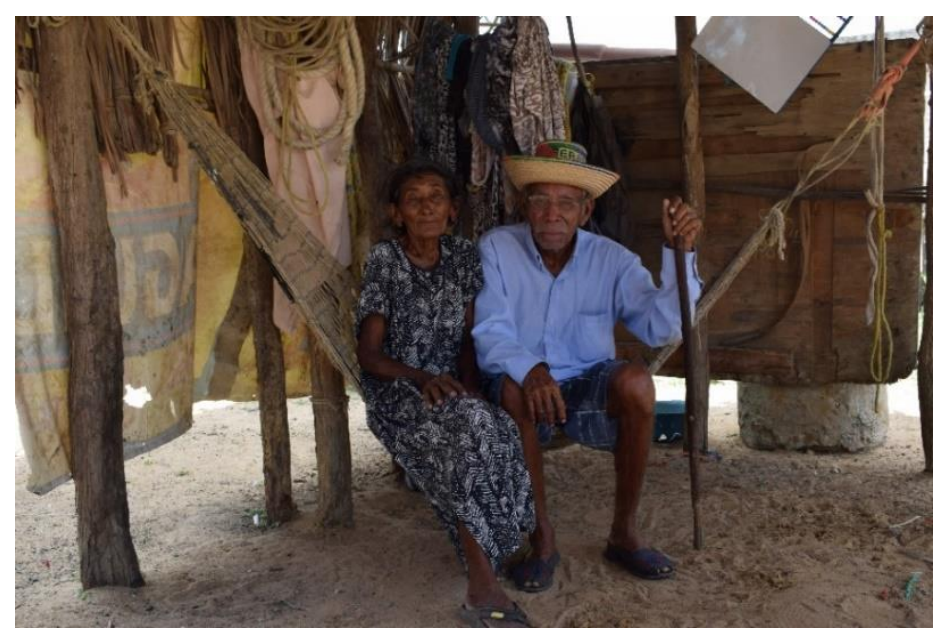

Figure 4. Mr. Ipuana, the traditional authority and his wife Mrs. Epieyu, Mayapo's midwife Source: Photograph taken by author.

Our last stop before leaving the community was to say goodbye to Margelis' aunt and uncle who we would visit occasionally and have coffee. Her aunt gave birth to a son two months earlier and seeing him that day reminded me that loved ones are lost and are also born (See Figure 5); where there is grief, there is also room for hope and happiness. Enigmatically, Margelis asked me, “Are you ready to be this boy’s godfather?” I just chuckled and made a mental note to ask her later if she was being serious or not.

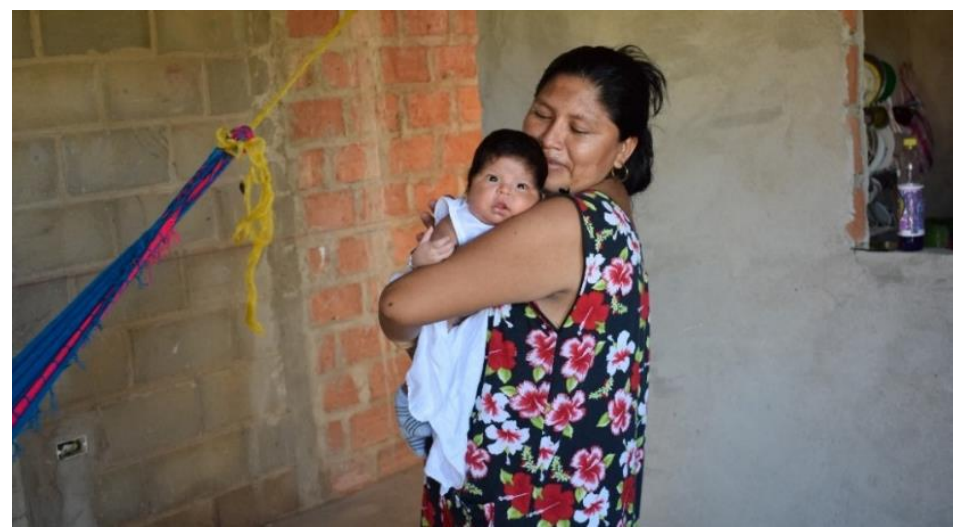

Figure 5. Mother, Zoila, and son, Samuel. A member of the Epieyu Clan is born. Source: Photograph taken by author. 


\section{Methodology, Phase III. Ethnographic and ethnohistoric data analysis}

The ethnographic and ethnohistoric data analysis phase entailed the organization, analysis and interpretation of the data. It also included a return to the academic literature and the integration of the theoretical framework with the empirical evidence. Ethnohistorical data analysis engages in both cultural and historical analysis, which merges methods from fields that have in the U.S. traditionally been separateanthropology, with a focus on non-Western cultures — and history, whose attention has been towards written documents within Western societies (Wiedman 1986; Harkin 2010; Barber and Berdan 1998). Ethnohistorical research methods were used to identify, collect and analyze historical archives, organizational documents and other written and oral historical data produced by Wayuu and non-Wayuu sources, including maps, reports, newsprint, websites, legislation, oral history and others.

I used Nvivo, a qualitative research software, to help me organize and code the primary and secondary information. Initially, and throughout the research, articles from various English and Spanish language websites about the water situation among the Wayuu were stored in NVivo. These sources included international, national and local news agencies, humanitarian assistance organizations, NGOs, development agencies and government agencies. I also used NVivo to store the interview transcriptions and fieldnotes. These were systematically coded based on coding themes created to isolate blocks of qualitative data based on a code book with categories and sub-categories developed out of the research objectives (Appendix 1) (Saldaña 2013).

With the information coded, the software allowed me to perform queries to the encoded information and the texts in general that produced word frequencies, allowed for 
word searches of key terms, identified relationships between codes and between different cases. Memoing, or "taking 'fieldnotes' on observations about texts" (Bernard 2006, 499), was another important activity during this analysis phase. Writing memos while coding and exploring the research material was key to recording any emerging ideas, themes, questions and connections. In other words, the organizing, coding, memo-writing and query-making allowed me to gain familiarity with the data, immerse myself in it and transform it into knowledge.

For the quantitative information of the surveys, Nvivo generated a data sheet to make comparisons between the different water users (Appendix 2). Using this data sheet and the GPS points of each residence, I created a household water distribution map based on the sample size of 60 households comparing the type of access the water users have to the two water supply systems operating in Mayapo (See Map 9, Chapter 7). The map shows the unequal access the households have to the two water supply systems with just over a third of the population with treated water piped to their house and half the population without service from either of the water supply systems. 


\section{THE WAYUU PEOPLING OF THE GUAJIRA PENINSULA}

Many theorists view increased mobility as a defining symptom of modernizing societies. Migrant pastoralists, however, are taken to be nothing but remnants of outdated social formations that have no place in our modernity.

Greener Pastures (Agrawal 1998, 20)

"All the horses and goats and many sheep around here were killed. Their bones still lie around. We live among their bones." And then he added: "When they reduced the stock, many men, women, boys and girls died. They died of what we call ch'éná, which is sadness for something that will never come back."

Diné medicine man quoted in Dreaming of Sheep in Navajo Country

(Weisiger 2009, 243)

Introduction

The uneven relationship between pastoralist societies and national governments is inherently power-laden and often prejudicial to the smaller herding societies since they do not follow the established norms of modernity such as sedentarism, land privatization and full participation in the market economy. Contradictions in theories and policies demonstrate the polarized views towards pastoralism and the highly contested nature of water governance by various actors at all levels-local, regional, national and international. Power inequalities and deep cultural divides between Western experts and pastoralists have led to miscommunication, misunderstanding and incompatible agendas, resulting in a history of failed attempts at sustainable development among these groups (Escobar 1995; Ferguson 1990; Scott 1998; Fratkin and Roth 2005; Gonin 2015).

This first part of this chapter describes the "bounded opportunities" of pastoralist societies by applying a political ecology approach. I analyze how disparate groupsIndigenous pastoralists, ranchers, farmers, capitalists, environmentalists, scientists and government agents - negotiate their interests and agendas within the dominant paradigms 
and worldviews of the era. By exploring the contested relations between various

pastoralist groups worldwide with the nation-states they are a part of, I wish to

demonstrate that the Wayuu pastoralists are part of generalized patterns and suffer similar problems that affect pastoralist societies worldwide. ${ }^{7}$

Conflicting interests and ideals over land use and management can be understood using two political ecology perspectives, Escobar's modernity/coloniality/decoloniality perspective (MCD) (2008) and Robbin's degradation and marginalization thesis (2012). These critical social theories deconstruct the prevailing discourses that position cultures as either "protectors" or "destructors" of nature, but in both cases as completely separate from nature. These are two extremes of human-nature relations that no human society could ever belong to, precisely because the destructor/protector, us/them, nature/culture and past/present binaries collapse upon close examination (Haraway 1989; Pred 2004; Butler 1999; Latour 1993; Sayer 1992).

Arturo Escobar's modernity/coloniality/decoloniality (MCD) perspective (2008) questions whose interests get served during development. He argues that unless the pattern of imposition by the dominant toward the disempowered is halted and the flawed Eurocentric worldview gives way to an acceptance and implementation of subordinate local knowledges, decontextualized and unsustainable development will continue to be the norm (Escobar 2008). The unquestioned emulation of "First World" societies by

\footnotetext{
${ }^{7}$ New World pastoralist societies figure far less in the body of literature on pastoralism. In a database search on pastoralists production systems by Golluscio $(2010,1330), 77.2 \%$ of the 451 results were from Africa, another 20.6\% from Australia and Asia combined, while only 2.4\% from the Americas. Most research on Indigenous pastoralism in the Americas has focused on Arctic reindeer and Andean camelid herding (Galaty and Johnson, 1990), both of which predate European colonization; lesser studied have been pastoralist societies in the American Southwest, Mapuche pastoralism in Patagonia and Wayuu pastoralism on the Guajira Peninsula of northern South America, all of which adopted Old World livestock brought by the Europeans to the Americas.
} 
small-scale "Third World" societies runs contrary to the tenets of the MCD framework. Traditional societies are not stuck in antiquity or premodernity just because they do not incorporate the logics and technologies of modernity as the dominant ideology of our time requires of them (Santos 2011; Latour 1993). Yet, even though various theories that position pastoral peoples as somehow acting irrationally, including the anthropological theory of unilineal cultural evolution, the Malthusian dilemma, and the tragedy of the commons, have been largely discarded by the scientific community, we still see evidence through the various examples presented in this chapter that the hegemonic relations these theories supported continue across the globe.

There persists a Western ideology that considers that civilized or modern societies have mastered nature and therefore are superior to those societies who are "ignorant" of resource management using scientific knowledge. Such hubris gives way to comments such as the following one by a 1930s New Dealer describing Navajo country in the American Southwest as, "a story of wasted rangeland, crumbling walls of mud, and nature thrown out of balance by man's wanton misuse of his resources" (Weisiger 2009, 41). This is in reference to the perceived overgrazing, erosion and desertification of the rangelands in the Navajo Reservation caused by the livestock of Navajo herders. On the other extreme, Paul Nadasdy draws attention to the inadequate and harmful assumption of the "ecologically noble Indian" (2005). He states that the dominant Euro-North American notions of environmentalism are problematic since they do not consider real Native Americans' relationships with nature but rather an ideal, static concept.

Centuries have passed since global colonialism got under way, producing the greatest threat to cultural and linguistic diversity, and devastating native societies across 
the globe. Modernity, in the form of neoliberal capitalism and development, continues to uproot and extinguish native traditions. Yet as more and more of humanity is drawn into the modernizing agenda, many Indigenous and pastoralist peoples preserve and adapt their beliefs, traditions, practices, relations and livelihoods to resist incorporation into the dominant society and serve as a critique of its unsustainable practices.

Sovereignty infringement and the imposition of state agencies and multinational corporations on pastoralist lands are evidenced on the Guajira Peninsula and in many regions of the world where pastoralists live. The first section of the chapter ends by providing points of comparison and insights into the past and present struggles of three other pastoralist societies from Africa, Asia and North America. From Asia, a politics of subordination and unrealistic development programs has pushed the Raika herders from Rajasthan, India to sedentarize, overgraze and increase their migration efforts in distance and time in order to survive (Agrawal 1998). From North America, the U.S.

government's New Deal stock reduction program on the Diné (Navajo) reservation in the American Southwest had devastating consequences for the Diné pastoralists during the 1930s (Weisiger 2009). The second epigraph of this chapter provides a testimony from a Diné healer of the incalculable social, spiritual and emotional cost the program had for the Diné. Finally, from East Africa, the Kuria cattle peoples have been forcefully relocated, have witnessed their lands reduced and divided by national borders and policies favoring ecotourism and have been subsumed by transnational market activities that have weakened their traditional non-market economies (Fleisher 2000; Ruel 2000). Each of the three pastoralist societies shows similarities and differences with the Wayuu pastoralists, of which important lessons and comparisons can be made. 
The second part of the chapter explores the co-emergence of the Wayuu and pastoralism on the arid Guajira Peninsula of northern Colombia. Prior to the current wave of interventions by non-Wayuu organizations and experts on the peninsula there has been a long history of interaction between the Wayuu and outsiders whose objectives included exploration, conquest, pacification, evangelization, commerce and assimilation. Indeed, ever since the beginning of the European conquest of the Americas, the Wayuu have been forced to defend their land and livelihood while embroiled in the struggle between world powers to claim, conquer and colonize territories in the New World. The northernmost point of South America and jutting into the Caribbean Sea, the Guajira Peninsula was of strategic importance for the Spanish Empire as well as other European powers who required provisions and labor from the mainland of South America to supply their vessels, war campaigns and the Caribbean islands they possessed. Throughout the conquest and colonial periods, while the Germans and Spaniards kidnapped, enslaved and exploited the Wayuu, the French, Dutch and British traded firearms and ammunition with them in exchange for slaves (African and Indigenous), horses, cattle, hides, timber and salt (Pacini Hernandez 1984; Polo Acuña 2005). With sizable stocks of advanced weaponry, skilled horsemanship and a large, dispersed population, the Wayuu became known as "indomitable" peoples, a depiction that has persisted throughout the colonial, republican and modern eras (Polo Acuña 2005; Kuethe 1970).

Their resistance to subjugation through cooperation with allies, confrontation on their own terms and adoption of selected Western artifacts and practices-including animal domestication - were adaptive strategies that allowed for the continuity (and transformation) of their society and culture. Yet their defiance and alterity also 
marginalized the Wayuu from the regional and national governing systems, obligating them to endure a long abandonment by the state that has left the Wayuu peopleaccording to national standards - among the poorest and most vulnerable populations in Colombia (Corte Constitucional 2017). Their ubiquitous practice of animal herding situates the Wayuu among the vast and variegated array of contemporary pastoralist societies whose primary livelihood faces various challenges but who have also found spaces and avenues for increased agency over water and territorial governance.

\section{Part 1. The bounded opportunities of pastoralists}

Ethnographies of the mid- $19^{\text {th }}$ century, influenced by a cultural ecology perspective, highlighted the ecological adaptability of pastoralists (Evans Pritchard 1969; Stenning 1959; Barth 1961) and stressed the deep cultural embeddedness, symbiotic relationship and importance of livestock, not only as an economic good, but as symbolic, natural and social capital. Melville Herskovits in the 1920s in East Africa described this human-livestock relationship as a cattle complex, which for some tribes meant "a matter of national existence" (Herskovits 1926, 267; Bodley 2011). Cultural ecology's focus on environmental adaptation and common property management was then infused with a concern on multiscale power relations by Julian Steward's student, Eric Wolf, who coined the term political ecology in 1972 (Sutton 2010, 26). This perspective gained popularity among environmental anthropologists and especially among geographers who gave greater attention to marginalized peoples' relations with nation-states and the effects of development policies (Sutton 2010; Fratkin 1997). A political ecology approach questions simplistic assumptions and hierarchical relations that blame the land users (micro level) for land overexploitation and proposes spreading the culpability to powerful 
external agents and institutions, global and regional economic processes, and hegemonic ideologies (macro level) (Neumann 2005; Robbins 2012).

More recently, pastoralism studies have focused on cultural politics of identity and pastoralist rights, and how these engage with the global Indigenous movement and localized struggles (Hodgson 2011; Upton 2014). Furthermore, academic and policyoriented research on pastoralism addresses the role of environmental services (KayeZwiebel 2014), climate change and adaptive capacities within socioecological rangeland systems (Rota and Sperandini 2009; Humanitarian Policy Group 2009).

There are approximately 500 million pastoralists and agro-pastoralists worldwide, with a high variation in how pastoralism is practiced. ${ }^{8}$ The most common categories are based on their degree of movement or farming and include nomadic, semi-nomadic, transhumant, sedentary and agro-pastoralism (Galaty and Johnson 1990). As opposed to conventional commercial ranchers who bring fodder and water to their animals in fenced in areas (intensive pastoralism), Indigenous pastoralists typically graze and hydrate their herds over wide areas of communally shared land (extensive pastoralism) (Sendalo 2009; Fratkin and Roth 2005).

Pastoralism is a subsistence strategy and a production system practiced across the globe that uses animals as capital resources, allowing for human habitation of drylands such as plains, savanna, tundra, desert, mountains and steppes that would otherwise be

\footnotetext{
${ }^{8}$ Succinctly, pastoralism can be defined as extensive livestock production in the rangelands (according to the United Nations Environment Program) while an economical definition distinguishes pastoralists from agro-pastoralists; pastoralists derive over 50\% of their income from livestock and livestock products while agro-pastoralists derive less than 50\% of their income from livestock and livestock products with most of the remaining income coming from cultivation (according to the International Fund for Agricultural Development).
} 
considered unproductive or economically unviable for exploitation (Fratkin, Galvin, and Roth 1994; Western and Finch 1986; Sowell 2001; Galaty and Johnson 1990). Pastoralists are Indigenous peoples who have adapted to these ecosystems by practicing animal herding that converts wild plants inedible to humans such as grasses and shrubs into protein and capital. For better or for worse, living on rangelands has also distanced pastoralists from state control.

For this reason, Sayre states, "what unifies rangelands is thus not so much a biophysical or 'natural' characteristic as a social one: marginality. Just as they are residual in classification systems, rangelands are peripheral to other, more lucrative types of land, and the people who inhabit and use rangelands are often (although not always) socially marginalized as well” $(2017,3)$. For the Wayuu, their rangelands were of little interest to the government for centuries until coal extraction began in the 1980s in the Lower Guajira and a current spike in enterprises to harness wind energy in the Middle and Upper Guajira.

Multinational land appropriation began in the 1970s when Colombia and Exxon partnered to begin coal extraction in the Lower Guajira. The megaproject included the construction of the coal mine in the southern region, a seaport in the Upper Guajira and a $150 \mathrm{~km}$ railway with a parallel road connecting the two (Pacini Hernandez 1984). The land acquisition and construction of the infrastructure began in 1980, impacting the Wayuu communities that lived in and around the three construction projects. Pacini provides a critical report of the construction process that revealed several irregularities and errors in the environmental and social impact assessments carried out by the company. She attributed the faults to the urgency to begin the project without regard to 
the impact on the local Indigenous and Afro populations, and the surrounding environment (Ibid).

The prospect of capitalizing on a resource for both national and international economic growth and development outweighed any ethical issues relating to collateral social or environmental problems that would affect the local Wayuu population. Escobar's modernity/coloniality/decoloniality (MCD) framework sustains that the imposition of a singular vision of development by a multinational extractive corporation on Indigenous lands is the continuation of the political dominance and economic exploitation by European powers that occurred during the colonial era in Latin America (Escobar 2008, Galeano 1971). For 50 years, the destiny of many Wayuu has been linked to the occupation of their territory by the multinational corporations ExxonMobil, the Cerrejón consortium and Chevron-Texaco.

For Sayre, rangeland science during the $20^{\text {th }}$ century claimed theoretical and methodological understanding for rangeland management yet relied on assumptions about nature's predictability and humans' control over it, which ultimately revealed the deficiencies of the nascent science. Yet the hubris and hegemony of Western science as the dominant epistemology led government officials and capitalists to expand their control into what Sayre considered the geographic limits of governance. From his discipline, Arun Agrawal adds "few political scientists have written about [pastoralists]. This form of livelihood, many believe, is doomed to oblivion, scarcely worth attention, belonging properly to the rubbish heap of History" $(1998,5)$.

While perceived land degradation due to overgrazing by pastoralists' herds receives greater attention by environmental managers, less attention is given to land 
dispossession that is detrimental to pastoralists who rely on large areas of land in order not to degrade it (Gonin 2015). Furthermore, pastoralists are participants in wider issues of economic growth, development and environmental sustainability, albeit on unequal terms with more powerful actors and institutions (Fratkin 1997). In the current globalized era underpinned by climate change, pastoralist resilience is further threatened by an increasingly unpredictable and destructive environment (Humanitarian Policy Group 2009). Considering this situation, Sendalo (2009) concludes that many pastoralists will be forced to abandon pastoralism and integrate into the dominant society unless policy makers acknowledge the legitimacy and importance of their livelihoods and take measures to protect their land and water rights.

Despite the boundedness by the pressures mentioned above, pastoralist societies persist through economic diversification, ecological adaptation and cultural continuity (Galaty and Johnson 1990), some managing to strengthen their collective identity as the "custodians of the commons" within conservation management through transnational activism and identity politics (Upton 2014). Pastoralists are a minority within the nations they inhabit and, as with most Indigenous peoples, occupy the lower echelons of national societies' social stratification. As will be shown in the following case studies, the marginalization of pastoralist societies has caused them to struggle and adapt to the imposition or abandonment by the state that threaten their society's survival.

Historically, in Latin America, nationalism and the pursuit of modernization fueled assimilative attempts focused on the incorporation of native groups (Assies, Haar, and Hoekema 2000; Clifford 2013; Sherzer and Urban 1991). For example, in Colombia, 
which declared independence in 1810, the dominant mantra proclaimed up until the 1991 constitution was a nation of one language, Castilian Spanish, one religion, Catholicism, and one culture, Colombian (Padilla 1996, 80-81). ${ }^{9}$

In East Africa, emerging nations such as Tanzania and Kenya in the 1960s and 70s strove to modernize by implementing nationwide villagization campaigns under the auspices of socialism and progressive land reform in the case of Tanzania (Scott 1998, Chapter 7), while in Kenya modernization efforts focused on privatization, in a process that began by transforming the commons into privatized group ranches (Galaty 2014; Bollig and Lesorogol 2016, 669). ${ }^{10}$ While some argue that these homogenizing policies brought peace, raised the level of education and strengthened the self-determination of African nations such as Tanzania (Kessler 2006; Britain, Legum, and Mmari 1995), others saw them as detrimental to the cultural continuity of pastoralist and Indigenous groups, whose livelihood did not conform to that envisioned by the dominant national societies (Scott 1998, Chapter 7; Charnley 1996). Using contemporary ontological theory and terminology these groups live in ontological worlds radically different from the national society they inhabit and are incommensurable with modern Western mandates.

\footnotetext{
${ }^{9}$ Colombia's 1890 constitution prioritized ecclesiastical authority to determine how Indigenous societies should be governed and educated (Art. 1, Law 89, 1890). During the $20^{\text {th }}$ century, in La Guajira, evangelization was led by the Capuchin order who built several Indigenous boarding schools across the peninsula. Many of these large, rural schools, as well as urban and peri-urban schools are now run by the archdiocese of Riohacha, which continue to educate thousands of Wayuu students, albeit under a multicultural educational format known as ethnoeducation.

${ }^{10}$ Scholarship on pastoralism is well-developed in African studies and includes extensive examples of pastoralist-government-NGO relations (Anderson 2002; Bassett and Crummey 2003; Benjaminsen, Maganga and Abdallah, 2009; Bollig 2006; Butt 2015; Coppolillo 2000; Coppolillo 2001; Ferguson 1990; Fratkin et al. 1994; Fratkin and Roth 2005; Galaty 2014; Galaty and Johnson 1990; Gonin 2015; Homewood et al. 2001; Maitima et al. 2004; Muyungi 2007; O'Connor and Kiker 2004; Rodgers and Homewood 1986; Sendalo 2009; Thompson and Homewood 2002; Upton 2014; Wurzinger et al. 2008).
} 
Consequently, their alterity becomes an impediment to nation-building, whose objective is to homogenize the population around a common language, set of values, customs and history.

\section{The Kuria of northern Tanzania}

In 1971, the Tanzanian government, under the leadership of its first president Julius Nyerere, implemented the ujamaa campaign (planned villagization), severely altering the livelihoods of rural peoples across the country, through large-scale resettlement and social engineering in an effort to improve the standard of living of rural Tanzanians (Fleisher 2000; Scott 1998; van Koppen et al. 2016, 592). At least 5 million people were resettled into villages, including the Kuria and other pastoralists, although Nyerere claimed that over 13 million, or 70\% of the population, had moved into 7,684 villages in a span of three years (Scott 1998, 245).

Nyerere's villagization campaign was meant to benefit the state and raise the standard of living of its citizens by facilitating the delivery of services, including water, increasing agricultural productivity through mechanization and socialist cooperation. Scott (1998) argues that this utopian vision was an attempt at making a scattered rural population "legible" through administrative efficiency and scientific knowledge. However, this homogenized vision of the nation made invisible the multiple rural livelihoods and ties to the land that depended on social cohesion, place-based knowledge accumulated over generations and, particularly for pastoralists, extensive rangelands, rather than concentrated settlements.

Pastoralist societies, like the Kuria in northwestern Tanzania, were not only forced to resettle through the ujamaa national villagization program but have also been 
restricted by the national governments from entering parts of their traditional lands to allow for large-scale agriculture, conservation and ecotourism initiatives. For example, the creation of the Serengeti National Park has limited the Kuria, as well as the Maasai, access to a portion of their traditional grazing areas (Igoe 2004). A history of land reforms and international and national intervention in Kuria country and throughout Tanzania has led to further pastoralist marginalization and land degradation by forcing their herds to overgraze on reduced lands. Tanzanian pastoralists have also qualitatively changed the way pastoralism is practiced by shifting to global market priorities or abandoning pastoralism and migrating to the urban centers in search of wage labor or becoming agriculturalists, as was the case with the Sangu (Hughes 2006; Homewood, Kristjanson, and Trench 2009; Sendalo 2009; Fratkin 1997; Fleisher 2000; Charnley 1996). Charnley (1996) documents how the Sangu of southwestern Tanzania have been forced to abandon animal herding and adopt rice cultivation in a region that they once used as collective lands but was usurped by farmers and other displaced pastoralists (Charnley 1996).

The Kuria historically practiced cattle raiding for non-market purposes, such as to acquire cattle for bridewealth and recover their animal populations from the rinderpest disease. Currently, cattle raiding has transformed into a more violent, market-oriented practice that spans local, regional and international trade networks. Fleisher considers that contemporary cattle raiding, far from being an integral part of their traditional economy is "tearing apart the social fabric of Kuria communities" $(2000,9)$.

The global and national hierarchy of water governance makes participation by less dominant groups in environmental management difficult because of competing 
interests that tend to favor those in power. Development projects bring water to herding communities but at a price (literally and figuratively); a negative consequence brought by the construction of boreholes and irrigation projects is the commodification of water and the concentration of populations around these areas, creating unintended overcrowding and overgrazing problems. For this reason, political ecologists have considered water development as part of a larger modernization campaign advocated by funders such as the U.S., Japan and the European Union (Goldin, Sneddon, and Harris 2013; Goldman 2007).

\section{The Raikas of Rajasthan, India}

Global and national discourse surrounding pastoralist environmental mismanagement was heavily influenced by Garrett Hardin's article "The Tragedy of the Commons" (1968) proclaiming the inevitability of unregulated resource exploitation, using as an example land degradation caused by maximizing self-interested herders. For Hardin, there were two options to avoid tragedy: government intervention or privatization. This conclusion solidified development planners' general cynicism towards pastoralism and provided the impetus to direct policy and programs based on one or both of Hardin's solutions.

Development organizations such as the UNDP, World Bank and USAID have led the way in implementing paternalistic and Eurocentric programs with pastoral groups. Their adoption of Hardin's thesis, as well as the idea of desertification, which considers local human populations as responsible for the increased desert conditions, led to "sweeping privatization of land and commercialization of livestock production" (Fratkin 
1997, 241) as well as sedentarization and institutionalized resource management

(Agrawal 1998; Fratkin 1997; Weisiger 2009; Fratkin and Roth 2005; Gonin 2015).

Beginning in the late 1970s state resolutions to protect the environment in

Rajasthan, India were voted on and passed by village councils. The enclosure of $30 \%$ of the village commons adversely affected the Raika pastoralists since they owned $90 \%$ of the sheep and camels in their village (Agrawal 1998, 3). By restricting the grazing of their livestock, the Raikas were forced to migrate more frequently and for longer periods in order to feed and water their animals. This resolution was justified by a council member who stated, "without action by the panchayat, villagers would have consumed the entire oran [village commons]. Their own poverty would force them to do so" (57). This statement, so similar to the tragedy of the commons' argument, is used to justify the decision of the village council, most of whose members own far fewer livestock, yet own more private lands than the lower castes, and therefore have little to lose by the enclosures.

Other state-led programs in India targeting ecologically fragile regions such as the Drought Prone Area Program, the Desert Development Program, and Pasture and Sheep Development Program, aimed to improve the lives of the inhabitants in these regions based on scientific knowledge and a certain vision of development (Agrawal 1998, 73). The World Bank-funded Pasture and Sheep Development Program sought to organize the herders into cooperative societies and sedentarize them on one-hundred-hectare pasture plots. Large amounts of money were spent on the project but Agrawal highlights that only 20 percent of it was spent towards direct services for the beneficiaries (67). After ten years the program had not met its objectives due to the irregularity and unpredictability of 
rainfall and fodder production but more importantly because of a lack of understanding of the social and political context in Rajasthan and the unintended consequences of unrealistic development programs.

Numbering roughly half a million, the Raikas of Rajasthan, India are agropastoralists who migrate anywhere between three and twelve months out of the year in search of water and fodder for their livestock. Arun Agrawal states that the Raika pastoralists are "one of the most marginal groups in one of the most marginal physical environments in India" (4). Inhabiting the dry, western region of the country, the Raikas belong to the scheduled castes of India's caste system, which institutionalizes their marginalization by limiting their social mobility, employment opportunities and participation in politics.

The fact that the state-sponsored multi-village formal council and the traditional village council (panchayat) are comprised of mainly upper castes even though $74 \%$ of the village households are made up of lower castes, illustrates the inequalities faced by the Raikas and significantly affects their lives $(42,49)$. A second factor to understand why the Raika are marginalized stems from their nomadic livelihood; they are a migrant group in a society of settled communities. For the state, territoriality is integral to its exercise of power and this is based on sedentary populations and the ownership of private property, neither of which characterizes the Raikas (74). Rather, mobility and the use of common property is a defining feature in their livelihood and identity, as it is for many pastoralist societies. The first epigraph of this chapter, notes the irony of how Western society is now characterized by mobility-linked to freedom, technological advances and dynamic economies_-but pastoralists' mobility is a sign of just the opposite: constrainment by 
environmental forces, a lack of technology to allow for sedentarism and a stagnant, nonmarket economy.

In defense of non-conventional resource management practiced by herding societies like the Raika, political scientist Elinor Ostrom and others refuted Hardin's unsubstantiated claims for public or private intervention by describing various mechanisms and institutions implemented by local groups to use common property resources without depleting them (Ostrom 1990; Acheson and McCay 1987; Acheson 1989). Nevertheless, the vilification of time-tested pastoralist land management practices had already been established. The depreciating nature of the interventions and their incompatibility with the pastoralist livelihood has led to distrust and distancing between the local populations and those working to bring water and other development projects to them.

Research on common property resources (CPR) among pastoralists has shown that there is not an evolutionary model nor the necessity of land management to lead from open access to common property to state-owned or private property (Galaty 2016). Recent literature on the commons has shifted from one documenting the negative effects of its fragmentation and enclosure to studies of initiatives where pastoralists have reasserted their rights to the commons, and government policies that establish "new commons" using Ostrom's guidelines for collective action (Bollig and Lesorogol 2016; Agrawal 2003; Galaty 2016). New or reasserted commons are those grazing lands that are on private farmlands, lands that have reversed from private lands into commons pasturage or state-owned lands that implement decentralized natural resource management (Bollig and Lesorogol 2016). The new commons differ from traditional 
common property because they are emerging institutions that do not have long-standing rules and norms nor a defined group of resource users (ibid). This increased access to grasslands deemed privately-owned or otherwise off limits to livestock has been brought about by the expansion of pastoralists' social networks, both horizontally (with neighboring farmers and other pastoralists) and vertically (with government and international NGOs). In this sense, negotiation with farmers, cooperation between different land-owning groups and formal and informal land reclamation are resilience strategies that pastoralists are employing to resist the continued encroachment and dispossession of their lands.

National laws on land tenure often contradict pastoralist rights that, according to pastoralist advocates, should include year-round access to sufficient pastures and water sources for their livestock in the form of collective resource rights. On the one hand, there is increased appreciation of the resilience of their mobile and flexible subsistence strategies (Fratkin 1997; Western and Finch 1986). Pastoralist mobility, the use of the rangelands as common pool resources and social norms such as reciprocity and sharing are now considered local adaptations to dryland ecosystems with high resource variability and limited productivity (Kaye-Zwiebel 2014). On the other hand, there is increased pressure on governments to increase intensive livestock and agricultural production, expand conservation areas and implement a host of other economic liberalization strategies (Sendalo 2009). As these initiatives are carried out, pastoralist marginalization increases and negatively affects their sovereignty, self-determination and resilience, limiting their ability to counter any "natural" disasters such as drought or cattle disease. 
Collective property rights are a means of protecting the continuity and control of the pastoralist livelihood and curtail assimilation into the national society (Sendalo 2009). Like mobile hunters and gatherers, pastoralists need extensive land to maintain their livestock throughout the year; land is crucial during droughts when they migrate to secondary water sources and more fertile lands. Uninhabited land used for grazing has been appropriated by governments for the expansion of more productive industries. ${ }^{11}$ What has been misunderstood or ignored are the cyclical and transhumant land use practices by pastoralists where portions of their rangelands remain unexploited allowing for replenishment of the pastures and serving as a safety net in times of drought. In Tanzania, since 2000, legislation and formalization of land ownership through certificates of ownership, in theory, safeguard the land rights of pastoralists. However, Sendalo notes that these advances are deceptive since newer laws and policies stipulating increased conservation, modernization of agriculture and commercial livestock herding contradict and supplant the previous provisions. Additionally, the certificates of land ownership are difficult to acquire because of the lack of pastoralist understanding of the legalbureaucratic system and national power inequalities that favor other stakeholders (Ibid). With increased land and water grabbing by foreign companies, formal water rights are being used to disempower less powerful stakeholders such as small farmers and pastoralists (de Bont 2016; Allan 2013). Nation-states issue formal water rights, or permits, in the form of a written document that define the conditions of water allocation

\footnotetext{
${ }^{11}$ To support his argument, Sendalo provides an example of a Tanzanian government policy, the 'Strategic Plan for the Implementation of Land Acts', which contained "two essential strategies, namely to sedentarize pastoralists and change their production system into a ranching system, and to introduce a system of minimum acreages for farmers through a resettlement scheme" (Sendalo 2009, 6).
} 
and abstraction to private (individual or company) and public users (Sokile 2004, 1351). These rights have been met with resistance at the local level because they are negatively associated with water fees, replace long-standing informal rights and also favor more powerful stakeholders (ibid). The following example shows how governments can also implement more drastic, paternalistic land management programs that are meant to benefit the pastoralist society yet fail because of flawed assumptions and unethical means.

The Diné pastoralists of the American Southwest

In Dreaming of Sheep in Navajo Country (2009), the environmental historian Marsha Weisiger analyzes the causes and consequences of the Bureau of Indian Affairs (BIA) and Soil Conservation Service's (SCS) implementation of a New Deal land management plan that included a controversial livestock reduction program in order to halt perceived overgrazing and land degradation on the Navajo Reservation during the 1930s. Weisiger explains how the Diné, as the Navajo call themselves, were forced by the BIA to reduce the overall livestock population by half without considering the centrality of the animals to their economy and culture. Women were especially affected since they were the owners of a large percentage of the sheep and goats, which they cared for and in turn provided them with financial security and prestige.

The conception of the livestock reduction program occurred when engineers of the Boulder Dam realized that a large amount of silt was washing down from the Navajo reservation and into the dam's reservoir. They concluded that the sedimentation of the dam would eventually threaten the very expensive federal project to bring electricity and water to a large portion of the Southwest, including to the burgeoning city of Los Angeles 
(Weisiger 2009, 24). The perceived overgrazing by the Navajos' livestock was deemed the source of the erosion, causing the silt to enter the Colorado River where the dam was located. Commissioner of the BIA, John Collier, oversaw the livestock reduction program and to him, "the threat to Boulder Dam was secondary: overgrazing and accelerated erosion endangered the very lives of the Navajos themselves. If the range continued to deteriorate, sheep and goats would starve, and ultimately, so would the Navajos" (24).

For the engineers and government agents, human-induced erosion was threatening both a major public works and the livelihood of a Native American group; for them the solution to both problems was to limit the number of livestock on the reservation to within the land's carrying capacity. This solution is an example of how a conventional scientific approach of "command-and-control" identifies the cause and effect of a problem and devises a technical solution without questioning the basic assumptions or analyzing the broader socio-ecological complexity of the perceived problem or the implications of the proposed solution. The New Dealers relied on theories of succession, equilibrium, carrying capacity and climax theory, the latter forwarded by the influential ecologist Frederic Clement, and considered the dominant scientific theory of the time.

These theories led soil conservationists to believe that the region's mature state had been grassland prior to the arrival and overgrazing by the livestock. Additionally, the government agents relied on earlier travelers' accounts of the region's vegetation that reinforced the scientific theories that the reservation had once been more verdant than its current state (38-39). While Weisiger considers the Navajo may have overgrazed, she points out that studies using dendrochronology provide evidence that the dry climate was an important factor in the region's lack of vegetation (43). What was not given much 
consideration was if or how such a program should be implemented so that its negative impact to the Diné people and more specifically the Diné women, would be minimal.

Through a political ecology lens, several elements of the livestock reduction program imposed upon the Diné pastoralists can be analyzed. First, the Indian reservation, made up largely of rangeland, was marginalized by the state and whose ecosystems in relation to the herding practices were not understood scientifically. As Weisiger shows, this is evidenced by the few government officials assigned to the reservation, the dearth of data related to the historical ecological patterns and the smallscale animal production on the reservation relative to the large-scale ranching occurring beyond its borders (ibid). Robbins' degradation and marginalization thesis (2012) redirects our attention to other causes of overgrazing, found in broader market processes and state intervention. In this sense, the delimitation of the reservation and the encroachment of Anglo and Hispanic ranchers on Navajo territory reduced the amount of grazing land available and restricted their transhumance patterns. This caused there to be more animals per hectare grazing more intensively during longer periods throughout the year.

Applying Escobar's modernity/coloniality/decoloniality (MCD) framework (2008), we can evidence sociopolitical relationships and inequalities that pervaded during America's colonial history. Native American reservations were under federal jurisdiction and the BIA had the legal authority to impose land conservation policy. Weisiger points out that paternal coercion and indirect rule were also implemented on the Navajo reservation by the BIA commissioner who wrote "perhaps an 'administrative power' could best achieve its goal 'by indirection,' that is, by encouraging Navajo leaders to 
make the desired decisions, "rather than by mandate"' (Weisiger 2009, 184). Weisiger continues, "Collier and his men—so certain that only they knew the answers—viewed Navajo counsel as only a means to ratify and legitimate decisions they had already made" (242). The federally funded, all-male Navajo Tribal Council served the interests of the government in detriment to the people and especially to Diné women, whose voice was effectively silenced. This formalized leadership structure starkly diverged from the traditional social position held by women, which allotted them significant power in their matrilineal and matrilocal society.

Weisiger contrasts this type of authoritarian governance to the way conservationists, in other parts of the country where overgrazing and erosion were a problem, sought cooperation with white farmers and ranchers rather than imposing draconian livestock reduction policies (233). The power asymmetry between a powerful government and a subjugated Native American people that began during the Westward expansion had resulted in genocidal war, ethnocidal assimilationist policies, territory fragmentation, misappropriation of tribal funds and forced displacement, among other cruelties. The Diné were victims of these actions and still held vivid in their collective memory the traumatic Long Walk and confinement in Bosque Redondo or Hwéeldi as they named it, where they were held captive by the U.S. government between 1863-1868 (ibid, 21-22). The livestock reduction program was carried out in an authoritarian fashion following a pattern that was congruent with the way the federal government had interacted in the past with Native Americans. 


\section{Part 2. The Rise of the pastoralist Wayuu}

The Wayuu, with an estimated population of $800,000^{12}$ (DANE 2019; INE 2011), are the only extensive pastoralist society in northern South America. Wayuu pastoralism, while providing an important example of pastoralism in the Americas, has remained obscure in pastoralist studies. Pre-colonial camelid pastoralism was not practiced in the Northern Andes of Colombia because llamas, alpacas and vicuñas are not well-suited to the wetter ecosystem of the northern páramos as compared to the drier puna region of the Central Andes, home to the Aymara and Quechua pastoralists (Steward 1963). Therefore, the integration of introduced livestock by the Wayuu in the mid- $16^{\text {th }}$ century makes theirs the only society that practices extensive pastoralism in northern South America and the earliest of the Indigenous societies to incorporate Old World livestock in the Americas (Polo Acuña 2005; Wilbert 1976).

\section{Scholarly work on the Wayuu}

The first to provide written documents on the Wayuu were early explorers, religious authorities, and travelers including Spanish chronicler Juan de Castellanos (1955), Jorge Issacs (1884), F.A.A. Simmons (1885), Joseph de Brettes (1898), Henri Candelier (1893), Gustaf Bolinder (1957) and Father José Agustín Barranquilla (1946). However, the most extensive literature comes from Colombian and foreign

\footnotetext{
12 According to Colombia's 2018 National Census, there are 380,460 Wayuu in the country, $89 \%$ of whom live in the municipalities of Uribia, Manaure, Maicao and Riohacha in the province of La Guajira (DANE 2019). Another 413,437 live in Zulia, Venezuela, according to that country's national census in 2011 (INE 2011), for a total Wayuu population of nearly 800,000. Due to the crisis in Venezuela, many Venezuelan Wayuu have migrated back to Colombia, shifting the proportion of Wayuu living in both counties. In Colombia, the Wayuu represent $20 \%$ of the national Indigenous population, while in the province of La Guajira, Colombia they represent $48 \%$ of the total population.
} 
anthropologists and archaeologists who contributed greatly to the formation of the discipline in Colombia and to the rich body of literature on the pre-Hispanic and contemporary Indigenous peoples inhabiting the Guajira Peninsula. During the first half of the $20^{\text {th }}$ century, prominent anthropologists who worked among the Wayuu include: Gregorio Hernandez de Alba (1936), Milciades Chavez (1946), Virginia Gutierrez de Pineda (1950), Roberto Pineda (1950), Gerardo Reichel-Dolmatoff and Alicia Dussán de Reichel-Dolmatoff (1951). These early ethnographers pioneered the study and appreciation of Indigenous cultures in Colombia by recording the particularities of the Wayuu society.

Following their example, several national and foreign anthropologists in the second half of the $20^{\text {th }}$ century contributed to the growing ethnographic body of work among the Wayuu: Lawrence Watson (1972; 1968a; 1968b), Johannes Wilbert (1976; 1972), Jean Guy Goulet (1978), Maria Barbara Watson-Franke (1983; 1987), Michel Perrin (1993), Benson Saler (1986), Gerardo Ardila (1990), Otto Vergara (1990), Claribel Ochoa y Alexis Carabalí (2002), Jorge González (2002), Alessandro Mancuso (2006) and Pablo Jaramillo (2014). It is important to note that Wayuu scholars have also contributed to our understanding of their society in both Spanish and their native language, Wayuunaiki, including José Antonio Polanco (1954), Antonio Lopez Epieyu (1957), Ramon Paz Ipuana (1972), Miguel Angel Jusayu (1975), Nemesio Montiel Fernandez (1974), Glicerio Pana Uliana (1981), and more recently, Weildler Guerra Curvelo (2015; 2002), Rafael Mercado Epieyu (2017), Estercilía Simanca (2005), Vicenta Sioci (1992) and Miguel Angel Lopez (aka Vito Apüshana) (2004), among others. 


\section{The semi-arid Guajira Peninsula}

The northern half of the peninsula, the Upper Guajira, is the most arid region of Colombia, its desert landscape receiving the lowest annual precipitation in the country $(125 \mathrm{~mm}-500 \mathrm{~mm})$ and the highest annual average temperature $\left(28^{\circ} \mathrm{C} / 82^{\circ} \mathrm{F}\right)$, reaching $45^{\circ} \mathrm{C} / 113^{\circ} \mathrm{F}$ during the hottest months (Aschmann 1960; Unión Temporal Atlas 2011). Contributing to the aridity of the region are the constant and powerful trade winds that cause erosion and inhibit the accumulation of clouds and the subsequent rainfall they produce. The Upper Guajira also forms part of the Indigenous resguardo (reservation) of the Upper and Middle Guajira, recognized by the Colombian Constitution of 1991 as the collectively-owned ancestral territory of the Wayuu people, with special privileges such as an autonomous political organization, an official native language ${ }^{13}$ and its own legal system, among others (Padilla 1996). The reservation, rich in marine and renewable resources, has an extension of $10,675 \mathrm{~km}^{2}$, about the size of Jamaica, and whose coastline borders the Caribbean Sea and the Gulf of Venezuela. Furthermore, because of its strategic geographical position, the peninsula has seen a long history of commerce — both legal and contraband — with Europe, North America, various Caribbean islands, Panama and Venezuela. These privileges notwithstanding, the Wayuu have had to deal with harsh and at times unforgiving environmental conditions, due primarily to the prolonged dry seasons, the desertification of the land and the lack of continuous, reliable water sources.

In addition to these climatic factors, the lack of permanent superficial waterways in the Middle and Upper Guajira limit the growth of the region's vegetation to cacti

\footnotetext{
${ }^{13}$ Wayuunaiki, the language spoken by the Wayuu, belongs to the Arawak linguistic family of South America. The language can be traced to a Proto-Arawak stock near the convergence of the Amazon River with the Negro River where it diverged from other Arawak languages around 5,000BP (Oliver 1990, 96).
} 
species (Stenocereus griseus, Opuntia wentlana), deciduous trees - including the prevalent mesquite tree (Prosopis juliflora) — and other xerophytic shrubs and thorn bushes. Furthermore, the proximity of the sea raises the salinity levels of the underground and superficial water sources of the peninsula, limiting the fresh water supply even more. These conditions have made the Guajira Peninsula a difficult place to live, however the Wayuu have shown that it is not inhospitable, forging a unique way of life despite the environmental constraints.

How the Wayuu represent, experience and interact with the land and the various ethnic groups that occupy it can be distinguished through their system of territoriality and social organization. Wayuu cardinal directions reflect their positionality on the peninsula and incorporate prominent features of the landscape: the north, is known as palaamüin or place of the sea; the south is called uuchimüin, place of mountains, the east is wuinpumüin, the place of water, and the west is known as wopumüin, the place of roads, among others (Vásquez Cardozo and Correa C. 1993).

Within these regions the Wayuu are organized into settlements based on extended matrilineal families known as apüshi. Each apüshi is linked to the territory they live on and to other territories based on residency, land usage and kinship. These families in turn form part of 26 e'iruku (matrilineal clans) associated with ancestral lands (Guerra Curvelo 2002) marked by clan cemeteries. The Wayuu distinguish between ancestral owners of a land and those that reside there or use the resources of the land without claiming ownership. Ownership can be passed on through matrilineal descent and is usually claimed by those whose ancestors are buried in the oldest cemetery on the territory. There are also ways that they label various non-Wayuu peoples. Generally, 
alijuna is the term they use to refer to all non-Wayuu, non-Indigenous people. Kusina is a term they use to identify certain Indigenous groups of the Sierra Nevada de Santa Marta and Paraujano is a term they use for the Indigenous people near the Lake of Sinamaica in Venezuela (Vergara 1990).

\section{Wayuu cosmogony}

Wayuu oral history narrates how the copulation of Juyá, the rain deity, with Mma (earth, supreme mother), originated the Wayuu people and how Maleiwa, the founder deity, organized the society into clans and territories. "Then Maleiwa distributed the Wayuu, as the sheep are distributed once they leave the corral: one over here, one over there... He led each one to what would be their land, as is done today with the passengers of a truck. That is how the Wayuu can say today where the ancestors of their clan were born” (Vásquez Cardozo and Correa 1993, 155).

Another myth tells of how the birth of the Wayuu people was made possible by one of Juyá's sons Maayüi. He and his twin brother Ulapia were sent by Juyá on a mission to remove the sharp teeth lining the vulva of Wolunka, Juyá's daughter and the first woman to be created. Unfortunately, her teeth-filled vagina dismembered the penis of, and killed, any man who attempted to copulate with her. Maayüi and Ulapia found her bathing next to a stream in the Makuira mountain range of the Upper Guajira. Taking advantage of a moment when she had opened her legs, Maayüi skillfully shot an arrow at her vagina, knocking out all the teeth and causing blood to flow onto the rock where she sat and into the stream. This event symbolizes the first menstruation of a woman, the origin of the colors and the origin of the Wayuu people (Chacín 2016, 80). 


\section{The pre-Hispanic past of the Guajira Peninsula}

Estimates based on archaeological and linguistic evidence trace a migration of the Arawak-speaking ancestors of the present-day Wayuu from the Amazon basin in central Brazil to the northern coast of Venezuela, culminating in the peopling of the Guajira Peninsula approximately 1,500 years ago (Vásquez Cardozo and Correa 1993). During Pre-Hispanic times, the various Indigenous groups inhabiting the land engaged in a variety of subsistence practices including horticulture, hunting, gathering, and fishing. Those living on the coast traded sea salt with inlanders, including Chibchan groups inhabiting the Sierra Nevada de Santa Marta mountain range. Coastal shell middens evidence the consumption of mollusks and other shellfish, while artisanal fishing supplemented their diet with a variety of seafood. Hunting was practiced by the native settlers who used the bow and arrow and traps to obtain small game such as deer, wild cats, armadillo, peccary, rabbit, iguana, certain bird species and others (Saler 1986); whereas the gathering of wild fruits, seeds, herbs and roots was essential for their medicinal and dietary needs, especially during the dry season when horticulture was limited. Farming was practiced on a permanent basis on the more fertile lands of the Lower Guajira where the Ranchería River supplied the horticulturalists with a perennial supply of fresh water (Langeback, Cuellar, and Dever 1998). The Upper Guajira, where most of the Wayuu currently live, was, and continues to be, a water scarce environment, without any rivers and low annual rainfall $(125 \mathrm{~mm}-500 \mathrm{~mm})$ that limited the possibility of, but did not impede, farming (Unión Temporal Atlas 2011).

In Colombia, archaeological evidence in what is today considered the southern Wayuu territory in the Lower Guajira around the Ranchería River, was first gathered in 
the 1940s and 50s by Alicia Dussán de Reichel Dolmatoff and Gerardo ReichelDolmatoff who discovered artifacts pertaining to two painted ceramic horizons, the first from 800 B.C.E. to 700 C.E. and the second from 700 to 1500 C.E. (Reichel-Dolmatoff 1951). These archaeological findings are thought to belong to early agricultural societies in the region. In Venezuela, Miguel Acosta, J.M. Cruxent and others uncovered lithic and pre-ceramic artifacts associated with Paleoindian hunters of the Pleistocene in the Paraguaná Peninsula in Venezuela, just east of the Guajira Peninsula, with dates varying significantly from as early as 16,000 BP to 10,000 BP (Ardila 1990). Linguistic evidence based on glottochronology traces a migration of several Proto-Arawak-speaking peoples out from the central Amazon basin at least 5,000 years ago, some moving northward into Venezuela, Colombia and eventually expanding into the Caribbean islands (Oliver 1990; Vásquez Cardozo and Correa 1993).

Early chroniclers mention numerous groups inhabiting the northern region between Colombia and Venezuela that included the Sierra Nevada de Santa Marta mountain range, the Guajira Peninsula, the Paraguaná Peninsula, the areas surrounding the Gulf of Venezuela and the Maracaibo Lake (See Map 2). Based on these early descriptions and subsequent linguistic, archaeological and historical evidence, the region was inhabited by various Arawak-speaking groups (Añu, Wuanebukan, Macuira, Eneal, Kusina, Wayuu, Kaketío, Coanao), Caribe-speaking groups (Burede, Bubure,Yukpa, Bari, Opone, Carare, Onoto, Aratomo, Tupe) and Chibchan-speaking groups (Tairo, Kogi, Arhuaco, Ika, Marocacero, Motilón) (Oliver 1990). 


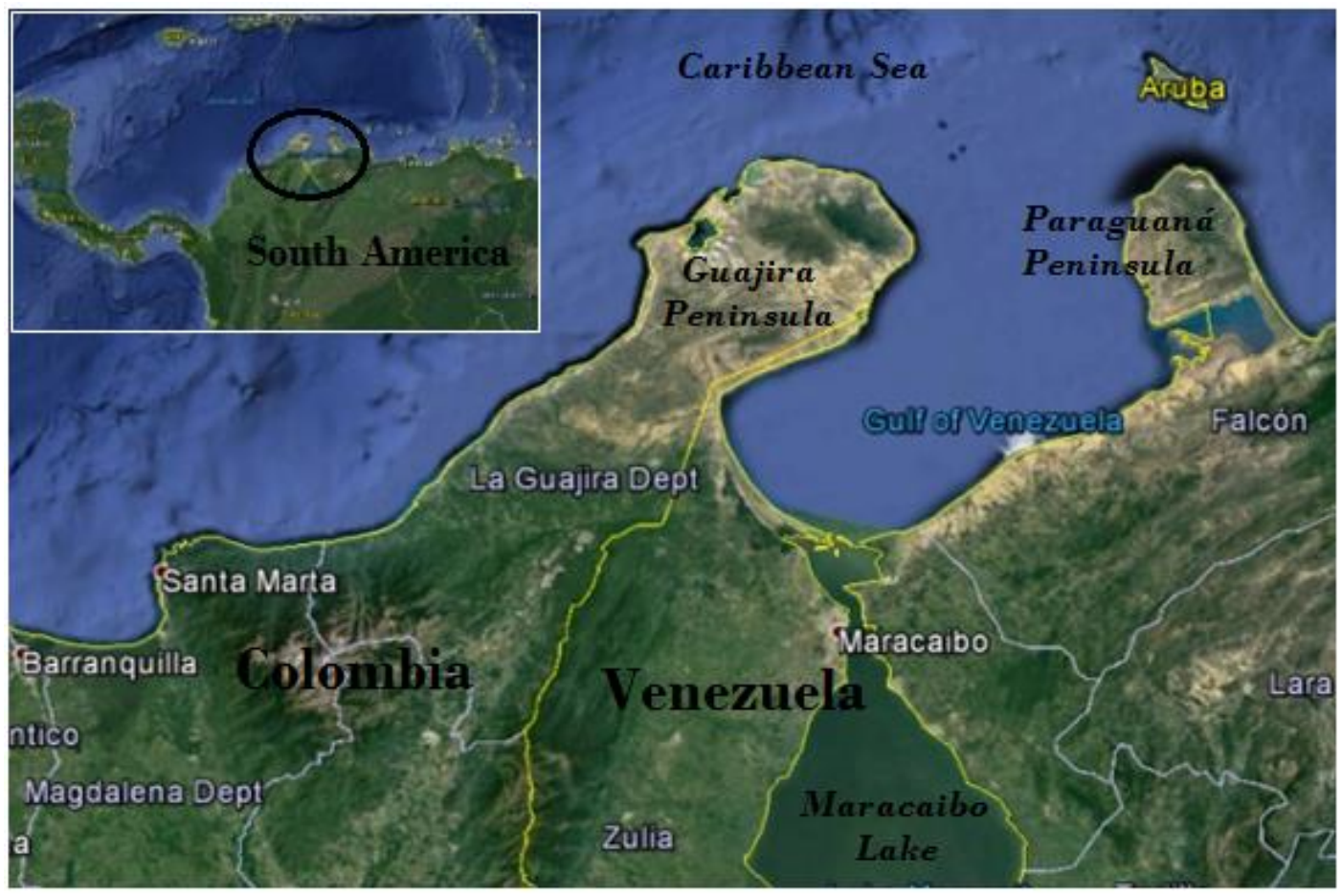

Map 2. The Guajira Peninsula, the northernmost point of South America

\section{The colonial era on the Guajira Peninsula}

In 1499 the first Europeans arrived on the shores of the peninsula, bringing with them Old World animals, technology and a market economy that would profoundly change the demographics and subsistence strategies of the native inhabitants. Within fifty years of the European arrival the inhabitants of the peninsula had acquired livestock through trading or raiding and by the $18^{\text {th }}$ century had become a pastoralist society (Castellanos 1955; Polo Acuña 1999). Hunting and gathering became secondary subsistence activities, while coastal fishing and seasonal horticulture were maintained (Polo Acuña 1999). The Wayuu, who, beginning in 1623 were called "goagiro" or “guajiro" (Oliver 1990), became a pastoralist society, gradually incorporating livestock into their social organization, legal framework, religious ceremonies and traditional economy. The accumulation of livestock, including cows, goats, sheep, donkeys, mules 
and horses became an indicator of prestige and a source of wealth, allowing for the redistribution of goods among matrilineal families, payment of offenses, inheritance, bride price, funerals, shamanic rituals, celebrations, offerings, bartering and monetary exchanges (Vergara 1990).

The centrality of pastoralism for the Wayuu is evidenced in its impact on their inheritance system, legal framework, religious ceremonies, and traditional economy (Aschmann 1960; Wilbert 1972). Anthropologist Lawrence Watson describes the traditional inheritance practices based on matrilineal kinship and the use of livestock, noting that there has been a shift towards Hispanic, patrilineal inheritance customs between father and children (Watson 1968a). Wilbert identifies possible Africanisms in the Wayuu kinship system and alludes to the possibility that runaway black slaves living among the Wayuu may have helped them incorporate pastoralism into their subsistence practices. He notes,

Not only were black slaves familiar with pastoralism to a varying extent before they arrived in the New World, but the intruding cimmarones may have run away from cattle-ranching owners... The Goajiro [Wayuu], on the other hand, were mainly hunters and collectors and incipient agriculturalists in their own area. It may very well be that in the process of taking over the business of pastoralism for his Indian master the black slave at the same time introduced cultural traits and norms of his own culture. (Wilbert 1976, 63)

Other texts support the early presence of black slaves in La Guajira during the $16^{\text {th }}$ century when they were taken to the coasts of the Guajira Peninsula to extract pearls. Pirate attacks to the city of Riohacha where the slaves were commercialized gave them the opportunity to escape and form communities along the southwestern coast of the peninsula and along the Rancheria River (Múnera Montes et al. 2014). Furthermore, Aschmann mentions that during the 1700s the Wayuu were trading pearls, dyewood, 
hides and provisions with the Dutch and the English in exchange for weapons and African slaves (Aschmann 1960). Although black communities had formed in the Lower Guajira territory usurped by the non-Wayuu cattle ranchers, none were recorded in the Upper Guajira where pastoralism was widespread and there are no black communities currently in the Upper Guajira. If black slaves were incorporated into Wayuu settlements as Wilbert claims, there is little evidence to support that they instructed the Wayuu in herding nor influenced their kinship system. Moreover, it would have been unlikely based on the dispersed settlement pattern inhibiting diffusion of herding practices within such a short time span, the low number of cimarrones that would have escaped to the peninsula and the lowly status they would have held within Wayuu society.

This notwithstanding, Wayuu oral tradition and scholarly work provide evidence that this Indigenous group has a long herding tradition dating back to the $16^{\text {th }}$ century when they rapidly shifted their livelihood from hunting, gathering and agriculture to pastoralism. Prior to the research carried out by the scholars mentioned above, chroniclers, explorers, government officials, priests and historians have recorded the Wayuu way of life for nearly five centuries, one of the earliest being a Spanish conquistador and priest named Juan de Castellanos who in the $16^{\text {th }}$ century wrote the epic poem Eligias de Varones Ilustres de Indias (Castellanos 1955). He wrote that the Spanish explorers of the Guajira Peninsula,

$$
\begin{aligned}
& \text { discovered wide open savannas } \\
& \text { covered with cactus and thorns, } \\
& \text { and inhabited by savage humans, } \\
& \text { those known as Cocinas... } \\
& \text { whose only sustenance and harvest }
\end{aligned}
$$


is that struck by a bow and arrow"...

there are copious hares and deer

and already a great number of cattle

(Castellanos (1955) cited in Hernandez 1936, 9).

Considering the quote by Castellanos and other historical, ethnohistorical, anthropological and archaeological sources, during the time period leading up to the European contact, the more fertile, Lower Guajira with the Rancheria River flowing through it was home to one or more agricultural societies, while the arid Upper Guajira was inhabited by other societies of fishermen, hunters and gatherers (Castellanos 1955; Langeback, Cuellar, and Dever 1998; Polo Acuña 1999; Oliver 1990). Pacini writes, "while colonization has resulted in the loss of much of their traditional territory in the southern and western portions of the Guajira (the better watered areas most suitable for agriculture), the central and upper portions of the Guajira continue to be occupied and used by Guajiros [Wayuu] in their traditional manner" (Pacini Hernandez 1984, 7). It is possible that the intrusion of non-Indigenous settlers and their livestock into the more fertile southern region pushed the native agriculturalists further into the Kusina territory, while the eventual adoption of livestock by the agriculturalists through raiding, trade and distribution allowed them to inhabit the Upper Guajira without shifting to hunting and gathering, but rather combining animal herding and small-scale, seasonal agriculture that relied on rainfall.

Historian Polo Acuña considers the existence of the Cocina-Wayuu and the Guajiro-Wayuu as "the face and tail of the same ethnolinguistic coin" $(1999,12)$. As pastoralism extended throughout Wayuu territory, the term Kusina was used by the pastoralist Guajiro-Wayuu to refer to those who rejected the adoption of raising livestock 
and were spurned by the matrilineal clans of the Guajiro-Wayuu (Ibid, 11). Reports during the colonial and republican eras document how the Cocina or Kusina hunters and gatherers would rob and hunt the livestock of both the Wayuu pastoralists and the Spanish/Creole cattle ranchers. Both waged war against the Kusinas, who were eventually overpowered and sold as slaves to Jamaica and Curacao or incorporated into the emerging native pastoralist society with a hierarchical social structure that included Indigenous slaves (Polo Acuña 1999). Despite the disappearance or assimilation of the Kusina into the predominant pastoralist Wayuu society, hunting and gathering are still practiced today to a lesser extent. Furthermore, hunting remains a central aspect in Wayuu myth and legend as documented by anthropologist Michel Perrin in The Way of the Dead Indians (Perrin 1993).

During the colonial period, cities were founded bordering Wayuu land, including Riohacha in Colombia and Maracaibo in Venezuela. The Ranchería River in Colombia and the Limón River in Venezuela were also considered natural borders between alijuna and Wayuu territory. Attempts were made to establish Spanish settlements and missions to the north of the rivers but for the most part these were unsuccessful (Polo Acuña 1998, Kuethe 1970). However, the intrusion by colonizers into the fertile southern region of the Wayuu territory over the last four centuries forced the Wayuu to move further north into the more arid Upper Guajira. Notwithstanding, the Wayuu territory today goes well beyond the southern bank of the Ranchería River, essentially surrounding the capital city and extending along the coastline into the municipality of Dibulla to the southwest where predominantly afro and mestizo populations reside. To the south, in the Lower Guajira, 
there are also significant Wayuu populations that make up 30\% of the total Wayuu population in La Guajira province (DANE 2005).

The colonial period between the $17^{\text {th }}$ and early $19^{\text {th }}$ centuries witnessed an expansion of the Spanish Empire and the extinction or reduction of Indigenous peoples across the Americas. Throughout this tumultuous historic period, the Wayuu resisted European domination, retaining most of their territory, increasing in numbers, adapting to the changing conditions around them while maintaining a unique, Indigenous identity. Toward the end of the $18^{\text {th }}$ century sources estimated the Wayuu population to be between 16,000 and 20,000; in the 1960's the estimates rose to 60,000 (Aschmann 1960, 414), in the 1992 binational census (Colombia and Venvezuela) the population was estimated at 297,454 (Guerra Curvelo 2002), the 2005 census in Colombia and Venezuela's 2011 census reported an increase in the Wayuu population to approximately $700,000^{14}$ (INE 2011; DANE 2005), and currently the total population has risen to nearly 800,000, with approximately half residing in Venezuela and half in Colombia (DANE 2019; INE 2011). The population growth of the Wayuu in both Colombia and Venezuela testifies to the ability of the Wayuu to implement strategies, which included seasonal migration and emigration, to overcome the water deficit present on the Guajira Peninsula. During the first decades of the $20^{\text {th }}$ century recurring droughts and water scarcity forced a mass migration of Wayuu from the Guajira Peninsula to the neighboring country of Venezuela, principally to the city of Maracaibo where an estimated 20,000

\footnotetext{
${ }^{14}$ According to Venezuela's 2011 national census, there are 413,437 Wayuu in that country while in Colombia's 2005 census the total Wayuu population for Colombia is 270,413. Significantly, in Venezuela $83 \%$ of the Wayuu live in the urban area while in Colombia, only 14\% live in urban areas (DANE 2005; INE 2011).
} 
migrants took up residence and were employed as unskilled laborers (Aschmann 1960, 415). The military, political and religious leaders of the Guajira in Colombia considered the large exodus of Wayuu to Venezuela a problem of national sovereignty and insisted that the central government resolve the water scarcity problem in Wayuu territory, considering that it would bring progress and demonstrate state presence in the region (Daza Villar 2002). Thus, in 1926, the Colombian government's Water Commission (Proaguas) began its operations on the peninsula and built 29 wind-powered wells between 1928 and 1946. Then, in the 1950s the national government, under the presidency of General Gustavo Rojas Pinilla, carried out a waterworks construction campaign heralded by older Wayuu to this day. Through the support and vision of Rojas Pinilla's, hundreds of Wayuu communities across the peninsula received wind-powered wells, reservoirs and large ponds-Mayapo, Cardón and Irraipa among them-many of which are still currently operative. However, their adaptive capacity is currently being tested by the effects of global warming, a more populated territory with an increasing demand on the natural resources and a loss of agency and autonomy regarding territorial and water governance.

\section{Mayapo, an example of Wayuu modernity}

Mayapo is a relatively large Wayuu community in the municipality of Manaure that has bridged the divide between the rural and urban differences through dramatic changes in its population size, economy, infrastructure and water supply. Mayapo encapsulates the shift occurring in some Wayuu communities towards "modernity," the benefits of which are also accompanied by the introduction of complex problems. If the Wayuu society is to be subsumed in the global tendency to urbanize, then Mayapo is one 
of the few forerunners among the thousands of rural Wayuu communities, and serves as an example of Wayuu modernity.

Mayapo is a located on the coast of the Caribbean Sea in the Manaure municipality, 20 minutes by car on a paved road from the capital city of Riohacha and within the Indigenous reserve of the Upper and Middle Guajira of La Guajira province. It has a population of 1,317 with 305 families, according to Mayapo's 2015 Integral Life Plan (Riasco Yepes and Uriana 2015). Most inhabitants identify with one of nine matrilineal clans present in the community, the most numerous being the Epinayu, Sijona and Epieyu while the Arpushana, Pushaina, Ipuana, Uliana, Wouriyu and Jusayu are also present. Compared to other rural Wayuu settlements that vary in size from 10 to 100 people, it is a relatively large community, although its inhabitants still consider themselves to all be related to each other, whether through common ancestry or marriage. This statement excludes a couple of store owners who are from different regions of Colombia and the arrival of several Venezuelan families in recent years.

As did many Wayuu communities, Mayapo began through the emigration of members from another territory, who decided for various reasons to start a new life elsewhere. In the case of Mayapo, its founding and peopling initiated in the early 1900s when two brothers of the Ipuana Clan, Juan and Kasai, decide to leave the territory of Popoya, a mere mile and a half away, because of an altercation with members of the Epieyu clan. First Juan, then his brother Kasai, followed by their two sisters Rita and Josefa, left Popoya with their livestock and built their houses in an area theretofore uninhabited by other Wayuu, with extensive beaches, sand dunes and mangroves. The 
name Mayapo (Mmayapu), which means "land of abundant sand" in the native language Wayuunaiki, was given to this area by Juan's young wife Cristina Apushana.

Cristina had lived in the Upper Guajira near Cabo de la Vela and had recently completed her coming of age ritual confinement. Facing a planned marriage she was not willing to accept, she decided to escape with her belongings and the livestock she owned, migrating southwest along the Caribbean coastline. She finally arrived to Mayapo and was received by Juan's generous hospitality, who provided her with shelter, food and water for her and her animals. Eventually he convinced her to stay and form a family with him (Anecdote by Leticia Arpushana cited in Ballesteros López 2010, 40-41). Since then, the settlement has received Wayuu from other territories, initially members of the Apushana, Epinayu and Epieyu Clans, followed by members of the Uliana and Sijona Clans, followed by the Pushaina and Wouriyu Clans and, lastly, the Jusayu Clan (Riasco Yepes and Uriana 2015).

Mayapo can be described as a Wayuu community in transition from a rural, traditional past towards an urban, "modern" future. "Modernity" is steadily making itself evident in Mayapo through the concentration of residences, the shift from bahareque to concrete housing, the increased use of basic utilities, the fencing of properties, the shift from non-market to a market economy and a paved highway that traverses the community and connects it with the interstate highway and the capital city of Riohacha. Furthermore, there is a host of specialized places within the community that are seldom found in smaller, more rural Wayuu communities such as: a Spanish-language based boarding school with a student body of over 1,600 students, a functioning health center, a Catholic church, a fisher's committee office, a community kiosk, an inspector's office, a 
tourist sector on the beach with over 50 restaurants and finally, the water treatment plant with its elevated storage tank rising above all other edifices in the town. Local Mayapo leader, Lazaro Deluque of the Sijona Clan describes Mayapo in the following way:

Mayapo has many advantages over other communities, because it is more populated and has leaders who have knowledge of the alijuna laws. It also has easy access for cars, for tourists who come from elsewhere and for the help that is provided to us here... Perhaps that is why other communities don't have access to that help, such as getting water from the cistern trucks. Those are things that this community has the advantage of. And it is very big, it has grown. It has not maintained $100 \%$ of the traditions and customs but there are always Wayuu who do maintain it. For example, now here in Mayapo you can't raise goats because it is practically a town. It has advantages but it also has disadvantages. Now in the dry season, Mayapo has maintained itself with its aqueduct and wells, but other communities don't have these advantages (Lazaro Deluque, Mayapo October 18, 2018).

The town holds three distinct governing institutions, the inspector's office, a community council and the Indigenous traditional authority. The inspector's office (corregiduría) is the smallest government office in the Colombian government structure that holds civil authority at the village level (corregimiento) and reports to the Municipal Secretary of Government. The inspector for the past 25 years of Mayapo has been Agustín Barliza, a Wayuu man of the Uliana Clan who understands and navigates the idiosyncrasies of both Mayapo and the provincial alijuna society. Mayapo's community council (junta de acción comunal) is a non-profit civic organization that seeks to find solutions to the community's needs relating to education, health, gender, religion, culture and sports. It is headed by Cristina Illidge of the Sijona Clan and a teacher at Mayapo's boarding school. She has a strong sense of belonging to the community and is committed to improving the quality of life of its members. The traditional authority is the official representative of an Indigenous community, recognized by the Ministry of Interior and 
provincial government. This figure in Mayapo is Erazmo Ipuana, the eldest of the elders and a direct descendant of the founding brothers of Mayapo from the Ipuana Clan. He has held this position since it was created by the Colombian government 25 years ago.

Interestingly, both he and the inspector were appointed in the same year, the inspector entering his office a few months prior.

\section{Discussion}

Pastoralist societies have undergone state pressure to modernize and sedentarize, via different strategies that bring to light power relations between the herders and external public and private institutions. Marginalization is a common factor among pastoralists; the Navajo were considered secondary citizens because of their American Indian identity and colonial history, the Raikas for belonging to a disadvantaged scheduled caste as well as for leading a nomadic livelihood in a sedentary society and the Kuria were stigmatized as cattle raiders and for their perceived unruliness.

The present-day Wayuu are the result of the peopling of the peninsula and their adaptation to the desert conditions present there. While the Wayuu possess many tribal features such as an acephalous, decentralized political system, clan affiliation, a traditional economy and a high level of autonomy, they also have a social hierarchy with various degrees of wealth, acquired through the ownership of livestock and socioeconomic ties to Western society (Vergara 1990). The legacy of their ancestors' incorporation of pastoralism has allowed contemporary Wayuu to subsist and proliferate on the arid Guajira Peninsula while fishing communities such as Mayapo occupy the extensive coastline, creating complementary socio-economic ways of life and becoming what today characterizes the Wayuu. 
Since the arrival of the Europeans, the Wayuu have been attacked and had their lands reduced and divided between two nation-states. They have been abandoned by the Colombian state until continued migrations to Venezuela due to droughts incited a response to provide lasting water sources across the peninsula. The arrival of the multinational Cerrejón coal mining company in the 1970s ushered in a new era of land appropriation, displacement and inequalities that persist to the present day. In a land rich in coal, natural gas, solar and wind energy, the disparities are noticeable between the rural Wayuu and the urban non-Wayuu Colombians regarding access to education, healthcare, food, water, sanitation, electricity, and other services.

The co-emergence of water and society is evident in the founding and growth of the Wayuu community of Mayapo from an uninhabited area one hundred years ago to the small town it is now. What began as an isolated settlement of pastoralists, became a bustling fishing and tourism-based community facilitated by the construction of a paved highway in 2008. The institutional support Mayapo receives from both the public and private sectors has also transformed the way its residents understand and relate to water. The central water-related problems in Mayapo have shifted from seasonality and difficult access, as in other more rural Wayuu communities (described in Chapter 5), to one of distribution, unequal access and the commodification of water, described further in Chapter 7. Their local water governance is currently being altered by national and international interventions on the peninsula aimed at mitigating perceived water crises related to water scarcity and water quality. The following chapter will focus on the different scales of water governance, from the dominant global, national and provincial scales to the weakened but persistent community water governance. 


\section{THE CONVERGENCE OF MULTIPLE SCALES OF WATER GOVERNANCE ON WAYUU TERRITORY}

In many governance circles, there is too often a linear path from scarcity to impending crisis to market-based reforms, and consideration of alternative means of confronting water-society dilemmas is sidelined.

Contemporary Water Governance in the Global South

(Goldin, Harris and Sneddon 2013, 39)

\section{Introduction}

Indigenous and pastoralist peoples are increasingly bounded by national and global mandates that undermine local water governance based on customary law, local traditions, values and adaptive strategies. Although cultural diversity, traditional knowledge and grassroots initiatives are paid lip service by global water institutions, water development has increasingly shown a unilineal progression towards global objectives and standards that marginalize non-conventional water relations, such as those that have historically been maintained by the Wayuu. Integrated water resources management (IWRM) is an example of how a dominant paradigm attempts to consolidate competing water uses at the global, national and local levels into a cohesive framework (Linton 2010). However, top-down administrative, technical and engineering solutions have remained the focus of IWRM (Budds and Sultana 2013), often obscuring the complex socioecological, economic and political realities and relationships that determine the distribution, access and use of water among pastoralists (Sendalo 2009).

Undoubtedly, Western science has made enormous advances in our understanding of water and devised technology to harness and improve water quality and quantity. The advances in modern medicine, water sanitation and hygiene have saved lives and 
diminished the risk of contracting water-borne diseases. However, the expertise, technology and the benefits they bring are distributed unevenly worldwide and at the expense of locally contextualized, more equitable and less expensive ways of managing health issues. Under this global water governance regime and Western water quality standards, the Wayuu are among the 785 million people who still lack a basic drinking water service and the 701 million who practice open air defecation (United Nations 2019).

There is a probability that the situation may worsen because of global warming on Wayuu territory and the continued growth of human and livestock populations. The Intergovernmental Panel on Climate Change's (IPCC) Fifth Assessment Report indicates that most deserts will become more arid with increased evapotranspiration due to global warming; furthermore, sea level rise is already impacting coastal zones (IPCC 2014). In addition, the IPCC assessment states, "risks are unevenly distributed and are generally greater for disadvantaged people and communities in countries at all levels of development" (ibid, 13). Based on these factors, the Wayuu are at greater risk than most since they are considered a "disadvantaged or vulnerable population" and their extensive coastline will be subject to a rising sea, causing saltwater intrusion to coastal freshwater sources. This will likely force coastal communities to relocate as well as reduce the overall land area within their territory. Furthermore, it is predicted that more frequent and longer-lasting droughts will exacerbate the already desert-like conditions. Temperature increases and decreased rainfall will not only negatively impact their seasonal agriculture and the pastures where the livestock feed, but also their water sources, mainly ponds 
where they harvest water and the groundwater supply that is tapped either by traditional or modern wells.

The United Nations Development Program (UNDP) characterizes water governance as "the political, social, economic and administrative systems in place that influence water's use and management - essentially, who gets what water, when and how, and who has the right to water and related services" (Stockholm International Water Institute 2016). Borrowing elements from Mollinga, who considers water management "a process of politically contested resource use" $(2008,10)$ and Karen Bakker's analytical framework of resource management $(2007,434)$, I understand water governance as the contested practices, processes and institutions among formal and informal organizations that govern water use, which I model in Figure 6. Water governance in any given setting is therefore enacted at different scales ranging from formal to informal, global to local, complementary to competing, and hierarchical to non-hierarchical (Figure 6).

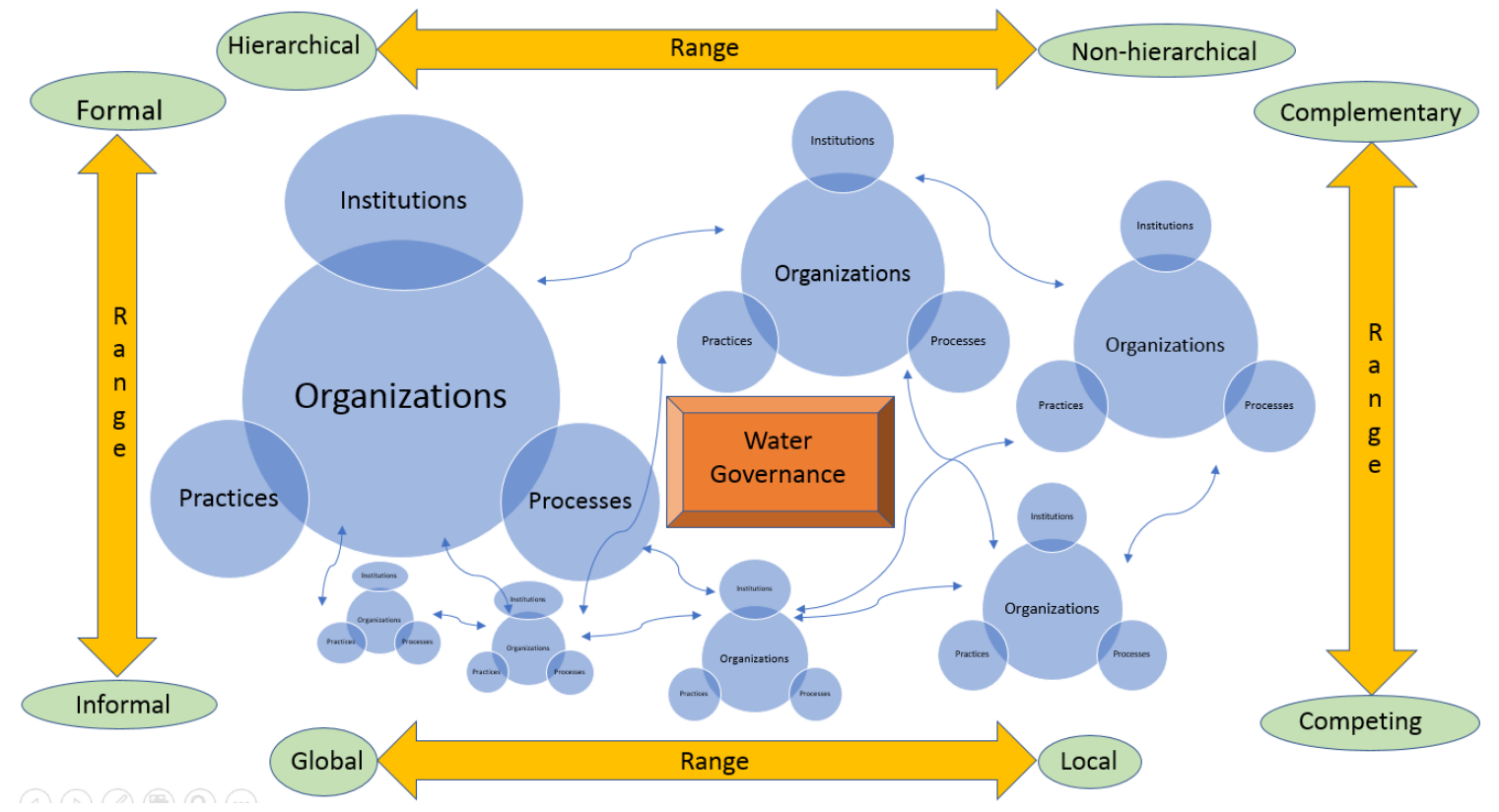

Figure 6. Water governance and its four ranges

Source: Created by author 
At the global scale, water governance is led by powerful international organizations such as the United Nations (UN), the Global Water Partnership (GWP), the World Water Council (WWC) and the World Bank who devise, disseminate and implement frameworks such as integrated water resources management (IWRM) and water security (WWC 2015; GWP 2016). At the national level, legislation and land reform informed by these global imperatives, and others on private property and progress, forcibly change human-land relationships of local communities. This vision of progress since colonialism, nation-state formation and into the current neoliberal era has assimilated and marginalized groups, including Indigenous and pastoralist peoples like the Wayuu (Fratkin 1997).

Despite these modernizing processes, at the local level, community or familial leaders, elders, women and spiritual leaders continue to manage, use and understand water through accumulated local knowledge, local beliefs and long-standing human and non-human social relations (Strauch and Almedom 2011). Worldwide, these informal water governances, and the multiple meanings of water, tenuously coexist with formalized water management and the dominant scientific understanding of water, with varying degrees of contestation. The figure below shows two types of water governance on Wayuu territory that include the actions of international, national, provincial and municipal governing institutions. For example, the picture on the left shows representatives of South Korea's government, the National Unit of Disaster Risk Management (UNGRD), the Red Cross of La Guajira, the provincial government of La Guajira and the municipal government of Manaure inaugurating a desalinization plant in the Wayuu community of Piedras Blancas, donated by South Korea (News from the 
Presidency of the Republic, April 5, 2016). The picture on the right shows a young Wayuu woman fetching water at a World Bank-funded reservoir in the Upper Guajira (photograph taken by author, July 2015) (Figure 7).
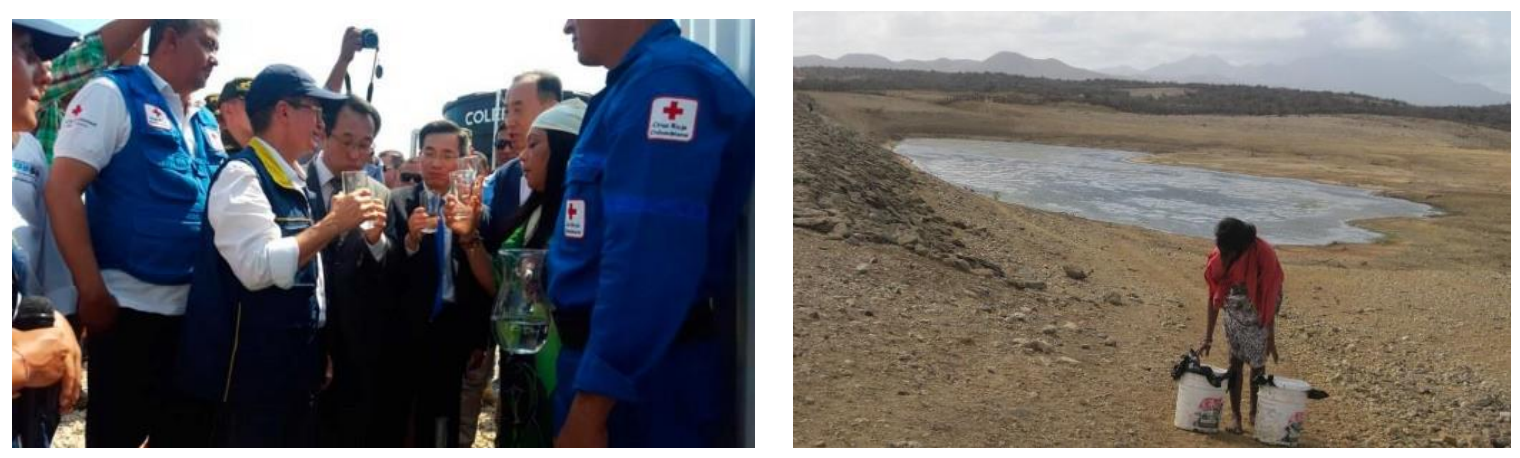

Figure 7. Two water governance moments, actors and places in Wayuu territory Source: Left: Presidencia de la Republica, Noticias April 5, 2016. Right: Photograph taken by author

Western science has also developed a deep and specialized understanding of water through fields such as hydrology, ecology, physics, chemistry, meteorology and engineering, to name a few. In this ontology, at the molecular level, water is the result of the joining of two hydrogen atoms and one oxygen atom $\left(\mathrm{H}_{2} \mathrm{O}\right)$. At the macro level, the hydrologic cycle shows how and why water moves through the earth's atmosphere, surface and subsurface. Furthermore, modern medicine and epidemiology explain the way water becomes contaminated by pathogenic microorganisms that cause illness and disease as well as providing solutions to perceived hygiene and sanitation problems.

Based on a modern, Western ontology and epistemology, science produces knowledge and the technology to provide the water sector with the necessary qualitative and quantitative assessments to establish an economic value to water and give it meaning as a commodity. Everything water-related from monthly water bills, the price of a bottle of water and definitions of water conservation, water scarcity, water legislation, water 
quality, water security and other water-related terminology become operationalized and legitimized. Faced with global warming, increasing water demand and decreasing fresh water availability, the UN's 2030 SDG targets and the integrated water resources management (IWRM) framework bring together institutions at all levels with clearly defined objectives, becoming a global, hegemonic apparatus shaping water relations while suppressing all others.

The following sections describe various scales of water governance. I begin with global water governance and the rise of integrated water resources management (IWRM) and water security as the overarching paradigms that dominate all other local water paradigms. Then, water governance at the national scale, provincial scale and by nonNGOs and the private sector are considered by identifying those entities that oversee water management and employ water governance practices. The chapter ends by describing water governance at the community level in La Guajira by the Wayuu leadership.

\section{Global water governance}

Conventional water management has been critiqued because of its inequitable distribution of water that favors large-scale agriculture, industry and hydropower (Sneddon 2013; van Koppen et al. 2016; Linton 2010). Water management worldwide has helped these sectors dominate nature through engineering solutions that have erected over 50,000 large dams and produced 280 million hectares of irrigated land in the $20^{\text {th }}$ century (Molle 2008). These advances in water productivity are noteworthy for their contribution to the food and water security for national populations, the provision of a cleaner source of energy, and their ability to strengthen national economies. However, 
they have also led to situations across the globe where small-scale farmers, fishers, pastoralists and foragers have been deprived of sufficient, continuous, quality water and the environmental services it provides in order to maintain their subsistence and livelihood activities.

In response to this growing water inequality between dominant and minority groups, rights to water have been addressed internationally in the Dublin Principles (1992), the U.N. Millennium Development Goals (2000), the Cochabamba Declaration (2000), the Brisbane Declaration (2007, 2018), the Declaration on the Rights of Indigenous Peoples (2007) and the U.N. Sustainable Development Goals (2015), all of which have promoted the protection of equitable access to quality water for human and ecosystem wellbeing. Nations have interpreted and incorporated these proclamations through legislation and policy, primarily through the integrated water resources management (IWRM) framework.

IWRM was put forth by global water development planners as the solution to the disjointed sectorial development towards interrelated environmental problems. In 1987, the U.N. World Commission on Environment and Development published Our Common Future, a report that recognized the "pitfalls" of past rural development efforts with a "flawed performance record" in managing the environment sustainably (The World Bank 1992; World Commission on Environment and Development 1987). This document was influential in setting sustainable development as a top priority and targeting poverty as a major obstacle to environmental sustainability. IWRM was also influenced by the four Dublin Principles, the last of which declared that "water has an economic value in all its competing uses and should be recognized as an economic good" (Linton 2010,218). This 
statement was interpreted by its supporters as legitimizing the transfer of substantial control to the private sector to improve water management (Bakker 2007). Subsequently, international financial institutions such as the International Monetary Fund and the World Bank included water privatization as a lending condition for debtor countries in their structural adjustment programs (Salzman 2006).

The World Water Council and the Global Water Partnership were created by the United Nations Development Program, the World Bank and other leading water sector experts to promote and implement the IWRM framework, with a focus on multistakeholder partnerships across the globe, whose main goals are known as the three Es: equity, environmental sustainability and economic efficiency (Linton 2010; van Koppen et al. 2016). IWRM is also designed to: 1) promote the cultural, ecological and economic values of water; 2) use a multisector approach; 3) integrate local, national and transnational water management; and 4) emphasize the participation of all relevant stakeholders in water management (Linton 2010, 216-17).

The implementation of IWRM in Africa (Mehta 2016) and in Tanzania in particular, has been well-studied (Maganga 2004; Stein 2011; Nindi et al. 2014; GLOWS-FIU 2012; Malley et al. 2008; Sokile 2004; Mbonile 2005; Komakech 2013; Cleaver 2006; Walsh 2012; Rajabu 2005; Strauch and Almedom 2011; Mehari 2009; Dworkin 1980). This body of literature on the implementation and results of IWRM among pastoralists in Africa provides lessons on water governance that apply to the Wayuu, who share socio-economic and environmental similarities with East African pastoralism and rangelands. 
Scholars critical of the global water governance framework have argued that these attempts at controlling complex ecological relationships maintain a conventional (command-and-control) management approach and are consistent with a capitalist neoliberal agenda (Lankford 2013; Goldin, Sneddon, and Harris 2013; Scott et al. 2013; Waughray 2011; Norman et al. 2013). Other critiques of IWRM show how it is dominated by government interests (Goldin, Harris, and Sneddon 2013) and provides little space for community engagement beyond standardized meetings and workshops that are considered unconducive to true participation (Maganga 2004). Rather, it further concentrates power among privileged networks (Goldman 2007; Faysse 2006). These deficiencies of IWRM have led to the conclusion that of its stated objectives-equity, environmental sustainability and economic efficiency—equity has received the least attention and has not been achieved (van Koppen et al. 2016, 588). ${ }^{15}$

Water security has become another prevalent term in the $21^{\text {st }}$ century, within global and national water discourse on water management (Lankford 2013; Bakker 2012a). Created in 2011, the World Economic Forum's multi-company Water Initiative deemed water security "the gossamer that links together the web of food, energy, climate, economic growth, and human security challenges that the world economy faces over the next two decades" (Waughray 2011). This statement encapsulates how the Forum and its

\footnotetext{
${ }^{15}$ For example, in Tanzania there is extensive scholarship on water management focused on the inadequacies of the water legislation (Luilo 2003), problems of water grabbing by foreign businesses (de Bont 2016; Mehta 2012; Allan 2013), pastoralists' continued reliance on local knowledge and institutions in water governance (Strauch and Almedom 2011; Maganga 2004; Sokile 2004), the limitations of water user associations (WUAs) and community participation (Dungumaro and Madulu 2003; Sokile 2004; Sokile 2005) and the formal-informal misfit of IWRM and the power imbalances it reinforces (van Koppen et al. 2016; Sokile 2003; Maganga, Butterworth and Moriarty 2002; Mehta 2016).
} 
powerful constituents have interpreted, appropriated and globally diffused their definition of water security, namely, to secure the world economy. Conceptually, Lankford hopes water security will provide more coherence in water research than IWRM and water governance by focusing on the questions, water security for whom? and water security how? $(2013,9)$.

There was a growing recognition in the 1980s and 90s within security studies that human and environmental security are interrelated in complex ways that have not been considered in mainstream state-centric policy and science (Huysmans 1998). Massumi describes the heightened sense of risk, vulnerability and limits to any security measures taken by stating, "Threat is as ubiquitous as the wind, and its source as imperceptible. It just shows up. It breaks out. It irrupts without warning, coming from any direction, following any path through the increasingly complex and inter-connected world" (2009, 160). Under these circumstances, national security can no longer be maintained by simply engaging diplomatically, militarily or institutionally with perceived external or internal threats to the dominant order. Neither can environmental security be considered a response to eminent or occurred "natural" disasters, crises and emergencies independent from human agency. Consequently, water security invokes a heightened awareness of an increasingly water insecure world and professes a need for urgent action.

Some authors have adopted the term Anthropocene to emphasize the current era of human-induced environmental change with a physical world susceptible to humanity's agency. The Anthropocene era also presents the ultimate test to the survival of the human race, which is faced with global warming that threatens our food and water supplies through various acute and chronic biospherical events (IPCC 2014; Dalby 2009; Clark 
2014; Mann 2012). Whether implicit or explicitly stated, water security and IWRM are in large part a response to this heightened sense of vulnerability.

Water security scholars also warn that "if water security is considered narrowly and primarily in terms of risks and threats, the only space for politics in the policy formation is through the 'politics of fear,' which would lead to the previously mentioned retreat to securitization and protection of 'our' water" (Lankford 2013, 8). Therefore, for Lankford, water security and military security are incongruent; rather he argues, actionoriented approaches that focus on environmental sustainability and collaboration should be the fundamental principles of water security.

\section{National water governance}

Paternalism and hubris have characterized Western science and societies since early colonialism in the $16^{\text {th }}$ century, the beginning of modernity, according to Escobar (2008). Paternalism occurs not only between the dominant local society and local Indigenous groups but also within regions of a nation and between nations and world regions.

At the national level, Colombia's centralist government, whose epicenter is the capital city of Bogotá in the Andean highlands, has long been considered paternalistic towards the country's lowland regions: the Amazon basin, the Orinoco basin, the Pacific Coast and the Caribbean Coast (Acosta Medina 2013). Escobar notes that in Colombia since the colonial era and into the republican era "writers established a direct connection between climate and territory and racial groups: the cooler Andean plateaus were inhabited by the civilized good white people of European origin; the humid, tropical lowlands by blacks and Indigenous groups incapable of reason and progress" $(2008,48)$. 
Consequently, a general sentiment of the inhabitants of La Guajira province in the Caribbean region toward the central government has been a feeling of abandonment, stigmatization and victimization resulting from internal neo-colonialism (Redacción El Heraldo 2014; Guerra Curvelo 2019).

Colombia's current constitution, established in 1991, provides a legal framework that emphasizes the individual and collective rights of Indigenous peoples and Afrodescendants (Roa-Garcia, Urteaga-Crovetto, and Bustamante-Zenteno 2015). These unprecedented rights begin with the recognition and protection of the ethnic and cultural diversity of the nation (Art. 7) and include the following: native languages became official languages (along with Spanish) within their reservations (resguardos) (Art. 10), the freedom of religion (Art. 19), intercultural education (Art. 68), the allocation of two permanent Indigenous representatives in the Senate (Art. 171) and autonomy of their territories (Art. 287, Art. 329) among others. The government also recognized and regulated the formation of formal Indigenous associations and traditional authorities.

Regarding natural resource and water management, Colombian legislation is ambivalent, evidenced in the mixed treatment towards water management. It promotes decentralization and privatization of water services while maintaining control over water distribution through the allocation of water concessions and water user fees (Ibid, 274). Decentralization and regionalization have been an increasing trend in Colombia. As an example, the Regional Autonomous Corporations (CARs) provide a clear example of Colombia's relationship with water and natural resources more generally. Modelled after the Tennessee Valley Authority, the 33 existing CARs are Colombia's provincial environmental authorities that began to operate in the 1950s (ibid). They serve a double 
function of managing investments and enforcing regulations of natural resources at the regional level. This governmental management institution acquires significant financial resources from the energy sector and distributes them towards natural resource management and conservation efforts. In 2006, the national government created the Provincial Water Plans (PDAs) with the purpose of further decentralizing water management and strengthening the business management of public works (Useche Melo 2012). In 2010, the Colombian government adopted the IWRM framework, issuing the POMCA (Ordering and Management Plan of Hydrographic Basins) as a technical guide to orient the Regional Autonomous Corporations in implementing the IWRM strategy. A novel court ruling in Colombia has set a legal precedence worldwide on how bodies of water are gaining protection by the state. In 2016, the Constitutional Court of Colombia passed Sentence T-622, giving legal personhood to the River Atrato in the province of Chocó, its tributaries, and its basin. The sentence determined that the river has the constitutional right to be protected, preserved, and restored by the State and the ethnic communities residing near it (Cano 2018, 8). New Zealand, India and Ecuador have also adopted legal mechanisms giving rights to rivers in order to improve their protection (ibid). These initiatives constitute a shift in the conventional understanding of bodies of water yet it remains to be seen whether de jure declarations translate into de facto implementations influencing water-society relations in Chocó and in Colombia.

\section{Provincial water governance}

The government agencies that are most involved in providing waterworks to the Wayuu communities are the municipal and provincial governments, the municipal aqueducts, the provincial environmental authority (Corpoguajira), the national 
Department of Social Prosperity (DPS), the National Unit for Disaster Risk Management (UNGRD) and the Vice-Ministry of Water and Basic Sanitation. The water service in the capital city of La Guajira, Riohacha, has only in the last decade become a continuous service, and for only certain sectors of the city; poorer and peripheral neighborhoods currently receive water service one day per week. The city's water service has been fraught with problems and the Ministry of Housing estimates that on average, water service operates only nine hours per day, the lowest in the country; the national average in urban centers is 18 hours (Ministerio de Vivienda 2018).

Currently, at the municipal level, political aspirants provide, or promise to provide, water infrastructure for the community during electoral seasons in exchange for votes. In Cardón for example, the ponds of Patsualalein and Wa'ali were built by political candidates in order to obtain votes from the population. In Mayapo, several residents lamented the fact that political aspirants promise to improve the water situation in the community as a strategy to obtain votes and then do not follow through with their pledges. Across Colombia, elections for governors, mayors and other local government positions were held in October of 2019. Once again, candidates proselytized in Mayapo, offering the usual assurances to the inhabitants that the water situation will improve if they are elected into office.

However, there is little room for optimism based on the instability and corruption that has beleaguered La Guajira, especially the governor's office which has been presided over by nine governors in the last four years, two by popular election and seven by presidential decree. Between 2012 and 2017, five consecutive governors of La Guajira were imprisoned for different criminal activities ranging from embezzlement to homicide 
(El Tiempo 27 Jan. 2017). Likewise, the mayor's office of Riohacha has not fared any better, with nine mayors taking office in the last four years (El Tiempo 5 Dec. 2018).

Because of this corruption and poor management by the local authorities, in 2017 the national government deemed it necessary to transfer control of water management in La Guajira from the provincial government to the Vice Ministry of Water and Sanitation, as well as its counterparts in the health and education sectors. The appointment of governors and the interventions of the national government in these sectors points to both deep and persistent governance problems in La Guajira as well as the continued imposition and control of the national government over provincial affairs.

\section{Private sector and $N G O$ water governance}

Water governance is not limited to the public sector; in La Guajira the private and non-governmental sectors have had a significant impact on water provisioning, especially in the rural Indigenous areas where the government presence has been weakest. The concept of social responsibility in Colombia is the way companies operating in the country can directly return part of the wealth derived from the territories of the communities. Although not mandated by law, social responsibility is recommended by the Colombian government as a form of solidarity and as an important part of ethical business practices. Since water security is a priority on the Guajira Peninsula, the companies operating there have all included water, sanitation and hygiene as a component of their social responsibility to the beneficiary communities.

Chevron-Ecopetrol has been operating in La Guajira for nearly 50 years and has off-shore and on-shore natural gas operations, the latter in an area in between the communities of Mayapo and El Pájaro. Both communities are recipients of the 
company's social responsibility programs because of their proximity to its operations. In Mayapo, Chevron-Ecopetrol has installed three drilled wells, as well as assisted in the construction of the boarding school, the health center and the fishing committee's office, among other community projects and social activities.

The Cerrejón coal mining company is the province's largest employer, with over 5,000 direct employees and exports over 30 million tons of coal annually. The company has a Social Responsibility department and maintains the Cerrejón Foundation, which provides water, sanitation and hygiene solutions to the communities within its area of influence. The communities of Cardón and others that are within two kilometers of the Cerrejón's railway receive assistance from the foundational arm of this multinational, which performs maintenance work on ponds, rehabilitates wind-powered wells, creates local water committees and delivers water using water trucks and the train. ${ }^{16}$

In other areas of the peninsula, national and international companies are also involved in social responsibility. The Public Services Company (EPM) is an energy provider that built the Jepírachi wind farm, the first in Wayuu territory, near the Wayuu communities of Kasiwolin and Arutkajui in 2004. As compensation, Kasiwolin received a drilled well and a water treatment plant from the company, among other benefits. Nevertheless, EPM's corporate social responsibility did not prioritize the economic and social wellbeing of the communities and the community members have felt frustration by

\footnotetext{
${ }^{16}$ For 2018, the Foundation reported the delivery of 27.2 million liters of water to 147 communities adjacent to the railway; the installation of water supply system in seven Wayuu communities, including one solar-powered water supply system; the rehabilitation of 12 wind-powered wells in Wayuu territory; and the distribution of storage tanks in 66 communities with a total capacity of 594,000 liters of water (Cerrejón Foundation 2019).
} 
the limited reach and impact of the benefits. For them, the clean energy transition has been far from transformational in their lives (Schwartz 2019).

From 2014 to 2016, the oil and gas company Repsol, in partnership with the United Nations' Development Programme (UNDP) installed two micro aqueducts and built four ponds in the northeastern region of the peninsula, as part of their social responsibility. Alpina is a national dairy, food and beverage company that has an affiliated foundation in La Guajira. The foundation focuses on local capacity building in order to improve food and nutrition security, specifically among the Wayuu communities of Puerto Estrella, Nazaret, Siapana and Aremasain. To this date, the communities of Irraipa do not receive support from the private sector, although the construction of a wind farm is underway in this area.

Humanitarian agencies and NGOs have also provided water aid in various forms and at different moments in Wayuu territory, including Oxfam, various United Nations agencies (UNDP, UNICEF, WFP, FAO), the World Bank, the Red Cross, Action Against Hunger, WaterAid and the local NGO, Aguayuda. Between 2014-2016, Oxfam, in alliance with the Colombian Ministry of Foreign Affairs and UNICEF, has repaired water supply systems, installed solar panels to pump water from drilled wells and donated water filters in 24 Wayuu communities in the municipalities of Manaure and Uribia. The local NGO Aguayuda has been working in La Guajira since 2006, and recently partnered with WaterAid to install and repair water infrastructure and donate water filters. Most of these NGOs and humanitarian organizations also provide hygiene education and help in the formation of water committees. 


\section{Community-level Wayuu water governance}

For the Wayuu, traditional water sources form part of the common property resources wherein members and non-members of a community can use the source. According to an elder of Cardón, in the past, water was shared with those who helped in its construction and maintenance. Those who were not from the community and wished to have access to the water source needed to bring food or something to exchange with the traditional owners of the land. An elderly woman, also from Cardón, recalled that when she was younger, she would go as far as Ipanalu, Kutchepen or other distant places where there was water because all the nearby sources would go dry. Sometimes she went with two donkeys, one to carry the amuchi (ceramic water jugs) and one for her to ride. She would also take the goats to drink water, food for herself and items to exchange for the water. She would use a tin can to scoop out the water from the wells. Even when she did not have items to exchange, the territorial owners would share the water. Now, things have changed, she says, and people do not want to share water like they did in the past.

Currently, human and livestock access to ponds is determined by proximity to the water source, presence or absence of fencing, participation in its construction or maintenance and the amount of restrictive control placed on it by the dominant clan. Clans that have ancestral ownership over the territory can also claim ownership of the water sources if they participated directly in its construction or negotiated it with an external actor. Clan leaders establish their power over the sources by maintaining and regulating their access. In this sense, in Irraipa the Ipuana Clan exercises power over the Marbella and Malairatu ponds, the Epieyu manage the Kulesiamana Pond, and the Pushaina Clan leader controls the local reservoir. Regarding this reservoir, another leader 
of the Epieyu Clan from a neighboring community is contesting his control because she was the leader who mediated with the government and the name of the reservoir is the same as the community she represents. In Cardón, the Pushaina Clan leadership conceded the land for the construction of the reservoir, the Uliana Clan controls the Wa' ali pond and the Epieyu manage the drilled well. While in Mayapo, the Ipuana are the founding clan but the main pond was negotiated and maintained until his passing by a leader of the Uliana Clan.

Traditional water sources such as ponds and wells are built and maintained by the community members who are called upon by the alaüla (family leader) to participate in collective work known as yanama. The leader provides food, uujot (corn-based drink) and liquor in exchange for the men's labor. While the men build and repair, the women members of the community prepare food and uujot. Yanama collective work unites the community members around a common goal, for example the construction, maintenance or fencing of a water source. Unlike paid labor, the workers will not receive a monetary payment since this type of work operates under the logic of reciprocity and communal benefit. The investment of time and effort will pay off not only in the improvement of the water supply and ensured access to it, but also greater social cohesion among the various clans and communities involved in the collective work and a greater sense of ownership of the infrastructure.

Local leaders are also interested in negotiating and managing water sources not only to satisfy the basic water needs of the community, but also to gain prestige. Relatives who hold public or private positions in the water sector are called upon to help prioritize the provision of water to the community by water trucks or the construction or 
repair of water sources. Since governmental and private institutions receive numerous requests to provide water-related assistance, local leaders and representatives must use their contacts, and be insistent and attentive to the state of their request because the assistance can be gained by another community.

\section{Discussion}

This chapter has described the multiple levels of water governance converging on Wayuu territory, forming what Mollinga describes as "a process of politically contested resource use" $(2008,10)$ and what Yates, Harris and Wilson consider "ontological disjunctures-conflicts over the very essence and being of water (2017:799). These two statements highlight the power-laden relationships surrounding water governance. Water actors at all levels - private water company stockholders, governmental policy-makers, water management experts, political candidates, waterworks engineers, water supply operators, technicians, and Wayuu leaders, shamans, water users and other-than-human water beings, among many others - each attempt to forward their individual, collective or institutional priorities and interests.

While Mollinga's statement focuses on the competition of water as a resource between various sectors of society, such as between industry, other non-industrial economic activities, domestic use and for ecosystem maintenance, Yates, Harris and Wilson direct our attention to different water ontologies. Therefore, the encounter of the multiple actors from the various levels of water governance on the Guajira Peninsula also bring into contact very different epistemologies and ontologies that struggle for supremacy. This is most notable between the global and the Wayuu levels of water governance although between these extremes I highlight how Colombia's national water 
governance office has delegitimized provincial water institutions, deeming them corrupt and uncapable of carrying out water policies and programs. Furthermore, the participation of non-water sector actors such as multinational fossil fuel companies and political candidates in water governance in Wayuu territory reinforces the use of water to forward competing agendas not always in the best interest of the Wayuu water users.

The next chapter delves deeper into Wayuu hydrosocial relations by presenting an ethnographic depiction of the water knowledge and practices of the inhabitants of Irraipa and Cardón. These communities maintain traditional water relations while also incorporating new ones that include increased interactions with non-Wayuu water experts and Western water technology. 


\title{
V. WAYUU WATER KNOWLEDGE AND HYDROSOCIAL RELATIONS
}

\author{
Kasakai wanakat sümaa wuñasu?
}

What is far when there is thirst?

Wayuu woman of Cardón, April 2012

Süka nojoluipan süitün, jaisü tü ma'akat. Nojotsü wuin jemetsü süpuna tü ma'akat. Ma'ulü shia'ane e'eka tü suwüirakat tü ma'kat sümaa pala'in shia.

Since it's not raining anymore, the ground is hot. There is no more fresh water under the earth. Now only saltwater is left, the tears of the earth.

Wayuu elder from Irraipa, August 2012

\section{Introduction}

This chapter will explore the hydrosocial relations that are formed by the coemergence and intermingling of the human, the natural and the supernatural worlds on Wayuu territory. This Wayuu water world is expressed through daily routines, practices and interactions related to the use and management of water by the Wayuu water users. Wayuu water knowledge is gained and maintained through oral history, customs and traditions, complemented by direct experience by the Wayuu with their surrounding environment. Far from static or in decline, this knowledge grows by accounting for both local socio-ecological conditions that are themselves in flux and new information and current events occurring beyond their territory that have local repercussions. Thus, information on climate change, the political and economic instability in La Guajira Province and in Venezuela, new legislation or court rulings, among others, circulate throughout the Wayuu society and are processed according to Wayuu epistemology.

Wayuu hydrosocial relations and water knowledge can be characterized as traditional ecological knowledge (TEK), defined by ecologist and resilience scholar Fikret Berkes, as "the cumulative body of knowledge, practice, and belief, evolving by 
adaptive processes and handed down through generations by cultural transmission, about the relationship of living beings (including humans) with one another and with their environment $(2012,7)$. Whether described as a body of knowledge or a way of life, the relationship the Wayuu have with water and the knowledge obtained from these interactions contrasts with the way alijuna public health officials and water management experts understand and relate to water.

The two prior chapters offered different angles and scales of analysis by which to understand the current context of Wayuu-water relations. Chapter 3 examined pastoralism at the global scale from a political ecology perspective to address how the Wayuu are situated within broader patterns and problems affecting pastoralist societies. That chapter also focused on the historical intraethnic and interethnic relations on the Guajira Peninsula that resulted in the current cultural configuration of the Wayuu nation, absorbed within the boundaries of two nation-states yet at the same time detached from the Hispanic national societies. Chapter 4 provided a multi-scalar analysis of water governance structures ranging from the global to the local that determine how conventional water management is carried out on Wayuu territory and limit the possibilities for non-conventional alternatives.

This chapter begins by presenting the relationship Wayuu livelihoods have with the seasons in a predominantly semi-arid environment with occasional rains. Extensive pastoralism and seasonal small-scale agriculture are two important subsistence strategies the Wayuu have developed over the centuries whose primary water source comes from the rains. A substantial portion of Wayuu water knowledge is used to strengthen the relationship between agriculturalists and pastoralists with the rain and the water sources. 
This entails water conservation strategies and understanding the water needs of the livestock and the cultivated plants. This chapter identifies the various challenges a dry environment such as the Guajira Peninsula presents for water provisioning for human consumption. I describe the extensive Wayuu knowledge used to develop standards of drinking water quality, to construct, maintain and protect water sources, and to navigate the natural and social milieu for greater accessibility and reliability of water sources.

Another important component of water knowledge among the Wayuu is understanding the seasonality of the water sources in their territory. The ability to identify and secure access to various water sources throughout the year-ponds, reservoirs, dug wells, drilled wells, water trucks, seasonal streams and water harvesting — is essential in a region where water availability and water technology reliability fluctuate greatly. To visualize the temporality of water sources on Wayuu territory and the distances covered to gather water, I present a series of maps showing the daily trips made by the residents of Irraipa and Cardón during the rainy season, dry season and times of drought. The maps are supported by ethnographic descriptions that show the complexity of water procurement not only because of the inherent biophysical limitations but also because of anthropic factors such as: the appropriation of water sources by local leaders, power struggles between clans, lack of institutional presence, contamination of the water sources, the politics surrounding water source construction and maintenance, and various others.

The last section of this chapter provides three interpretations of Wayuu-water relations using a conventional approach, a political ecology approach and a relational ontology approach. The conventional approach is framed using Santos' five logics of his 
sociology of absences that identify how inexistence is produced by only allowing to exist the scientific, the advanced, the superior, the global, and the productive $(2011,30-32)$. The political ecology approach centers on the historical and contemporary power relations between the Wayuu and the non-Wayuu that has enabled the unequal distribution of fresh water throughout the province of La Guajira. Finally, the relational ontology approach underscores the construction of meaning by questioning the universality of terms such as drought and water security. This final section introduces the spiritual dimension of Wayuu-water relations that will be discussed in Chapter 6.

\section{Wayuu livelihoods and the seasons}

Wayuu livelihoods and water-related activities are place-based, closely linked to the land and sea. They follow the annual cycle of the seasons and the availability of rainwater and groundwater. Most Wayuu men who live in the rural area consider themselves aruleewi (herders) or if they live along the coast, ejimeji (fishermen) (also known as alojui jime, fish hunters or apalaanchi, seafaring people). Farming, herding, hunting and gathering are Wayuu subsistence strategies that necessitate or benefit from the rains, ponds, aquifers and soil moisture. Wayuu fishermen also agree that the rainy season is the best time of year for fishing because streams and run-off carry sediment from the land to the coastal zone, attracting smaller fish to the coast and consequently, larger fish.

The Guajira Peninsula has two rainy seasons, juyapu, the primary rainy season, and iiwa, a minor rainy season. Jиуари usually begins in late August or early September and can last until late October or early November. On good years, juyapu provides enough rainfall to revitalize wild vegetation, stimulate crop growth and form potent 
streams that flow across the landscape filling ponds and replenishing aquifers (Vergara 1990; Perrin 1993). Iiwa occurs in April or May and delivers a few days of rainfall at most. Besides juyapu and iiwa, Paz Ipuana (2016b, 221) describes over 24 types of rains that the Wayuu distinguish. For example, patünainjana are the rains at the end of iiwa that occasionally fall in the month of May; although rare, these are considered by some Wayuu to be the best rains because they extend the short rainy season, which precedes the longest, hottest and driest season of the year, jouktale 'u (also known as jouktai jamü, which literally means hunger winds), extending from May to September. On the contrary, there is another type of damaging rain that follows the primary rainy season of juyapu known as jichi. Jichi is known to occur during the first days of November, associated with the Day of the Dead and consists of "hot" rains that "burn and dry" the vegetation. Towards the end of November to January, jemiai (short summer, literally meaning cold) is the season that follows juyapu, characterized by a weather marginally cooler than the rest of the year. Then, in February and March, jouktai, the windy season, sets in, characterized by strong and constant northeasterly trade winds that blow across the peninsula until they lose force allowing for iiwa, the minor rainy season, to take place. Unfortunately, the rains of iiwa do not always come and the people of the peninsula must endure a prolonged jouktale'u (dry season), from November to September of the following year (Cano Correa, van der Hammen Malo, and Arbeláez Albornoz 2010).

\section{Pastoralism}

For the Wayuu, livestock is a main source of wealth; ownership of many animals is synonymous with prestige. This "wealth on the hoof" is used in Wayuu social events of all kinds: as currency for the reparation of crimes and offences, as bridewealth during 
marriages, as offerings to the spirits and for gifting and consumption during primary and secondary funerals, collective work (yanama), celebrations and other important moments. Live goats and sheep are also sold in the city markets or their meat is sold within the communities. The animals most adapted to the semi-desert environment of the Guajira Peninsula are goats and sheep, requiring less water than cattle and equines and whose diet is more varied. As mixed eaters, sheep, and especially goats, eat various types of vegetation (grasses, shrubs, cacti, trees), including leaves, seeds and stems. Cattle, on the other hand, drink 10 times more water than goats and are grazers, whose diet is limited to grasses and low vegetation (Walker and Hillman cited in Cerrejón Foundation for Progress of La Guajira 2009, 25). Goats and sheep account for 92\% of the livestock owned by the inhabitants of Irraipa, Cardón and Mayapo. In Irraipa, which has the largest livestock population and the smallest human population of the three areas, there are on average 7 animals per person. Considering the large number of goats and sheep in the Wayuu territory, pastoralism is an activity that demands a significant amount of water throughout the year (See Figures 8 and 9).

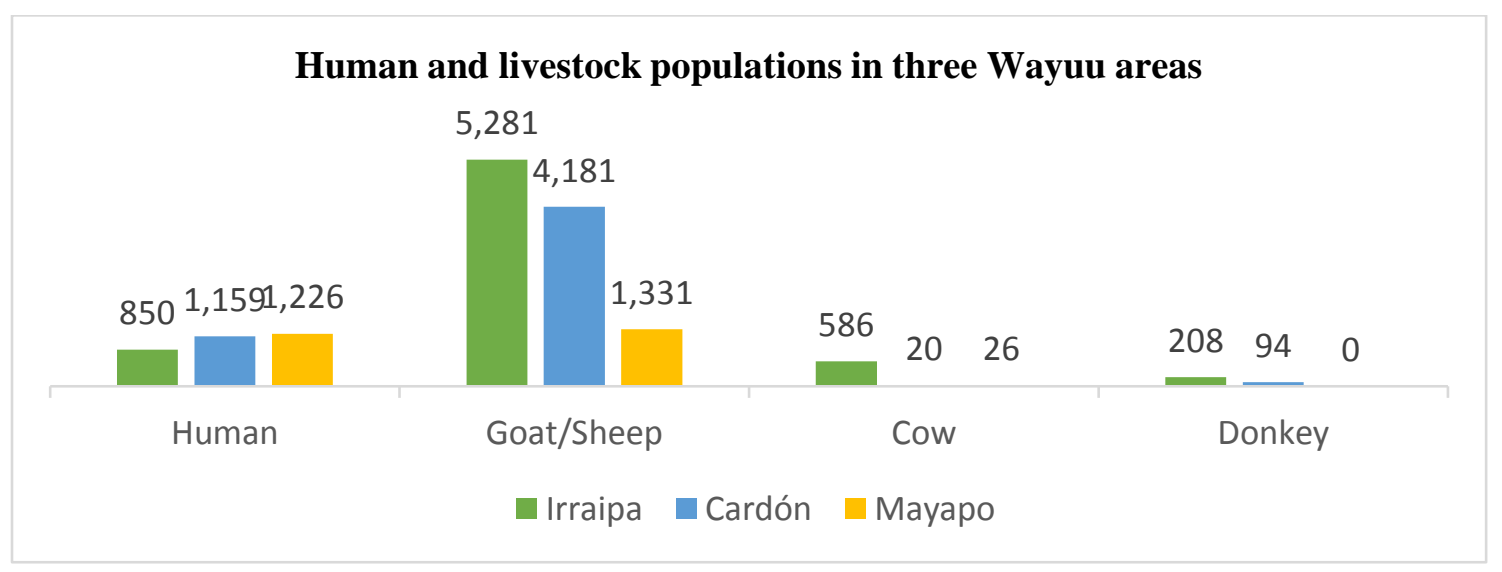

Figure 8. Human and livestock populations in Irraipa, Cardón and Mayapo Sources: Cerrejón Foundation for Progress of La Guajira (Irraipa and Cardón, 2012), Author's fieldwork (Mayapo, 2018). 
The better months for herding are those during and following the rainy seasons. This is also the time when the animals tend to give birth and whose newborns have a better chance of surviving than if they were born during the dry season. Livestock milk production is used by the Wayuu to make yahaushi (corn-based porridge), cheese and curdled milk, either for domestic consumption or for sale in the cities. The animal hides are also sold to the regional leather industry or used to make Wayuu drums (kasha) or arts and crafts. Wayuu herders spend less time herding during the rainy season because the water sources and pastures are nearby and plentiful, allowing them more time to farm.

Among the three research locations, the lower the human population, the greater the livestock population and vice versa (see Figure 10). Irraipa, which has the lowest number of inhabitants, also has the largest extension of land and the largest livestock population. Whereas Mayapo has the largest number of inhabitants, the smallest land extension and the smallest livestock population. This pattern may reflect the limitations the environment places on human and population growth, because of the limited plant and water resources. It also reflects the different livelihoods; Wayuu communities in the interior of the peninsula, such as those in Irraipa, tend to have more domesticated animals than coastal communities because the latter dedicate more time to fishing. Accordingly, Mayapo and Cardón are primarily fishing communities while Irraipa's communities are herding-based. In the case of Mayapo, the concentration of residences and the fencing of properties is not conducive to animal husbandry that requires extensive, open areas for grazing.

The ownership of cattle and horses is a status symbol among the Wayuu; those who own these species are considered wealthy Wayuu. However, the aridity of the 
peninsula limits their numbers since they require large amounts of water and pasture.

Horse races were common events in the past and racetracks in the form of a long strip of land were cleared for this purpose. During the 1970s, when marijuana trafficking was at its peak, these racetracks were used by drug running planes as clandestine airstrips in Wayuu territory. They also serve as territorial markers, along with cemeteries, ponds, wells, streams and other land formations.

The traditional authority of Mayapo reminisced that in his youth he would compete in the horse races. People would come to Mayapo from the surrounding communities to see the event and participate in festivities and the yonna, a ritual dance organized by his mother, the outsü (shaman) of the community.

I remember that my grandmother bathed the animals with alouka [Croton malambo]. She was also an outsü, and among her beliefs was that the animals had to be bathed with alouka to ward off the spirits that could wipe out the animals. We sang to the animals and played the kasha drum. There were three days of dancing. Cows were sacrificed and goats were given to the attendees. I am a rich Wayuu since I own lots of animals, even though many have died due to the strong summer we have experienced (Erasmo Ipuana, October 2018).

The statement indicates how this social event served various purposes. Via shamanic ceremonies, the supernatural and the protective properties of the alouka medicinal plant were summoned to safeguard livestock from disease, strengthening the ties between the spiritual, the natural and human worlds. Also, community members celebrated together with food, song, dance and horse racing, promoting social cohesion and solidarity. Wealth was redistributed in the form of livestock gifting, reaffirming the social role and status of the traditional leaders and the organizers of the event. Lastly, the shaman, the musicians, the dancers, the cooks, the horse racers and the livestock owners all contributed to the continuation of the Wayuu traditions and cultural identity. 
The first part of Mr. Ipuana's last sentence, "I am a rich Wayuu since I own lots of animals", supports the culturally specific Wayuu measurement of wealth and poverty in the form of livestock numbers. His wealth and prestige are evidenced in his ownership of most of the community's cattle, which he daily guides to drink water at an enlarged ditch under the bridge next to the boarding school as one enters Mayapo. As the traditional authority of Mayapo, he negotiated with the administrators of the boarding school the use of its drilled well to fill the ditch with water for his cattle and those of other local herders. This example shows how leaders gain power and prestige through livestock ownership and use that power to secure water to maintain and increase their livestock numbers. In this case the water supply infrastructure was installed by a private company (Chevron) on the property of a public school, whose water was then shared with the leader and other herders for watering the animals beyond the school's property. As in Mayapo, leaders of other communities lobby for private, public and non-governmental organizations to provide or improve their water sources intended for both human and livestock use. As is common in Indigenous societies, sharing and redistribution of wealth, in this case, water resources, are social norms and obligations that maintain order and serve as leveling strategies against social inequality, here, an unequal access to the water sources in the community.

The second part of his last statement, "many [livestock] have died due to the strong summer we have experienced," highlights the effects that the drought has had on his livestock, and reaffirms how droughts in general take a heavy toll on domesticated animals, many of which do not survive these climatic events. While most attention by the Wayuu and non-Wayuu is given to the negative impacts that water scarcity and droughts 
have on the livestock, there is little discussion of the positive impacts, namely 1) the reduction by natural means of the excessive number of livestock and their demand on the natural resources of the territory and 2) the evolutionary process of natural selection that continuously favors the propagation and adaptation of the more fit flora and fauna to the current environmental conditions on the peninsula, while limiting the reproduction of less fit specimens. Those cows, sheep, goats, donkeys, horses and mules that withstand the extreme climatic conditions pass on these adaptive traits to their offspring. This also applies to the wild plant life and the human selection of cultivated crops that have adapted to the arid conditions of the Guajira Peninsula over the centuries and millennia.

The Wayuu also form part of the local socio-ecological system and have coevolved through countless generations with the chronic environmental conditions as well as the cyclical disruptions of the food and water sources. Consequently, the Wayuu have also adapted to their environment, noting that in their case the adaptation is both cultural and biological. Although there is an absence of local scientific evidence supporting this claim, it is widely believed by both Wayuu and alijuna that the Wayuu can tolerate "unclean water" and the heat of the sun more than an alijuna. This is similar to the regional belief that foreigners who visit La Guajira, especially those from developed countries, are also more likely to get sick from consuming local street food or water than the locals, whose immune systems have developed a resistance to local strains of germs and bacteria.

A recent study does provide evidence of how the Wayuu may have adapted to living on the Guajira Peninsula. During a medical assistance campaign carried out in 2017 in Mayapo by the U.S. Navy, NGOs, the Colombian Ministry of Health, and the 
Colombian Navy and Army, demographic and health data were gathered and concluded that,

Although the Wayuu live in an arid desert with chronic sun exposure, they have no apparent affliction from squamous cell carcinoma or melanoma. They live almost exclusively through manual labor, yet rarely develop osteoarthritic joint disease. Their incidence of hypertension is $35 \%$ lower than their US age and gender matched cohort. Although their region is known for extreme poverty and malnutrition, their weight-for-age curve from 2 months through 17 years is similar to their US cohort (Lennon et al. 2019:1).

Although this study was critiqued by Tuesca-Molina et al. (2019) for its insufficient and biased data, which "distorts the sad reality of a marginalized population and does not reflect the heterogeneity of the population" (Ibid, 1), the study questions the prevalent discourse that the Wayuu, especially Wayuu children, are unhealthy because of food and water insecurity. Lennon et al. $(2019,4)$ also raise the question if genetics or a particular diet are providing the Wayuu with protective factors that make them as healthy or healthier than Americans regarding the above-mentioned ailments. Biological anthropology's study of human variation has shed light on how different human groupings have adapted to heat stress, cold stress, solar radiation, hypoxia, among other climatic and environmental pressures (Larsen 2019:116-121). However, convincing data that reveal how societies such as the Wayuu have undergone genetic adaptation to water stress has yet to be produced.

Figure 9 compares the human and livestock water consumption in Irraipa, Cardón and Mayapo. Notice that in Irraipa the livestock water demand is highest, approximately $20 \%$ higher than the human population in Irraipa and double the amount consumed by livestock in Mayapo and Cardón, combined. This is due not only because Irraipa has the greatest number of total livestock, but also because of the greater number of cattle in that 
area, which require a larger amount of water than sheep and goats. Irraipa has 586 head of cattle compared to the 46 combined head of cattle in Cardón and Irraipa. On the other hand, Mayapo has the highest human water consumption because it has the largest human population and because of the greater daily water consumption per person. The water consumption by the animal population in Mayapo is the lowest, accounting for only $6 \%$ of the total amount of water consumed in that community.

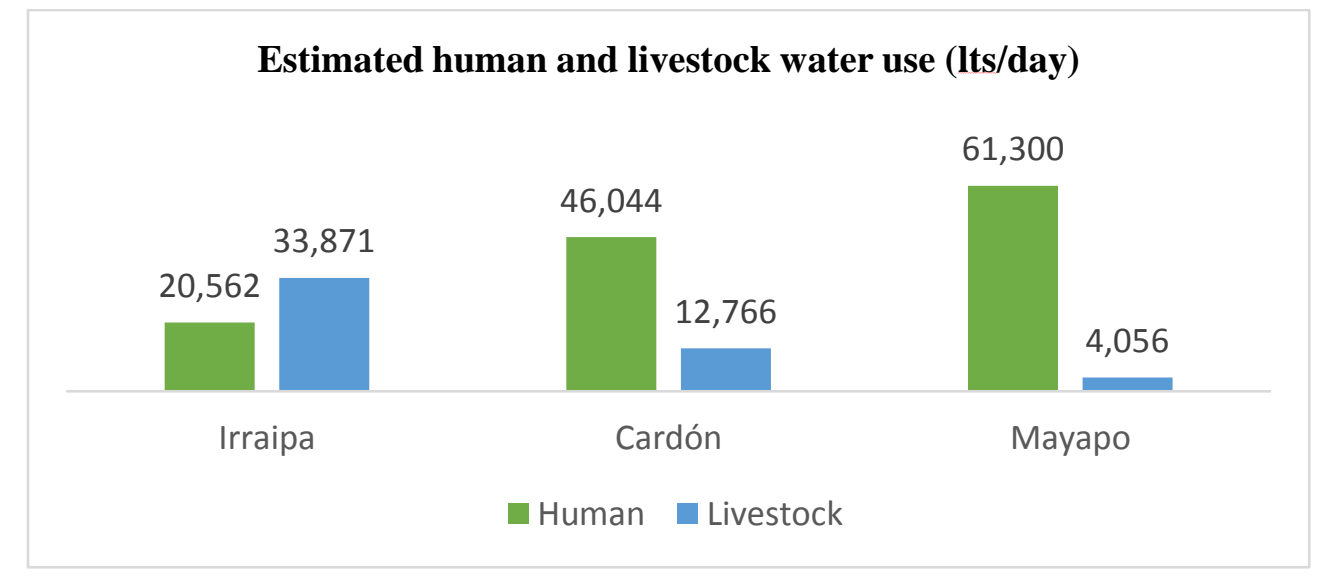

Figure 9. Estimated human and livestock water use in the three study areas Sources: Cerrejón Foundation for Progress of La Guajira (Irraipa and Cardón, 2012), Author's fieldwork (Mayapo, 2018)

The estimated water consumption for humans was reached by information provided by the community members during semi-structured interviews, household surveys and participant observation in the three study areas. In Irraipa and Cardón, the head of each household was asked how much water each family member used on a daily basis for: drinking water, making uujot (corn-based drink), cooking, personal hygiene, washing clothes, farming and others (such as water for pets or domestic animals, watering trees, water for settling the dirt around the house or washing vehicles). In Mayapo, the water consumption estimate was based on the amount of water the sample of 60 households used on a daily basis, considering the number and capacity of the storage 
tanks, the number of times these were filled per day or week and the use of different water sources. Direct observation complimented and corroborated the information provided by the interviewees.

The livestock water consumption was estimated by first taking a census of the livestock population of the three study areas, distinguishing the different types of animals (cattle, goats, sheep and donkeys) and calculating the per capita consumption using dry season indicators for goats (2.45 lts/day), sheep (2.8 lts/day), cows (28 lts/day) and donkeys (17.5 lts/day) (Walker and Hillman cited in Cerrejón Foundation for Progress of La Guajira 2009, 25).

\section{Farming}

Farming is another traditional subsistence activity practiced by the Wayuu. For farmers, rain means life for their crops and upon harvest time, more food and an improved diet for their families. During much of the year, the crop fields lie fallow; generally, the Wayuu do not use a water supply other than rain to water their crops. Local varieties of beans, squash, and watermelon are the most planted crops because of their ability to grow in the arid climate. Other crops include local varieties of cantaloupe, millet, manioc, corn and cucumber. These fruits and vegetables are used for household consumption and local exchange for three or four months a year.

Before the arrival of juуари (wet season) in October, farmers clean the crop fields and repair the fences. As the crops grow, farmers weed and take preventive measures so that animals and pests do not damage the crops. Harvesting begins three or four months later, first by gathering the beans, squash, watermelon and cantaloupe, followed by the

corn and manioc. If the shorter rainy season in April brings rain, the Wayuu partake in 
another cycle of sowing and harvesting. With low rainfall and water scarcity, agriculture is a seasonal activity that provides food for a few months out of the year during years when enough rain falls to farm.

During years with low rainfall, the Wayuu go without the homegrown food items and rely heavily on food purchased at the local stores and the food markets in the urban centers. In Mayapo, as in most coastal Wayuu communities, fish catches are divided for sale and for domestic consumption, providing the fishermen with a steady income and their families with a consistent source of protein. However, in Mayapo, only $28 \%$ of the population sampled stated that they farm while $47 \%$ affirmed they own livestock. A pilot study I conducted in 2014 for the World Food Program on food and nutritional insecurity among the Wayuu found that $73 \%$ of the 26 households sampled in four Wayuu communities use between half or all their income towards purchasing food (DPS/PMA 2014). However, not all food is store-bought; from this same study, an average of $48 \%$ of the food produced through fishing, farming, hunting, gathering or herding is used for domestic consumption (ibid). Coastal communities have the advantage of supplementing their diet with almost daily consumption of fish and other seafood. Families that own chickens, pigs and livestock across the Wayuu territory occasionally consume them as well.

Up until Venezuela's food shortage problem a few years ago, the Wayuu obtained a large proportion of their food products by bringing them directly from that neighboring country, or from stores in the urban centers of Maicao, Riohacha, Manaure or Uribia that sold both Colombian and Venezuelan products such as manufactured rice, sugar, coffee, flour and other packaged food products. Mayapo's proximity to the provincial capital of 
Riohacha and the paved highway that was constructed in 2008 facilitated the provisioning of this community with food products. Due to these two factors, the food shortages across Wayuu territory caused by the Venezuela's humanitarian crisis beginning around 2013 has not been felt nearly as much in Mayapo as within those communities distant to Riohacha and closer to the Venezuelan border.

\section{Local water quality standards}

For the Wayuu, there are distinctions between water suitable for human consumption and water that should not be consumed. Ponds, for instance, are locally classified into two categories: those suitable or not suitable for human consumption. Ponds in the first category are fenced in, contain troughs along their perimeters and are looked after more closely than those destined for animal use alone. Water for human consumption includes rainwater, water from dug wells, water trucks and water from fenced ponds that are considered clean. Likewise, water from these sources is considered jemetsu (clean, tasty) while water from ponds without fences, green water or that which has been contaminated by corpses and related waste is considered charutsu (dirty) and is not to be consumed by humans. Water with high salinity is classified as palaasu; if the water is brackish it is irasu and bitter water is ishisu. Depending on the season, a single source can produce different qualities of water. For example, the Malailatu Pond water in Irraipa is considered jemetsu (clean, tasty) after the rains, but as the months go by it becomes ishisu (bitter); even then, the water is consumed. When the pond dries, the water from the well dug in its bed is irasu (brackish) and only consumed by the livestock.

The turbidity or color of the water is also a characteristic that determines its quality and usefulness. Transparent. colorless water is desired, like rainwater or water 
from the aqueduct. On the other hand, greenish, brownish and murky waters indicate a lower quality and are avoided. Besides the flavor and color, another way of determining the quality of the water is through the care given to the water source and the use that is given, as expressed by a local elder in the Irraipa area, "When the pond was already being built, we had to fence it with either cactus or tree trunks so that the livestock did not have direct access to it. The families that had rights to use the source had to build their own troughs for their livestock and be mindful of some rules or habits to keep the water clean" (Fernando Epinayu, Sept. 12, 2012). In times of drought, the water quality of the ponds gradually deteriorates until the people stop using it and is used only by the livestock. In some cases, when the ponds are almost empty and the water is no longer consumed by the people, the herders open an entrance in the fencing, giving the animals access to drink from the unclean water.

Very few Wayuu use household water treatment methods such as boiling or adding bleach; some Wayuu mentioned placing a cloth over the receptacle as a filter to remove any organic material from the water. In the past, the Wayuu would settle the impurities of the water by peeling and placing in it chunks of the prickly pear cactus (Opuntia goiana) or the organ pipe cactus (Stenocereus griseus) (Daza, Serna and Carabalí 2018, 28). The cactus served as a flocculant, attracting suspended particles and settling them at the bottom of the container. Currently, this method is rarely practiced. Martina Urariyuu, a midwife and teacher from Irraipa, explained another technique used by the Wayuu to purify water during the coming of age ceremony of adolescent girls. A couple of handfuls of white earth called kasushi are placed in a bucket of unclean water and left to settle for 20 minutes, settling along with it any residues and leaving the water 
transparent. This water is given to the adolescent girls to drink and bathe with during their ritual enclosure.

\section{Water use and management}

As detailed in the sections below, ponds are the primary source of water in Wayuu territory. They are places where people congregate to fetch water, bathe, water their livestock and wash clothes, bicycles and cars. Each site has its use, understood and respected by the inhabitants. The regulation of these sources starts when young children learn the proper way of interacting with the pond and with people and livestock at the pond. Pond socialization occurs when children accompany adults to the pond and assimilate the various gendered water activities. Men and women show and explain methods of water extraction, bathing, washing clothes, as well as what practices are allowed and disallowed in the various ponds used by the community members. Through listening, observation and imitation the youth learn to interact with water. When someone breaks a rule relating to water use, he or she may be scolded at the time of the infraction. If the prohibited practice is repeated or is of greater consequence, community members may gather to discuss the problem and find a solution.

Daily, water must be obtained to cook and wash food, wash clothes, bathe, drink and for other water-related activities. Depending on the season and the availability of water sources, water gathering requires time and effort by those who are responsible for its use and management. Those responsible for the day-to-day tasks relating to water management within the communities is determined by gender and age. For the Wayuu, as with many societies the world over, this responsibility falls mostly upon women and girls. The man, in his role as herder, waters the livestock and, if needed, will help fetch 
water at the local pond or well using his bicycle or motorcycle. The woman performs all the tasks related to the domestic use of water: she brings water to the house, usually with the help of a donkey or a wheelbarrow, prepares meals, makes uujot (corn-based drink), washes clothes, and bathes the small children. In many cases fetching water is delegated to the children, mainly girls, who must make time between their school activities or sometimes interrupt them to fetch water.

Water protection at the source includes fencing the pond or covering the well with branches and carrying out practices that reduce the contamination of the water source. Often, large, flat stones will be placed on the shoreline of the pond so that a person can stand on it to fill the containers, thus avoiding entering the water and disturbing or dirtying it. If it is necessary to enter the pond to gather water that is less turbid, an effort is made to maintain the water still and lift as little matter as possible. At the fenced ponds designated for human and animal consumption, wooden troughs are placed outside or along the fence line so that livestock do not drink directly from the pond, thus contaminating the water by defecating or urinating in it. The herder hauls water from the pond to the trough using a bucket or a simple water distribution system (see Figure 10). Around the ponds people also bathe and wash clothes, usually in places with vegetation that serves as covering and far enough so that the water used does not reenter the pond. Water storage containers at the residences for human consumption are usually covered so as not to let in dust, insects and other animals. 


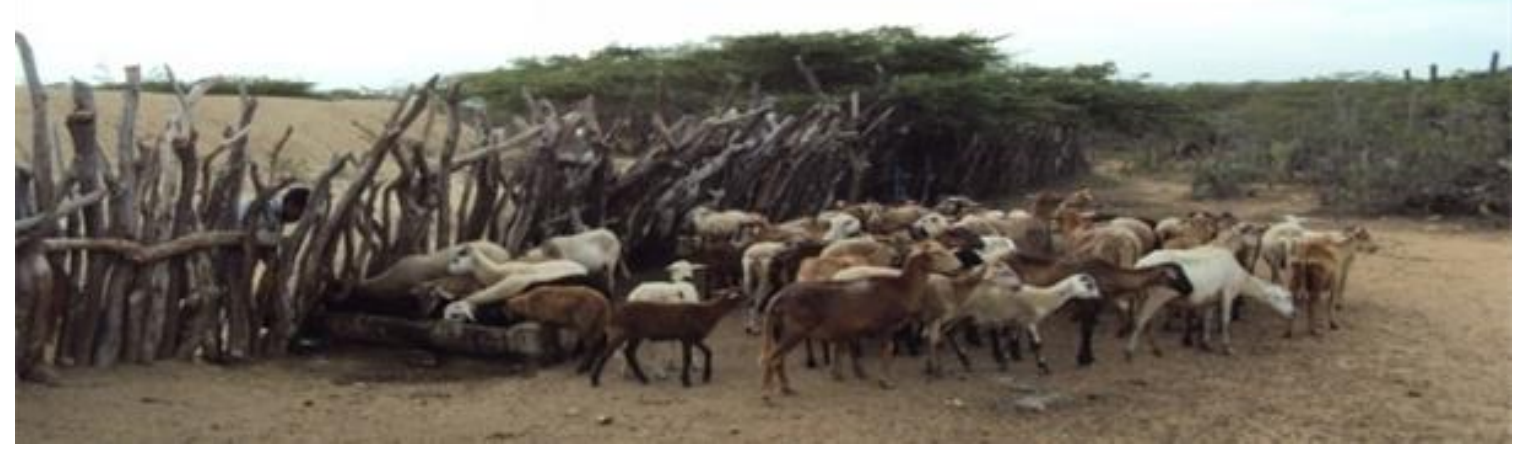

Figure 10. Herder watering his sheep in the community of Pasadena Source: Photograph taken by Arnoldo Pimienta

The containers the Wayuu use to store water have changed over time.

Traditionally, ceramic jugs of different sizes were crafted using local clay to transport and store water and the corn-based drink, uujot. Smaller jugs (amuchi) used to transport water could hold between five and twenty liters of water. To carry them, women would usually place them inside a woven bag (piuula) and carry it by placing the strap over her head with the jug hanging on her back. A larger, wide-mouthed jug called juraa, was used to store water in the residence and could hold up to 80 liters of water. These larger containers were also used as urns during secondary funerals when the bones of the deceased were exhumated after several years, ritually cleaned and reburied in their ancestral cemetery. Although the ceramic containers are less common today, the Wayuu agree that the amuchi ceramic jugs give the water a better flavor and maintains the water cooler than water stored in plastic containers.

Greater interaction and commerce with the alijuna society also introduced containers of different materials that began to replace the ceramic jugs. In the mid-1900s, tin cans that contained lard or other food and beverage products would be cleaned and reused by the Wayuu to transport water. These containers ranged in size and were more 
resistant than the ceramic containers and easier to transport. In recent decades, the introduction of plastic water tanks and jugs replaced the tin containers and the construction of concrete and plastic cisterns has allowed for the storage of large amounts of water. However, across the Wayuu territory, private or community cisterns, including those of the schools, are supplied irregularly by water trucks from the municipal capital. Many of them remain empty and due to lack of maintenance or poor construction, fall in disuse and disrepair.

\section{Seasonality of water sources in Irraipa and Cardón}

The number of water sources and the amount of water available fluctuates during the year because of the seasonality of the water sources. Distance, time and effort to gather water are reduced during the rainy seasons since there are more sources of water in the vicinity of the residences and water is more abundant. During the rainy seasons, multiple sources of water are tapped to meet daily needs. Streams from the peninsula's interior rapidly flow towards the coastline traversing territories, filling ponds, reviving the surrounding plant life and providing an unbroken channel of fresh water for bordering communities. Occasionally during the wet season there is an excess of water to the point in which flooding occurs and large areas of the peninsula become inaccessible.

Across the Wayuu territory ponds continue to be the primary source of water during most of the year; some have been enlarged or deepened by public or private institutions or political aspirants using heavy equipment. During the dry season and times of drought when ponds dry up, artisanal wells dug by the local inhabitants become the primary source of water for many Wayuu. In some communities, such as in Mayapo, drilled wells, water treatment and desalinization plants have been installed. Others 
receive water by cistern trucks that distribute water from aqueducts located in urban centers such as Riohacha, Manaure, Uribia and Maicao, or from the rural Wayuu communities of Nazaret and Siapana in the northeastern region of the peninsula.

Drilled wells differ from dug wells because the depth of drilled wells is much greater, they are built using machinery and materials such as cement, PVC tubing and steel rods and their construction is carried out by non-Wayuu labor and institutions. The depth of the drilled wells has changed since the 1950s when water was obtained at 24 to 30 meters below the surface. In the 1980s the water level was between 50 to 70 meters underground and currently it is necessary to drill at least 100 meters before finding fresh water. Water from these wells is extracted using windmills or electric water pumps and may include a storage tank or a distribution system. Since the Wayuu lands are on a peninsula surrounded by seawater, many deep-water wells provide brackish water unsuitable for human consumption nor farming. A common pattern with the wells in Mayapo and other communities is the transition over the years from fresh water to brackish water, which has been a concern for the Wayuu, expressed in the second epigraph of this chapter by an elderly man from Irraipa. This shift from fresh water to brackish water forces the community members to limit the source's use to bathing, washing clothes and other domestic uses besides drinking and cooking, and for watering the livestock. The source may be abandoned completely if the water is too salty. For the brackish or salty water to be drinkable, it requires desalinization, which has been a costly, complex and unsustainable process in most of the Wayuu communities that have desalinization plants (see Chapter 7). 
On Wayuu territory there are also a limited number of reservoirs, artificial lakes created by clearing and damming up natural depressions where streams flow during the rainy season. Ipanalu, Porshina and Yotojoroin are some of the reservoirs built in the last century by Proaguas that continue to be important sources of water. In 2012, the provincial government constructed eight reservoirs in the municipality of Uribia, some of which have benefitted hundreds of Wayuu families. Both Irraipa and Cardón have one of these reservoirs, the former stores approximately $457,000 \mathrm{~m}^{3}$ while the latter has a water storage capacity of $98,000 \mathrm{~m}^{3}$ (Gobernación de La Guajira 2011, 123).

During the wet season the primary water sources are found on or close to the household's premise; rainwater harvesting, and small, natural or manmade ditches are the closest and require the least amount of time and effort to gather the water. The Wayuu channel rainwater that falls on the rooftops of their houses into storage tanks using a catchment system. For this reason, many of the roofs are no longer built using the traditional yotojoro (heartwood of the dried cactus) but with zinc or asbestos roofing that capture a greater amount of rain without the organic residues left by the yotojoro. Following local sanitation norms, the Wayuu usually do not store water from the first rain, allowing the rainfall to clean the dirt and debris off the roofs and gutters. The receptacles used to store water are also cleaned during this first rain. The water containers range in size from 100, 200 or 500 lt. plastic barrels found in most households to concrete cisterns that hold up to 10,000 liters that are communal or privately owned by the most affluent families of the Wayuu communities. These concrete cisterns are mainly used to store water distributed by water trucks from the municipal aqueduct. 
For the Wayuu, rainwater is the cleanest type of water and is well-protected. The storage tanks are covered so that dust, debris, insects or other animals do not contaminate the stored water. Occasionally, a small ditch is excavated on the household premise that serves to collect water for uses other than cooking and drinking. With each rainfall these storage places are filled, and the inhabitants are laxer on the amount of water consumed. Furthermore, these on-premise sources reduce the amount of water hauled from the local ponds or the number of water-gathering trips made. When the rainy season passes water becomes less abundant and the Wayuu begin to limit the expenditure of the stored liquid. Rainwater harvesting is discontinued and the water level in the streams, ditches and smaller ponds gradually lowers until they dry completely, usually within the first two months after the rains stop.

Ponds (laa) are the most ubiquitous water supply during the rainy and dry seasons in Wayuu territory, used for human and livestock consumption. A pond can be a natural or manmade depression in the ground that captures run-off or stream water during the rainy season. The Wayuu, or other non-Wayuu actors, then enlarge the pond and improve the channeling of the water so that it can fill more quickly and hold more water. Each Wayuu community has access to a pond, whether located on their territory or a neighboring one. While community members use the local pond, as the summer months go by without any rainfall, smaller ponds go dry or their water quality deteriorates, prompting the locals to seek out larger ponds still containing drinkable water. Through increased demand, water seepage and evaporation, most ponds provide water between four to eight months. 
During the years when both rainy seasons take place, these larger ponds last long enough to provide water in between the rainy seasons. However, drought years and successive years of drought have occurred in the distant and recent past on Wayuu territory. After two successive years of above average precipitation between 2010 and 2011, considered a "disaster situation" due to widespread flooding and material damages, the Upper Guajira underwent four years of drought between 2012-2015. The water shortage created another type of humanitarian crisis that coincided and was aggravated by the deteriorating economic situation across the border in Venezuela.

With the onset of climate change, experts have determined that what is "normal" is shifting towards a drier climate with rainfall distribution becoming more concentrated and dry spells more prolonged, as evidenced in La Guajira these past few years. This shift is supported by the reports of the Intergovernmental Panel on Climate Change (IPCC) that has determined that one of the effects of climate change is the increased occurrence of extreme events such as heat waves, droughts, floods, cyclones and wildfires as well as the increased vulnerability of human societies (IPCC 2014). When drought sets in, even a community's most reliable ponds go dry and the inhabitants must recur to dug wells on their territory, ponds or reservoirs of extraordinary water capacity outside their territory or by purchasing water from water trucks.

During droughts (müle'u jouktai) certain stream and pond beds are tapped for spring water by digging artisanal wells $(i s h i) 1$ to 10 meters deep. Groundwater seeps up from the bottom of the well and is then extracted manually. The process of extracting water from dug wells depends on its depth. If the well is shallow and can be reached by the outstretched arm, the water is carefully scooped out using bowls or pitchers of one or 
two liters and poured into another container. As it is collected, the water springs up slowly; filling a 20 -liter container can take 15 minutes or more. When the water is a few meters deep, two strategies are used to obtain the water. The first requires lowering a person tied to a rope to the bottom of the well who then fills a bucket that is pulled out by someone at the top. The second strategy consists of enlarging the mouth of the well and building a diagonal stairway to the water. In both strategies, logs are placed across the well to support the weight of a person, who balances him or herself on them in order to pull the bucket vertically out of the well. After its use, logs and tree branches are usually placed over the well to prevent the entry of polluting objects or an accidental fall by a person or livestock. Both the construction of wells and the abstraction of water requires time, effort and patience. This labor can also be strenuous and dangerous. Cave-ins while someone is in the well and people falling into wells have occurred, causing death or serious injury. For example, when a young man from Irraipa fell to his death in the Yelentu Well, its use was prohibited by the local traditional authority who attributed the death to a supernatural power within the source. Nevertheless, dug wells are essential during times of drought when there are no other sources of water in the surrounding area. Transhumance (seasonal migration) and permanent migration have also been linked to water scarcity. Prior to the national government's initiative in the 1920 s to construct or renovate ponds throughout the peninsula, the Wayuu practiced o'onowaa (seasonal migration) when the pastures were depleted and the ponds went dry. Entire families would migrate to more fertile lands that offered food and water, relying on kinship ties to gain access and homestead there until the following rainy season, upon which they would return to their own territories. For this reason, $19^{\text {th }}$ and $20^{\text {th }}$ century 
accounts of the Wayuu described them as a semi-nomadic society. Currently, most Wayuu have sedentarized, although some families still maintain the practice of o’onowaa.

The Wayuu living in the southern region of the peninsula trace their ancestral roots to the northern region where oral tradition and Wayuu cosmogony place the origins of the Wayuu people. Greater quantity and more reliable water sources became a pull factor for those leaving drier areas of the Upper Guajira to the more fertile Lower Guajira. Mass migrations during the past century to neighboring Venezuela and the subsequent growth of the Venezuelan Wayuu population was due in part to the recurrent droughts in the Colombian Guajira and the rise of the bordering Venezuelan state of Zulia as a rich oil-producing region. Maracaibo, Venezuela's second wealthiest city, attracted thousands of Wayuu, mainly men, to work on haciendas around the urban area. With the current humanitarian crisis in Venezuela, many of the Wayuu who migrated there, and/or their descendants, are returning to their ancestral territories in Colombia. To curb food contraband, the Venezuelan government has increased restrictions on Wayuu bringing food back from Venezuela for their families or from businesses importing food from Venezuela. The heightened enforcement and confiscation of food at the border has had a negative impact across the peninsula that has historically relied on Venezuela's lowpriced food products. Venezuela's decadence, beginning around 2013, has only worsened the persistently high malnutrition rate and food insecurity in the peninsula.

\section{Water gathering in Cardón and Irraipa}

Unlike Mayapo, the dispersed, remote communities of Irraipa and Cardón are distant from the provincial capital and rely primarily on ponds, reservoirs and dug wells, 
rather than on treatment plants, drilled wells and water trucks. An inventory of the water sources of the three areas, shown in Table 1, lists the various water sources used, the seasonality of the ponds and the unequal distribution of the drilled wells, water treatment plants and water truck service.

Table 1 Water sources in the study areas

\begin{tabular}{|c|c|c|c|c|c|c|c|c|c|}
\hline \multicolumn{10}{|c|}{ Water sources in the study areas } \\
\hline \multirow[t]{2}{*}{ Area } & \multicolumn{2}{|c|}{ Pond } & \multirow{2}{*}{$\begin{array}{l}\text { Rainwater } \\
\text { harvesting }\end{array}$} & \multirow{2}{*}{$\begin{array}{l}\text { Seasonal } \\
\text { stream }\end{array}$} & \multirow{2}{*}{$\begin{array}{l}\text { Dug } \\
\text { well }\end{array}$} & \multirow{2}{*}{$\begin{array}{l}\text { Drilled } \\
\text { well }\end{array}$} & \multirow[t]{2}{*}{ Reservoir } & \multirow{2}{*}{$\begin{array}{l}\text { Treatment } \\
\text { plant }\end{array}$} & \multirow{2}{*}{$\begin{array}{l}\text { Water } \\
\text { truck }\end{array}$} \\
\hline & $\begin{array}{l}\text { Wet } \\
\text { season }\end{array}$ & Drought & & & & & & & \\
\hline Irraipa & 18 & 1 & Common & 2 & 3 & 0 & 1 & 0 & Infrequent \\
\hline Cardón & 62 & 5 & Common & 3 & 3 & 1 & $1^{*}$ & $1^{* * *}$ & Occasional \\
\hline Mayapo & 5 & 0 & Common & 2 & 1 & 3 & 0 & $2^{* * * *}$ & Daily \\
\hline
\end{tabular}

Source: Adapted from Cerrejón Foundation for Progress of La Guajira (2013)

From a geographic perspective, location and accessibility to the communities play a role in the availability and continuity of water service. Of the three study areas, Mayapo is in the most advantageous position because of its proximity to the provincial capital of Riohacha (20 minutes by car) and a paved highway that facilitates transportation. Although it is the Wayuu area with the least number of sources, it is the most diversified, with the most continuous and accessible water services. Cardón, while relatively distant from Riohacha, is situated approximately 30 minutes by car from the municipal capital of Uribia and has an unpaved road that also facilitates access. This area has access to the greatest number of ponds and has at least one of each type of the water

\footnotetext{
* The water stored in Cardón's reservoir was brackish in 2012 and was not being used by the community members.

** The water treatment plant in Cardón, in the community of Kasiischon, was broken down when I visited in 2017.

*** The water treatment plant in the boarding school of Mayapo was not functioning when I visited in 2018. The community's treatment plant has limited functioning (Chapter 7 details this situation).
} 
sources. In contrast, Irraipa is two hours from Uribia by motor vehicle, of which one hour is by an unpaved road and one hour using dirt trails. According to the figures, Irraipa is the least water secure, without drilled wells or treatment plants on the territory and the least frequented by water cistern trucks. If these three cases are considered as part of a broader pattern in Wayuu territory, then the greater the distance and the more difficult the access to the area, the greater the isolation and the weaker the institutional presence and the delivery of all types of services including water, health, education and electricity.

There are 24 water sources in Irraipa, including ponds, dug wells, streams and a reservoir (see Table 1). Of the 18 ponds in this area, all of them dry completely as the summer months go by and drought conditions set in except for one, Kulesiamana Pond. Irraipa has two streams, Malailatu (also known as Yelentu) and Ichien, that run through the territory during the rainy season, as well as three traditional wells that are tapped by the local inhabitants during the dry season. Only the most affluent families purchase water by cistern truck from Uribia's municipal aqueduct, which costs the equivalent to $\$ 60-\$ 80$ USD for 10,000 liters of water. The residents of this area also rely on water sources beyond their territory during the dry season and times of drought to meet their water needs. The Uraichi Pond, approximately seven miles west of Irraipa, is an especially important water source for the communities in Irraipa when droughts occur (see Map 8). To improve the water availability in Irraipa, the government built a reservoir in 2012. However, the area currently does not have any drilled wells or water treatment plants.

The water sources available in Cardón include 16 traditional ponds, 46 roadside ponds, three dug wells, three seasonal streams, one reservoir and one drilled well, for a 
total of 71 water sources (see Table 1). Rainwater harvesting is also employed by most residents in Cardón during the rainy season. Water trucks from the aqueduct of Uribia occasionally sell water to the locals upon request or deliver water at no cost when a humanitarian crisis due to drought has been declared in the area. For those communities that are within two kilometers of the Cerrejón's railway, this coal mining company delivers water by cistern trucks every two weeks as part of their social responsibility program. The drilled well in Cardón was under construction at the time of the initial study in 2012 and was not functioning during a follow-up inspection in 2017. The Apalaa streambed, the bed of the Iluwapanalu Pond and the bed of the Youle and Kajuule roadside ponds are used by the locals to dig artisanal wells during the driest months. There are also places beyond their territory where they have access to dug wells, drilled wells, larger ponds and reservoirs. However, most of the Cardón village district is not apt for drilling wells due to the high salinity of the aquifers, so the primary water sources are those that use surface water.

Although there are natural and manmade ponds scattered all over Wayuu territory, the construction of the road and railway in the late 1970s that connects the Cerrejón coal mine in the Lower Guajira and its port 93 miles away in the Upper Guajira formed hundreds of depressions along both sides of it that fill with water when it rains. Adjacent Wayuu communities such as those in Cardón have benefitted from the water that accumulates in the manmade depressions. In the mid-summer month of May 2012, 13 of the 46 roadside ponds and three of the 16 community ponds in Cardón held water. According to the locals, during droughts, only four roadside ponds and one community pond, Wa'ali, maintain water. 
The Wayuu living in Cardón and Irraipa gather water every day because piped water from an aqueduct or well is nonexistent in the 347 residences in these two areas and only a few families can afford to pay for water truck delivery. Water consumption by people and livestock and the significant amount lost to evaporation deplete the water stored in the ponds and obligates the residents to gather water from secondary and tertiary water sources, some at great distance from their homes. Pond water deemed dirty by the residents because of natural or anthropic contamination will no longer be used for human consumption. Rather, they will only use it for bathing, washing clothes or for watering livestock.

The following table shows the consolidated information of 137 households in 34 communities in Irraipa and 210 households in 27 communities in Cardón showing the distance covered roundtrip, number of daily trips and time spent walking to and from the water sources during the rainy season, dry season and times of drought (Table 2).

Table 2 Daily water gathering distances, time spent and number of daily trips in Irraipa and Cardón, Upper Guajira

\begin{tabular}{|l|l|l|l|l|l|l|l|l|l|}
\hline \multicolumn{7}{|c|}{ Daily water gathering distances (roundtrip), time spent (walking roundtrip) and number } \\
of daily trips
\end{tabular}

Source: Adapted from Cerrejón Foundation for Progress of La Guajira (2013)

Mayapo is not included in this chart because most residents no longer use the ponds and dug wells but rather receive water directly to their residences through piping or by water 
truck delivery. For those that do gather water at the local ponds and wells, these sources are within 15 minutes from their residences.

The distance to the water source, the means of transporting the liquid and the storage capacity in the residences determine Wayuu water provisioning practices. The most common strategy for the Wayuu in these areas is to make daily water gathering trips to the ponds or other water sources. Once all the water is consumed in the household, another trip is made to the water source. The amount of water hauled from the water source to the residence depends on the availability of donkeys, bicycles, motorized vehicles or family members with the capacity to carry the weight of the water. A donkey, a man riding a bicycle, a motorcycle and a wheelbarrow can carry between 40-60 liters of water (See Figure 11). Few families manage to store water for extended periods, since most do not have large storage tanks.

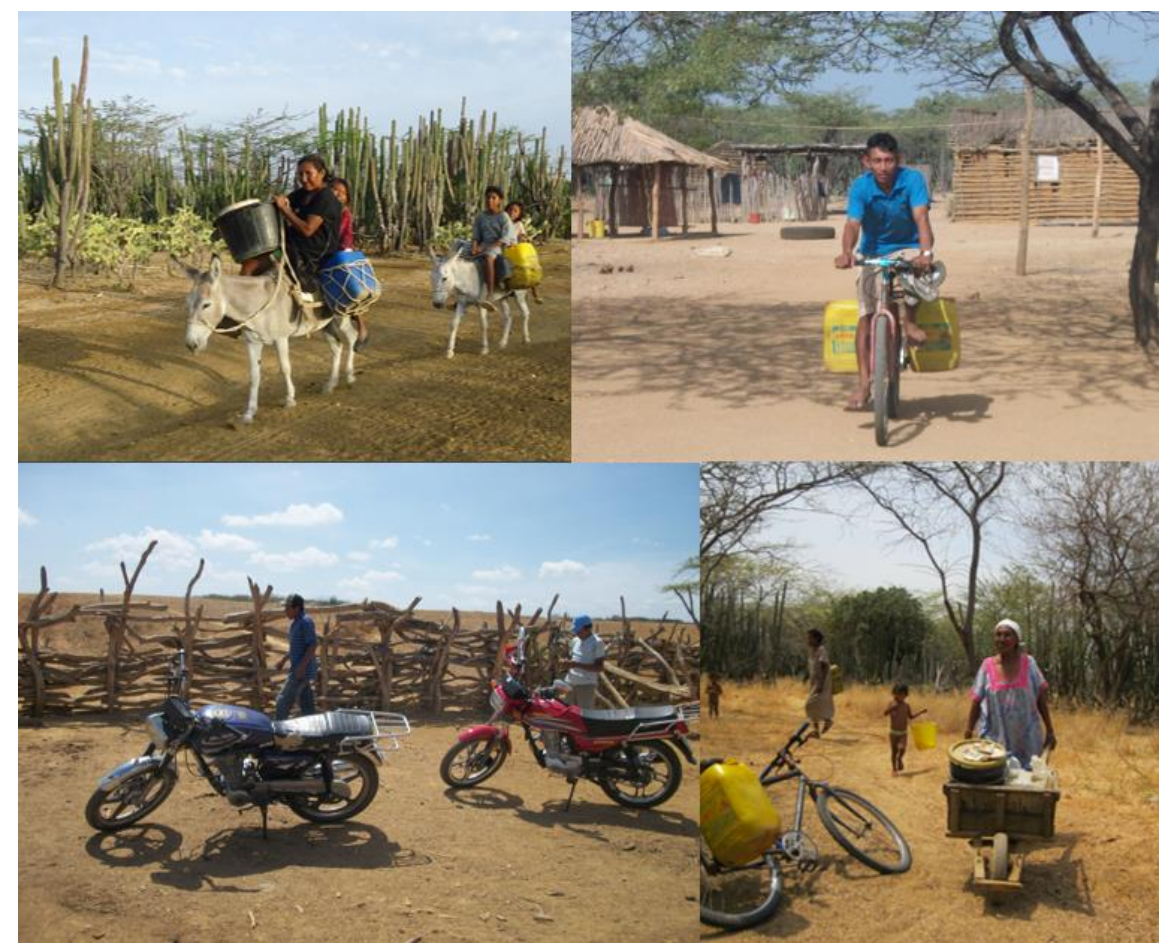

Figure 11. Wayuu modes of transporting water

Source: Photographs taken by author 


\section{Rainy season water gathering}

As shown in Table 2, during the rainy season in Irraipa and Cardón, the nearest water sources are on average 600 meters from the residences (a 10-minute walk, one way) and the locals make on average three water gathering trips per day. Many residences during the rainy season have no need to fetch water because they practice rainwater harvesting using storage tanks that can hold from 100 to 2,000 liters of water or more that gather and store rainwater from the rooftops of their residences. When the rains stop, the stored rainwater is rationed and used only for cooking and drinking water.

The inhabitants of Cardón obtain water during the rainy season from 10 ponds in the territory — four roadside ponds and six traditional ponds - and two seasonal streams for a total of 12 water sources. The ponds used for human consumption in this area include Wa'ali - the most frequented pond of Cardón-Patsualalein, Motchulia, Maishen, Pamsali and Parusou. All but one of these ponds have fencing to prevent the entry of livestock. Roadside ponds such as Paroujamana, Atatchon, Jaroutamana and Youle are mostly unfenced and are used primarily for watering the livestock, washing clothes and bathing (See Map 3). Three seasonal streams pass through Cardón, before flowing into the sea, Pajala, Kaiwa and O’ukule (also known as Apalaa). These last two are used by the surrounding communities as their primary water source during the rainy season. 


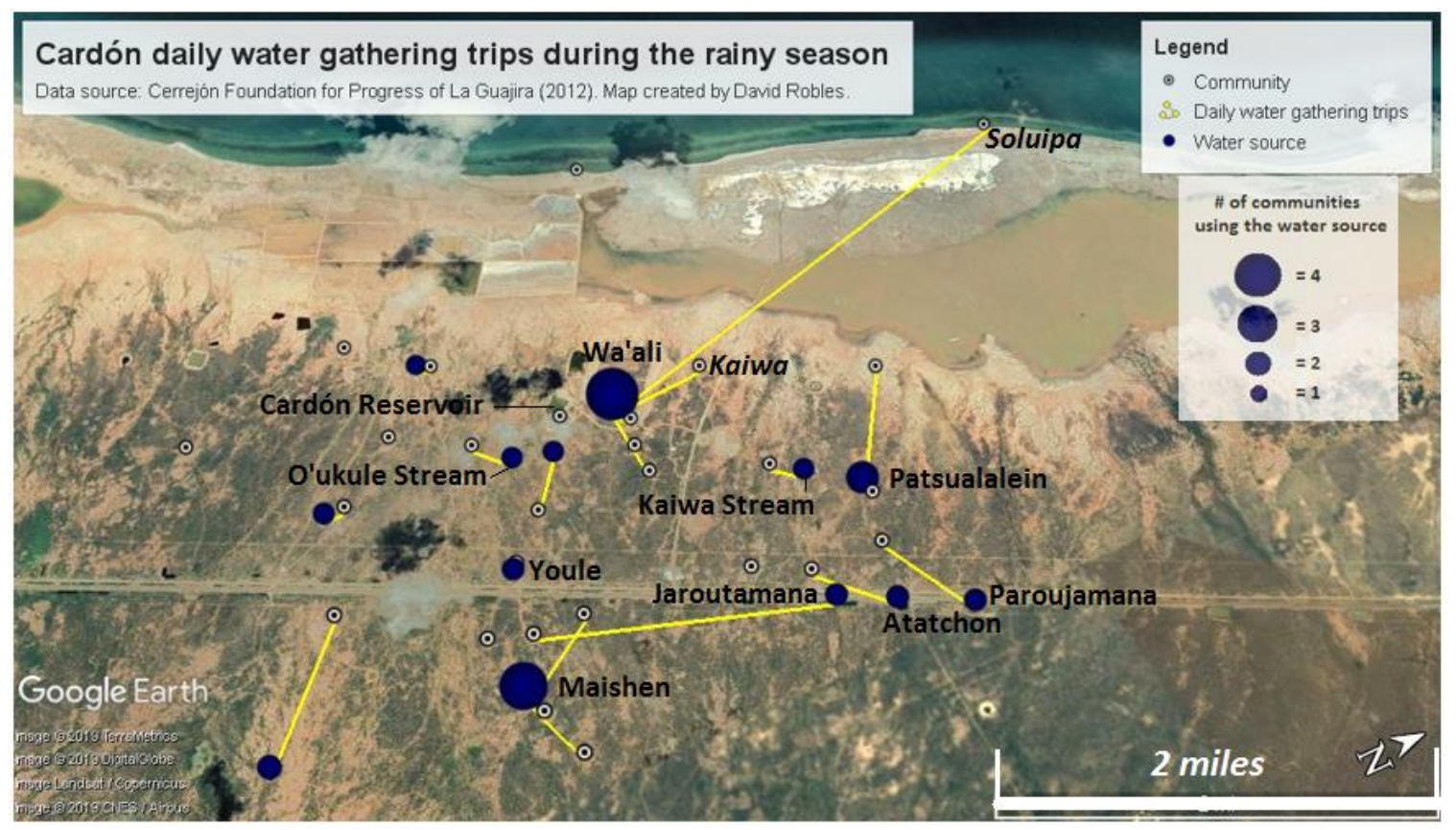

Map 3. Daily water gathering trips in Cardón during the rainy season Source: Adapted from Cerrejón Foundation for Progress of La Guajira (2012)

The distance of the community to the water source influences how many times the water users fetch water daily. When the water source is close, more trips are made per day compared to the communities that gather water at farther distances. For instance, the inhabitants of Patsualalein makes on average 10 trips per day to the pond of the same name, located 70 meters away or a five-minute walk roundtrip from their residences. Whereas the Kaiwa community members make on average two trips per day from their residences to the water source, taking them about one-hour roundtrip by foot. As for the inhabitants of the beachside community of Soluipa, in addition to rainwater harvesting, they make the longest water gathering trips during the rainy season in Cardón, walking to the Wa'ali pond 5.5 kilometers away. For this reason, they make only one trip daily. The rainy season also brings hardship for this community because coastal flooding creates a seasonal lagoon that isolates the community, making it difficult to leave or enter. 
The provincial government built a reservoir in Cardón in 2011, which filled with water during the rainy season of that year. However, salt in the soil seeped up into the reservoir, turning the water too salty to drink for both humans and livestock. Some of the older residents who were present during the construction of the Kaiwa and Iluwapanalu ponds in the late 1950 s remember how the water initially stored in them was also brackish. They recalled that after two or three rainy seasons the water became drinkable. They explained that the streams that feed the ponds carried mud and sediment into them, forming a layer on the pond beds that prevented the salt from mixing with the water. They are confident the same process will happen in the reservoir and it will gradually lose its brackishness; other community members are not so optimistic. In the summer of 2015, I made a follow up visit to the reservoir, which was empty and revealed a thin layer of salt. There were three dug wells and a few kids gathering water out of one of them. They said the water was a little salty, but it was the water they were using to drink because all the ponds in the area had dried up.

The communities in Irraipa take advantage of 13 water sources closest to their homes during the rainy season, including the Malailatu and Ichien streams, 10 ponds and the reservoir (Map 4). Eleven of the communities, one third in the Irraipa area, use one of the two streams as their primary water source during this season. The Karasira pond is the most frequented pond, however this pond has become heavily sedimented and only supplies water for a couple of months out of the year. Some households in the communities of Irraipa, Kaleruwou, Utalen and Pachaka do not fetch water because they have concrete cisterns where rainwater or water purchased from the municipal aqueduct are stored. Residents of Apuluwou on the other hand, spend the most time and effort 
gathering water in Irraipa, dedicating one hour once a day during the rainy season to and from the reservoir, two miles from their community.

Map 4 shows how the residents of Apuluwou and other communities do not necessarily use the water source closest to their community. Wayuu norms regarding common property resources, such as a pond, a pasture or a crop field, allow or limit access to them. Social relations such as kinship and friendship ties with the community where the water source is located is a primary factor that grants access to the resource, as is having participated in its construction or maintenance. Others decide which source to use based on the quality of the water, ease of access, out of respect for taboos and prohibitions or to avoid encounters with enemies, rather than its proximity.

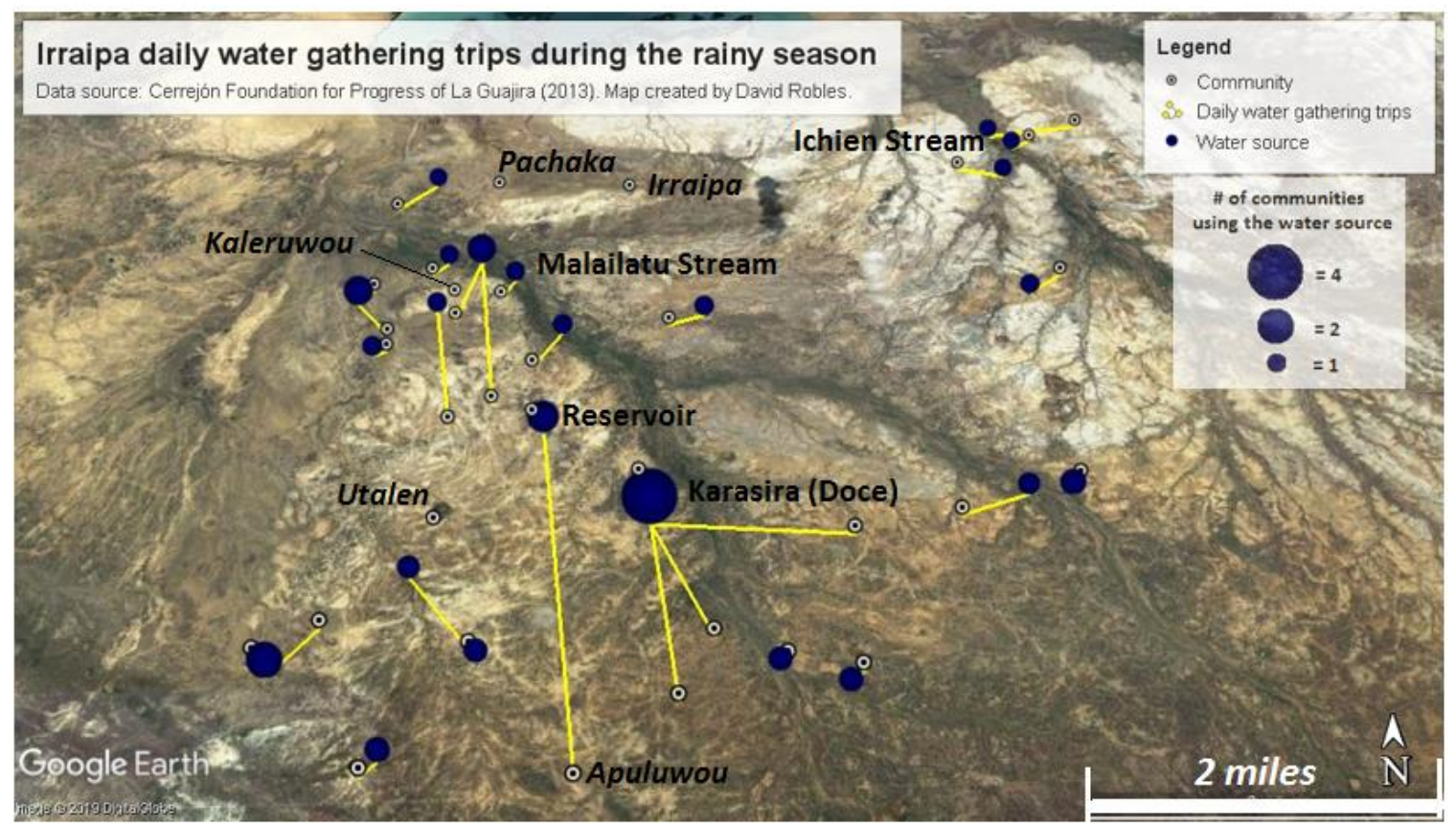

Map 4. Daily water gathering trips in Irraipa during the rainy season Source: Adapted from Cerrejón Foundation for Progress of La Guajira (2013) 


\section{Dry season water gathering}

The dry season is characterized by a considerable decrease in water availability in Irraipa, Cardón and throughout the Upper Guajira compared to the rainy season and an increase in the time spent gathering water. As the months go by after the rainy season, the smaller ponds nearest to the residences dry up and the Wayuu must turn to secondary, more distant water sources with a greater capacity to store water. The two study areas evidence an increase in distance travelled to gather water from an average of one kilometer in the rainy season to an average of four kilometers in the dry season. In time, this represents an increase from a 20-minute walk to one that takes just over one hour, roundtrip. On average, the residents also reduce the frequency of trips to gather water from three to two per day.

The communities in Cardón use a total of 18 water sources for human consumption during the summer months: 11 traditional ponds, four roadside ponds and three dug wells. In the dry season the inhabitants of Soluipa rely on three water sources (Wa'ali and Patsualalein ponds and the dug well in the bed of the Iruwapanalu Pond) and spend on average two hours roundtrip to gather water once a day. During the dry season, Wa'ali Pond becomes the most important source of water in Cardón, provisioning 11 of the 27 communities with water (See Map 5). Wa'ali was constructed over 20 years ago by a political candidate proselytizing and is known for its capacity to maintain water for most of the year. In the past, the leader of the community where the pond is located and who lobbied for its construction would ask those who used it for food in exchange for water. Currently, the pond's fencing is in disrepair allowing livestock access to the water, which is also used for household chores, food preparation and consumption. In July 2012, 
the water of the pond had turned greenish and residents of communities such as Kashkiru, 300 meters from Wa'ali, decided to stop using it and have opted to use Manaalen Pond, 2.2 miles distant. This pond received maintenance by the Cerrejón Foundation in 2011 and now provides greater quantity and improved quality of water for consumption.

Maleiguamana is a community adjacent to the unpaved road with the only secondary school in the area. It has a community concrete cistern tank that is filled regularly for use by the students and the community members. It is the only community that reported the use of water trucks as their primary source of water throughout the year. However, when water is not delivered, they practice rainwater harvesting during the rainy season, use the roadside pond near their community in the dry season and go as far as the dug wells of Kutchepen during times of drought. Even though the inhabitants of Maleiguamana have become accustomed to water delivery they still maintain knowledge of multiple methods for obtaining water and the social relations necessary to have access to the water sources. This capacity to preserve the traditional alternatives to obtain water is vital since the reliability and frequency of water delivery by the alijuna is generally low.

Other communities in Cardón during the dry season turn to water sources beyond their territories, such as Iramasein and Toolinchi that use the dug wells of Kutchepen three miles away, and Uyaliwapien, whose inhabitants gather water at Teresamana Pond, two miles away from their community. The roadside ponds are also an important source of water for the communities of Cardón, six of which continue to provide water during the summer months. 


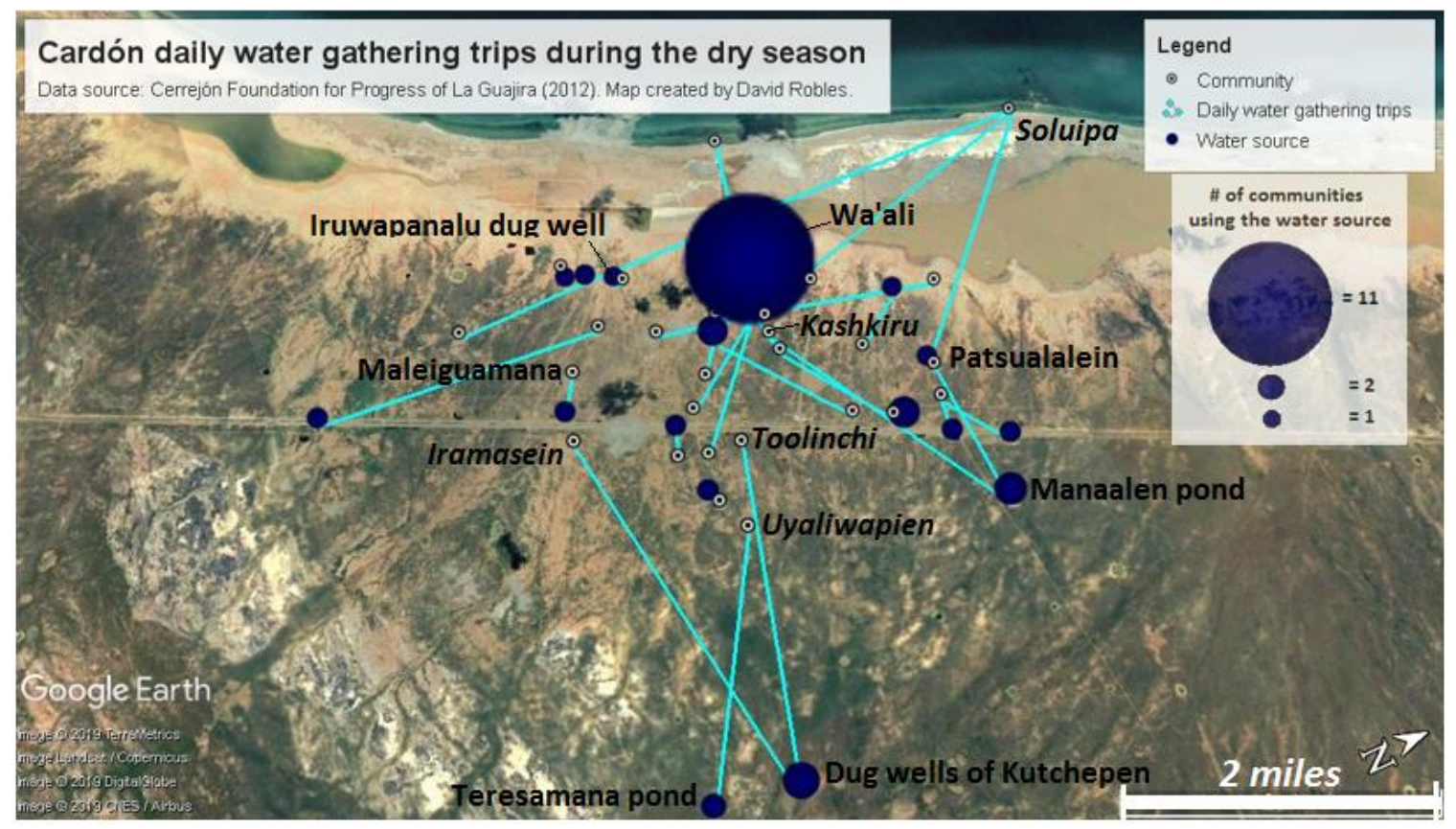

Map 5. Daily water gathering trips in Cardón during the dry season

Source: Adapted from Cerrejón Foundation for Progress of La Guajira (2012)

In the dry season, 18 water sources are used by the communities in Irraipa, the majority of which are ponds (14), three dug wells and one reservoir. The two most important sources are the Kulesiamana Pond and the Irraipa Reservoir, each frequented by six communities (See Map 6). During the mid-year of 2012, 16 of the 18 ponds in the area of Irraipa had already dried up, leaving only the Kulesiamana and Marbella ponds and the reservoir as the remaining surface water sources within the territory. More distant sources beyond the territory are used during the dry months, including the Wampilalen and Aponojoushi ponds, southeast of the territory and the Pashala and Uraichi ponds towards the west.

Irraipa's most important pond, Kulesiamana, was built 35 years ago and was enlarged by the Municipality of Uribia ten years ago and is considered by many residents as having the best water quality of the local ponds and largest storage capacity, providing water between 10-12 months. The pond has fencing in good condition and is equipped 
with livestock watering troughs. A local community leader of the Epieyu Clan oversees the care and maintenance of the pond.

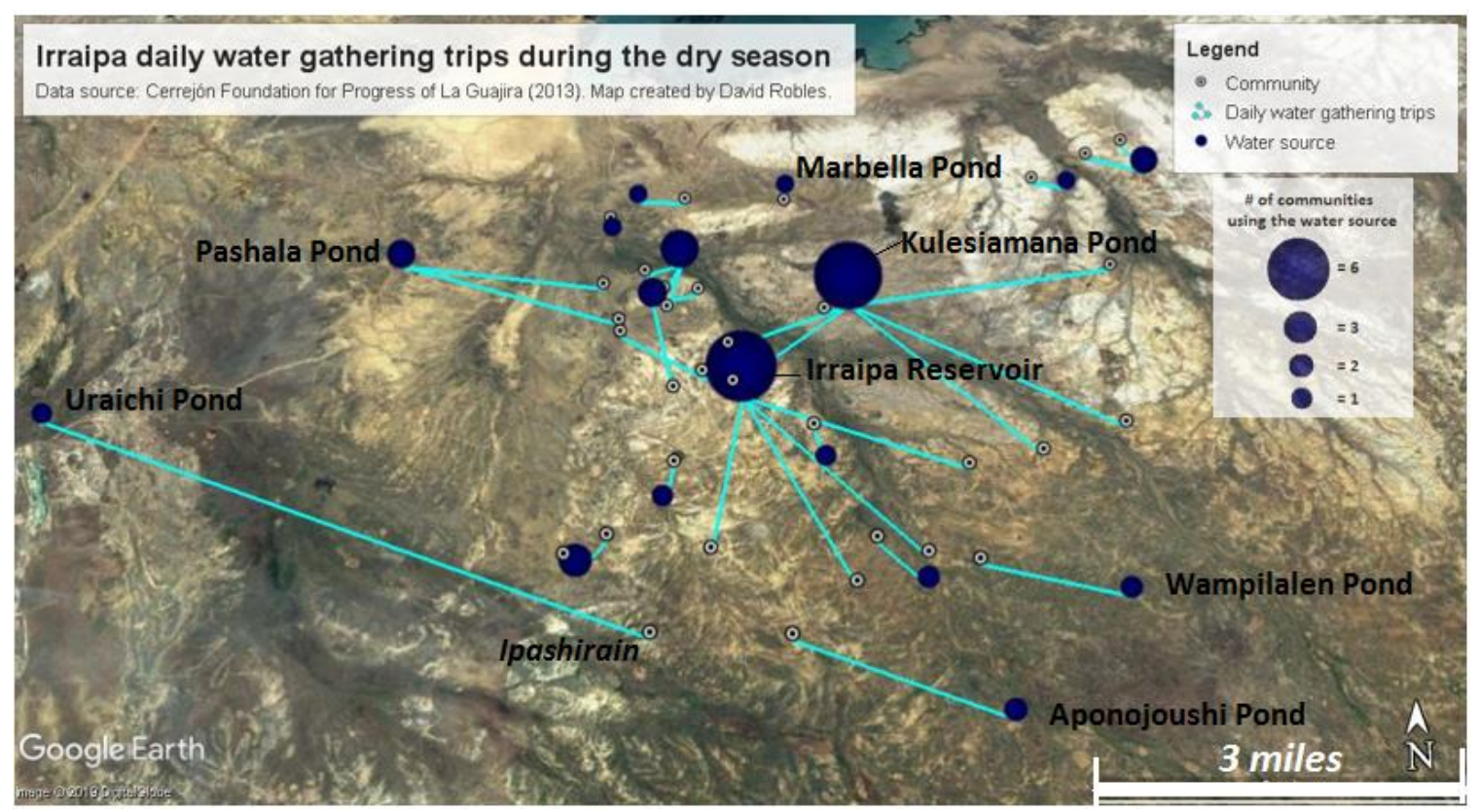

Map 6. Daily water gathering trips in Irraipa during the dry season Source: Adapted from Cerrejón Foundation for Progress of La Guajira (2013)

As for the Marbella pond, it was built approximately 45 years ago by the clan leader Clara Gomez, who brought together in yanama (collective work) her brothers and other community members to build the pond. They purposely made it small to avoid the influx of people outside their family circle. Years later, Mrs. Gomez negotiated the enlargement of the pond with the Municipality of Uribia. After this leader's passing, her relatives continue to manage the pond and share the water with family members of the area of Portete, Kaleruwou and Irraipa.

Unlike the reservoir built in Cardón, the reservoir of Irraipa became an important solution to the local water scarcity problem upon its construction. However, since the fence had not yet been installed, the water was exposed to the urine and feces of the 
livestock that entered to drink water. This situation generated complaints by some of the users and caused some to abandon the source and use more distant, but cleaner water sources. To mitigate the contamination of the water, the traditional authority of Jamuchero, Mr. Alejandro Pushaina, intended to enclose the area of the reservoir that contained water, using the wooden posts and barbed wire that surround the sedimented Karasira Pond. Although the installation of the fence was an obligation of the constructor, at the time of the study several months had passed without any presence or communication from the construction company. Making matters worse, nine cows and one donkey had gotten stuck in the mud at the shore of the reservoir and died as a result, causing both an economic and symbolic loss for their owners.

The initiative by Mr. Pushaina to organize the communities surrounding the reservoir in yanama (collective work) demonstrates his concern for the wellbeing of the inhabitants, his leadership capacity in the territory and his appropriation of the public reservoir. The dismantling of the old fence of the Karasira Pond, its transportation to the reservoir one mile away and the construction of the fence around the reservoir would have required significant time, manual labor and resources to feed and hydrate the workers. Earlier in the year, the reservoir's dike was built by men of the surrounding communities, who were paid by the constructor to break apart, haul and pile large rocks, as stipulated by the commitments of the prior consultation. For the fencing proposed by the traditional authority on the other hand, the workers would not receive any payment other than the food and chirrinchi (distilled liquor made by the Wayuu using hardened sugar cane molasses) they consume. Rather, their investment in time and effort would provide individual, familial and community-wide benefits such as: the improvement of 
the water quality of the reservoir, the strengthening of social cohesion between the neighboring communities, a greater sense of ownership of the water source, and guaranteed access to the reservoir for their families in the future.

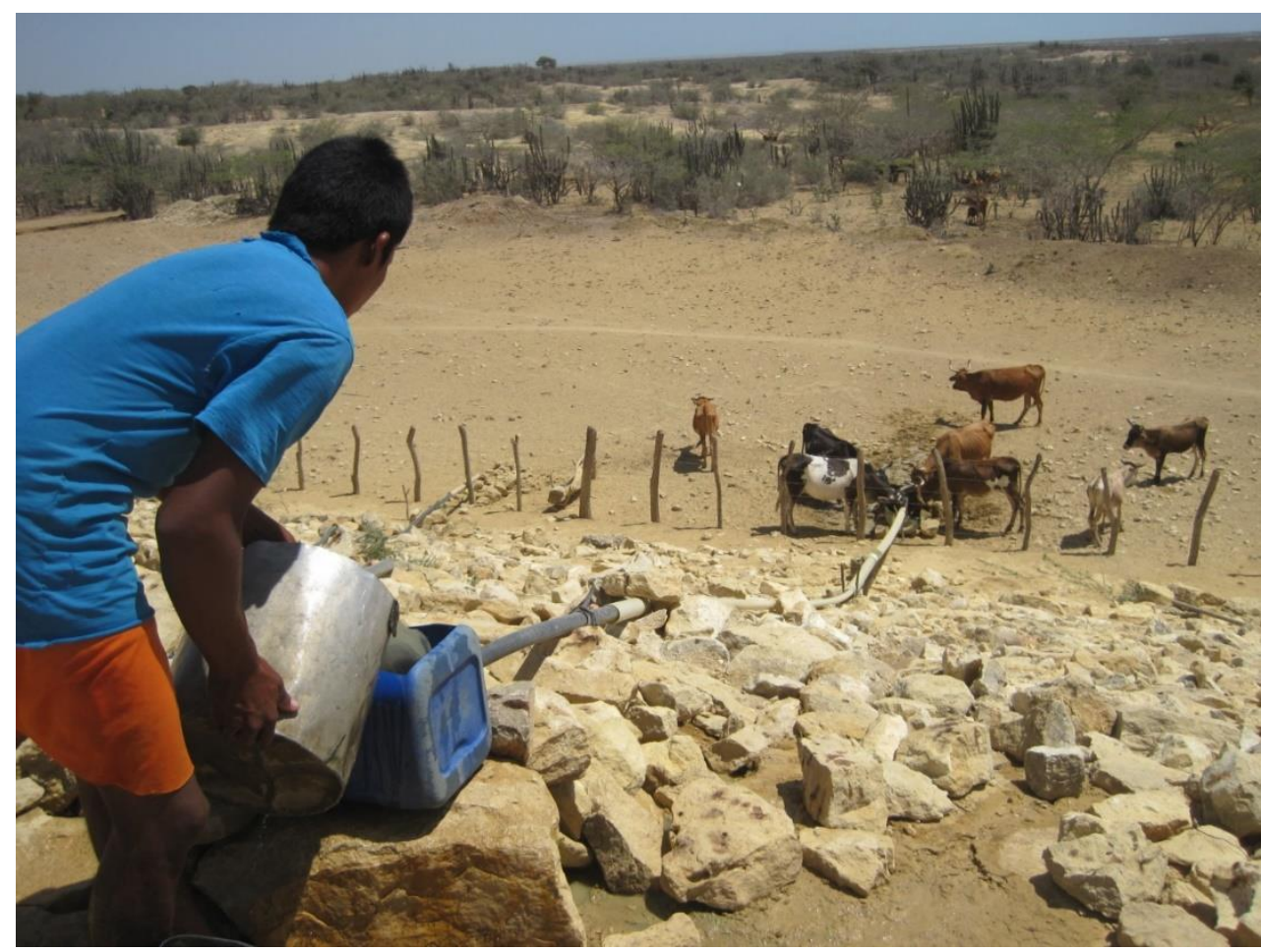

Figure 12. Fencing and troughs around the Irraipa Reservoir (August 2015) Source: Photograph taken by author

The fence was eventually built by the constructor (Fig. 12), however, the decision of the local authority to fence the reservoir was met by opposition by a neighboring authority of the Ipuana Clan who wanted it to remain accessible to the area's livestock population. The two leaders had already been disputing the ownership of the territory near the reservoir, each claiming that the territory belonged to their respective family. The construction of the reservoir revived the dispute because its location was moved from the territory of the Ipuana Clan to the disputed territory of the two clans because the topographic and hydrologic conditions were better in the latter. The Ipuana Clan leader 
conceded to this change in location so that the reservoir would remain in the area, even though this meant transferring negotiating and decision-making power (i.e. ownership) to the Pushaina Clan leader. The reservoir became a point of contention and an instrument in the power struggle between these two rival authorities whose relationship had deteriorated during the time of the study.

Restrictions in the use of the reservoir, a public waterworks, was also evident in Irraipa because of internal feuding. Residents of Ipashirain stated that they did not use the reservoir and limited their movements within the Irraipa area as precautionary measures to avoid hostilities with certain clans because of a years-long internal conflict. Rather, they opted to trek six miles one way outside the territory to gather water at the Uraichi Pond rather than go to the reservoir at half that distance (see Map 6).

The conflict began in 2005 when members of Clan $\mathrm{A}^{17}$ accused members of Clan B living in Ipashirain of animal theft, resulting in a dispute and the death of a Clan A member. In 2011, a similar accusation was leveled against the members of Clan B of Ipashirain by Clan C and led to confrontations that caused two deaths and one injured person of Clan C. The traditional authority of the sector, and member of Clan D, was sought to mediate and attempt to restore the relations between the clans, but his mediation did not produce any positive results. At the time of this study (2012), Clans A, C and D were enemies of Clan B and these two sides avoided entering each other's communities. As seen in this situation, Ipashirain's isolation has had social and economic

\footnotetext{
${ }^{17}$ To protect the identity of the actors involved in this conflict, the letters A, B, C and D are used to replace the clan names.
} 
repercussions, since its members do not participate in interclan social activities and do not receive benefits that arrive to the area, such as access to the public reservoir.

The two cases described above - the territorial dispute between two clan leaders over a public water source and the limitations to water access by inhabitants of Ipashirain because of interclan hostilities - demonstrate how internal social and political issues also impact water-related activities. While traditional ecological knowledge (TEK) emphasizes "ecological" information that is useful for a land or water manager, it constitutes only a small portion of a vast knowledge system necessary for water provisioning. Just as important, or more so, are the individual and group capacities to apply mechanisms for social cohesion, strengthen kinship ties, practice reciprocity, respect the Wayuu normative system and recognize the complexity of horizontal and vertical social relations. Furthermore, since the alijuna are responsible for a large part of water provisioning in Wayuu territory, the Wayuu must also understand alijuna forms of oral and written communication and follow alijuna bureaucratic and administrative protocols in order to obtain public or private water services.

\section{Drought time water gathering}

When the rains of April (iwa) do not come, drought conditions set in and water provisioning for the Wayuu becomes more difficult, demanding greater time and effort or money, if the water is purchased. Tertiary water sources such as dug wells, reservoirs and ponds of extraordinary capacity and water trucks are turned to by the Wayuu to meet their daily water demand. Compared to a normal dry season, the average distance covered to fetch water in Irraipa and Cardón during times of drought is two and a half times greater, and eight times greater when compared to the rainy season. While water 
gathering in the two study areas show similarities in time spent and distance travelled during the rainy and dry seasons, they show a marked difference during times of drought. Irraipa's water users cover almost double the distance and employ double the time to obtain their daily supply of water.

Of the 16 traditional ponds and 46 roadside ponds in the area of Cardón, only one traditional pond (Wa'ali) and four roadside ponds (Kaliinapalao, Jotomana, Atatchon, Parojamana) maintain water during times of drought (See Map 7). Over half of the communities in Cardón rely on dug wells as their primary water supply for human consumption when their surface water sources dry out. The dug well (ishi) in the bed of Iluwapanalu Pond is the most important source for water in the Cardón area, with seven surrounding communities using it as their primary water source. At roughly five kilometers from Cardón, the dug wells at Kutchepen are the second most visited source of water in times of drought. The Ipanalu Reservoir and the Teresamana Pond are also distant water sources used by residents of Cardón. During droughts, the average time spent gathering water by the residents of Cardón is two and a half hours, covering nearly seven kilometers roundtrip. Youle and Kojuule spend the lowest amount of time gathering water in the area, each spending ten minutes on their daily trips to the dug wells in the bed of the roadside ponds next to their communities.

The communities of Yosuchon, Waliichito and Maleiguamana have enough resources and the infrastructure to have water delivered by water truck from the municipal aqueduct in Uribia. The concrete cistern tanks, usually on the premise of the traditional authority, can store approximately 10,000 liters of water. As mentioned in an 
earlier section, the communities of Cardón next to the railroad also receive water regularly from the Cerrejón Foundation.

The daughter of the traditional authority of Yosuchon built a large community cistern storage tank in the neighboring beachside community of Soluipa. The storage tank is filled irregularly by a water truck with water from the municipal aqueduct of Uribia. The person who oversees the use of its water lives next to the tank and restricts its use by the inhabitants to 40 liters per week. For an average family size of six to eight members, this small amount has generated discontent among the inhabitants who must walk long distances to complete the water necessary for the various domestic uses. During fieldwork a family from Soluipa decided to emigrate indefinitely to the Carrizal village district north of Cardón because, according to their neighbors, they were having difficulties securing a regular water supply.

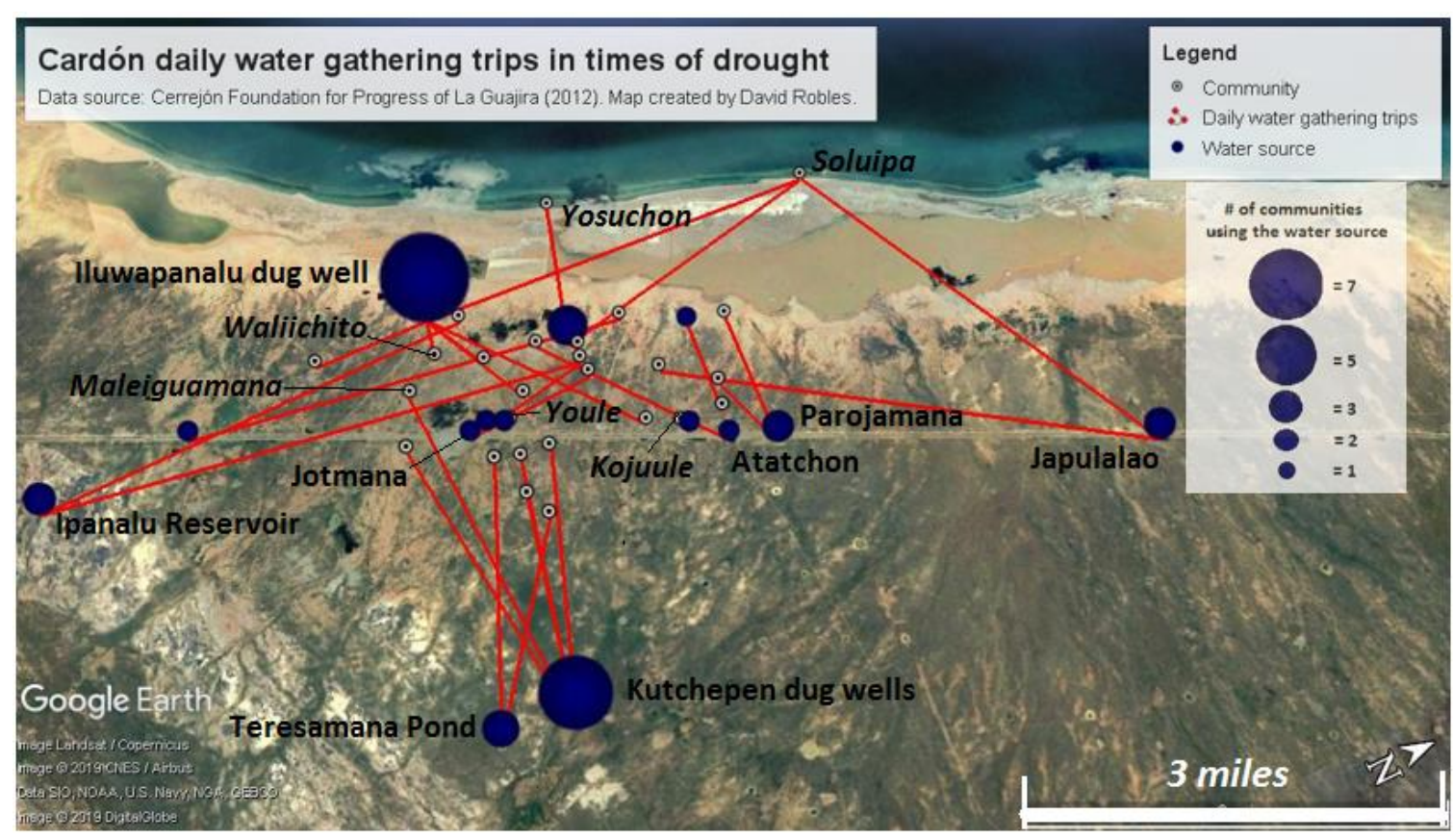

Map 7. Daily water gathering trips in Cardón during times of drought Source: Adapted from Cerrejón Foundation for Progress of La Guajira (2012) 
In Irraipa, droughts create extreme water shortage conditions because of the prolonged period without rain, intensified evaporation, constant pond water seepage and local human and livestock water demand. As a result of these environmental and anthropic factors, the number of water sources in the area is reduced substantially, from 24 to four, leaving only two surface water sources, the Kulesiamana Pond and the Irraipa Reservoir, and two dug wells, in the pond beds of Yelentu and Malailatu. Consequently, most inhabitants must make daily trips beyond their territorial limits to the Wulu, Uraichi and Pashala ponds and the Iruwain and Yaliwanichi dug wells (See Map 8). The wealthier families in the communities of Kaleruwuo, Kululumana and Pachaka have concrete storage tanks and are able to provision themselves by requesting water trucks from the aqueduct of Uribia.

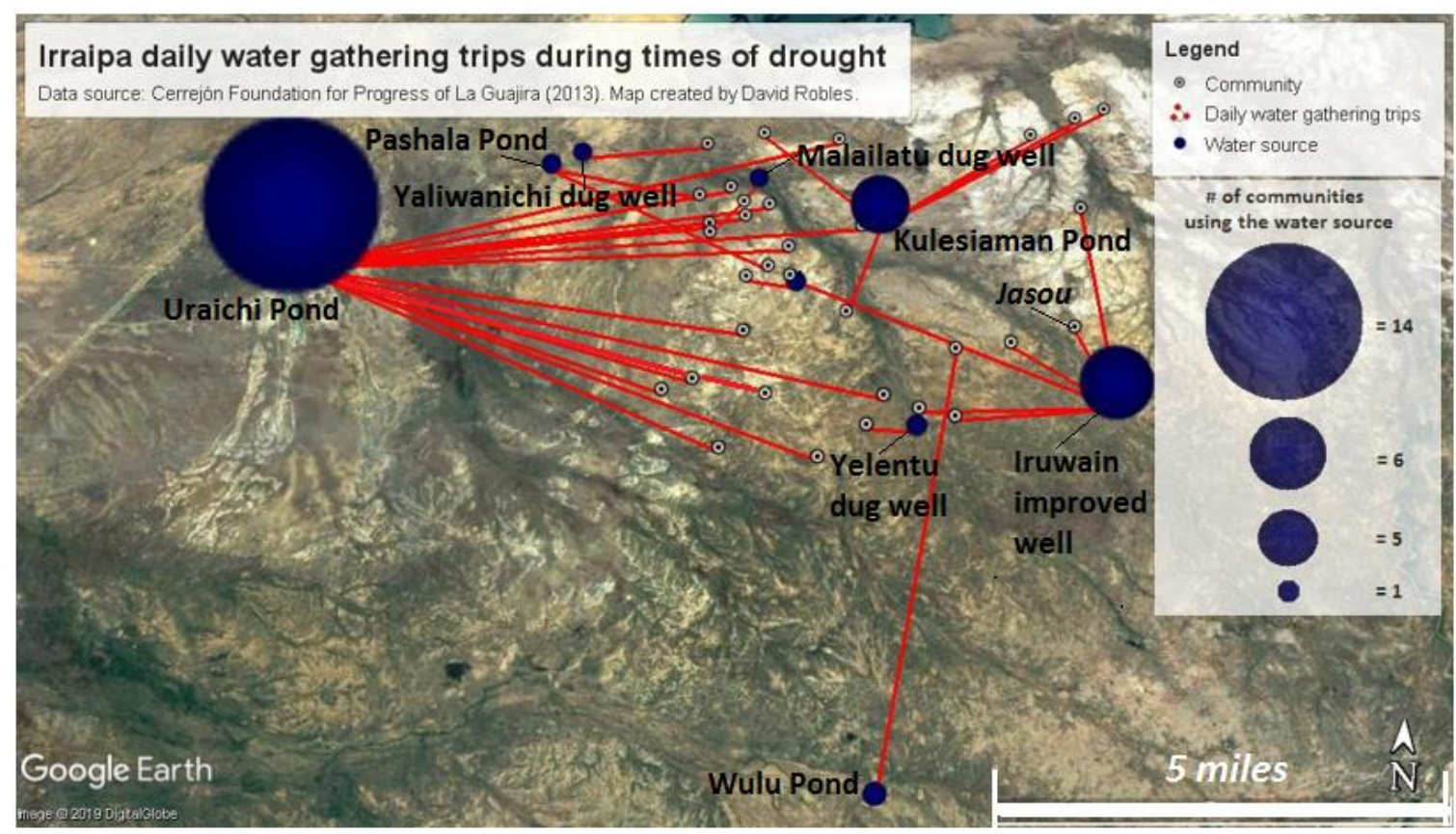

Map 8. Daily water gathering trips in Irraipa during times of drought Source: Adapted from Cerrejón Foundation for Progress of La Guajira (2013) 
Uraichi Pond is located on the east side of the unpaved road to the Cerrejón port (Km 124 marker), in the north of the peninsula. Uraichi Pond was traditionally a place where the Wayuu from this region would migrate temporally (o'onowaa) with their livestock during times of drought when the pastures and water sources had been exhausted in their own territories. It continues to be an important water source during droughts for communities near and far; $42 \%$ of the communities in Irraipa use it as their primary water source during droughts, with an average distance of 10.5 kilometers and a four-hour walk, one way. The pond is said to be inhabited by a Pulowi because of its inexhaustible water supply. The Irraipa and Kulesiamana communities reported the longest water gathering trips in the area, even though they are near the long-lasting Kulesiamana Pond. The water users of these two communities stated that when this pond goes dry, they too seek water in the Uraichi Pond, covering $24 \mathrm{~km}$ and spending over eight hours, roundtrip.

Other communities, such as Jasou spend one hour per day to gather water, the lowest in the area. Jasou, along with Kuluisou, are the only two communities that use more time to gather water in the dry season than in times of drought. Jasou's inhabitants prefer to walk five kilometers in the dry season to get better quality water in the Kulesiamana Pond, where they also have kinship ties. Only when this source is depleted do they switch to the Iruwain well, which is two kilometers away from their community, but whose water is slightly salty, and there is less familiarity with the owners of the territory where the well is located.

The Guajira Peninsula where the Wayuu live is made up of thousands of small clan territories that are delimited by borders unperceived by non-locals. Hills, streams, 
rock formations, trails, cemeteries, crop fields and other landmarks are reference points that show where one territory ends and another begins. Jasou, for example, is a community close to its territorial clan border. Its proximity to the Iruwain well does not mean the community members of Jasou have equal access to it as do the Wayuu who live within the territory of the owners of that well. Therefore, reciprocal relations, kinship ties, yanama (collective work), visiting and other social events create bonds that are stronger between Jasou and other communities within its territory-even though they are at a greater distance - than those communities that may be closer but lie beyond Jasou's territory. As for Kuluisou, its inhabitants get water from the reservoir three and a half kilometers from their community during the dry season, while during droughts they use the dug wells in the pond bed of Yelentu, approximately one kilometer away. Although the distance is shorter to the dug wells, they consider it their last option because of the effort and risk involved in using them; these wells are five meters deep and require careful use.

\section{Discussion}

According to one's theoretical approach or preconceptions, water use and management by the Wayuu living in rural areas, such as Irraipa and Cardón, can be interpreted in different ways. In the following sections I present analyses and critiques from a conventional approach, a political ecology approach and a relational ontology approach.

\section{A conventional interpretation of Wayuu-water relations}

A conventional interpretation, based on contemporary hegemonic water management standards, perceives the Wayuu in these areas as living in constant water 
insecurity in a water scarce region. Here, Santos' five logics that form his theory on the sociology of absences can highlight the elements that a conventional interpretation may include (Santos 2011).

The first logic of the sociology of absences, which Santos calls the monoculture of knowing and the rigor of knowing, focuses on epistemology $(2011,30)$. Under this form of producing inexistence, Western science, particularly that associated with public health and water management, determines what is knowable about water and how we understand water. Anything that does not follow this logic is deemed ignorant or inexistent. Therefore, when Western standards for water accessibility, quality and quantity are not met, there is an ethnocentric predisposition to reject or denigrate the way other cultures use and understand water, especially if they are not based on scientific facts and predominant sanitation and hygiene standards. For those in decision-making positions, the reaction is to delegitimize the undesirable practices by targeting them with corrective engineering and technoscientific solutions.

Under this logic, the quality of the drinking water in Irraipa and Cardón is considered poor because ponds and dug wells are unimproved water sources that provide untreated water prone to contamination by human and animal feces. This lack of access to clean water, as well as the malnourishment of Wayuu children and the deficient health service in Wayuu territory have impelled the Colombian government and the international community to regard the situation a humanitarian crisis and in violation of the constitutional rights of the Wayuu (Ruling T-302 of 2017). As evidence of the crisis, the Ministry of Health in 2013 reported that the mortality rate for children under five years of age in La Guajira province was 32.54 for every 1,000 children while the national 
average was 6.76 (ibid, 39). Furthermore, the Ombudsman's Office assures that this figure is well below the actual number of infant deaths because a very high number of them go unregistered (ibid, 40).

Regarding water quantity and availability, the Wayuu in these areas do not attain the minimum amount of water deemed necessary by the World Health Organization (WHO) of 50-100 liters per person per day for their domestic needs and healthy living (Howard and Bartram 2003:22). In Irraipa the daily water consumption per capita (1/c/d) was estimated at 22 liters and in Cardón, 37 1/c/d (Fundación Cerrejón 2013b:165). ${ }^{18}$ Including the figures from two other studies by the Cerrejón Foundation, the average daily water consumption for 776 households in 182 Wayuu communities (Including Irraipa and Cardón) in the Upper Guajira was estimated at 25 l/c/d (Ibid: 13). The WHO also determined that there is a high risk to a person's health if the water source is between 100-1,000 meters distant or if the total collection time is between 5-30 minutes; the health risk becomes very high if the water source is more than 1,000 meters away or the total collection time is over 30 minutes (Howard and Bartram 2003, 22). If we compare these figures to those in Table 1, we see that even during the rainy season when water is most plentiful, the health of the Wayuu residents in these two areas is at high risk and during most of the year, the Wayuu of Irraipa and Cardón are at very high risk. Emphasis is placed on distance covered and time spent gathering water as factors influencing the

\footnotetext{
${ }^{18}$ In the Foundation's reports, the area of study I identify as Irraipa is called Kaleruwou because 1) that is the name of the community where the reservoir was to be built, 2) it is also a larger area that encompasses several communities and 3) it is the name given to the reservoir. Kaleruwou is within the jurisdiction of Irraipa, the village district. The same applies for Cardón, which is called Kaiwa in the reports. Kaiwa is a community within the Cardón village district, a larger territory that includes several communities and also the name of the reservoir. I use Irraipa and Cardón because these are the names of the village districts (corregimiento) that contain the communities in those two areas.
} 
health of the water users. In a conventional interpretation, water security is also characterized by the proximity and continuity of a water source to a household. Comparing Wayuu water sources to those of contemporary Western societies the differences are stark because in "developed countries," and many cities in the Global South, clean water is available with the turn of a faucet.

Another aspect related to this first logic of the monoculture of knowing is the suppression of shamanic knowing and water spirituality, which will be discussed in the following chapter. These immaterial elements add another layer of meaning and value to water yet are not recognized by Western science as valid forms of knowledge and are thus discredited or invisibilized. The knowledge the Wayuu gain from dreams is also considered unscientific and premodern. The advances in the scientific understanding of water and water technology leads to the next logic in the sociology of absences that creates inexistence.

Santos' second logic, the monoculture of linear time, highlights how conventional Western discourses give superiority to progress and the advanced, epitomized by the production of knowledge, institutions, sociality, values, among others, originating in the developed countries of the Global North (2011,30-31). Like anthropology's theory of unilineal cultural evolution, anachronism is produced when representatives of the First World meet with representatives of developing countries "stuck in the past," what Santos refers to as "a simultaneous encounter of non-contemporaries" (ibid, 31). According to this logic, the evolution of waterworks and the advances in water management mark breakthroughs on a unilineal progression towards the current state of water use and management in the Global North. Consequently, what was done in the past, or what is 
currently done in other parts of the world "stuck in the past," are considered out-of-date, backward, wrong and in need of replacement with the "correct" strategy or technology.

However, filtered, piped and continuous water to private residences is a relatively recent achievement in the Western world. Only in the last century were important cities in the Global North such as London and New York able to provide this service to its populations (Salzman 2006). These improvements were made after industrial activities during the $18^{\text {th }}$ and $19^{\text {th }}$ centuries contaminated the local ponds, springs, wells (and the Thames River, in the case of London) and epidemics broke out obligating the local governments to act. Salzman cites a character in a 1771 British novel that describes the condition of the River Thames as,

impregnated with all the filth of London and Westminster. Human excrement is the least offensive part of the concrete which is composed of all the drugs, minerals and poisons used in mechanics and manufactures, enriched with the scourings of all the wash tubs, kennels, and common sewers within the bills of mortality. (Salzman 2006, 21)

The Thames, according to this person, is the repository of not only domestic waste but also, and more polluting, industrial waste. The shift from rurality and artisanal craftsmanship to urbanization and industrialization in some societies produced an unhealthy living environment that demanded strict water management solutions. The fact that some societies "developed" while others remained "undeveloped" is critically analyzed in Escobar's Encountering Development (2012), which describes the rise and dissemination of the concept of development by the richest nations post-World War II (former colonial powers). With "expertise" and power concentrated in these First World nations, a hegemonic apparatus was devised to direct international and national politicoeconomic policies and relations according to this neocolonial agenda. Over time, 
Eurocentric technological solutions to water quality, quantity and access became standardized and universalized by powerful global institutions that set the standards and guidelines by which all societies and individuals are classified and targeted by "experts."

The classification of world regions into Global North/South, Developed/ Developing, First/Third World, also forms part of Santos' third form of creating absence, the logic of social classification and the monoculture of the naturalization of differences $(2011,31)$. Patriarchy and racial superiority are two forms of social classification that have been naturalized at a global scale. Under this logic, inferior races (colored peoples) or the inferior gender (women) are inherently and insurmountably inferior to their superior counterparts. In this sense, a Wayuu woman shaman or artisan, and any knowledge or skills she may possess, are labeled as inferior to a white male engineer, biologist, artist, etc. because of this naturalization of racial and gender differences. As discussed in the introductory chapter, the contributions of Indigenous peoples have been underappreciated by most nation-states. Throughout Latin America and worldwide, certain words are loaded with racial significance, status and hierarchy. For example, Indigenous languages are considered dialects, their knowledges are labeled beliefs, their religions are branded mythologies or idolatries and their artworks are categorized as handicrafts; each of these terms implies a lower status and a lack of legitimacy, authenticity or high culture as opposed to the terms used to describe their Western equivalents.

Locally, the Wayuu have been stereotyped as lacking morality and compassion when it comes to the care given to their sick children. A common perception among the non-Wayuu inhabitants of La Guajira is that the Wayuu invest more time, money and 
effort in preparing for and performing funerals than in trying to save the lives of the ailing family members. This sentiment has been internalized by the government institution in La Guajira that looks after the health and wellbeing of children and families, the Colombian Institute of Family Wellbeing (ICBF). The Constitutional Court of Colombia responded to this discriminatory attitude by issuing the following statement within the Sentence T-302 of 2017:

The Court considers that the solution to the malnutrition crisis of Wayuu children requires that all public entities overcome ethnic prejudices and stereotypes. It is unfair and discriminatory to generalize over the entire Wayuu population to argue that "they" — referring to all Wayuu Indigenous people — "do not let themselves be helped" - as if the welfare aspects of rights were not obligatory, but optional, when it comes to these communities, and as if the communities were asking for "aid" or assistance from the State, when the truth is that the Wayuu communities reject assistance measures (Corte Constitucional 2017, 2).

The logic of the dominant scale is Santos' fourth logic of the production of inexistence, namely the superiority of the universal and the global and the suppression of the particular or local $(2011,32)$. Here, globalization becomes hegemonic, global entities, processes and realities are superimposed or juxtaposed with local, small-scale alternatives, creating an atmosphere of mutual contestation, oftentimes at the expense of the local or Indigenous. As described in Chapter 4 and discussed further below in the section on relational ontology, the convergence of multiple scales of water governance is also an ontological struggle over the relationship between humans and water, creating ontological conjunctures and disjunctures at the local scale (Yates, Harris and Wilson 2017). Context-specific Wayuu water use and management practices such as water gathering trips, drinking from untreated sources such as ponds and wells, open-air defecation, livestock watering, as well as their supernatural relations with water and rain 
spirits, fall within the local scale and are therefore considered illegitimate forms of existence.

The fifth logic within the sociology of absence is the monoculture of capitalist productivity that demands unquestionable economic growth and the productiveness of both nature and human labor (Santos 2011, 32). Thus, lack of productivity, as in sterile nature or an idle person, are undesirable and to be rectified. The dry rangelands that make up most of Wayuu territory were of little interest to the Spanish and Colombian mestizos during the colonial and republican eras because it lacked forests, arable land or precious metals and minerals. Only after coal extraction began in the 1980s, and after the more recent "discovery" of the area's potential for wind farming, did this land become "productive" in most non-Wayuu people's eyes. As for the Wayuu people, they do not follow the capitalist logic of increased production because of their adherence to nonmarket economic practices that include extensive rather than intensive pastoralism and rain-based rather than irrigation-based farming. Furthermore, their preferences for small-scale fishing rather than industrial fishing and hand-made crafts rather than industrial products, have contributed to their limited participation in capitalist enterprises.

Wayuu common property resource regimes, which are based on water sharing, reciprocity, and local rights, are unlike the payment for water services regimes that are prevalent in the Western world. As has occurred throughout Africa, Asia and Latin America, the introduction of improved water infrastructure is accompanied by marketbased water governance framework and the privatization of water where the users pay for access to better quality water (Goldman 2007:790). Water management under this regime must also consider affordability of water, along with other requirements such as quality, 
quantity, continuity and accessibility. Attempts in Wayuu territory to transform water users to paying customers has had little success. In the case of Mayapo, the water meters installed in 2013 never functioned because of problems with the water distribution system (Chapter 7 provides a description of Mayapo's faulty water distribution system). Mayapo's community members, nevertheless, were obligated to become paying customers - not to the municipal water service provider in charge of the aqueduct as was intended - but to the private water trucks that supply most of the residents with potable water from the provincial capital's municipal aqueduct.

A political ecology interpretation of Wayuu-water relations

From a political ecology standpoint, water scarcity can be a biophysical reality, but more importantly, attests to the contested nature of water access, as understood in the following quote by political ecologists Goldin, Sneddon and Harris,

our identification of scarcity as a hegemonic concept does not deny that water shortages are persistent and consequential for many of the planet's people and places; rather, our goal is to highlight how such scarcities are co-constructed by both material conditions and power relations that define the boundaries of water control and access (Goldin, Sneddon, and Harris 2013, 3).

If we consider this quote in the Wayuu context, the determining factor for water access among the Wayuu is not necessarily their semi-arid environment but the social milieu with unequal relations between the historically marginalized rural Wayuu society and the Spanish-speaking alijuna urban society. The material conditions referenced in the quote refer to the hydrological and meteorological characteristics of the Guajira that determine the natural availability of water.

The Spanish-speaking alijuna society colonized the more water-secure Lower and Middle Guajira that receives between 1,000-2,100mm of annual rainfall on average while 
the Wayuu live in the dry Upper Guajira, with an annual rainfall of between 3001,000mm (Unión Temporal Atlas, 19-21). Furthermore, there are 11 rivers in the province of La Guajira, all of which are in the Middle and Lower Guajira (Ibid:41). Municipal aqueducts use the water from these rivers to provide water service to the urban centers, rural communities and industries of the southern region of the province.

The Ranchería River is the longest $(380 \mathrm{~km})$ and northernmost river in the province, traversing nine of its 15 municipalities. This river is also the only one that enters Wayuu territory, in the Manure and Riohacha municipalities towards the end of its course. The Ranchería River was dammed in 2010, reducing the flow of the river to these downstream municipalities, yet upstream from the Wayuu communities, rice cultivation and the Cerrejon coal mine, the largest open-air coal mine in Latin America, continue to use it for their production needs (Chapter 7 has a further description of the impact of this controversial dam). Thus, historical and current hierarchical relations between the Wayuu and non-Wayuu have resulted in greater water security for the Spanish-speaking urban areas whose water service coverage is $90 \%$, while producing water scarcity or water insecurity for the predominantly Wayuu rural areas of La Guajira, where water service coverage is a mere 4\%, the lowest figure in Colombia (Ministerio de Vivienda 2018, 45).

Political ecologists would attribute this unequal access to water and water services, in part, to the historical marginalization of the Wayuu people. Categorized as uneducated, unorganized and aggressive indios, whose culture, language and livelihoods differ from those of the non-Indigenous Colombian majority, interethnic communication has been difficult, and the defense of the Wayuu's constitutional and human rights mired 
with obstacles. The non-Wayuu mestizo ruling class in La Guajira have traditionally had the advantage over the Wayuu to secure water resources. While far from optimal, water service in the cities and towns has been prioritized, as well as water for agriculture and industry.

For example, the Cerrejón company has secured large amounts of water for its coal mining operation while also investing in its public image as a "regional partner for water" highlighting the company's efficient and responsible use of water, its comprehensive management and contributions to improve the water supply in La Guajira province (cerrejon.com). The company's multi-pronged defense of its water use and good water governance is a strategy to maintain good public relations despite its disproportional use of a contested resource for an industry that has been increasingly under attack both locally and globally for its unsustainability and destructive consequences for life on earth.

Considering the various actors and hierarchical relationships between them, water governance in La Guajira has advantaged the urban areas over the rural areas, the alijuna over the Wayuu and industrial use of water over its domestic use. As for water management, the initial phase of water infrastructure installation has been prioritized over securing its monitoring and maintenance. Consequently, non-functional waterworks abound in Wayuu territory, explained in greater detail in Chapter 7.

While this section has given greater attention to inter-ethnic contestation of water governance, intra-ethnically, some Wayuu communities and community members within communities have greater access to improved water services, as presented in this chapter. Large communities such as Mayapo and others close to the urban centers, or within the 
area of influence of Cerrejon's railroad, have greater water security than those small, rural, remote communities. Affluent families and territorial owners within Wayuu communities are also able to gain greater control over local water sources or afford to build concrete storage tanks and purchase water from the municipal aqueducts.

While a political ecology analysis helps to understand how and which social groupings can secure water while others are obligated to live in water insecurity, it assumes water scarcity and water security are understood equally or are to be adopted cross-culturally. To complement a political ecology analysis, the following section explores the ontological differences that question the concepts that the water sector experts and political ecologists take for granted.

\section{A relational ontology interpretation of Wayuu-water relations}

A third interpretation to the water situation on Wayuu territory, consistent with a cultural relativist or relational ontology approach, understands Wayuu practices as enduring adaptations in order to maintain a locally established standard of water security in a place where people and territory have coemerged. This interpretation places the attention on hermeneutics, or the construction of meaning of water, water quality and quantity standards, its accessibility, availability and associated phenomena. Western conceptions of meteorological, hydrological and other biophysical conditions as well as concepts such as water scarcity, water stress and water shortage are questioned or critiqued by relational ontology for maintaining Western epistemological frameworks.

For instance, Goldman, Daly and Lovell (2016) argue that droughts as defined and characterized in the Western sense do not always align with an Indigenous understanding of drought, as in the case of the Maasai pastoralists of northern Tanzania. 
The authors note that the Maasai do not have a word for drought; they use the adjective sapuk (large/substantial) to alamei (dry season) to refer to a drought (Ibid, 31). Similarly, the Wayuu also distinguish droughts from the dry season by adding the adjective müle'u (long) to the term for dry season (jouktai or jouktale'u).

This raises the question if there is an ontological difference in the thing or process we know of as drought. Among the Maasai pastoralists of East Africa and the Wayuu pastoralists of northern Colombia, droughts are enacted or recognized because of their effects on the livestock. When water sources and pastures are depleted because of an extended period without rainfall, the Wayuu must move their livestock to more verdant regions with water sources or risk the death of the animals by starvation and dehydration. Therefore, among these two pastoralist societies, factors such as having animals that withstand water stress, access to alternative pastures through reciprocal relations and access to money or medicine can create situations where droughts are felt more in some areas than others or extend droughts to places outside drought-affected regions because of the added pressure by animals that are moved there. These considerations are not included in the standardized measurements by planners and scientists, which leads the authors to conclude with a question, "if there are different droughts, which one is recognized as 'official'? Which spurs distribution of food aid or gets documented as 'climate change' for the IPCC?” (ibid, 32).

Wilson et al. advocate for an understanding of water security that goes beyond the material dimensions and that considers "the complexities of Indigenous peoples' relationships to water through the use and value of traditional water sources... [and] the 'non-material' dimensions of water security including emotional, affective, relational and 
spiritual relationships to water" $(2019,2)$. The first part of this statement is evident among the Wayuu whose seasonal and spatial relationship with their traditional water sources (rainwater, streams, ponds and wells), as well as water's endowment of spiritual and supernatural properties are unlike any Western society's relationship with water. A Wayuu understanding of water security pays less attention to the presence of microbial contaminants or the absence of a continuous supply of water within the household. More importantly, the Wayuu rely on customary water quality standards that include judging the water by its organoleptic characteristics (color, taste, odor), the presence or absence of fencing around the water source and knowledge of and access to multiple sources of water throughout the year.

For the Wayuu, who have adapted to the environmental conditions of the semiarid Guajira Peninsula, water scarcity is not equal to water insecurity. Their water use and management practices are attuned to living with seasonal water shortage. Water security is a Wayuu's attunement to the regularity and cyclical nature of the decline in the water supply and its replenishment. For example, knowing how much water is in the local pond, how much longer it will last with drinkable water, when the rains might fall again and where to go for water if the pond dries, all form part of a Wayuu traditional water knowledge undervalued or ignored by conventional water management.

The second part of Wilson et al.'s statement points to the non-material dimensions of water security. My inquiries into the resurgence of Mayapo's local pond as an important water source revealed to me the presence of Pulowi, an other-than-human person residing in the pond. Pulowi, a female water being, and Juyá, the masculine 
supreme rain being, are the two most pervasive nonhuman persons whose actions transverse the hydrosocial relations among the Wayuu.

The Wayuu can communicate with the spirit world through dreams and especially through the shaman who becomes a medium by which the spirits communicate with the Wayuu. As I describe in the following chapter, the Pulowi of Mayapo was summoned by the local shaman so that I could ask her directly about the importance of water and the pond for her and for the community members. Through the increased acceptance of Western medicine, education and religion in Mayapo and across the Wayuu territory, the authority and ability to transmit knowledge by the Pulowi and the shaman have been diminished but are still maintained. While this suppression can been seen as another example of Santos' sociology of absence, positively, it may be described as the not yet; Santos defines the not yet as "on the one hand capacity (power), and on the other, possibility (potential)," a characteristic of a sociology of emergence that identifies alternatives to the future that lie in latent form in concrete social experiences $(2011,33)$. 


\section{A WAYUU WATER WORLD}

When a Wayuu dies, the soul does not go to Heaven or Hell. When a Wayuu dies, the soul goes on a journey in the form of a spiral to the Jepira world, a mystical place in the deep sea where the soul is purified and can be transformed into rainwater.

Josefa Pushaina, outsü (shaman) of Cardón, March 10, 2012

We orient the way, as it must be, since we already know how the process is, how the pond is, because we are the owners of the pond since the beginning.

Malena, the Pulowi water spirit of Mayapo, November 19, 2018

\section{Introduction}

Water's vitality, materiality, connectivity and necessity for life has elevated it within the social sciences as a "theory machine" (Helmreich 2011), understood as both a substance and a symbol, making human life literally and metaphorically unthinkable without it (Krause and Strang 2013). The co-emergence of water and society has been described as Mauss" "total social fact" where all domains of social life are connected with water and depend on it (Orlove and Caton 2010:402). Water permeates all aspects of society and the environment, whether tacitly through virtual water (the water footprint of a product) or green water (soil moisture used by vegetation to grow) and visibly as bodies of water that are used and valorized by both urban and rural societies, creating countless hydrosocial relationships through time immemorial.

Peoples inhabiting forests, mountains, wetlands, drylands, tundra, small islands, or other ecosystems have each developed unique water relations that crystalize into multiple ontologies of water or water worlds (Hastrup 2009; Barnes and Alatout 2012). World religions and belief systems provide examples of how water is understood and 
used in ritualistic and spiritual ways. Water is imbued with curative, protective, therapeutic and supernatural properties that not only serve a purpose for the user but also shape the way water is viewed and given value. In this sense, rivers, rainfall, springs, the ocean and other bodies of water take on deeper meanings than those perceived by the senses alone. Scholars have noted that water and human societies form an assemblage of mutual becoming, as evidenced in the aquatic spaces within black communities on the Pacific coast of Colombia (Oslender 2016), the ritual management of water by Balinese temples (Lansing 1991) and water cosmologies incorporating other-than-human beings in the Andes (Stensrud 2016, Boelens 2014, de la Cadena 2015), to name just a few.

In Chapter 4, I identified various scales of water governance from the global to the local that direct and constrain Wayuu-water relations, and in Chapter 5, I described the hydrosocial practices and understandings of the Wayuu water users of Irraipa and Cardón. This chapter further explores a Wayuu water ontology (the nature of water) and epistemology (how water is understood) by exploring the supernatural realm of water relations in Mayapo using the concepts traditional ecological knowledge (TEK) and hydrocosmological cycle. The term hydrocosmological cycle was coined by Rutgerd Boelens after analyzing an Andean hydrologic cycle that welds social and natural aspects of water to the supernatural $(2014,235)$. In the native Andean water ontology, water's creation and circulation include the active participation of Mamacocha (Mother Lake, the ocean), Pachamama (Mother Earth), apus (mountain deities, territorial protectors), amarus (snakes, the representation of water) and other huacas (deities) (ibid). Even though the arid Wayuu territory is water scarce, it can nevertheless be understood as a 
spiritually infused water world because of the centrality and transversality of water in the spiritual, social, natural, and oneiric levels of Wayuu existence.

However, Boelens' analysis of water flow in the Andes is based on a political ecology approach, rather than a relational ontology approach. He argues that the Andean water world is shaped by struggles over water control between various local actors, including ruling groups that strategically employ cultural politics and water representations to control water governance $(2014,235)$. According to Boelens, the social construction of a metaphysical water reality, "resembles the ways in which contemporary (scientific and interventionist) 'water policy myths' contribute to shaping those socionature representations that suit ruling groups' interests" (235).

In this sense, I diverge from Boelens' argument that the hydrocosmological cycle is part of a hegemonic apparatus socially constructed to further the interests of a dominant group. I employ the term to highlight the deep connections between the spiritual, oneiric and human worlds that shape the Wayuu worldview and constitute equally important elements of the water cycle on their territory. In the Andean context, with a long history of pre-Hispanic and Hispanic empire-building and domination, Boelens' may be right in asserting that native cosmologies have been appropriated by the ruling class to establish control over water. On the Guajira Peninsula, however, tribal relations persisted among the Wayuu during pre-colonial and colonial times, impeding the formation of chiefdoms or incipient states and their accompanying class inequalities. I therefore introduce the term hydrocosmological cycle within a relational ontology approach rather than the political ecology approach adopted by Boelens. 
This notwithstanding, I end the chapter by summarizing the obstacles Paul Nadasdy identified for the integration of TEK into a conventional environmental management framework. Nadasdy's critiques incorporate both political ecology and relational ontology analyses by not only stressing the uneven power relations between Indigenous groups and state institutions but also the incommensurability of ways of knowing due to radically diverging cultures or ontologies. These obstacles are analyzed taking into consideration the Wayuu context and the other viewpoints from the epistemologies of the South.

The first section of this chapter introduces two other-than-human beings, Juyá the embodiment of rain and father of crops, and Pulowi, a water spirit and custodian of wild plants and animals. To do so, I initially use texts on Wayuu mythology and shamanism from the 1970s that described the spiritual and ecological aspects of Wayuu-water relations, notably Michel Perrin's, The Way of the Dead Indians: Guajiro myths and symbols ([1976] 1993) and Ramón Paz Ipuana's Ale'eya: Cosmovisión Wayuu relatos sagrados (Ale'eya: Wayuu Cosmovision and Sacred Stories 2016a) and Ale'eya: Conceptos y descripciones de la cultura Wayuu (Ale'eya: Concepts and Descriptions of the Wayuи Culture 2016b). ${ }^{19}$ The information gathered by Perrin and Paz provides a foundation for exploring the role of these two central mythical figures in a Wayuu hydrocosmological cycle.

The descriptions offered by Paz and Perrin in the first section are then compared with what contemporary Wayuu of Mayapo say about Juyá and Pulowi. This comparison

\footnotetext{
${ }^{19}$ The two volumes of Paz Ipuana's Ale'eya are posthumous publications of an unpublished manuscript, Cultura, Literatura y Cosmovisión Wayuu (Wayuu Culture, Literature and Cosmovision) written in the early 1970s.
} 
will serve to expand, contest and support Wayuu water beliefs/knowledge of the early 1970s. Continuities of a Wayuu water ontology and epistemology are evident among contemporary Wayuu as are divergences from the findings of these two researchers, gathered nearly 50 years ago. While some may consider these divergences as an example of an aspect of Wayuu culture succumbing to contemporary assimilative forces, they are better thought of as a dynamic definition of culture, always adapting to changing social conditions (Jackson 1995, 18) and demonstrating the agency and capacity of the Wayuu people to reproduce a unique culture in novel and nonlinear ways. The continuities found among past and present representations of Juyá and Pulowi attest to the slower pace in which change occurs among Indigenous groups, their steadfast struggle against a OneWorld World in the form of Euro-North American modernity (Escobar 2016, 15) or the ahistorical nature of other-than-human beings.

The next section introduces the outsü (shaman) Ocari Pushaina and describes her role in the community and the importance of water in her profession. She also tells how she became a medium for a Pulowi (water spirit) and other asheyu (helping spirits) to communicate with the human world. Following the section on Mrs. Pushaina, I present excerpts from an interview with Malena, the Pulowi who enters Mrs. Pushaina's body during healing rituals. Malena gives her version of the conversion of Mrs. Pushaina into a shaman, her relationship with Juyá, her ability to enter dreams, the importance of Mayapo's pond and the meaning and value of water to her. I end the chapter with a discussion of the importance of the metaphysical aspects of Wayuu hydrosocial relations for their society and its potential contribution to more sustainable and committed global 
water governance practices and principles, using Santos' epistemologies of the South (2011).

\section{Wayuu other-than-human water beings}

I use the terms other-than-human person and other-than-human being to describe entities who disrupt the humanity-nature binary and who inhabit lesser known divergent multi-natural worlds (Viveiros de Castro 2004; Blaser 2010). Examples of other-thanhumans include Andean earth beings such as the mountain apus and deities (huacas) described by de la Cadena (2015), the supernatural bahluts (original specimens) who inhabit Yshiro territory in Paraguay (Blaser 2010), the Amazonian predator persons (runa puma) (Kohn 2013), and Wayuu wanülü (malignant being), pulowi (water being) and Juyá (rain deity) — all of whom have been traditionally called spirits or supernatural entities.

According to Paz Ipuana, in the primordial past there existed the forming principles Sawai-Piuushi (darkness of the night, supreme grandmother) and Arraliatu'u Warattui (light of the sky, supreme grandfather). The Wayuu people were born from the union between Juyá (rain, spirit of fertility) and Mma, (earth, supreme mother) through the creative capacity of Maleiwa (supreme being, ordering principle) who formed them using parts of the plants and animals (2016a, 42). However, it is the contemporary union of Juyá with his Pulowi wives that brings rain to the Guajira Peninsula, producing and maintaining all life. Juyá and Pulowi are two of the most important other-than-human beings within the Wayuu hydrocosmological cycle whose actions influence the lives of the Wayuu in many ways. Both are intimately related to water and can both produce or preserve life or bring death to the elements of the natural world. 


\section{Perrin's ethnographic data and analysis from the 1970s}

Juyá is described by Perrin as "hypermasculine", mobile and unique, insurmountable in the seduction of women and in hunting prey (152). He lives in the sky wielding thunder and lightning as his bow and arrow, travelling over the Wayuu territory bringing the rain when he copulates with his many wives, the Pulowis. In contrast, Pulowi is "hyperfeminine", fixed and multiple, with the power to seduce mortal men with only a gaze (152). The word pulowi derives from the verb pülaa that means "to have supernatural powers or to be dangerous, malevolent, prohibited, taboo or wise." It also designates the female mythical figure when capitalized and a qualifying adjective in other cases (Perrin 1993, n.146). From the various bibliographic accounts reviewed and my own ethnographic studies, the adjectives also fit the description of Pulowi, the mythical figure. The feared Pulowis live in underground or underwater spaces and represent opposing forces: drought, death and disease on the one hand, fertility, procreation and abundance on the other. With her powers, Pulowi protects the land and aquatic ecosystems from hunters, fishermen and those who abuse their abilities to over-exploit natural resources, including water sources.

According to Perrin, these two figures reflect Wayuu gender roles (ibid, 172). Polygyny is practiced in the Wayuu society when the man is wealthy enough to pay the bride price for two or more wives. When a man has more than one wife, they usually do not live in the same community. Therefore, like the Wayuu man who travels to spend time with his other wives, Juyá is mobile, crossing the Wayuu territory, bringing with him rain in the form of brief but violent localized storms (153). On the contrary, Pulowi is multiple and sedentary. Like Pulowi, Wayuu women do not travel to see their 
husbands, but rather live in their communities, with members of their own matrilineal family (apüshi) (172).

True to a structuralist approach, Perrin considers Juyá and Pulowi opposing beings. Table 3 summarizes some of the binaries that distinguish the two. Perrin also presents the formulation: rain is to wanülü what Juyá is to Pulowi (rain:

wanülü::Juyá:Pulowi) (199). A wanülü is a malignant spirit that shoots invisible arrows causing serious illness or death to its human targets if not treated by an outsü (shaman). In order to understand this formulation, an explanation of how the Wayuu understand the afterlife is needed.

Table 3 Perrin's Dualistic Comparison of Juyá and Pulowi

\begin{tabular}{ll}
\hline Juyá & Pulowi \\
\hline Masculine & Feminine \\
\hline Mobile & Fixed \\
\hline Singular & Multiple \\
\hline Above & Below \\
\hline Uniformity of appearance & Diversity of appearances \\
\hline Life & Death \\
\hline On the side of the hunter & On the side of the animals \\
\hline Cultivated plants & Wild plants \\
\hline Cold & Hot \\
\hline Light & Dark \\
\hline
\end{tabular}

Source: Summarized from Perrin 1993, Chapter II

Wayuu burials mark the departure of a person's soul to the afterlife in Jepira, where the yoluja (soul) retains its individuality and identity. During this period, it is still possible for the soul to be recognized when it visits the human world through dreaming or waking encounters. After a few years, the Wayuu perform an exhumation of the remains and transfer them to the ancestral cemetery of the matrilineal clan. At this moment, the remains, as well as the soul, lose their individual identity. The material remains become part of a collective whole of anonymous ancestors and the immaterial 
soul, in the realm beyond death, undergoes another transformation from yoluja (soul) to either wanülü (illness) or rain. Consequently, the soul of the living Wayuu returns to the human world in the form of life-giving rain (juyá) or death-bringing wanülü, associated with Pulowi (ibid, 199). Over forty years later, the first epigraph of this chapter, told by an elderly Wayuu shaman of Cardón in 2012, demonstrates a continuation—by at least some members of the older generations and special knowledge holders—of a Wayuu hydrocosmological cycle wherein the souls of the departed Wayuu, after journeying to an aquatic afterlife world to be purified, return as rain. Perrin further explains,

this cycle gives meaning to death: life on earth is marked by the presence of the dead and the dead are necessary to it. What is more, it testifies to a human presence even in areas that are the province of nature; climatic phenomena, diseases and death, and, indirectly, fauna and flora" (Perrin 1993, 199).

\section{Paz Ipuana's ethnographic data from the 1970s}

Paz Ipuana considers that, for the Wayuu, rain is both a meteorological phenomenon, juyá, and a spirit Juyá, specifically the "spirit of fertility" (genio fecundante) (2016b, 207). Paz describes Juyá as the providential deity par excellence, father of the crops and harvests, father of the living generations of humans and nonhumans and the personification of rain (Ibid). In exchange for giving the Wayuu rain, farmers offer Juyá the fruits of their first harvest through feasts. Also, before Juyá's arrival, dances (yonnas) are organized as a tribute to the great provider (ibid, 207).

When Juyá feels drunk, he remembers the sufferings and famines his children and grandchildren have suffered during his long absence. Then, he cries copiously and sheds his life-giving tears on the dry land. All of nature is enlivened and laughs. Everything is reborn with his dew. But Juyá is bad-tempered and becomes irritated when drunkenness consumes him. Then he throws his lightning everywhere to destroy what it randomly hits. (Paz Ipuana 2016b, 208) 
Paz's findings, as opposed to Perrin's, attributes rain to the tears shed by Juyá, who is saddened by the suffering his abandonment has caused to his human, animal and plant descendants. On the other hand, Perrin attributes rainfall to the result of the sexual encounters between Juyá and Pulowi.

While the other-than-human rain being known as Juyá is central to the production or absence of rain in Wayuu territory, the Wayuu have also accumulated a vast amount of empirical knowledge of rain as a natural phenomenon. Through careful observation of the skies, the shape and disposition of the clouds, the position of the moon and stars, the behavior of certain animals, and other ecological conditions, the Wayuu have come to understand the idiosyncrasy of the rains in their territory, which includes forecasting the possibility, extent and severity of future rains. During the late 1960s and early 1970s, Paz Ipuana compiled twenty-five types of rain recognized by the Wayuu, who distinguish them by the time of year the rain falls, the flora and fauna associated with each type of rain and their defining characteristics. (Paz Ipuana 2016b, 222-228). Many of these rain types are remembered through legends and ancestral jayeechis (Wayuu songs) that detail the various personifications and adventures of Juyá, the effects of each type of rain on the plants, animals and human subsistence activities, as well as their relation to the stars, constellations, wind and other atmospheric phenomena (ibid).

While Perrin associates Juyá with life, Paz notes that excessive rains can cause death and destruction. The wet environment is ideal for the spread of diseases, harmful insects such as mosquitos, flies, and tics abound, torrential storms and flooding devastate and isolate communities, crops fail because of oversaturation of the earth and malevolent spirits such as Wanülüï (illness, malignant spirit) and Keeraliee (fatuous fire, ghost of the 
savanna) become more active at night (Paz 2016b, 218). Too much rain is also bad for the livestock for the following reasons: the weakest livestock do not survive the cold; other livestock get sick and their hooves, horns and udders suffer from rain rot; and plants that intoxicate the livestock proliferate (217). Inundated and exasperated by copious amount of rainfall, Paz gives an example of the lamentations yelled at Juyá by the Wayuu,

You bother us too much! You become more unbearable every day. Because of you the plagues will come, bringing scourge in their mouths. Because of you diseases will come, bringing death in their bowels. Because of you the crops will perish. Go away from here, far, far away! Go to the heart of your origin. Go to the house of your Pulowi, the treacherous enchantress who will listen to your insolent voice! (Paz Ipuana, 2016b, 209)

As for Pulowi, Paz does not provide much information on her as a mythical figure, but rather as an enchanted place. Paz considers the Pulowi a very ancient being from a time when the world was in its formative stage. "These inanimate beings had a mysterious energy that enlivened them; they formed the First-Generation Humans who then transformed into haunted places, Puloi [Pulowi]" (Paz 2016b, 248). Other generations prior to the Wayuu include the elements $\left(1^{\text {st }}\right.$ generation $)$, the plants $\left(2^{\text {nd }}\right.$ generation) and the animals ( $3^{\text {rd }}$ generation) (Paz 2016a, 42). He does, however, give one anecdote of how Pulowi, the mythical figure, had all her cattle stolen from her by Irualaa, son of Juyá. Since then, she is without livestock and poor, in the solitude of her dark and enchanted dominions (Ibid, 192). Contrary to Perrin, who considers Wanülü̈̈ (malignant spirit) an emissary of Pulowi (1993, 160), Paz considers Pulowi one of many messengers of Wanülüü (2016b, 272). Therefore, a place becomes enchanted, dangerous 
or taboo (pulowi) because it is inhabited by Wanülüu. These places include tree trunks, ravines, caves and underground and underwater places.

Taken together, the writings of Paz and Perrin broaden our understanding of the comingling of social, natural, oneiric and supernatural elements, which form a distinctly Wayuu hydrocosmological cycle. The following section presents contemporary understandings and representations of water in Mayapo, which should be understood as a portion of a much larger body of knowledge of a native Wayuu hydrocosmological cycle. The responses from the inhabitants of Mayapo both support and stray from Perrin's structuralist perspective and Paz's emic perspective. Fishermen, farmers, pond users and other residents of Mayapo, especially the older generation, were all familiar with the two supernatural beings. Some residents stated that rituals are still practiced to attract the rain or please Juyá, the rain deity. Others have had first-hand encounters with Pulowi during healing rituals, dreams or sightings near the local pond, wherein it is believed she resides. Contemporary Wayuu conceptions of Pulowi and Juyá in Mayapo

Juyá

The Wayuu of Mayapo use the terms tatuushi (grandfather), taatchon (uncle) or tashí (father) when referring to Juyá, the other-than-human rain being. He is described by the older generation in Mayapo as a handsome, elegant man who is often seen riding a horse and enjoys drinking.

There was once a man who met Mr. Juyá near Maicao. Mr. Juyá asked this man, who was drunk, where he was going. The man replied that he was going to Maicao. He asked Juyá the same question and he said he'd come from there. When the man looked toward Maicao, he saw that it was cloudy, and it was raining, raining. They say wherever Juyá passes, it rains. Juyá asked the man for a drink, so he gave him one and after that they became friends. Juyá told the man not to be lazy but to go and sow the ground because Mr. Juyá was going to give 
him rain so that he would have crops. And so, it happened. A while later, he sowed everything - corn, watermelon, cantaloupe, squash, manioc and plantain. He was the only one with such as harvest. People would come to ask him for some. The man said Juyá was a real person and they became very good friends. (Manuel Uliana November 13, 2018)

Mr. Uliana tells the story of a man who befriended Juyá by sharing his liquor with him and in return Juyá promised him rain on the condition that he plant crops. The man did as Juyá requested and Juyá followed through with his promise by bringing the rain to his territory. Through encounters as the one described above or through dreams, Juyá's appearances reinforce Wayuu traditions associated with agriculture. Juyá provides the water necessary for the crops, encourages the Wayuu to plant and is pleased when he is offered his preferred dishes that are made from the harvested produce.

Sometimes we dream that a person arrives on horseback, a horse so robust and beautiful, and that he looks over to the sea and returns his look and people ask him in the dream "So, where do you come from? I come from the sea and I am looking to see where I will sow," he replies. That means the water will arrive here soon. It is such an important thing. If the dreamer said Juyá is close it's because he already came to visit. (María Elena Alarcón October 3, 2018)

The passage above shows how the sea is a recurring theme in the Wayuu hydrocosmological cycle of the distant, formative past and the present-day. According to Paz Ipuana, Palaa (Sea) is the daughter of Arraliatu'u Warattui (Clear Sky, supreme grandfather and forever father), the twin sister of Mma (Land, supreme mother) and the supreme grandmother of all the sea creatures (Paz 2016a, 47). Palaa birthed Juyá from her union with her brother, $K a$ ' $i$ (Sun) (Paz 2016b, 201). The sea is currently understood as the location of Jepira, the afterlife place where souls are purified to return as rain (recall the first epigraph of this chapter) and as the source of rain or the place where Juyá comes from, as Mrs. Alarcón recounts in the foreboding dream. Another shaman from 
Mayapo said "the rain that falls here comes from the sea. It's just that he [Juyá] changes the taste when it arrives here" (Ebaristo Uliana October 3, 2018).

While the senior residents of Mayapo communicated their knowledge of or anecdotes about Juyá, the mythical figure, most of the interviewees younger than 40 years of age did not. This suggests that in Mayapo, there is a break or weakening of the transmission and continuation of a central aspect of the Wayuu water world. Some Wayuu state that the Upper Guajira, the heart of Wayuu territory, has best maintained the ancestral beliefs and traditions while the younger generations of Wayuu living in the Middle and Lower Guajira have tended to abandon them. The older interviewees of Mayapo recalled that in the past, yonnas (traditional Wayuu dance) feasts and ritual bathing of children (amaichajaa tepichi) would be carried out to celebrate or invoke the rain (juyá)/rain being (Juyá) so that their crops would grow, and their livestock would have water to drink.

Our ancestors used to perform rituals to bring the rain. When we were children, they did it. The outsü [shaman] organized dances that were requested through dreams and the kasha [drum] was played. At that time, there were many children who were bathed. There was so much food! They made pooi with toasted corn and cheese. All those rituals attracted the rain. This food is offered to Juyá because they are the products of the rain during the harvest... We still do it in Mayapo, we still play the kasha and make pooi. Recently, we made some because of a dream that someone had. At the time, there was no water. That ritual came from the Upper Guajira. (Antonia Mengual October 2 ,2018)

Even though Mrs. Mengual affirms that the rain ritual is still practiced, another resident interviewed explained that in the past it was an important event but, "these days, everything has changed regarding the customs. The people who live here have already taken on Western customs. It is no longer gratifying to perform those rituals" (María del Carmen Epieyu October 4, 2108). Many residents of Mayapo share Mrs. Epieyu's point 
of view, stating that those rituals ended when the previous generation of Mayapo and the older outsüs (shamans) passed away. In Mayapo, as in many communities throughout the Wayuu territory, the ability of the outsü to assert authority over the entire community by organizing ceremonies and feasts has declined over the years.

The residents of Mayapo offer this as one reason why Juyá does not visit them as much as he did in the past, bringing rain with him to the region, while others have different explanations.

Juyá has a brother-in-law, the lizard, who said "What if I go and look for something to eat, now that I'm so hungry?" He went looking for Juyá over there, but he didn't want to return with him. "I left those people to their luck, because of their wrongdoings", Juyá said, "because of their actions, for killing my animals. That's why I abandoned them." And the lizard replied, "don't abandon your children, they suffer there, they don't bathe... and I'm hungry." That's why it didn't rain again for so long. (Juande Mengual October 2, 2018)

In the account told by Mr. Mengual, Juyá is not only on the side of the hunter, as characterized by Perrin, but also on the side of the wild game, a role Perrin attributes to Pulowi. Here, Juyá punishes the Wayuu for overhunting by denying them rainfall. It is evident from listening to the Wayuu talk about hunting and spending time in Wayuu territory that the deer and the oncilla (Leopardus tigrinus) have all but disappeared from La Guajira because of overhunting and deforestation. The following comment also associates the widespread killing of an animal, the donkey, to the lack of rain in Wayuu territory.

We do not know why it doesn't rain as before. Wherever we go, the elders have different versions. Some say that it's because there are no more donkeys. The donkey has disappeared from La Guajira. Wherever we go they tell us that; the donkeys are being killed. We found one tossed aside without its skin. In the Upper Guajira they comment that the death of the donkeys has driven away the rain 
because water is attributed to the donkey. With it we look for water. (Ricardo Gonzalez October 2 ,2018)

Local accounts such as the one described by Mr. González and news reports attest to the widespread robbery and killing of donkeys across the Upper Guajira beginning in 2016 (Caracol Radio 2016). Local Wayuu leaders have denounced the killing of donkeys, signaling that Venezuelan delinquents and local gangs are commercializing the skin of the animal, which has increased the price of one threefold. Others rumor that the donkey's skin is being used in drug smuggling. The disappearance of the donkeys has affected many Wayuu families, who rely on the donkey for transport, especially by women, to fetch water. Furthermore, as indicated by the elders of the Upper Guajira, the absence of the donkey has had repercussions on the hydrocosmological relationship, which has suffered a rupture by the removal of what can be considered a keystone species in the Wayuu water cycle. During the five months of fieldwork in Mayapo, I only witnessed one donkey that was owned by a person who came from another community. The absence of donkeys in Mayapo starkly contrasts with its prevalence in the community during the past century. In the case of Mayapo, the proximity of the water sources and the spread of motorized vehicles initially lowered the need to own this working animal, but their complete disappearance is also attributed to the illegal seizure and slaughtering during the past few years.

Other residents of Mayapo ponder whether the disappearance of the rain rituals and the widespread neglect of Juyá by the Wayuu people is what is diminishing the rain across the Guajira Peninsula. One elder from the area of Gran Vía in the Upper Guajira noted, "they no longer play the kasha drum to Juyá for it to rain. Now the Evangelicals 
pray” (Nájera, Pimienta and Iguarán 2010, 32). For centuries, Catholicism has had a presence on the peninsula, most notably the Capuchin order with its long-standing missions in Uribia, Nazareth and Siapana in the Upper Guajira. Despite this presence, the Wayuu maintained their spiritual beliefs and, in some cases, established a syncretism between the native Wayuu and European religions. Catholic baptisms are widespread among the Wayuu, patron saints have been adopted and celebrated in some Wayuu communities and Christian crosses adorn Wayuu graveyards. While most Wayuu do not attend mass and important Catholic events are few and far between, other Christian denominations have established themselves on Wayuu land with local churches offering daily services and vigils. Since the 1970s, the presence and expansion of Pentecostal, Jehovah's Witness and Evangelical Lutheran churches have successfully converted and maintained the allegiances of scores of Wayuu individuals, families and entire communities.

Those Wayuu who convert to Christianity distance themselves from the Wayuu religion but do not sever themselves completely from their cultural-religious Wayuu identity. In Gran Vía, for example, the authors noted, "religious thought persists in explaining the occurrence of rain through transcendent supra-historical principles that guide human life" (Nájera, Pimienta and Iguarán 2010, 32). One Evangelical convert from the area of Puerto López in the Upper Guajira and member of the Macedonian Christian Mission, explained that Wayuu Evangelicals still believe in premonitory dreams and in supernatural beings that have always existed in the Wayuu society, but they no longer participate in the Wayuu rituals to prevent calamity or summon Juyá. Rather than ritually bathe, sacrifice animals or participate in yonna dances where 
drinking also occurs, Evangelical Christians pray to God (Maleiwa) so that harm does not befall upon the potential victims of evil or to ask God to provide rain.

Pulowi

Unlike Juyá, who is celebrated with dance and food in exchange for his awaited arrival, Pulowi is not awarded such adulations. However, Wayuu fishermen habitually take a container filled with bark from the alouka tree [Croton malambo], entangle it in their nets or sprinkle water mixed with alouka on the bow of the boat as an offering to the Pulowi of the sea or as a protective agent against her wrath. Numerous stories of disappearances of men who have been seduced by the Pulowis who inhabit the sea and the land have instilled fear in the Wayuu of this supernatural figure.

There are two kinds of Pulowi, the one that comes out in a mysterious way in the pond and the one that appears out on the high seas. She appears to whomever she wants to appear to, not to everyone. In the pond she has been seen washing clothes. Her hair is long, and she always dresses in white. She appears a lot in the pond. She appears to the person that is to her liking. On the high seas she appears to the fisherman and whomever she likes. She gives him good fishing days, giving him the best fish during his outings. It is said that to whomever she grants this privilege, is a man she likes. That man at night dreams. She appears in his dreams (María del Carmen Epieyu, Mayapo resident, October 4, 2018).

Pulowi has been seen by some of Mayapo's inhabitants, while others recounted tales told to them about her appearances around the pond and of another Pulowi who lives in the sea. The Wayuu attribute the capacity of some water sources to retain water for very long periods of time to the presence of Pulowi, such as the Uraichi Pond near Irraipa and the Atatchon roadside pond near Cardón. She has also been signaled as the culprit of deaths and disappearances of Wayuu men visiting these inexhaustible water sources during the nighttime or of fishermen who do not return from sea. 
I have never seen her, but they tell me that she is there, in the pond. It is said that she comes out. People have seen her. She lives in a big stone. My mother was washing very late in the night and saw her. My mother said that she told everyone there, "Why are you taking so long to wash clothes? Hurry up, leave without looking at me!" She shouldn't be bothered because then she gets irritated. She is still there, in the sea. She lives there, she has never left. Many fishermen have seen her; they say she sits on the edge of the boat in the high seas. It is said that one of the fishermen lost his life because the Pulowi drowned him. She does that with people who take too much fish from the sea. They pay for it with their lives. (Antonia Mengual Epinayu, Mayapo resident, October 2, 2018).

The above testimony from Mrs. Mengual conveys the fear the residents have of Pulowi, and justifiably so, since both the Pulowi of the sea and the Pulowi of the pond are thought to have taken the lives of men in Mayapo and throughout Wayuu territory. Like Juyá, Pulowi is temperamental, and is powerful enough to kill as she is to heal. In fact, both Perrin and Paz associate Pulowi with Wanülü (illness).

One of my children is a fisherman and in one of his fishing trips he brought back a lobster that had a gold ring in its mouth. He did not return it to the sea but instead brought it back and showed it to everyone in the town. She [Pulowi] appeared one night asking for the ring. In the dream she said that if he had not shown the ring to others, she would not have returned; that it was a gift from her to my son. But since he showed it to everyone, she got upset. She came using the body of a niece, Ocari. The Pulowi spirit was inside her. She spoke saying that we needed to have a feast and drink beer. They even gave her money that the Pulowi took with her to the sea. I witnessed all of it. It was amazing. She said she was rich and had many animals. After all this happened, I bathed my son with medicinal plants (jawapia) to avoid a calamity and so this event would not affect him later. (Diotista Wouriyu October 2, 2018)

In his work, El Mar Cimarrón (The Wild Sea) (2018), Wayuu anthropologist

Weildler Guerra describes the Pulowi of the sea as the owner of the marine animals with numerous flocks of livestock in the form of sea turtles, fish, lobsters and many other sea creatures. She is not only richer in livestock than the Pulowi of the land-who only possesses deer, foxes and a few other wild animals — but also because she has red jasper and other jewels from the sea (ibid, 86). Both Pulowis serve as protectors of the wild 
marine and terrestrial animals, who for them are their domesticated animals. Fishermen and hunters alike can be punished by these other-than-human beings if they exceed themselves in their captures or are unfortunate enough to be to the liking of the Pulowi.

Mrs. Wouriyu mentioned that the Pulowi of the sea revealed herself by using the shaman Ocari Pushaina's body as a medium. During an interview with Mrs. Pushaina, she said she occasionally invites the Pulowi of the sea to assist her in healing but her main helping spirit (asheyu) is the Pulowi of the pond, Malena, described in the following sections. She added that the Pulowi of the sea is more powerful but also enjoys drinking too much; she only appears during healing rituals and does not concede to interviews as does Malena.

An Interview with Ocari Pushaina, the outsü (shaman) of Mayapo

Ocari Pushaina Riveira of the Epinayu Clan is a middle-aged woman who works part-time as a custodian at the local boarding school, is a weaver of mochilas (hand-made Wayuu bags) and an outsü (shaman) in the Wayuu community of Mayapo (See Figure 13). The outsï, and shamans in general, interact with the spirit world either through trance or possession. The shaman, with the assistance of this supernatural being, can cure illnesses whether they be spiritual or natural in origin (Eliade 1972). Perrin defines the asheyu as "an immaterial entity, spirit, soul, or power possessed only by shamans, with which they are able to communicate. From it they receive information about sickness and how to cure it; in return, the shamans are reputed to give the asheyu material goods of which they are the custodians and the sick person and his kin the providers" (Perrin 1993, 150). 


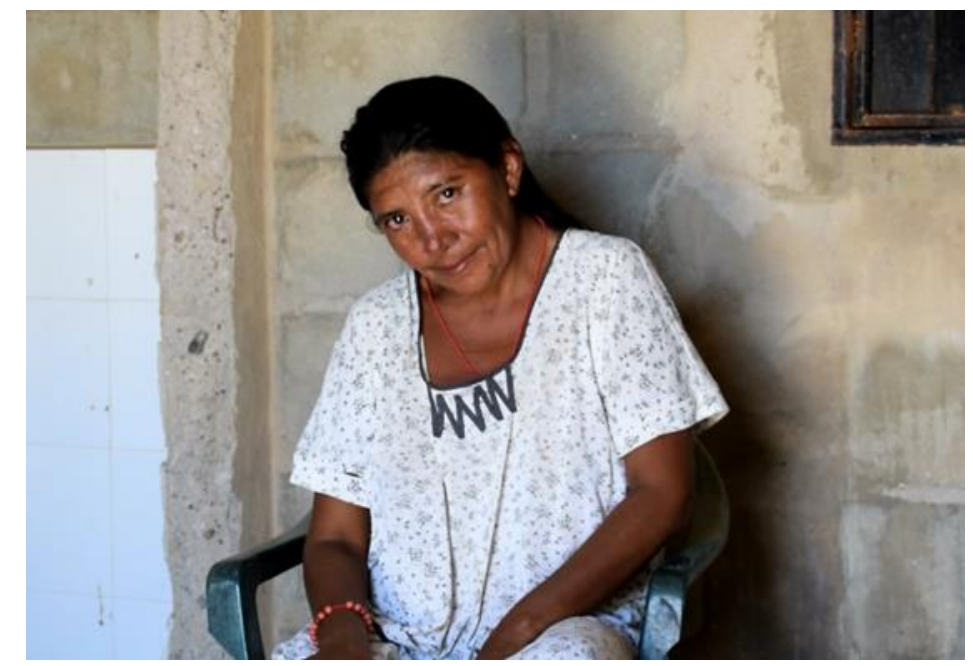

Figure 13. Ocari Pushaina, the outsü of Mayapo

Source: Photograph taken by author.

In the following passage, Mrs. Ocari Pushaina explains how she became an outsü.

Initially, I entered this line of work because I encountered a Pulowi in the pond. My little sister and I went to look for water and she [Pulowi] told me to take her to my house, and so she came with us. We were arriving at the house and suddenly she disappeared. It was noontime on a cloudy day. Nothing happened to my sister, but after a while I started to faint. At that moment my mom took me to an outsü to treat me and take out that spirit that had gotten into me. They looked for help with the Christian churches. I went to Riohacha with them, but nothing was possible. I went a month without eating anything, I just drank water. I was so thirsty and again I was taken hold of and I fainted. The spirit was coming more frequently, along with more fainting spells. She spoke to me to accept her, but I did not want to be an outsü because I was scared. Many people said being an outsü was not easy and I could end up dying because of the same spirit. After that, my two uncles talked to me, saying that I should accept her because there was nothing else to do to prevent me from becoming an outsü, and that maybe I was doing well by becoming one. I spent two years looking for ways to avoid becoming what I am today. Finally, I ended up accepting because there was no other way out. It was that or die. I have been an outsü since I was 8 years old and I have never been sick. Also, I am not the one who gives the indications of what I am going to do or what medicinal plant I use. It is the asheyu [helping spirit] that gives me the indication as to the procedure in each situation. (Ocari Pushaina September 24, 2018)

For Mrs. Pushaina, water is essential during her shamanic healing sessions when

she uses it to ritually bathe her clients or to infuse with medicinal plants. Often a 
premonitory dream by a Wayuu requires that he or she be ritually bathed during the night to dispel potential harm. Annually, during the month of December, Mrs. Pushaina holds a communal ceremony with drumming, traditional dancing and feasting known as amaichajaa tepichi, when children are ritually bathed with medicinal plants so that they will be protected from illness during the following year. During this ritual, held at 4am, her asheyu (helping spirit) Malena leads the bathing while three other asheyu are invited to participate. One spirit, Mrs. Pushaina says, is deaf and mute, the second drinks too much liquor and the third enjoys drinking coffee. Each, in turn, enters the shaman's body, and after a while bids farewell and departs. Mrs. Pushaina is left weak and tired after the event. Furthermore, those who have been in the company of the shaman when she is possessed by the inebriate spirit, attest that no matter the amount of alcohol consumed by the spirit, once she leaves her body, Mrs. Pushaina is completely sober, without even a scent of alcohol left on her breath.

Towards the end of the interview with Mrs. Pushaina, she mentioned that one of her asheyu (helping spirits) was the Pulowi from the pond and that her name was Malena. Malena uses Mrs. Pushaina as a medium to interact with the human world by entering her body when she enters a trance. People from Mayapo seek out Mrs. Pushaina who helps cure their illnesses by calling on the expertise of Malena and other asheyu. She added that if I wanted to, I could also interview her helping spirit. Thrown off guard by the invitation, I cautiously responded that it would be interesting and that I would give it some thought before giving her an answer. Perhaps from what I had been told and what I had read about Pulowi, I had mixed feelings about seeking out an encounter with a powerful supernatural being. I asked Margelis, my interpreter and member of Mayapo, 
about her thoughts on the interview with Malena and she hesitantly responded that it was up to me. I recalled that at one point during the interview with Mrs. Pushaina when we were listening to her talk about her asheyu, Margelis became increasingly anxious and interrupted the interview, saying it was a good moment to take a break and have a snack. Perrin similarly noted that Wayuu tales regarding supernatural beings, "are listened to at times with a mixture of fear and respect" $(1982,75)$.

Margelis, at the time, was a college student in her early twenties and a native speaker of Wayuunaiki and Spanish. She effortlessly moves between the alijuna and Wayuu worlds; she has even lived part of her life in Bogotá. Margelis nevertheless maintains the Wayuu worldview that raises emotions and concerns not unlike those mentioned by Perrin. Nearly two months after Mrs. Pushaina's interview, towards the end of the fieldwork, Margelis and I agreed to go ahead and interview Malena. We met with Mrs. Pushaina once again to set a date and time and review some of the possible questions I had formulated to see if Malena would find any inappropriate.

\section{An interview with Malena, the Pulowi of the pond}

The interview with Malena was conducted in a room detached from Mrs. Pushaina's house that is used to attend clients. Before beginning, we gave Mrs. Pushaina a small bag of ground coffee and sugar as she had requested. As we waited under the lumá, a sunroof used by the Wayuu to receive guests or rest, Mrs. Pushaina cleaned the room we would soon enter, while her 10-year-old son made the coffee. The room was made from construction blocks, concrete floors and two metallic windows that remained shut. Inside the room, three chairs were placed in a semi-circle as well as a tray on the floor with two small cups and a thermos with the freshly made coffee. Natural light from 
the open front door filled the otherwise empty room. Not knowing if I was addressing Mrs. Pushaina or Malena, I asked in Spanish if I could film the interview and place a microphone on the collar of her house dress. Margelis then translated my request to Wayuunaiki, the native language, and she replied that it would be fine. I then placed the microphone on her and the camera's tripod near the entrance to the room and began to film.

Unbeknown to us up until that moment, while we were still waiting outside, Malena had entered the body of Mrs. Pushaina and was the other-than-human person we interacted with from the time we entered the room. The semi-structured interview, conducted in Wayuunaiki, lasted about half an hour. What follows are excerpts from the interview with Malena the Pulowi. Her manner of speaking differed from that of Mrs. Pushaina, her voice louder, quicker and more assured. She also occasionally used the word “daughter" when addressing Margelis, something Mrs. Pushaina had never used before with her. Before we began asking her questions, she introduced herself in the following manner:

My name is Malena. What you will need me to tell you, is that I was previously inside the pond. I work in the pond. My work is not a big deal. You know that people's jobs now have a way of being. Rather, our job is to walk within the water, explore behind anything on the bottom of the pond. That's what we do. We do not work as one would say, "that's my job." This is what we do. If we see something, we pick it up. If we are shown something, we take it. And what we know is similar to what the alijunas call "doctors." Similarly, we recommend where to go. "I've already been through that," our relatives say about the things around the pond. Perhaps you will encounter something there. So, we also orient the way, as it must be, since we already know how the process is, how the pond is, because we are the owners of the pond since the beginning. What arrives there, we are responsible for arranging it; we say how it should be. "This must be so; it must be placed like this." So, we do as is told. "Take it there," we say. "Take it wherever it won't be lost." We do not toss it where we can't find what we are placing. That is how we do this. 
Malena often spoke using the first-person plural to explain the Pulowis' activities and duties in the pond. This may be because there is not just one Pulowi, but many, and she is speaking on behalf of all the Pulowis that reside in bodies of water, including ponds, wells, rivers, estuaries and the sea. She also mentions that what the Pulowis know is what doctors know, referring to their knowledge of medicines and the ability to heal. She says they are the "owners of the pond since the beginning," implying they have extensive knowledge about the pond because of their accumulated experience, giving them the authority to make decisions, recommend, orient and "say how things should be."

When asked about how she became Mrs. Pushaina's asheyu (helping spirit), she gave her version of the encounter,

From the beginning, I chose her, and I've stayed with her. I saw her washing and went to her. It looked as if she needed something and I said to myself, I better wait here by her side. There were two at the beginning, and I said I better wait with them. What could happen to them if I wait with them? I waited next to them and I don't know why, but I ended up grabbing her. I took her and ended up staying with her. I liked her. It's as if it was something good for her. We agreed to work together. I promised her that I would treat her well, that she would do well with me in the future, that nothing bad would happen to her, that I was going to help her a lot and that she wasn't going to lack necessities. I told her this and ever since I've been with her in her daily life.

Malena has been Mrs. Pushaina's asheyu for approximately 40 years and has kept her promise of providing Mrs. Pushaina with an additional income through shamanic healing and keeping her in good health. Like other initiates among the Wayuu and in other parts of the world, Mrs. Pushaina went through a near death experience in order to become a shaman. Similarly, an elderly outsü from Cardón recalled when I interviewed her in 2012 how she was first possessed by a spirit at the age of ten,

I remember that I was very young, I was completely unconscious to the point of not remembering anything. When the spirits first incorporated into me, it was as if 
I had died. People wondered what had happened to me, so my father brought an outsü. Her spirits told her that I was in a trance because there were some spirits who wanted to enter my body and wanted to know if I was willing to accept the gift of being an outsü. The outsü needed to prepare me by smoking tobacco over me and as she began to sing, I felt that something was entering my body. I said yes. (Josefa Pushaina, Cardón. March 10, 2012)

Eliade (1972:33) notes that shamanism is a magico-religious institution found in several societies the world over that is characterized by the symbolic death of the initiate, whether through sudden illness or ritual initiation, and a symbolic resurrection as a shamanic healer. After recording testimonies of shamans and other Wayuu in 1947, Pineda considered the symptoms of a potential Wayuu shamanoccurring early in the life of mainly girls, usually between the ages of 8-12-include, sudden sickness, fainting spells, convulsions, weakness, trembling of the body and dreams, visions and voices in her head asking for tobacco. Pineda attributed these symptoms to the introduction of a "wanurú, the spirit of death" (1950, 12-13). He adds that the vocation of being a shaman is inescapable; once the spirit has chosen the person, defying its will would bring death to the individual (Ibid, 13). It is also the case that those who have a parent or grandparent who is or was a shaman have the predisposition to become shamans.

Margelis: Where are you from?

Malena: My primary house is the pond, the pond of Mayapo. The pond that was there long ago. That pond has been there for many years. It used to be small stones but now it has grown. They have fixed it. Before it wasn't much, it was a very small pond. It was only stones before.

The pond Malena is referring to is called Miiruku (large pond) or Catapilamana (place of the bulldozers), because of the Caterpillar brand bulldozers and excavators that enlarged the pond in the mid-1950s. The heavy machinery dug until reaching boulders 
impossible to remove, even damaging some of the bulldozers. This pond is one of many built or amplified across the Wayuu territory during the presidency of General Gustavo Rojas Pinilla, who was a strong proponent of public works and infrastructure. While ousted from government by a dissatisfied Colombian populace, among the Wayuu he is remembered fondly for constructing so many large ponds and wind-powered wells that are still reliable sources of water after 65 years. As one Mayapo elder commented, "It was Mr. Rojas Pinilla who built the pond. He was president and that was one of the gifts he gave us. The only thing that we needed to do was give goats, chickens and fish to the alijunas who did the work with the excavators. That was a great benefit for all the Mayapo community. It was an excellent job on behalf of Mr. Rojas Pinilla. Unfortunately, he has already passed away.” (Manuel Uliana November 13, 2018).

Margelis: How do the people who live here treat the pond water? Malena: They do not waste it; they take care of it. You know there are those people who do not like that water. The owner has taken so much care of it, the one who has always been there, who preserves it. For example, if people waste it, they are punished. The water brings anguish to the owners. It is an offense to them that must be paid. If people do not respect it and bathe in it, it hurts and it costs, my daughter. It's taken care of so that they do not bathe in it. The water should only be taken out with a bucket. It should remain still and quiet. They should not disturb it. For example, if someone bothers it, that person can be dragged in by it, if it is bothered. But if someone just goes and takes the water silently, nothing happens to that person.

Several Mayapo residents recalled a case of a drowning in the pond and attributed it to the Pulowi. Later in the interview she gives her version of what happened. In the above excerpt, she switches to the third person, speaking of the owner, which is herself. She uses the terms and concepts from the Wayuu customary law that states that offences require compensation. If rules such as no bathing in the pond are not followed then the 
owners, or the water itself, can punish the offender by pulling in and drowning the

person.

Margelis: How do you feel with the water, what makes you happy?

Malena: I am happy with my water. I feel good with it, with its freshness. But if I don't have my water, I get sad and I go to some other pond that has water and refreshes me. Since my pond is fine now, I am happy with it, because it now has water. I'm grateful that this pond now has water. It must be taken care of. Do not waste it, I'm talking about the pond, since it can't go dry so soon. Because I need that pond. It's my home.

Margelis: What happens when all the water in the pond dries up?

Malena: I stay right there, in the well they dig. If they dig it, it gives water. The little water that comes out makes me feel better, as if it were a faucet. It's the same, when you dig there, water springs from it.

The Pulowi needs water both emotionally and physically. Without it she is sad and must leave her home in search of another water source. In a sense, Pulowi depends on humans to conserve the pond water so that it does not go dry and to dig wells within it when it does dry up. Consequently, global warming and the lack of pond maintenance have also affected Malena's quality of life. While many of Mayapo's inhabitants no longer use the pond, much less maintain it, there are still those that dig wells within its bed when it dries. According to one Mayapo leader, an army lieutenant spoke with Mayapo's traditional authority in 2018 about a project to deepen the pond using heavy machinery. However, the rains came in October of that year, filling the pond and postponing its maintenance until it once again dries up.

Margelis: Do you know the old man Juyá? What is he to you?

Malena: Juyá is my grandfather. He is the one who gives water. He would be my grandfather.

Margelis: Do you know others, such as Ma' a [Earth] or Maleiwa [God]?

Malena: Maleiwa has a separate place, he is the only God.

Margelis: What does he have to do with you?

Malena: He has nothing to do with us. He is alone. He is of Juyá, Maleiwa. He is the one that waters the land, mainly. The one who first gives water to the earth is Maleiwa. 
According to Malena, Juyá is not her husband, as is widely thought, but her grandfather. Others say they are a couple, but they are also enemies. Maleiwa, who Perrin describes as a cultural hero responsible for creating the first Wayuu, figures less prominent in Mayapo's collective memory and in the lives of the Wayuu. Christianity has adopted the term Maleiwa to refer to the Christian God in the Wayuu language and many Wayuu now understand Maleiwa in this sense. For example, a religious syncretism is evidenced when Malena refers to Maleiwa as "the only God" but also describes how he is intimately related to rain, essentially conflating the rain being Juyá and Maleiwa into one, "He is of Juyá, Maleiwa."

Margelis: What is water used for in your work? For example, when you cure a sick person, do you use water?

Malena: Yes, we use it. It is necessary for a person who is sick. We bring it and use it to clean the sick person. It is boiled and the water is used to massage and refresh them. That is why water is very necessary. Where else will the water come from if not from the pond, the owners say? It is necessary to take care of it. It is of great importance, the pond. From it we live. People are healed, many people have been healed thanks to it.

Water plays a preponderant role in the treatment of affected patients, purifying and protecting their body and soul. An elderly woman from Cardón explained, "each time we have disturbing dreams we customarily take a bath with abundant water so that nothing happens, given that the water expels the nightmare and drives away the bad that could occur. By not doing so there could be deaths or dire consequences" (Ana Isabel Uliana, Cardón, March 10, 2012). In other realms of life water is also used as a purifying and protective agent. Guerra (2001:118) states that outsüs bathe men that are going out to battle with gourdfuls of cold water and mouthfuls of liquor to make them stronger and more resistant against enemy attacks. When a majayut (girl coming of age) is enclosed 
during her rite of passage she is bathed and given water mixed with kasuushi (white earth) to drink daily. This concoction is considered cleansing; by bathing and drinking she'll be healthier, and her skin will maintain its tautness. Those who exhume the skeletal remains of the departed during secondary burials must also be subjected to ritual bathing with abundant water for three days to decontaminate their body from the polluting properties of the bones. Siosi (2010:21) explains that in Wayuu communities, women tend to throw water over the footprints of a departing putchipü'ü (mediator) so that the problems do not come back; young women will throw water over the chair where an undesired suitor sat and along the path where he walked, thus preventing his return. Another shaman living in Mayapo also expressed how he always uses water in his shamanic healing: in ritual baths, hot water for massaging or water mixed with alouka or other medicinal plants to be drunk by the patient. He affirmed that any type of water works, whether it be sea water, pond water, from the river or the aqueduct. In all cases, either the asheyu (helping spirit) or dreams determine what type of water and how it should be used. He shared the following account of his use of water.

Once I dreamt about a boy. The dream told me to tell his father to bathe him with twelve blocks of ice, broken into pieces in a bucket. After the bath, he stayed home and the car he was going to leave in was involved in an accident and he was saved, he was saved by that dream. After that dream he was fine. It all occurred as it was told in the dream. For example, if a dream tells me, "something will happen to that person and he won't recover, he's going to die. Bathe him with this so that he will be alright." He is bathed and what was going to occur doesn't happen. (Ebaristo Uliana October 3, 2018)

We also asked Malena if she communicates with people through dreams.

Malena: Yes of course, I make it happen. I say, "I know something and is it okay to let you know in a dream?" I ask them, and if they tell me that it is fine, if that's how I want it. Although there are other people who like it differently. It's true about the dreams, for people that I like and that they like this thing to happen to them. That's how it is, daughter. 
The Wayuu pay close attention to their dreams, which contain clues, lessons and communications from ancestors and other-than-human persons if they are interpreted correctly. For example, Wayuu epistemology dictates that groundwater can be located by following the instructions of the spirits, who reveal through dreams where to dig for it. In case of being chosen for such a prodigious gift, the person should comply with all the prescriptions or requests made by the supernatural donor.

Some dreams require a ritual to be performed so that an evil does not come to pass. A Cardón elder told that in the Apalaa community there was an ishí (dug well) belonging to a man whom the spirits told him in a dream: "You're going through hard times and in need of help. In this place there is water, dig here" (Lorenzo Ipuana, Cardón, March 28, 2012). In addition, the spirit asked him to drink liquor, sacrifice a black cow and perform the Wayuu yonna (traditional Wayuu dance). The man died, people said, because he did not go through with the indications of the spirit.

Another respected elder of the community of O'ukule in Cardón recalled that people started to dig artisanal wells in the Iruwapanalu Pond after an incident in the lagoon that existed in the place where that pond is now. He tells how long ago his grandfather died in the lagoon. Then, during the dry season, an uncle dug in the pond bed looking for water but did not find any and went home. During a dream that night someone said,

Why did you give up so fast if the water was close to where you stopped digging? Keep digging and you will see that you'll find water. But you must kill a goat and roast it right in the upper part of the pond. You all should drink liquor, and every time you dig wells you should repeat this same procedure. (Ramón Epieyu, March $30,2012)$ 
This ritual, according to Mr. Epieyu, was performed as compensation for the death of his grandfather in the pond. The well in the pond is now one of the most important sources of water during times of drought.

A prior head of the defunct public waterworks provider, Proaguas, explained how an important discovery of an aquifer in the early 1980s came about because of a dream a Wayuu had. He narrates,

I have a remarkable story. In the area of Jonjoncito, that area seems as if a volcano had destroyed everything, the stones are black. It's a zone that is difficult to find water. I began to drill and never got any water. When I was ready to leave because I was frustrated for not getting to the water, an Indian Wayuu came and told me that he had dreamed - the Indian believes a lot in dreams-that there was a point where I had to try because there was water there... So, I arrived and started to drill. I reached 24 meters and all that came out was rock. When I was about to leave, one of the Wayuu workers told me, "Doctor, why don't you make one last attempt and drill here. And so, I drilled and I got the freshest water that could come out! The man who worked with me, they called him Macho, and I named the wind-powered well Macho Man. (Roberto Gutiérrez, Chief Engineer of Proaguas August 1, 2016)

The story, as Mr. Gutiérrez mentions, is not only remarkable because underground water was found based on a dream but also because the alijuna engineer obliged the request of the Wayuu, based on a wholly unscientific, non-empirical logic. Mr. Gutiérrez noted that most importantly-besides these waterworks not costing the Wayuu a single cent—was that Proaguas hired Wayuu to work as drill operators as well as maintenance workers. Surely, as Mr. Gutiérrez's anecdote evidences, the provisioning of water in Wayuu territory by an alijuna company with Wayuu workers led to crosspollination of epistemologies. The continued hiring of Wayuu employees by governmental agencies, private companies and NGOs providing water solutions in 
Wayuu territory is commendable and necessary but not enough to level the disparities in decision-making of water governance priorities on the Guajira Peninsula.

Malena: Well I think we're done with this, daughter. I must say goodbye to you. Well, I'm leaving. Tell the person who owns the body if we are to see each other again, okay? If you ever need anything, then tell me, you hear? So that they don't say "no, she..." I will be here for you. Okay daughter, I'm leaving.

At the end of the interview, Malena asked Margelis to serve the coffee, which we drank as we asked her a few more questions. Then she requested a payment of $\$ 150,000$ Colombian pesos ( $\sim 50$ USD) for the interview, explaining that, "this sort of thing is not cheap." She counted and placed the bills I gave her in her dress pocket for Mrs. Pushaina to find and said the closing remarks above. She reached out and shook our hands, covered her face with her hands, and with a brief shudder of her head and a couple of sighs, Malena departed. Mrs. Pushaina then lowered her hands, fanned herself with the collar of her dress and told us she was tired. She later said that she did not recall the interview, as is the case when she is in a trance state. For that reason, she uses a secretary, her mother, to record what the asheyu requires of her. For our interview, her mother was not present.

\section{Discussion}

The previous chapter ended with a relational ontology interpretation of Wayuuwater relations that questioned and expanded the Western concepts of drought, water scarcity and water security. That chapter also focused on how the Wayuu overcome problems of water accessibility in a water stressed environment by using water knowledge to navigate a fluctuating waterscape throughout the year and during times of drought. This chapter has explored the metaphysical level of a Wayuu water world by examining past and present spiritual and esoteric ways of knowing held by the Wayuu 
populace, shamans and a Pulowi water spirit. Taken together, the vast amount of constantly evolving Wayuu water knowledge identified in these two chapters includes both practical and specialized knowledges or ways of knowing. The former is necessary for the daily provisioning of water for human and livestock consumption, by maintaining human to human and human to nature social relations while the latter fosters human to other-than-human social relations and is held primarily by elders, shamans and otherthan-human beings who have insights on the hydrocosmological cycle and the metaphysical curative properties of water.

My account of a Wayuu water world can be analyzed using Santos’ epistemologies of the South (2018) and critical analyses from political ecology on the integration of traditional ecological knowledge (TEK) by conventional environmental management (Nadasdy 2003). Santos' critical social theory characterizes the current era as a "desertification of alternatives" and asserts, "we do not need alternatives; we need an alternative thinking of alternatives" $(2018,6)$. In the water sector, the spread of a hegemonic water meaning as a resource and Western water management as a universal framework has led to the weakening or disappearance of multiple water ontologies worldwide. Furthermore, the displacement of Wayuu healing practices, spirituality, knowledge transmission and livelihoods by Euro-North American forms of medicine, Christianity, formal education and market-oriented, urban economies have all contributed to the waning of a Wayuu water ontology.

If an enduring, albeit less universally accepted, Wayuu ontology presents counterhegemonic alternatives to the dominant water regime, what sort of alternative thinking is necessary to stimulate their emergence? Are the alternatives comprehensible 
and commensurable with their hegemonic Western counterparts? These questions, and many others regarding validity, justice, authorship, methodology and pedagogy—if seriously thought through, discussed and negotiated within and between the Wayuu society, non-Wayuu water sector experts and researchers-could lead to the transformative intercultural translation advocated by Santos in his ecology of knowledges (Santos 2011, 35). However, as critical theory continues to uncover the deep ties between scientific knowledge acquisition and neoliberal capitalism, subjugated knowledges face overwhelming obstacles to entertain nonhierarchical dialogues with the reigning ontological and epistemic orders (West 2016).

Adopting a relational ontology approach, water's ontology—its nature of beingis different for the Wayuu from water of the Colombian society, that of other Indigenous groups or a Western scientific or layman's water ontology. This dissertation has put forth two non-conventional perspectives on the nature of water among the Wayuu, using political ecology and relational ontology as different but complementing theoretical approaches. Any other framework-i.e. socioecological system (SES), traditional ecological knowledge (TEK) or from another sub-discipline of anthropology-from someone else's positionality, would have resulted in a different comprehension of what water is for the Wayuu. Therefore, if water's comprehension is limited by the theoretical lens used and by the transcriber, then an alternative way of thinking about water is constrained by the same biases.

Defending a cultural relativist or relational ontology stance, the Wayuu way of knowing and relating to water is unique and should be understood and appreciated for its fruition and continuity despite the pervasive and shapeshifting forces of globalization and 
assimilation. Outdated anthropological models that envisioned societies located on different rungs of a ladder or levels of a pyramid, each in a unilinear progress towards an idealized (or real) society at the pinnacle, persist in the form of global indicators and objectives that direct change in the name of sustainable development and universal human rights. An alternative, ontological model would highlight the independent rise and exceptionality of world societies without defined stages of progression or hierarchical relations. Consequently, other societies should not and could not imitate or strive to reproduce Wayuu hydrosocial relations and vice versa.

It is important to ask, is integration possible between Indigenous knowledge and Western science? Are attempts at incorporating and synthesizing non-Western worldviews, traditional practices and knowledges flawed from the start, since crosscultural translation involves eradicating alterity and extracting only the information deemed useful by Western standards? Rather than asking how to integrate vastly different knowledge systems, we should ask, what might an indeterminate ethical encounter between Western and Indigenous modes of knowing entail? That is, how do we work across difference while maintaining the differences rather than trying to eradicate differences through translation and integration?

Noteworthy attempts at raising awareness of the importance of Indigenous knowledge have been underway since the 1980 s by international organizations such as the United Nations, the International Conservation Union and the Centre for Research and Advisory Network which have made efforts to gather, record and disseminate the multitude of ways that local peoples understand and relate with their surroundings (Berkes 2012:22-25). This increased awareness of the benefits of TEK has been 
continued by environmental agencies and nation-states who have extended Indigenous territorial rights and implemented policies that gives them custodianship of nature reserves. These are positive gains since Indigenous peoples have historically been unable to communicate their relationship with the land and their particular socioecological problems to the nation-state that envelops their society because their voices have been absent or underrepresented in the decision-making process of environmental management. This absence is partly due to their low population numbers-Indigenous peoples account for only 5\% of the world population with many Indigenous groups having critically low membership — and because of their marginalized status. Yet they are stewards of $20 \%$ of the earth's territory (Tauli-Corpuz et al. 2010), largely fragile ecosystems in the circumpolar regions, deserts, mountains and rainforests that are more susceptible to the impacts of climate change (IPCC 2014; Crate et al. 2009).

Nevertheless, if a Wayuu water world is to serve as a source of alternatives to the dominant water regime, as envisioned by Santos' sociology of emergence $(2011,32)$, various problems must be solved related to the adoption of Indigenous alternatives by Western scientists and resource managers (West 2016, Blaser 2010, Nadasdy 2003). Nadasdy's research on the relations between the Kluane First Nation and the government of Canada has shed light on the politics surrounding the term "traditional ecological knowledge" (TEK) and the obstacles Indigenous peoples face when they participate in conventional environmental management $(1999 ; 2003 ; 2007)$. Whether through lands claims, environmental impact assessments or resource co-management, the Kluane people were forced to participate using Western values, language, timeframes, administrative bureaucracy and understandings of TEK (Ibid). Nadasdy's ethnographic 
work among the Kluane hunters and Western bureaucrats uncovered several issues that hindered the incorporation of traditional knowledge into mainstream management and policy.

Nadasdy elaborates three key problems with the TEK framework, all of which are relevant for understanding the Wayuu relationship with water and rain. The first concerns the common Western conceptualization of TEK as a "body of knowledge" or a "set of data," rather than a way of life or worldview. Second, for the knowledge to be manageable, Nadasdy argued that TEK must go through a compartmentalization process, according to established epistemologies, professions, disciplines and institutions (Ibid, 5). Third, a distillation process is also necessary by the Western experts to make TEK comprehensible and to separate the "important" quantitative information from the "unwarranted" qualitative information $(1999,8)$.

The first critique of TEK addresses its simplification within natural resource management by compressing an Indigenous "way of life" (Nadasdy 2003) that includes metaphysics, ethics, epistemology, aesthetics and logic (Pierotti 2010) into a "body of knowledge" or a "data set" of practical information about ecosystems and management techniques (Williams and Hardison 2013). While anthropology prides itself as being holistic by using a four-subfield approach and including emic and etic descriptions, the term holistic takes on another meaning when used by Indigenous knowledge bearers. Holistic understandings and spiritual relationships between humans and nonhuman entities characterize Indigenous epistemologies, which blur the borders between the natural and the supernatural, nature and culture, "us" and "them" and other commonly used dichotomies (Kovach 2009; Smith 2012; Wildcat 2009; Pierotti 2010). 
Nadasdy notes that hunting is the single most important activity for the Kluane, as it is for many subarctic Indigenous peoples. For them, Nadasdy emphasizes, "hunting is synonymous with life itself" $(2003,63)$. Because of a completely different history and understanding of hunting for Euro-North Americans, the activity is only superficially comparable as "simply a matter of killing animals" (Ibid). Therefore, any "traditional knowledge" about hunting produced and communicated by the Kluane would travel through various layers of cultural, emotional and linguistic filters within the minds of non-Kluane interlocutors that would distort the meaning and render it legible only as chunks of practical data disassociated from the rest of Kluane life. If hunting knowledge is essential for Kluane survival, rain and water source knowledge would be the Wayuu equivalent. While the Kluane have limited options to obtain food in the Yukon and must rely on hunting and fishing, the water scarce Guajira Peninsula obligates the Wayuu to hone various water management strategies based on ancestral knowledge.

A second critique by scholars of Indigenous epistemologies underscores how compartmentalization is common in Western science, including scholarship within the “TEK” framework (Deloria 1995; Nadasdy 1999; Cajete 1999). The social sciences are segregated from the natural sciences and each one groups disciplines that focus on distinct aspects of society and nature, respectively. Subdisciplines exist within each discipline, further fragmenting and narrowing the scope of research into topical, theoretical and regional subdivisions. The advantage of compartmentalizing is the deep and sustained engagement with specificity, allowing scientists to accumulate information and devise solutions on particular material and immaterial elements of this world and beyond. However, this advantage is also compartmentalizing's downside, expressed in 
the following way by a Kluane hunter, "none of these people knows anything outside of their own specialty... these specialists attempt to 'educate' one another; and even then no one really understands the environment as a whole" (Nadasdy 1999, 6). Many scientists and environmental managers are aware of this deficiency and inter-, cross-, or transdisciplinary studies and projects are growing but remain the exception rather than the norm.

The compartmentalization of knowledge occurs consistently when non-Wayuu professionals interact with the Wayuu to provide information on a wide range of topics. Agronomists or agricultural engineers instruct Wayuu farmers on improving farming techniques, nutritionists advise the Wayuu what to eat, social workers facilitate communication between the Wayuu and the alijuna, engineers lead construction projects, marine biologists or fisheries scientists monitor the practices of Wayuu fishermen, veterinarians check the health of Wayuu livestock, teachers teach school subjects that reinforce the partitioning of knowledge, and so forth. This type of knowledge transmission largely flows one way, from the alijuna expert to the Wayuu. Thus, each professional is equipped with specialized (Western) knowledge employed to impart information yet is ill equipped or unwilling to receive information.

When Westerners study the Wayuu, their ways of knowing are compartmentalized using common categories, such as Wayuu subsistence practices, Wayuu law, Wayuu ethnomedicine and Wayuu cosmology. As I have tried to convey in this dissertation, water permeates all aspects of Wayuu society; each category mentioned above would only partially be understood if water were to be ignored. Even Wayuu law, where water may be considered less relevant, is based on compensation through the 
exchange of livestock with a significant water demand. When treated as a distinct category, water use and management by the Wayuu is often limited by the epistemological framework of the discipline employed. Unless theologians, philosophers or anthropologists interested in shamanism (like myself) are hired to study water's supernatural attributes, this realm of reality would be largely ignored by a conventional water management framework.

If cross-cultural intelligibility is an obstacle for mutual understanding so too is cross-disciplinary intelligibility within Western science. The specificity of knowledge and specialized terminology (ontology or hydrocosmological cycle, for example) limits the interest and comprehension to a select group of readers. In this sense, if most scholars are hard-pressed to assimilate the message conveyed in publications beyond their very specific area of expertise, then the task is daunting for politicians, policymakers, environmental managers and water sector experts.

Western scientists overcome the incommensurability of Indigenous knowledge by choosing what to incorporate and what to ignore, a process Nadasdy terms distillation $(1999,7)$. This third critique reveals the ontological and epistemological divide between Indigenous and Western knowledge production. Translation of TEK goes through a process of distillation that identifies and incorporates to some degree the practices and quantitative empirical observations related to geographic and demographic information of specific plants, animals and other biospheric events. Nadasdy explains how the distillation process occurred in the Yukon with Kluane TEK,

the imperative of incorporating TEK into the state management system has caused researchers to focus on extracting from communities only that kind of information which can be expressed in a few very specific ways - that is, in forms that can be 
utilized within the institutional framework of scientific resource management, such as numbers and lines on maps contained in reports, books, and other written documents - and then to interpret it in a manner consistent with the assumptions of scientific wildlife management. $(1999,9)$

Devalued or ignored are the non-quantitative understandings, principles and values transmitted through stories and explanations of social relations with nonhumans that reinforce the way of life of that particular Native group (Ibid).

Lastly, Nadasdy and others question whether sharing Indigenous knowledge actually benefits the native communities or if it perpetuates unequal colonial relations that further concentrate power in administrative centers rather than transfer power to the Indigenous groups (Williams and Hardison 2013; Nadasdy 2007). Indigenous peoples may be further disempowered by their continued role as an object of study and a source of information by institutions designed to prioritize cause and effect, cost-benefit, efficiency and simplification.

The ontological divide between Euro-North American modernity and Indigenous peoples is both an obstacle for Indigenous epistemologies to be incorporated by Western science and for Western science to expand its explanatory power and adherence among small societies of the Global South, like the Wayuu. The following chapter addresses the possibility of incommensurability — whether ontological, cultural or due to uneven power relations - by identifying and analyzing failed water interventions and white elephant waterworks introduced by foreign and national organizations on Wayuu territory. 


\section{FAILED WATER INTERVENTIONS AND WHITE ELEPHANTS ON WAYUU TERRITORY}

\section{White elephant:}

A possession that is useless or troublesome, especially one that is expensive to maintain or difficult to dispose of.

The Oxford Dictionary

A public construction that has a negative impact on the community because it has been abandoned or is unfinished, its cost exceeds the benefits of its operation, it is not used, or its use is different from the one for which it was created.

Secretary of Transparency, Government of Colombia

Look at the aqueduct that the community has. They never made an official handover and that is an immense white elephant in the community that has never worked as such.

Mayapo leader, October 2018

Introduction

In The Anti-Politics Machine, James Ferguson problematizes the concept of "development" by analyzing the discourse and mechanisms global entities such as the World Bank employ to interpret and intervene in the impoverished Global South. He also reveals the conflation of two widespread usages of the term development. The first entails "a progression toward a known end point, usually modern industrial capitalism," while the second usage means "the improvement in quality of life or standard of living, and the elimination or alleviation of poverty" $(1990,55)$. If this conflation links Western modernity with quality of life on the one hand, and non-Western modes of living with poverty on the other hand, then development become a hegemonic apparatus to extinguish alternative livelihoods by imposing Western standards of living. 
This chapter will provide ethnographic descriptions and analysis from the critical social sciences to question the nature and intent of water development interventions on Wayuu territory. I begin by exploring the concept of "white elephant" water projects and their paradox of both providing water security and water insecurity. The second section provides examples of failed or faulty waterworks throughout the Guajira Peninsula to illustrate a generalized pattern of poor construction and abandonment of water interventions. I then examine in greater detail two interventions that were meant to improve water quality and quantity by introducing modern water supply systems. Ethnographic data from the "beneficiary" communities and text analysis of World Bank reports are used to question the sustainability and commensurability of introduced waterworks in Wayuu communities. I end the chapter by once again placing in conversation a political ecology and an ontological approach to understand more holistically the water problem on Wayuu territory.

Why water security is water insecurity and vice versa

Global mandates such as the UN's sixth Sustainable Development Goal (SDG) of ensuring availability and sustainable management of water and sanitation for all, are adopted by funding agencies, development institutions and nation-states whose national water policies are transmitted to the regional and local water and development sectors for implementation (discussed in Chapter 4). The resulting institutional actions-whether targeting water access, provision, distribution, quality, quantity, hygiene or sanitationintroduce an ideological or material change to which Indigenous societies, their leaders and community members must adapt. The installation of high-tech water treatment plants, desalinization plants and solar powered deep-water wells serves to highlight the 
confluence of multiple scales of water governance from the global to the local, becoming sites of politically contested water ontologies (Yates, Harris and Wilson 2017). These waterworks are meant to increase water security for the Wayuu communities but often end up producing the opposite when they break down. Consequently, Mayapo and many other Wayuu communities have water supply systems that produce water insecurity and increased vulnerability.

Over the past century, the upsurge in the number of waterworks - mainly windpowered drilled wells, ponds and reservoirs - across the water-deprived Wayuu territory has increased the availability of water for both human and livestock consumption, creating or improving important primary, secondary and tertiary water sources, as described in Chapter 5. On the other hand, the new or repaired water infrastructures also result in unequal access to improved water sources between beneficiary and nonbeneficiary communities, introduce or fuel power struggles among the local leadership over the management of a public construction on collective lands and increase the dependency on non-local experts for their maintenance and repair; these services are often much more delayed and costly than if they were to be accomplished locally. Consequently, when a breakdown occurs, there is a high risk that the community will be left with an abandoned water system, one that is useless or too expensive to maintain, a perfect example of a "white elephant."

Despite the construction of public waterworks in the $20^{\text {th }}$ century and the increased water interventions of the early $21^{\text {st }}$ century in Wayuu territory, efforts to provide water for the Wayuu have fallen short of solving the limited access to secure water sources. On the contrary, Saler notes that conventional water management projects 
on Wayuu lands have stifled local initiative in the construction and maintenance of traditional ponds and wells, as they increasingly opt to use, but not maintain, the public works instead (1986:41-42). Most interviewees in the three study areas agree that there was greater respect and attention given to the local water sources in the past. In Mayapo, a resident noted that the local pond lost importance, "ever since the old men died, who were the ones who did maintenance to the fencing. They didn't let people bathe near it, so that the dirty water wouldn't flow in. Now, it doesn't have a fence" (Eduardo Gomez, September 26, 2018). An elderly woman from Cardón compared the current and past water situations in the following manner,

Water is more accessible now because there are many water sources, but the quality of the water was better before. There was no contamination, nobody dirtied it. Since it was very scarce everyone took care of it. Neither did they relieve themselves near the sources. But now nobody is careful with the multiple sources that exist." (Corina Pushaina, March 16, 2012)

These statements from residents of Mayapo and Cardón summarize a common sentiment among the Wayuu about the water quality and quantity of their traditional water sources. Water sources were better taken care of and the water was cleaner in the past compared to the increased number of present-day water sources whose water quality has suffered because of a loss of local interest, initiative or ability to maintain them.

The loss of agency in local water governance is compounded by the increased reliance on complex, costly and unsustainable technology that requires non-Wayuu experts for their maintenance and repairs. This situation has weakened Wayuu resilience and self-determination because even though state and non-state organizations currently pay increased attention to water supply and quality, waterworks on Wayuu territory have by and large been unsuccessful. Nevertheless, public, private and nongovernmental water 
organizations have positioned themselves within Wayuu territory, gaining more authority and causing disruptions in the traditional water governance structure and practices.

The discourse by the organizations providing water supply solutions on the Guajira Peninsula ignore or do not comprehend the negative impact of their interventions and highlight only the positive impact they have on the beneficiary Wayuu communities. Their reports, websites and YouTube videos expound on the benefits that range from better water access, a dramatic decrease in time spent fetching water, the installation of clean energy technology, improved water quality, quantity, hygiene practices and sanitary conditions, and an overall improvement in the Wayuu standard of living. Did anything not go as planned? How are these projects holding up six months, one year or five years later? These questions go unanswered and unpublished. The reality in Wayuu territory is more akin to the situation of development projects studied by James Ferguson in the 1970s in the African country of Lesotho in which, "the history of development projects in Lesotho is one of almost unremitting failure to achieve their objectives...by any criteria, successful projects have been the exception rather than the rule" (1990, 9; see also Murray 1981, 19).

\section{White elephant waterworks}

The three epigraphs of this chapter show how the term "white elephant" maintains the essence of its early symbolism as a valuable but useless possession. As a venerated animal in Buddhism across Southeast Asia, in the $17^{\text {th }}$ century a white elephant was purportedly gifted by the King of Siam to courtiers in disfavor, bringing financial ruin to its owners because of its high maintenance (History Extra 2019). Thus, a white elephant presents a paradox both in its historical origin and current figurative sense; it is of great 
value but also brings with it great cost. Prasser describes and gives examples of white elephants in Australia as "big, mega or iconic infrastructures" that embody the misallocation of funds, reveal poor project management and fail to have a clear purpose or function $(2007: 47)$.

In Colombia the term white elephant (elefante blanco) has been wholeheartedly adopted by the government and civil society to designate uncompleted, abandoned or nonfunctional construction works associated with squandered money and corruption. A search of the term on the websites of Colombia's two most important newspapers, El Tiempo and El Espectador, resulted in 1,875 hits. Confronting the ubiquity of white elephants across the country, in 2014, the Secretary of Transparency of the Presidency of Colombia and the Ministry of Information and Communication Technology, released a cellular phone app, Elefantes Blancos,

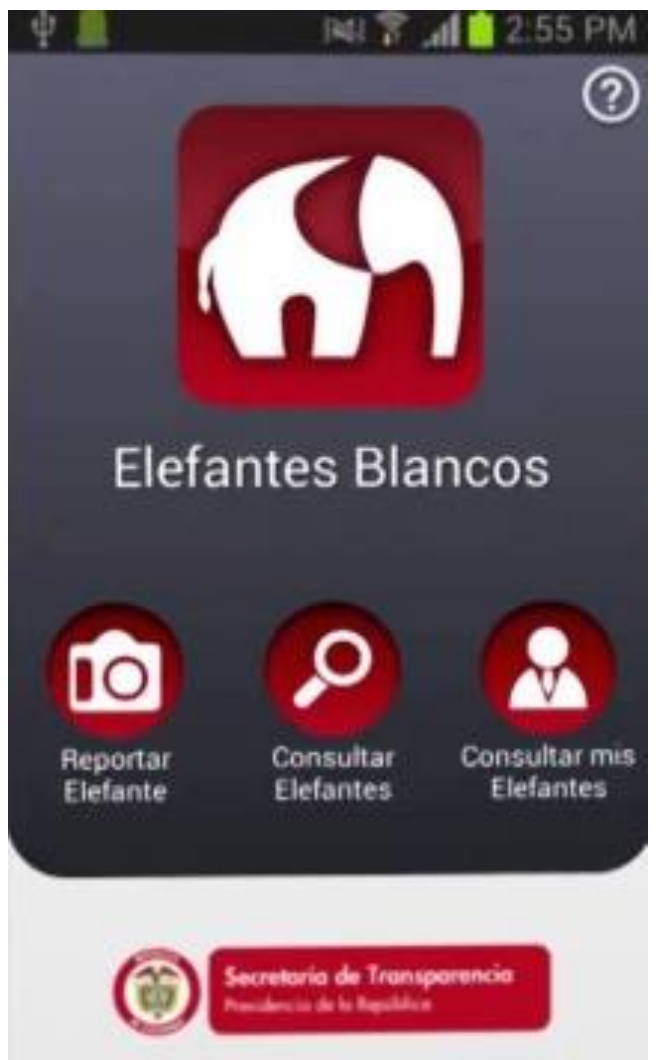

Figure 14. White Elephant app Source: Secretaría de Transparencia de la Presidencia de la República as a way for the citizenry to assert social control and take an active role by reporting directly to the government white elephant public works (See Figure 14). On November 13, 2019, the National Comptroller's Office asserted that it identified 1,193 "white elephants" with a total inversion equivalent to \$2.5 billion U.S. dollars (Iguarán 2019). This same year, a bill to register and monitor works denoted as white elephants had been 
approved by the Colombian House of Representatives and is now being debated within the Senate, which will decide if it becomes law (Jerez 2019).

White elephants and the provision of unsustainable waterworks on Wayuu territory also take an emotional toll on the individual "beneficiaries," the recipient community and the Wayuu society in general. Disillusionment with the promise of water and a growing distrust of outsiders' efforts result when the infrastructure remains unfinished, functions sporadically or is abandoned for long periods of time or indefinitely. When waterworks break down, a community may be more vulnerable than it was before the intervention because of an increased dependency on the introduced water supply and the foreclosure of local alternatives to the water shortage.

Between August and November 2017 and again in May of 2018, I carried out assessments of the state of the local water sources in 16 rural Wayuu communities in the municipalities of Uribia, Manaure and Riohacha. The findings illustrate how water management in La Guajira has emphasized the installment of improved water supplies while disregarding the monitoring and continued maintenance of the waterworks. Of the 16 communities, ten had an improved water supply, either a drilled well or a treatment plant. Within these ten communities, there were 15 improved sources, three communities having more than one improved source. Seven of these 15 waterworks were not functioning, two had limited functionality and six were functioning properly (See Table 4). Comparing older technology (wind-powered drilled wells) to newer technology (solar-powered drilled wells, treatment and desalinization plants), the older technology proved more sustainable ( $100 \%$ of sample functioning) than the new technology $(20 \%$ of sample fully functional). 
Table 4. State of water supply systems in 16 Wayuu communities

Local water supply systems in 16 Wayuu communities (August-November 2017)

\begin{tabular}{|c|c|c|c|}
\hline Municipality & Community & Improved water supply & State of supply \\
\hline \multirow{12}{*}{ Uribia } & \multirow{2}{*}{ Wososopo } & Wind-powered drilled well & Functioning \\
\hline & & Reservoir w/treatment plant & Functioning \\
\hline & Wuarpana & $\begin{array}{l}\text { Piped water from treatment plant in } \\
\text { Siapana }\end{array}$ & Not functioning \\
\hline & Topia & No improved water supply & N/A \\
\hline & Parajimaru & Reservoir w/treatment plant & Not functioning \\
\hline & \multirow{2}{*}{ Punta Espada } & Treatment plant (inside naval base) & Functioning \\
\hline & & Solar-powered drilled well & Not functioning \\
\hline & Palants & No improved water supply & N/A \\
\hline & $\begin{array}{l}\text { Cabo de la } \\
\text { Vela }\end{array}$ & Desalinization plant & Not functioning \\
\hline & Carrizal & No improved water supply & N/A \\
\hline & Soluipa & No improved water supply & N/A \\
\hline & Cardón & Drilled well with treatment plant & Not functioning \\
\hline \multirow{7}{*}{ Manaure } & $\begin{array}{l}\text { Piedras } \\
\text { Blancas }\end{array}$ & Desalinization plant & Not functioning \\
\hline & Chuchupa & $\begin{array}{l}\text { Piped water from El Pájaro w/ treatment } \\
\text { plant }\end{array}$ & $\begin{array}{l}\text { Limited } \\
\text { functioning }\end{array}$ \\
\hline & Couchachon & No improved water supply & N/A \\
\hline & \multirow{4}{*}{ Mayapo } & Treatment plant w/ distribution system & $\begin{array}{l}\text { Limited } \\
\text { functioning }\end{array}$ \\
\hline & & $\begin{array}{l}\text { Wind-powered drilled well w/ } \\
\text { distribution system }\end{array}$ & Functioning \\
\hline & & Treatment plant in school & Not functioning \\
\hline & & Wind-powered drilled well in school & Functioning \\
\hline \multirow{2}{*}{ Riohacha } & El Ahumao & Wind-powered drilled well & Functioning \\
\hline & Perraput & No improved water supply & N/A \\
\hline
\end{tabular}

Source: Fieldwork carried out by the author

Six examples of failed or faulty waterworks

The following six waterworks are a sample of the nonfunctional water supply systems in Wayuu territory that point to a broader pattern of unsustainable waterworks. Subsequently, two more examples of problematic water projects will be described and analyzed more fully, based on extended fieldwork. The first is from the Wayuu town of Mayapo with a malfunctioning aqueduct, and the second, the unsuccessful attempt to 
provide purified water to hundreds of Wayuu communities in the Upper Guajira, including those of Cardón and Irraipa.

1. Piedras Blancas desalinization plant: In April 2016, amidst praise-worthy news coverage, the South Korean government donated a water desalinization plant to the Wayuu coastal community of Piedras Blancas in the municipality of Manaure with a cost of $\$ 360,000$ USD. The plant was to benefit 7,500 people from the community and surrounding area, by converting 150,000 liters of sea water to potable water per day (Presidencia de la República 2016). The responsibility to oversee and maintain the infrastructure was assumed by the National Unit of Risk and Disaster Management (UNGRD), the Colombian Red Cross and the Municipality of Manaure. Yet three months after its installation in April of 2016 the desalinization plant broke down and has been non-operational ever since. A local leader of Piedras Blancas stated that the Red Cross has attempted to dismantle and take the plant from the community, but the community leaders have not allowed it. They are adamant that the waterworks was donated to the community and must remain in the community, whether functioning or not (Juan Pushaina, October 12, 2017).

2. Putaimaru reservoir: The Putaimaru reservoir near Punta Espada in the extreme northern zone of the municipality of Uribia was built in 2006 because the local leader and mediator (putchipu) Edicto Barrozo negotiated its construction. Punta Espada's inspector recalled that it was not built properly; the construction workers used mostly sand and loose dirt and then covered it with a thin layer of rocks and concrete, making it "pretty on 


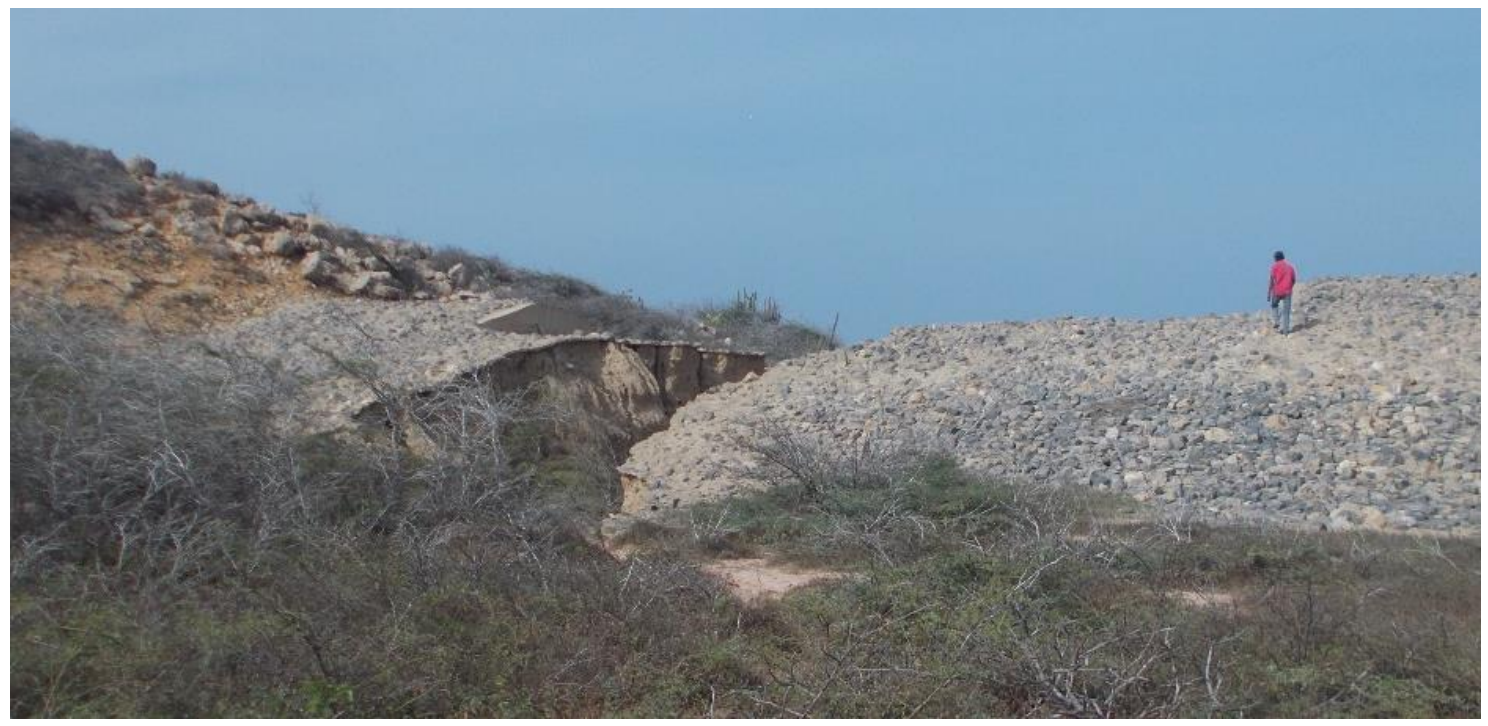

Figure 15. The collapsed Putaimaru Dam in 2017

Source: Photograph taken by author

the outside" but ultimately unstable. He went on to explain, that upon the first heavy rainfall many people had gathered around the large reservoir, happy with the prospect of having such a large water source. Unfortunately, as the reservoir filled with water the dam suffered a rupture and a section four meters wide collapsed, rendering it useless (See Figure 15). According to the testimony of the local leader of Punta Espada who witnessed the collapse, said "the dam lasted one hour." Eleven years later, during a visit to the site in 2017 , the dam had yet to be repaired.

3. Cabo de la Vela desalinization plant: The desalinization plant of Cabo de la Vela, the top tourist destination in La Guajira and in Wayuu territory, has been functioning irregularly for years. In order to provide water to the local population and the large number of tourists who visit, water needs to be purchased from water trucks that bring the liquid from the aqueduct in Uribia 40 miles away. During an inspection visit to the plant in August 2013 with representatives of the public and private water sector, along with local leaders, the local operator of the plant told us that the filters had been 
damaged. One engineer observed that the incorrect placement of the water intake tube that suctions the seawater and the lack of percolation were two factors that allowed organic material to reach the membranes, eventually forming a viscous substance that damages them. Furthermore, the tube that pumped the water from the plant to the raised water tank for its distribution to the town was in shambles. During another visit to Cabo de la Vela in September 2017, a concerned local leader expressed,

Water has never been optimal for consumption. When [the desalinization plant] is sort of running we barely have enough water to bathe and wash clothes. We are forced to buy water from Uribia. We've gone four months with the plant damaged and there is no plan B to bring water in tanker trucks. There is a huge need for fresh water here (Aaron Laguna, September 26, 2017).

4. Cardón's desalinization plant: The installation of a drilled well and desalinization plant in the community of Kasiischon in the Cardón village district (corregimiento) began in 2012, and after two years of interrupted construction, it became operational in 2014. Since then, it provides an irregular water supply service. When a breakdown occurs, the leader of Kasiischon must travel to the municipality office in Uribia and place a request for a technician to find out what the problem is and fix it. The response is usually delayed, and she has had to make several trips to follow up on the request and pressure the staff to consider her case before the multiple requests similar to hers. When I visited the community in October 2017, the treatment plant was damaged and had been awaiting repairs for three months.

5. Punta Espada's solar-powered drilled well: In 2015 Oxfam and the Ministry of Housing installed a solar-powered drilled well in Punta Espada, along with three 2,000liter plastic storage tanks, two enclosed rooms for bathing, a laundry washing station and a grease trap (See Figure 16). 


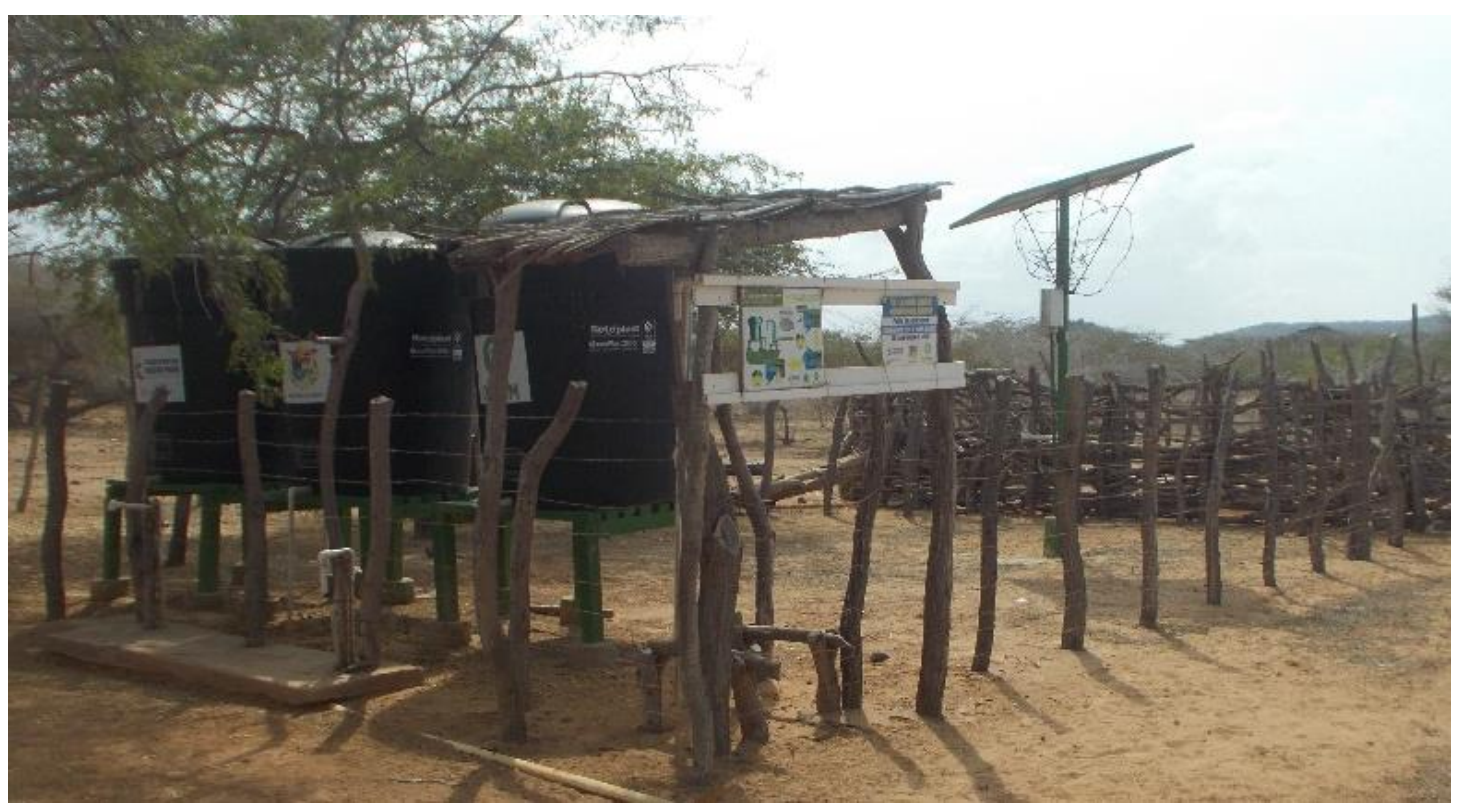

Figure 16. Punta Espada's damaged solar powered drilled well (May 2018)

Source: Photograph taken by author

In a press release, an Oxfam representative highlighted the benefits of the

photovoltaic system, which eliminates the need for gasoline, required by the wells that run with generators. The representative further highlighted that this system did not require batteries, which typically wear out quickly and raise the maintenance costs for the community (El Tiempo February 16, 2016). Nevertheless, during an inspection visit in May 2018 with Jorge Girnu, a local leader of Punta Espada, he explained that the system had broken down in December of 2017, six months earlier. Since Oxfam had finished its project and was no longer present in the province, the residents were not able to report the breakdown to that entity. An engineer from the nearby naval base in Punta Espada told Mr. Girnu that the problem seemed to be in the inverter, but he did not have the expertise nor the parts to fix it. In November of 2019, Mr. Girnu communicated to me that the water system had yet to be fixed. 


\section{The Cercado Dam: The controversial damming in 2010 of the Ranchería}

River - the principal river of the province and the only river that runs through Wayuu territory — has yet to achieve the objectives it was built for: 1) delivering water to two irrigation districts, 2) supplying water to nine municipal aqueducts and 3) providing hydroelectric power to a neighboring community. The Cercado Dam, winner of the 2006 National Engineering Award, cost \$250 million USD (\$700 billion COP) to build and has a capacity to store 198 million $\mathrm{m}^{3}$ of water (See Figure 17).

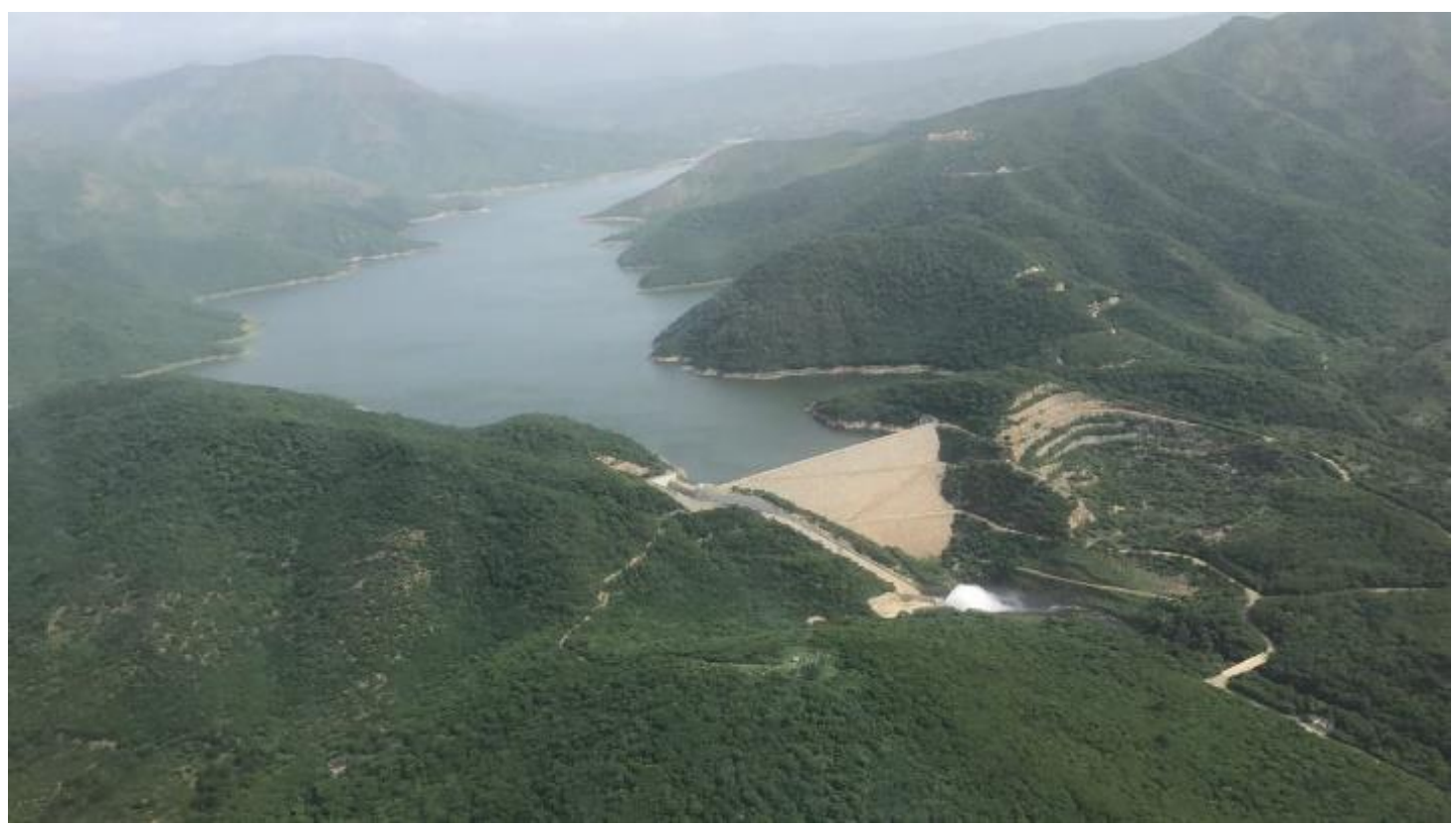

Figure 17. Aerial view of the Cercado Dam Source: Procuraduría General de la Nación https://twitter.com/PGN_COL/status/1012010015757144064

This notwithstanding, the national Comptroller's Office reported in 2017 that it has only served to store and regulate the flow of water (Contraloría General de la Nación 2017). For this reason, and with such high expectations and an even higher investment, the stalled megaproject is now being called another "white elephant" by local farmers and residents who stand to benefit from its operation (CONtexto Ganadero 2017), by the 
Environmental Conflicts Observatory (UN Periódico Digital 2019) and by several local, regional and national media sources (El Espectador October 26, 2018; El Heraldo August 22, 2019; La Guajira Hoy September 2, 2019; Caracol Radio December 16, 2017). In 2015 the Inspector General of Colombia, Alejandro Ordóñez stated "The main problem of the region [La Guajira] is not the drought, but corruption, because royalties have been stolen for many years and the public works needed to withstand natural events that, while foreseeable, were not planned for" (Brodzinsky 2015). The same article that published this quote denounced the overuse of the river water downstream from the dam by large rice and palm cultivators, ranchers and the Cerrejón coal mining company that has left little to no water for the Wayuu who live along the river further downstream (Ibid).

Vidal Parra (2019) documents the legal battles that some Wayuu representatives are waging for the human right to water with the Inter-American Commission of Human Rights, the Bogotá High Court and the Colombian Supreme Court of Justice. He claims that the "Cercado Dam turned a public good such as the waters of the Rancheria River into what is in practice, a private asset that only supplies water for the mining project and a few landowners" (Vidal Parra 2019:52). These accusations of inequitable distribution and consumption of water by the public and private sectors in detriment to the Indigenous inhabitants who live along the river can be summed up with Robert F. Kennedy Jr.'s phrase that dismantles engineering logic and captures the power-infused relations inherent in dam construction and river use: "We are witnessing something unprecedented: Water no longer flows downhill. It flows towards money (cited in Swyngedouw 2009, 56). 
Mayapo's malfunctional water supply system

Water treatment plants across the Wayuu territory have been by and large unsustainable and Mayapo's is not an exception. After two years of setbacks, Mayapo’s aqueduct began functioning in 2013 with a structural flaw in the elevated water tank. The water provider decided to redirect the purified water to a smaller tank located next to it from an older distribution system in Mayapo (See Figure 18).

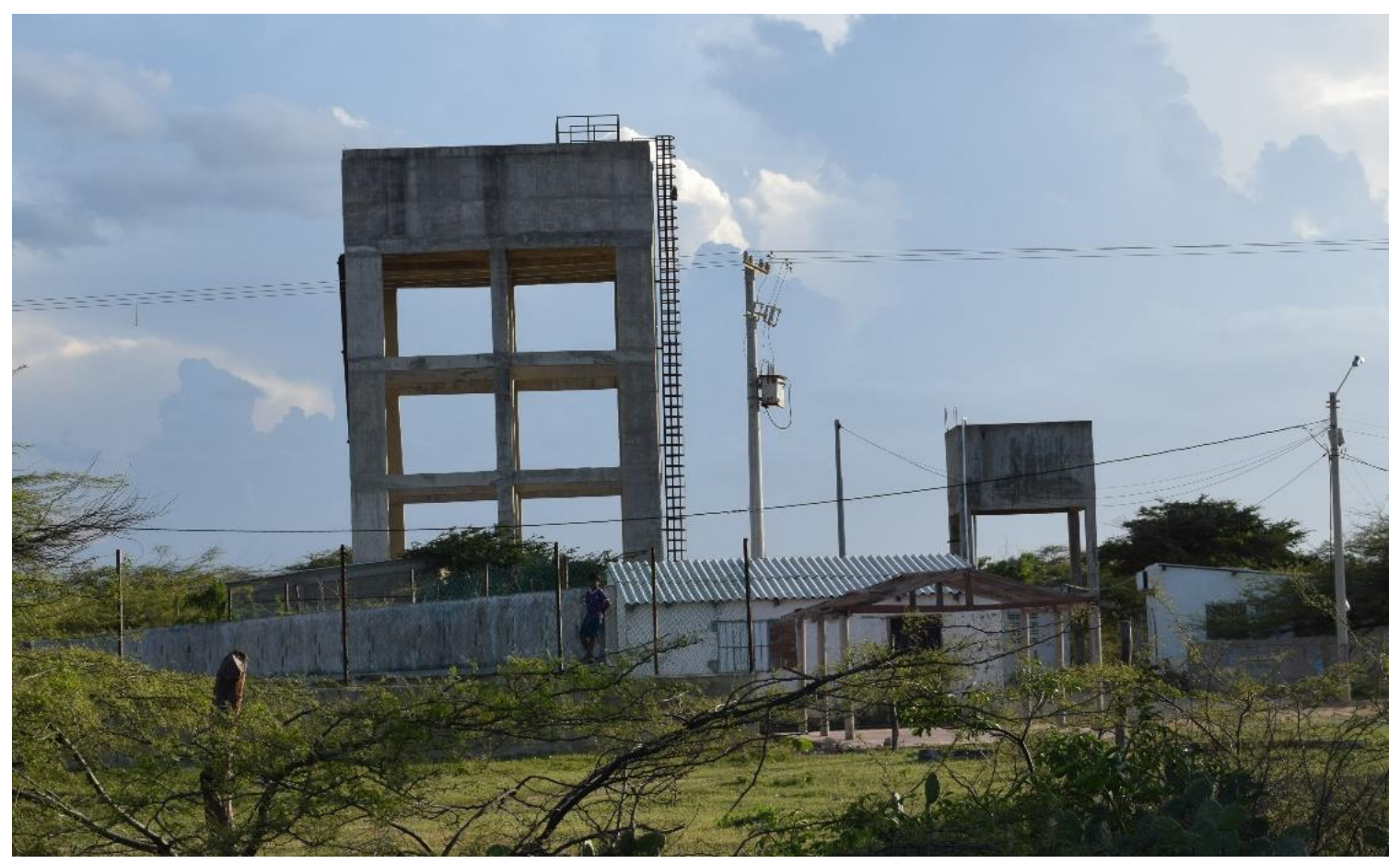

Figure 18. Mayapo's inoperative (left) and operative (right) elevated water tanks Source: Photograph taken by author

This switch drastically reduced the amount of water the residents would receive; only a third of the households receive water from the treatment plant for only one hour per day, excluding Sundays. A resident of Lower Mayapo (western side), summarized the installation in the following manner,

That project was led by the mayor, Mr. "Tico” Martinez. They came to install everything, the elevated tank, everything was alright until "Tico" leaves and 
"Kika" enters. When the project was completed, it was assumed that they did an initial test and it worked. That was the day when fresh water first came to all of Mayapo. They said, "well, it will be a good project." It turns out that the elevated tank did not work, it didn't hold up; it began to break. It wasn't apt for the amount of water that was needed for the town. So basically, the elevated tank was poorly constructed. If it is filled it could explode and the people who are closest would be the most affected. They also didn't do the pipelines well. They made "rice with mango," they didn't do anything right! (Amarilis Iguarán October 3, 2018)

The aqueduct in Mayapo was co-financed by the Municipality of Manaure and the Ministry of Housing in 2011. It uses a deep-water well already operating in the community and a water treatment plant that desalinizes and purifies the brackish water using reverse osmosis. The water is then pumped to the small elevated water tank, which also seeps water, for its distribution to Mayapo's residences (See Figure 18). The plant is connected to the community's electric grid, which provides irregular service and occasional power surges, dips and outages that affect its operation. Initially, a standard rate of $\$ 9,000$ Colombian pesos ( $\$ 4$ U.S. dollars) per household was to be charged plus a variable cost based on household consumption. To measure water usage, water meters were installed in all of Mayapo's households connected to the system (See Figure 19).

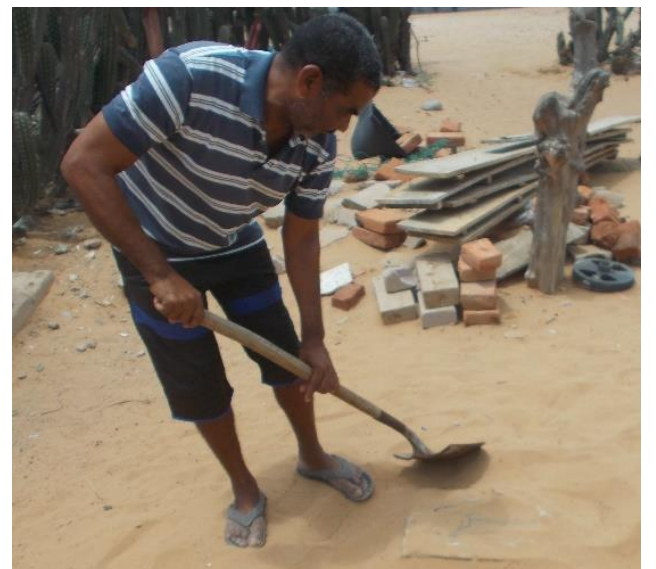

Figure 19. Mr. López unearthing his unused water meter Source: Photograph taken by author
Furthermore, a water cooperative made up of local leaders was created by the community, with the support of the Chevron-Ecopetrol Association, to oversee the operation and maintenance of the aqueduct. This Wayuu water cooperative, Kotta Supüla Kasaa Anas

Woumainpa E.P.S. (United for the Wellbeing of our Territory), was the first initiative of its kind 
among the Wayuu. While the cooperative had been accredited as a public utilities' provider (E.P.S.), was supported by the Chevron-Ecopetrol Association, was led by competent and committed individuals and had a strong organizational structure, it failed to materialize. Mr. Pedro Siosi, the cooperative's coordinator, affirmed that it encountered resistance from the municipal government, which had initially recognized the Wayuu cooperative as the aqueduct's operator but ultimately chose a regional, private-sector water provider, Triple A. The municipality chose, or was pressured, to follow the conventional water management regime rather than give the opportunity to a grassroots Wayuu water cooperative to demonstrate its capability and potential to manage the local waterworks. Mr. Berli López (shown in Figure 19) was involved in the initial formation of the cooperative and was assigned to supervise the proper functioning of the water meters. However, most of the town's water meters are now buried, broken or in poor condition, having never been used. He says the only remnants of the cooperative is an abandoned one-room office next to the treatment plant that was built by ChevronEcopetrol. Now, only one person from the community, hired by Triple A, serves as operator of the treatment plant and reports any malfunction to the provider, whose office is in the municipal capital of Manaure.

Map 9 is a satellite image of the town of Mayapo showing a sample of 60 of Mayapo's 306 households (19\%). Mayapo has two water distribution systems; the older, generator-powered drilled well (green flag) and the newer water treatment plant (blue flag). Each has its own set of piping to all the houses in Mayapo except to a few distant ones and those recently built. The town also has two wind-powered drilled wells (yellow flags), both installed by Chevron-Ecopetrol. One is a communal well with a concrete 
storage tank in the southeastern section of the town and the other is located within the Laachon Mayapo Indigenous Boarding School in the southwestern sector of Mayapo. The latter provides water to a treatment plant that is also on the school property (red flag). While the two wind-powered wells are currently operational, the school's treatment plant has not functioned since 2017. In order to provide drinking and cooking water for the 1,600 students, the foundation that administers the school must purchase water from the cistern trucks every three to four days. Just south of the community is the Miiruku Pond, Mayapo's traditional water source - home to the Pulowi, as described in the previous chapter - and which continues to be an important water source for the community. The generator-powered drilled well was installed by the Chevron-Ecopetrol Association and the Municipality of Manaure during Mayor Sara Aguilar's administration in 2000 and distributes untreated, brackish water on a continuous basis to about $15 \%$ of the households, mainly in Upper Mayapo, the eastern section of the community (See Map 9). It also provides the water used by the treatment plant. The privileged households in Mayapo regarding water access are those marked in pink. These residences make up approximately $11 \%$ of the households and, because of their location and connectivity to both distribution systems, receive both treated and untreated water. The blue points, $25 \%$ of the sampled households, are those households that receive treated water (one hour per day). Diogenis Epinayu, a local leader of Mayapo whose residence receives piped treated water, had this to say about the unequal access to clean water in the community, 


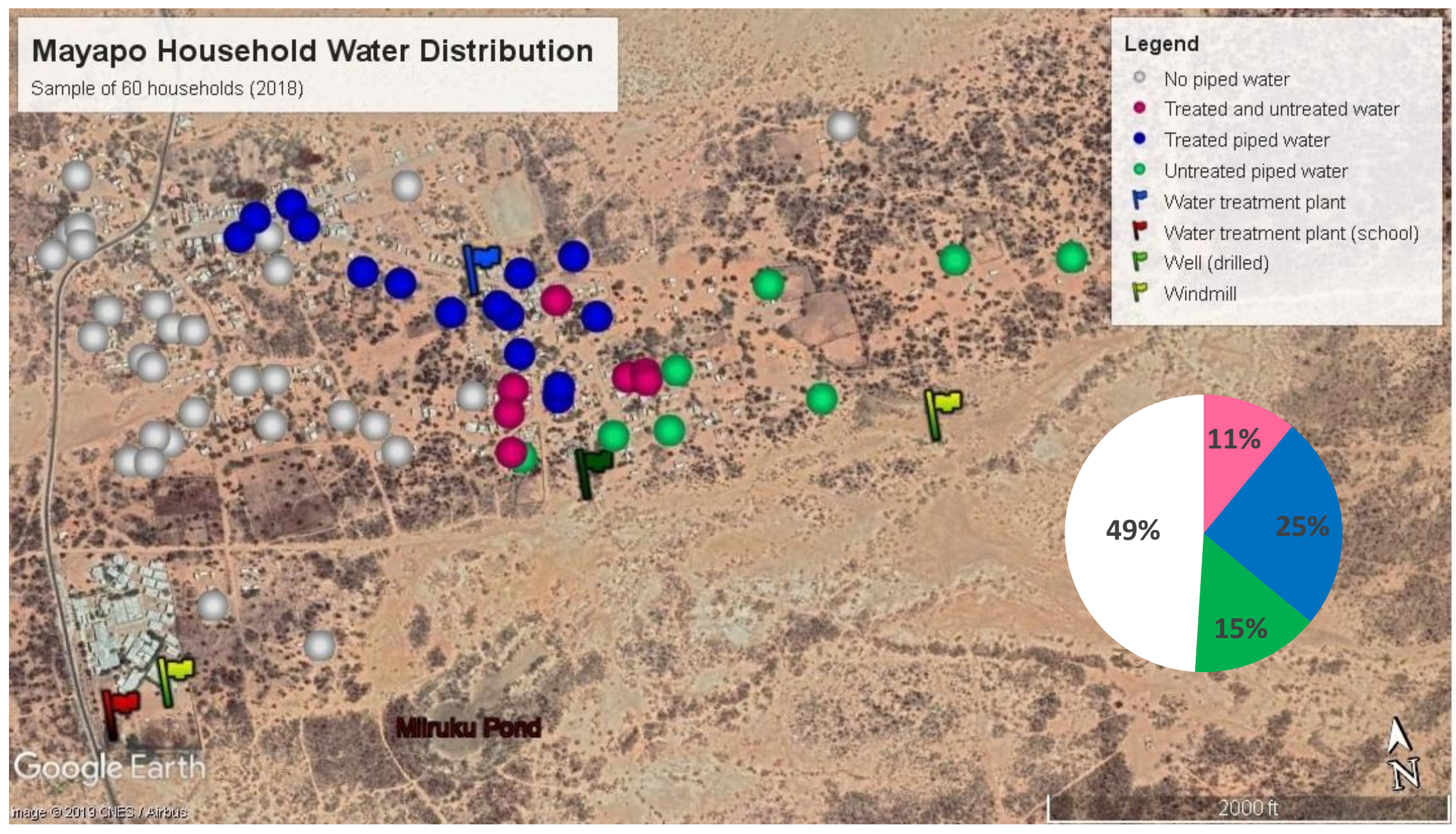

Map 9. Household water distribution in Mayapo

Source: Adapted from Google Earth (2019) with field work data from Mayapo (2018) 
There are people here who are having a hard time in the different sectors. For example, those located just to the west are slightly better, but from there on there is no water at all. Those people really have it bad. Only a few houses are fine, there aren't many... Sometimes when the water arrives, many people come, then problems arise among them. Since there is not enough water, they must distribute the little amount among everyone and some leave without water. (Diogenis Epinayu September 24, 2018)

Nearly $50 \%$ of the sample, represented with the white points on the map, do not benefit from either of Mayapo's two water distribution systems. These residences are located mainly in what the locals call Lower Mayapo. Most of this western sector does not receive either treated or untreated water even though there is piping installed for one or both systems. They must buy water from the trucks, ask neighbors or family members for water or gather water at the communal wind-powered well, the pond or dug wells to meet their daily water needs. Mrs. Rosario Mengual lives in Lower Mayapo without services from the aqueduct or the drilled well. She describes her situation as follows,

We are going through a lot of hardship, now more so since the pond has no water. We do not provision ourselves with water from the elevated tank, much less from the aqueduct. We look for water elsewhere. When we are too lazy to look for water, we buy it-when we can, because we don't have money. We have piping installed but the water does not arrive here. They say the elevated tank doesn't work and the plant breaks down all the time. My brother receives fresh water but not me, not even brackish water. There are a lot of people in this sector around the crop field, but not enough water. The truth is I get tired of looking for water. I have a storage tank, but I have no money to have it filled. The money I earn from making handicrafts I use for food. I must feed my grandchildren. (Rosario Mengual September 27, 2018)

Regardless of the water accessibility or location, $95 \%$ of the households sampled acknowledged that they buy water from the water trucks when the local water supply is not enough. Some buy water to complement the brackish water they receive through piping or fetched at the drilled well. Others buy water only when the aqueduct breaks down. Still others buy water on a regular basis for all their water needs. On average, the 
sampled households purchase $\$ 14,000$ Colombian pesos (\$4.15 USD) worth of water per week. A few residents of Mayapo only purchase one or two 20-liter jugs of water at a time — at a cost of $\$ 600-\$ 1,000$ pesos per jug (\$0.18-\$0.30 USD)—because they do not have enough money to buy more or do not have larger containers to store more water.

On a stormy night in early October, under the cover of darkness and muffled by the sounds of the rainfall and thunder, the drilled well's indispensable and expensive submergible pump was stolen, disabling both of Mayapo's water distribution systems. The residents questioned why someone would steal something so beneficial to the entire community. Others blamed the system's operator who did not replace the broken door to the room where the pump was installed. Others criticized the family who lived closest to the well for not noticing or acting when the robbery took place. Still others pointed the finger at the Venezuelan immigrants, saying they were the culprits.

Unable to acquire the replacement part for several months (October 2018 to March 2019), the community plunged into water insecurity, without service from either of the idle distribution systems. Fortunately, it was the rainy season and Miiruku Pond had been filled, which many Mayapo residents turned to for washing clothes, bathing and other household chores while rainwater harvesting and water trucks provided water for drinking and cooking.

Mayapo's adoption of complex water infrastructure and its multiple water sources has altered the relationship the Wayuu living in this community have with water. The transition from gathering water at the ponds and dug wells to water provisioning from wind-powered wells to receiving treated water through piping to (some of) their houses or from water trucks, shows how water access has evolved in Mayapo. I asked the 
inhabitants to reflect upon and compare the water situation of the past to the current water situation. Their responses were varied, some affirming that they are better off now than in the past, while others argued the opposite.

Before, there was very little water to be found since there was only one well where the water we consumed came from. At that time there was no pond. Then they dug the big pond that is here in Mayapo and the animals had their canoes [wooden troughs] to drink water from. (Joaquín Wouriyu, November 22, 2018).

Alfredo Mengual of the Uliana Clan, along with other elders, took care of Miiruku Pond, constructed by the national government in the 1950s. They placed a barbed wire fence around it with two gates so that livestock would not enter the pond and made sure no one bathed or washed clothes in or near it. Inhabitants of Mayapo remember how the pond would maintain clean water for up to three years. A local leader recalled,

before, when we drank water from the pond, it was so good. We didn't get sick because the water was clean. Girl, do you remember? That clean water, when you poured it into a cup and you could see the bottom. Everyone drank it as it was, without having to boil it (María Elena Alarcón, October 3, 2018).

After Mr. Mengual's passing, nobody continued his role of caretaker of Miiruku Pond.

The barbed wire fence corroded, broke and was eventually taken out. The livestock drank directly from the pond, trash made its way into it and the people forgot the rules established and enforced by the elders. Thus, the water quality deteriorated and the quantity of water the pond could hold diminished because of sedimentation.

The water that we consumed before, came from a well near the bridge. Here, we suffered a lot without water. Although we had the well, it was very far away. We had to get up early to go get the water, also at night. It was a lot of work during those times but nowadays the situation has improved a bit from what it was before. Now it's easier to obtain water. (Eusebia Sijona October 1, 2018) 
Mrs. Sijona speaks of the time before Miiruku Pond was constructed when the residents would walk to and from a dug well, approximately three kilometers away from the community, in the bed of Paimana Stream. For many Wayuu, as described in Chapter 5, these long water-gathering trips continue to predominate throughout the Wayuu territory. She considers the current water situation of Mayapo better because of the reduced distance, time and effort needed for water provisioning.

It's better [now] than before because previously the older generation had to drink dirty water from the pond. Nowadays, we drink fresh and clean water. Although on the other hand it was good before because they did not have to pay for water. Now, we must buy water from the cistern truck, but the water is fresh and clean. (Ocari Pushaina September 24, 2018)

Mrs. Pushaina prefers the current water situation because the water is fresh - as in tasteless, not salty — and clean — transparent and not associated with illness. Although she also recognizes that in the past the Wayuu of Mayapo did not have to pay for water. This statement addresses the general rise in the cost of living in Mayapo, where items without a monetary value have now been commodified, such as water, motorized transportation, cellular phone communication, TV and internet entertainment, and certain food items. These additional expenditures place added pressure for the Wayuu living in Mayapo to make money, through wages, salaries, tips, commissions or product sales.

I liked it before, because we just had to go get the water from the pond. Now, if there is no water from the tap or the water truck doesn't pass, we struggle. Or if we don't have money to buy it. When we don't manage to get water using these options, we must walk long hours in search of someone who can give us some water. (Diotista Wouriyu October 2, 2018)

Mrs. Wouriyu recognizes the greater water availability currently in Mayapo but also the intermittence of the water service and the difficulty of obtaining water from others. For these reasons, she considers the local pond of the past as a better water source because it 
was continuous, free and accessible. As a common pool resource, no one from the community was denied access to the pond. However, the pond in the past had a greater capacity to store water and was better protected. Mrs. Herrera in the following quote emphasizes the precarity of the current water situation, despite the technological advances, as compared to the past.

It is worse [now] because before at least we had the pond water, because it was clean. During the dry season they would dig wells and take care of them. Now we go through hard times without water. With this new technology, things have changed a lot; it is not the same as before. Here, a lot of brackish water comes from the two wells. If this water were purified, we would be much better than before, having water in the house without the need to fetch it. We would not be going through this situation. Now, we must pay for water. (Yojanis Herrera October 3, 2018)

For Mrs. Herrera, the local pond provided greater water security because of its clean and abundant fresh water, unlike the water service of today that is intermittent and provides brackish water. When the pond went dry, dug wells became the alternative. She alludes to the aqueduct and its distribution system as a possibility rather than a reality, because roughly two-thirds of Mayapo's population does not receive purified water piped to its residences. She too reinforces the general sentiment that the downside to receiving clean water from the water trucks is the money needed for this service, a scarce resource in Mayapo and more so throughout the Wayuu territory.

In this sense, water security, in the form of a treatment plant and a distribution system, was promised to Mayapo's water users. All Mayapo was to benefit from treated, fresh, piped water to its residences, solving the community's problems of water quality, quantity and accessibility. However, due to its broken elevated water tank, the system failed to deliver the much-anticipated vital liquid to most of Mayapo. Instead, water 
insecurity and unequal access to potable water was introduced, refiguring Mayapo's topographic waterscape into haves and have nots.

Perhaps Mayapo's aqueduct does not fit Colombia's definition of a white elephant because it partially functions. The water insecurity may have been worse if the water supply system did not function at all. Those that receive the treated water share what they have with others; of the 38 households sampled that do not receive treated piped water, $40 \%$ acknowledged they collect water from a neighbor or family member who receives treated water. As expressed by the traditional authority of Mayapo, water hoarding is frowned upon.

It's necessary to orient the people, but since there are so many, it takes time to speak to them all. I tell them, "even if it's just a lit bit, share it. Water is very necessary; people suffer a lot without it. When the water arrives do not take it all, take some and leave the rest for the people, when you gather water, leave some." Poor people... (Erasmo Ipuana August 28, 2018)

Water sharing then becomes a social obligation and a leveling strategy against water inequality. By small and daily acts of solidarity and sharing, Mayapo has found a way to deal with its water insecurity and inequality.

Modernity in Mayapo is evidenced in the introduction of a complex and costly aqueduct that was meant to replace less complex and less costly water supply systems such as drilled wells, dug wells and ponds. The "progress" towards a modern relationship with water in Mayapo has increased the reliance on high tech and commodified water solutions while traditional water sources has seen a decrease in the attention given towards them, a tendency Saler observed across Wayuu territory as well (1986:41-42). An important moment in Mayapo's water modernization process occurred when the elder who maintained Miiruku Pond, Alfredo Mengual, passed away and the pond 
and the wells dug within it were gradually abandoned by most of Mayapo's inhabitants. One leader from Mayapo explained how the pond's abandonment was accompanied, or brought about by, a noticeable shift in attitude towards the pond during the mid-1980s. She and other elders have identified several factors contributing to the decadence of Mayapo's pond.

First, none of the Uliana clan members, considered the owners of the pond, took over the role as caretaker after Mr. Mengual's passing. Second, the ever-increasing number of inhabitants in Mayapo devalued, disrespected and lost interest in the pond. These two factors led to the infringement of the established norms for its use, namely: no bathing, no washing clothes, no defecating, no littering and no livestock in or near the pond. Third, drilled wells were constructed and later water trucks began serving the community, shifting the way water users understood and related to water. Clean water became associated with groundwater and water trucks while dirty water was associated with the pond and dug wells. This association was later altered to consider potable water from the aqueduct and water trucks as clean and water from all other water sources as unclean. Fourth, Mayapo's older residents agree that there has been a decline in rainfall over the last decades, causing the pond to be less viable as a permanent water source.

Despite its water shortage and internal disparities to water access and availability, Mayapo, in both a conventional and a Wayuu sense, continues to be more water secure than many other smaller Wayuu communities. The residents have retained the ability to turn to its traditional water sources yet also resort to purchasing water when the drilled wells and treatment plants break down. This is not the case in the communities of Irraipa and Cardón where the water supply is more limited, as described in Chapter 5. The 
following example describes the objectives and outcome of another ambitious project that was to provide continuous, abundant and clean water to thousands of Wayuu across the Upper Guajira.

The "technical non-feasibility" of provisioning the Upper Guajira with purified water

The pilot project to build eleven reservoirs with their accompanying water treatment plants in the municipality of Uribia, La Guajira, began in 2007 and ended in 2018 with the construction of eight of the eleven reservoirs and without the installment of the water treatment plants in any of the locations. These water supply systems were to be built by the provincial government with a $\$ 4$ million loan from the World Bank (World Bank 2018:1). Initially, socio-cultural information gathered in four of the eleven areas by the Cerrejón Foundation for Water in La Guajira (now the Cerrejón Foundation for Progress of La Guajira) would be used to inform the design and implementation of a sustainability plan for the reservoir-based water supply systems. The World Bank project aimed to improve the way development projects are undertaken in rural areas, specifically addressing,

the lack of social accompaniment in the installation of the systems and information given to the communities about its characteristics; the individual or familial appropriation of the water sources that limit their benefits to a reduced population; the installation of the systems without settling with the communities about the actions necessary for its operation and maintenance; and the absence of training for the care and maintenance of the water (Gobernación de La Guajira 2011, 95).

The same obstacles mentioned above were faced and reproduced by the reservoir project, with a negative impact on its viability. The first insurmountable obstacle to the project's sustainability occurred in 2010 when the water supply system to be installed in the area of Cabo de la Vela was discontinued. The construction of the reservoir was 
initially approved by the traditional authorities of the beneficiary communities during three official prior consultation meetings taking place in November 2009, February 2010 and July 2010 (Fundación Cerrejón 2013d). Among those in attendance in these meetings were representatives of the Vice Presidency of the Republic, the Ministry of the Interior and Justice, the Provincial Government of La Guajira, the Municipal Mayor's Office of Uribia, the designated construction company, and local representatives of the Wayuu communities of Cabo de la Vela, Kasushi, Sarima and Moishoun (Ministerio del Interior 2010; Fundación Cerrejón 2013a). One month after the last prior consultation meeting, in August of 2010, the construction of the reservoir was suspended because members of the local communities would not allow the workers to continue (Fundación Cerrejón 2013e).

The opposition to the donation of a water supply system that would greatly improve the quantity and quality of water in this water-stressed region shows the complexity of water provision among the Wayuu and the problem of communication and representation during the prior consultation process. The root of the problem stemmed initially from the underrepresentation at the prior consultation meetings of most of the local Wayuu leadership from the area surrounding the proposed location of the construction site (Fundación Cerrejón 2013d). Representatives from four communities (Cabo de la Vela, Kasushi, Sarima and Moishoun) assisted these meetings while the representatives of 29 other surrounding communities were not present (Ibid). A second problem centered on the name given to the reservoir by the project; it was officially named Reservoir of Jotomana, which was taken by the local inhabitants of other communities to imply that the reservoir belonged to the community of Jotomana (Ibid). Those opposed to the project firmly rejected various attempts by the local government to 
renegotiate the terms originally established and rectify the name given to the reservoir. The Wayuu of this area ultimately decided that they would not allow the project to continue in their territory in order to avoid further internal conflict that would ensue from the construction of the waterworks.

This same project would receive another setback when the foundation in charge of the sustainability plan, the Cerrejón Foundation, decided to suspend its contract with the provincial government in August 2013 because of diverging perspectives on how to proceed with the sustainability plan (Fundación Cerrejón 2013e). The turning point for the viability of the treatment plants occurred when the results of water quality testing in two of the reservoirs showed high levels of cyanobacteria (above the WHO's alert level 1 of 2,000 organisms/ml) (Fundación Cerrejón and CINARA 2013). Studies showed that acute and chronic health risks were associated with the consumption of water with high levels of certain cyanobacteria, including skin irritation, gastro-intestinal diseases, liver damage, cancer and internal bleeding, which could result in death (World Health Organization 1999; Fundación Cerrejón and CINARA 2013). The agency in charge of the testing, CINARA, advised that in order to eliminate the cyanobacteria, a more advanced and costly water treatment plant using carbon filtering and coagulationflocculation techniques would be needed. This ruled out the relatively low-cost, low technology treatment plant using multi-stage filtration originally proposed by the agency and considered more adequate for the Wayuu context (Fundación Cerrejón and CINARA 2013). The way to proceed became a point of contention between the provincial government and the Cerrejón Foundation, which eventually withdrew from the partnership and was replaced by another organization. 
While the results of the water quality tests were the subject of debate among the water sector experts and were disseminated to various health agencies at the municipal, provincial and national levels, the local inhabitants were not included in the debates nor the search for solutions. Any local knowledge or understandings on water quality and its health effects were neither solicited nor considered as legitimate information worth including in the exploration of solutions.

Eventually, after five extensions and eleven years of implementation, the project cycle came to an end and the reservoirs remained without their water treatment plants. A 2017 report by the World Bank noted that, "the potabilization component has been removed from the original contracts due to technical non-feasibility" (World Bank 2017a, 7, italics added). Nevertheless, in its Implementation and Status Report No. 22, published in April 2018, the World Bank reported that 7,456 people in rural areas were provided with access to improved water sources under the project (World Bank 2018, 3). However, the construction of a surface water source, such as a reservoir, is not considered an improved water source, a category that includes "piped water, boreholes or tube wells, protected dug wells, protected springs, and packaged or delivered water" according to the World Health Organization (WHO) and UNICEF's Joint Monitoring Programme (2017).

Upon further scrutiny of the reports by the World Bank and comparing their information to the findings of the Cerrejón Foundation's socio-cultural studies presented in Chapter 5, the World Bank data is exaggerated and inaccurate. For example, the World Bank's No. 16 Implementation Status and Results Report, published in 2015, states, "the construction of 8 rural reservoirs has significantly decreased the time spent by Wajuu [sic] communities in fetching water from 5 hours to 54 minutes and the time saved is 
spent on income generating activities such as rising $[s i c]$ of livestock, agriculture, fishing and the production of handcrafts as well as on schooling for the children" (World Bank 2015, 2, italics added). This information was then disseminated on the World Bank website and a YouTube video in 2017 and again in 2019 (World Bank 2017b; World Bank 2019). Likewise, the current national government's water program in the province of La Guajira, Guajira Azul (Blue Guajira), put forth its own uncited baseline data, "women and children employ seven hours per day to gather water in the rural zones" (Ministerio de Vivienda 2018, 11 italics added).

The way the World Bank framed the issues and results of the reservoir project on Wayuu lands echo Fergusons' analysis of the "development" discourse by the World Bank in Lesotho in many ways (1990). The World Bank assertions of Wayuu water gathering are produced by, and at the same time reinforce, hegemonic water understanding by simplifying and generalizing complex human-water relations. Similar to what Ferguson uncovered in his text analysis of the World Bank reports in Lesotho, the Guajira reports inflated pre-intervention baseline information on time spent gathering water and post-intervention results showing the decrease in time for this activity. In both cases, the projects are justified by portraying a depiction of underdevelopment prior to the intervention, then demonstrating through facts and rhetoric the introduction of what is deemed characteristics of development. What is created is a command-and-control development discourse that includes an identified/identifiable problem (lack of water) a logical solution (installation of a waterworks) with a measurable and foreseeable cause (distant, dirty water source) and effect (wasted time, water-related health problems). The intervention results, such as those presented by the World Bank, invariably demonstrate 
the positive impact of the interventions - better water accessibility, improved water quality.

In the World Bank results, the reader is led to believe that the entire beneficiary population spent five hours fetching water all year before the intervention, which was then reduced to 54 minutes after the intervention. These statements do not take into consideration the seasonality of water availability in the Wayuu territory, as discussed in Chapter 5 in the areas of Cardón and Irraipa and as shown in Table 2. In these areas, the average time spent fetching water roundtrip during the rainy season is 20 minutes and during the dry season rises to one hour and ten minutes. During times of drought (not normal years) the time to and from the distant water sources elevates to $3 \mathrm{hrs} .43 \mathrm{~min}$. Since the World Bank financed the Cerrejón Foundation's studies, it would have had easy access to the above statistics but did not use them. Without any citations in the report, it is impossible to know whether the data presented by the report was an exaggeration of the results of the Foundation's study or if uncited data was used from another study or source.

According to the report, the reduction in time spent fetching water to 54 minutes is also misleading or false because 1) a follow-up household survey or ethnographic study was not conducted to compare with the initial study conducted by the Cerrejón Foundation, 2) it assumes that the reservoirs replaced the other local sources of water used before their construction - in the case of Cardón, the reservoir was not considered a water source because of its high salt content — and 3) it also assumes that the reservoirs do not dry up during times of drought. 
During an inspection visit in August 2015 to five of the eight reservoirs, I found that two were completely dry (Cardón and Gran Vía) and three were nearly dry (Irraipa, Puerto Virgen and Kespalau). Furthermore, the distribution systems installed in the latter two were in a state of disrepair. It is possible that the World Bank report is a summary of a more extensive undisclosed report with citations and details that support its assertion. Based on the report reviewed, the dominant discourse of development that asserts the local situation has been improved by the intervention seems to have biased this report and trumped scientific rigor and objectivity.

The second part of the above-quoted statement by the World Bank notes that the time saved on fetching water was used on income-generating activities. This assertion can be analyzed using Santos' sociology of absences, which argues that non-conventional alternatives are actively delegitimized by those entities in charge of maintaining Western modernity $(2011,30)$. The fifth logic of the production of nonexistence in his sociology of absences focuses on the monoculture of capitalist production criteria. Here, nonexistence is performed by maligning the activity of water gathering, as wasted time. Furthermore, an unproductive activity (water gathering) is replaced by productive, "income-generating activities." However, the report wrongly correlates the reduction in time fetching water to an increase in income-generating activities.

All the economic activities listed in the World Bank statement (herding, farming, fishing, weaving) are traditional subsistence strategies that have been practiced for hundreds of years and may or may not be "income generating activities." Weaving has shifted towards a market economy, although a significant amount of the hand-woven bags and hammocks are for domestic use. Fishing is both for subsistence and for the 
market, while herding and farming are for the most part non-market economies.

Furthermore, these activities would not be significantly altered by the introduction of a new source of water closer to their residence and a follow-up study was not conducted to support this claim.

Lastly, there was also no consideration whether becoming more efficient and productive (the rational, utility-maximizing human known as homo economicus) is a life goal for a Wayuu individual, community or the entire society. It is, however, a maxim in Western societies that productivity is a virtue, documented by Max Weber in The Protestant Ethic and the Spirit of Capitalism (Weber 1958) and maintained as an ethos in contemporary American society. The statement that the Wayuu now invest the time that they save from the new water sources into income-generating activities thus contributes to the Western readers' perception that the project was a "success."

The global discourse on water-gathering has been one-sided, highlighting the waste of time and energy, its unproductiveness and the negative health consequences of water gatherers, who are said to suffer physical ailments from carrying too much weight (Geere, Hunter and Jagals 2010). However, the water sector's disapproval of timewasting water gathering trips is not consistent with the World Health Organization's Declaration of Diet and Physical Activity.

Realizing that sedentarism and overconsumption had become a public health problem worldwide, the World Health Organization (WHO) in 2007 put forth the declaration urging, "national governments to promote healthy diets and regular, adequate physical activity as major factors in the promotion and maintenance of good health throughout the entire life course" (Wiedman 2010,40). An alternative discourse to water 
collecting would underscore the negative effects of a sedentary lifestyle, which has been documented by health scientists and anthropologists alike, and consider water gathering as part of a lifestyle that promotes daily exercise. Anthropologist Dennis Wiedman argues that the transition to modernity by Native Americans and other Indigenous groups has increased the incidence of metabolic diseases (MetS) among them, such as obesity, diabetes, dyslipidemia, gall bladder disease and hypertension due to "chronic everyday behaviors that limited physical activities, while promoting high caloric intake and chronic psychosocial stresses" (Wiedman 2012, 603).

Water fetching for many Wayuu in the rural area is indeed a daily routine that requires physical activity. Other activities practiced daily, occasionally or seasonally by the Wayuu that require walking or sustained physical exertion include chopping wood, herding, fishing, gathering wild fruits and plants, construction and repair work, hunting, farming, walking to school, playing sports, salt mining, keeping the homestead tidy, among others. Rural life, not only for the Wayuu, but in general, is more physically demanding than urban life.

This is not to say that physical labor is not performed in the city. The English terms "white collar" and "blue collar" illustrate how manual labor is perceived in relation to class and status. The lower-paying blue-collar work is associated with physical labor that requires less formal education while the more prestigious white-collar work is associated to higher pay and desk work with little to no manual labor. Perhaps it is because policymakers and water management experts are by and large white-collar urbanites that physical activity is given a negative connotation (unless it is recreational) while mental and "income-generating" activity is rewarded. 
Lastly, in the efforts to provide water security, there is never any mention or consideration of what may be lost when long-standing relations with traditional water sources are changed. Fetching water at the pond or the well is a tradition passed on from mother to daughter and taking livestock to the watering hole a tradition passed from father to son. At an early age, children expand their mobility beyond the residential space and comingle with their surroundings in various ways and often along gender lines.

For boys, this means learning the ways of a pastoralist and a hunter, becoming familiar with the rangeland, with the domesticated and wild animals, and with the proper ways of interacting with the watering places. Girls also gain knowledge of their territory by learning to identify, locate and gather fruits, berries, medicinal plants as well as becoming responsible for the procurement and management of water in the household. Water fetching is both a chore and a privilege for women and girls; the basic functioning of domestic life requires the task be carried out yet it also forges intimate relations with water and with the people, places and myriad beings in the milieu they come across beyond the confines of their homes.

These gendered spaces and activities provide moments when grandmothers, aunts and mothers create bonds with nieces, daughters and granddaughters. So too, grandfathers, uncles and fathers spend time with nephews, sons and grandsons. Each learns from the other by discussing serious or superfluous matters; they exchange life experiences, tales, aspirations and disappointments. Eventually, the youth carry out the activities without the accompaniment of adults. With this growing independence, the territory, and especially the ponds, become important meeting places for friends, family members, suitors and lovers. The aquatic space becomes a place of gathering, rich in 
cultural, historical and spiritual meaning for the community. Each pond or well has a story of who built it, how it was built, why it was given the name it is known by, how it should be used, how long it lasts before going dry, how the water tastes, whether Pulowi resides within it or not, and other defining characteristics of the pond.

Without consideration of the collateral impacts and social repercussions mentioned above, the reports and website publications by the World Bank describe the results of the intervention in a positive light, proclaiming it a success despite the setbacks. These communications highlight the provision of cleaner water for the Wayuu beneficiaries, a shift from "time wasted" fetching water to more productive endeavors and an improved standard of living overall. This is not only a discourse used by the World Bank but by all water sector institutions and development agencies in general.

\section{Discussion}

Form a relational ontology perspective, the diversity and complexity of Wayuuwater relations form part of an ontological world vastly different from the modern colonial world or the One-World World (OWW), which currently directs water relations on a global scale. For Escobar, the OWW, "has taken over the right to be 'the' World, subjugating all other worlds to its own terms or, even worse, relegating them to nonexistence; it is about a world in which only one world fits" $(2016,15)$. The Wayuu ontological world ranges from communities with high-tech waterworks and water truck dependence — such as Mayapo - to smaller, isolated communities whose only water sources are ponds and dug wells. Water interventions in Wayuu territory, as in countless places around the world, then become a process of asserting or imposing a global technologically driven ontology over a place-specific ontology (Yates, Harris and Wilson 
$2017,801)$. Consequently, the failure of most complex waterworks identified in this chapter results from this ontological disjuncture.

Can the Wayuu territory be described in terms of an incommensurate world, as understood by Elizabeth Povinelli (2001, 321), where miscommunication, misunderstanding and misinterpretation dominate intercultural interactions in a context of radical social and linguistic alterity? Are Wayuu hydrosocial relations another example of an "uncontrolled equivocation... because the interlocutors are unaware that different worlds are being enacted (and assumed) by each of them" (Blaser 2009, 11)? Language and hermeneutics become key components to the invisible barrier separating ontological worlds. If this is the case, the numerous definitions and concepts imparted by water sector experts during workshops, community visits and training sessions on hygiene, sanitation, water conservation, and water and waste management, are futile attempts at delivering the intended message and the subsequent acceptance or implementation of the instructions communicated. Povinelli, citing Davidson, argues, "if we cannot find a way to interpret the utterances and other behaviors of a creature as revealing a set of beliefs largely consistent and true by our own standards, we have no reason to count that creature as rational, as having beliefs, or as saying anything" $(2001,322)$.

In this sense, incomprehension and the subjugation of knowledge is not limited to the dominant global water governance institutions; it works both ways. Here, ethnocentrism, the evaluation of other cultures using the standards of one's own culture, complements the argument of incommensurability between worlds. The Wayuu have maintained their customs and traditions because it has allowed them to populate and persist in an arid region with a limited water supply. Their adoption of what they perceive 
to fit within their ontological world is seen in their selective incorporation of ponds, plastic water jugs, fencing around ponds, water troughs and to some extent wind-powered wells, and their resistance to certain Western hygiene and sanitation practices, water irrigation systems or water management principles.

From a political ecology perspective, the failed water interventions on Wayuu territory form a part of the historical imposition of global, national and provincial social orders that have had deep and lasting repercussions on the current state of affairs among the world's Indigenous groups. The exploitation and impoverishment of the colonies during the colonial era was reconstituted in the post-colonial era under an increasing dominant neoliberal capitalist agenda, maintaining the Global North's (former colonial powers) supremacy over the Global South (former colonies). Within this modern colonial world system, Colombia established its own internal colonialism, marginalizing the lowland Pacific coast, Caribbean coast and Amazonian regions while concentrating power in the Andean highlands with the capital city of Bogotá at the epicenter. La Guajira's historical isolation and abandonment shifted to one of economic exploitation with the production of coal and natural gas. As discussed in Chapter 5, the current urban/rural and alijuna/Wayuu socio-administrative groupings unevenly distribute the wealth of the province.

Using a political ecology approach, Mayapo's elevated water tank never worked and has never been repaired or replaced because the primary objectives of these large and costly infrastructures are not to benefit the community but to expand the dominant water management regime, enrich those involved in its installation, and bring status and recognition to the organizations or governmental bodies who paid for them. There is also 
pressure by the UN for countries to meet the targets of the Sustainable Development Goals (SDGs), one of which is "by 2030, achieve universal and equitable access to safe and affordable drinking water for all." Goldman notes how a few global water firms dramatically expanded their market dominion from less than 51 million U.S. and European customers in the 1990s to 460 million users throughout Africa, Asia and Latin America within 10 years $(2007,790)$. "Dealing in water has become one of the most lucrative markets for transnational capital investors. According to one water analyst, 'the global market for municipal and industrial water and sewerage goods and services is currently estimated to be in the region of US\$200bn-\$400bn per annum"” $(2007,790)$. Colombia, La Guajira and the community of Mayapo have all been subsumed in the globalization of privatized water. For this reason, the Municipality of Manaure awarded the operation of the aqueduct to Triple A, a private water company (with a majority ownership by the Spanish-based company Inassa), rather than the locally based Wayuu water cooperative. The private sector water trucks have also exploited Mayapo's water service instability by creating a community-wide consumer base for delivered water. The second case study on the World Bank-funded water supply systems documented a failed attempt by the private sector to install 11 water treatment plants and enter an untapped region of potential paying water users. Nevertheless, the World Bank focused on what was accomplished, the construction of eight reservoirs, and altered the facts to rationalize the intervention's results and show progress towards the above mentioned SDG target of "universal and equitable access to safe and affordable drinking water for all." 
Global development entities such as the World Bank present their results employing a discourse that only highlights the positive aspects of their interventions. A critical analysis of this discourse revealed not only their partiality but also how far removed they are from the ethnographic data presented in this dissertation. The novel by George Orwell, Nineteen Eighty-Four (1949), captures the essence and extent to which a totalitarian government employed propaganda to maintain hegemony over the population. Similarly, the (mis)use of statistics by global entities has led me to question how reliable the information they provide is, and more broadly, how we know what we know and what is fact and what is belief. Facts are usually associated with science while beliefs are associated with statements about reality that are not scientific. Yet fact and fiction can become each other, depending on the source of the assertion and its time and place of inception. Geographer Alan Pred explained this melding of fact and fiction using a play on words, "Nothing gums up fiction like facts... Nothing gums up facts like fiction... Gumming it up. Both ways. Fictions begumming (f)acts. (F)acts begumming fictions. Begumming one another" $(2004,132-33)$.

This epistemological conundrum can be explored using Santos' monoculture of knowing, which allows for only the scientific to exist and the monoculture of the naturalization of difference that bestows superiority to white Western societies, as discussed in Chapter 5. A fictionalized account of the time employed by Wayuu to gather water (five hours) became fact since it was presented and disseminated by a renowned global institution, which is the de facto dominant scale for producing and propagating policy-oriented information (Santos 2011:32). In doing so, fiction became fact and fact- 
the varied, temporal nature of Wayuu water gathering - became fiction, forced into nonexistence.

By critiquing the content of the World Bank reports, I am not disavowing the work done by that organization or UNICEF, UNPD, FAO, WFP, USAID, Oxfam, Red Cross, WaterAid, Action Against Hunger, Chevron, Cerrejón, EPM, Repsol, Alpina, Aguayuda, Corpoguajira, ICBF, DPS and other public, private, non-governmental or donor institutions who have carried out interventions or are currently working in Wayuu territory to provide solutions to the water and food shortages. Many Wayuu I have spoken with are thankful for the assistance received, whether it be a one-time intervention during a humanitarian crisis, such as Oxfam's installation or repair of a water supply system, or an ongoing program related to social responsibility, such as ChevronEcopetrol's presence in Mayapo. The residents of Mayapo recognize and are grateful for the contributions of Chevron-Ecopetrol to help improve the town's water, education and health sectors, among other social programs. They also understand that the assistance is temporary; Chevron has been scaling down its natural gas production operations and its contributions to the community for several years now while the Cerrejón's coal mining operation in La Guajira is programmed to shut down in 2034.

Other areas in Wayuu territory, such as Irraipa, have not benefited (or suffered) from the presence of multinational corporations but will soon become engulfed by the current wind energy boom. With nine wind farms with licenses to begin operating in 2022 and 56 more projected to be built by 2031 across Wayuu territory (Semana Sostenible 2019), a new era of Wayuu-alijuna relations has initiated. For the windy but water scarce Guajira Peninsula, water will surely be a central negotiating point to be 
included in the social responsibility programs of the incoming companies. It will be up to the Wayuu of these areas to reflect on the past experiences of water interventions and their current water situation in order to collectively define and have some measure of control over the future of their hydrosocial relations. 


\section{CONCLUSION - INDIGENOUS WATER GOVERNANCE IN THE ANTHROPOCENE}

Governance needs to evolve in the same way as complex life itself - through local adaptation.

Resilience: The governance of complexity (Chandler 2014, 40)

Humanity is witnessing the advent of the Anthropocene era, a physical world increasingly susceptible to human agency, and characterized by human-induced global warming, biodiversity loss and sea level rise (IPCC 2014; Mann 2012; Dalby 2015; Clark 2014). Compounding the situation, natural resources such as fresh water are becoming scarcer while the demand for them becomes greater. Not only is the global human population increasing — currently at 7.7 billion and expected to reach 10 billion in 2056 , according to the UN—but humans are also consuming more per capita. The Western world's fixation on unrestrained economic growth and progress towards material prosperity has globalized, fueling the flames of an imminently harsher and more terrifying future scenario of the Anthropocene (Escobar 1995; Mignolo 2000; Santos 2018). Stabilizing climate change through drastic, collective, immediate and sustained measures will be the ultimate test to our adaptive capacity. This common threat to our collective existence is currently more acute among disadvantaged populations living in coastal and arid zones, such as the Wayuu.

In this sense, the Wayuu territory on the Guajira Peninsula in northern Colombia is a microcosm of a morphing Anthropocenic world and a harbinger for what many world regions will face. With an extensive coastline, high temperatures, low rainfall, recurrent droughts and water scarcity, global warming is not only negatively impacting the Wayuu 
society's rain-based agriculture and the rangelands where their livestock feed, but also reducing an already limited supply of fresh water. Reflecting the human population growth globally, the Wayuu population has also grown considerably since the mid- $20^{\text {th }}$ century from approximately 60,000 to its current estimate of 800,000 (Aschmann 1960, 414; DANE 2019; INE 2011). This figure includes the Wayuu living in both Colombia and neighboring Venezuela, currently experiencing a tumultuous social crisis and political instability that is exacerbating the social and biophysical conditions described above.

Destabilizing forces such as violence, natural disasters, governance failure and unemployment have been on the rise across the globe, causing mass migrations. With an extensive and porous border with Venezuela, the Colombian Guajira has become a primary destination for Venezuelan migrants seeking a place to live. Statistics by Colombia's migration office reported that since the economic crisis began in Venezuela approximately five years ago, approximately 150,000 Venezuelans have immigrated to La Guajira Province, the region with the most Venezuelan immigrants after Bogotá, Colombia's capital, and Norte de Santander, another bordering province (Morales 2019). Many of the Venezuelans migrating to Wayuu territory are Wayuu Venezuelans who emigrated from the Guajira Peninsula to seek work in Venezuela when that country was prospering during the twentieth century. Others are the descendants of those who migrated and have property or family in La Guajira, Colombia.

While it is difficult to determine the carrying capacity of the Wayuu land, a recent study by Colombia's Hydrology, Meteorology and Environmental Studies Institute (IDEAM) found that 90\% of the soils of La Guajira have been degraded due to 
salinization, the highest in Colombia (Pesquisa Javeriana 2018). Extensive land degradation, a much larger population and the growing consumerist practices of the Wayuu, are three important factors that threaten the peninsula's natural resources and its continued occupation by the Wayuu.

Consequently, international humanitarian agencies, private companies, nongovernmental organizations, and governmental water, food and disaster management agencies are currently responding to two, interrelated humanitarian crises in Wayuu territory. The first is the violation of the fundamental rights of Wayuu boys and girls to food, water and health, as determined by Sentence T-302 (Corte Constitucional 2017). The second is the economic crisis in Venezuela that has affected the Wayuu in several ways. For the Wayuu living in Colombia, the Venezuelan crisis means that, 1) Venezuela no longer serves as a safety net during hard times, either for work opportunities or for support from family living there; 2) access to low-cost food items obtained from Venezuela has been severed, severely affecting their food security; and 3) the mass migration to La Guajira has caused tensions between the Colombian Wayuu and some of the returnees reclaiming their lands, as well as increased competition for employment and the use of natural resources on their territories.

Under these circumstances, it is evident that multiple problems at the international, national and local scales combine to create a complex situation the Wayuu now face. My dissertation research has led me to question the effectiveness of interventions by non-Wayuu organizations while understanding that without their assistance, the Wayuu may not be able to overcome the challenges of living in an increasingly interconnected and disaster-ridden Anthropocene. Nevertheless, because the 
Wayuu and other Indigenous peoples of Latin America have maintained intimate, spiritual and nonlinear relationships with their environment since pre-Hispanic times, they serve as sources of both critique and contestation to what Escobar terms the One World World of Western modernity (2008). They also offer alternatives to the toxic relationship established between humans and the rest of the earth's biosphere, if only "modern" institutions would develop an alternative thinking of those alternatives (Santos 2018, 6).

Throughout this dissertation, I have relied on arguments from decolonization theory (Santos 2011; Escobar 2016; Santos 2018), political ecology (Ferguson 1990; Nadasdy 2003; Escobar 2008; Escobar 2012; Robbins 2012) and relational ontology (Povinelli 2001; Blaser 2010; de la Cadena 2015) to forward a depiction of the water situation on Wayuu territory as a site of politically contested water ontologies (Yates, Harris and Wilson 2017). On the semi-arid Guajira Peninsula multiple levels of water governance converge and compete to define the correct relationship between the Wayuu society and water.

In Chapter One, I presented the challenges of bridging Western and Indigenous epistemologies by grouping them into two broad interrelated categories, power struggles surrounding environmental management and the cultural or ontological incommensurability between radically different Western and Indigenous societies. The first category emphasizes the politics and contested nature of water accessibility between different social actors and is the purview of political ecology. The second category, a hallmark of ontological anthropology, underscores the deep ontological divide that impedes communication and mutual understanding. 
In Chapter Two, I reflexively described my own positionality along with the theoretical and personal biases that are inherent in the dissertation. As an alijuna with a beginner's level understanding of Wayuunaiki, the language of the Wayuu, my ability to comprehend a Wayuu water world is restricted and distorted. The language barrier limited my communication with some of the participants and my preconceptions and theoretical framework guided my interpretation of the "facts" provided to me by a relatively small selection of Wayuu individuals. Under these conditions, I carried out ethnographic fieldwork and data analysis, cognizant of why I was writing the dissertation and who I was writing it for.

Although I have attempted to incorporate a holistic approach to the study of water among the Wayuu, this dissertation nevertheless compartmentalizes Wayuu knowledge into socially constructed categories, such as social, natural, supernatural and oneiric. This document will be stored in a library database under "Social Sciences" and will be consulted by a small fraction of social scientists, mainly English-speaking anthropologists, interested in either the Wayuu people or "cultural" aspects of water management. Although the dissertation may have limited viewership, I aim to communicate the message I present here in different formats and different languages (Wayuunaiki and Spanish) to make it more accessible to a broader audience, including alijuna policy makers, water experts, students, teachers and the Wayuu people.

Chapter Three first identified the challenges faced by pastoralists and the "bounded opportunities" at a global scale and explored the unequal relations between three pastoralist societies, the state and other populations they interact and compete with for local, national and international resources. In this sense, the Raika of Rajasthan, India, 
the Diné (Navajo) of the American Southwest and the Kuria of East Africa provided insights into how global processes impact the Wayuu pastoralists on the Guajira Peninsula. The second part of the chapter included a biophysical description of the Guajira Peninsula and a historic overview of the Wayuu people. The chapter ended by introducing Mayapo, a Wayuu community that has shifted from a "traditional" mode of living to a "modern" one, and whose problems, water and otherwise, have become more complex as it transforms from a rural to an urban settlement.

In Chapter Four, I critiqued a conventional Western water management framework that is devised and circulated by powerful global entities, which is then adopted and implemented by international, national, provincial and municipal public health and water sector experts. Their objectives are congruent with the targets and indicators established by the UN's $6^{\text {th }}$ Sustainable Development Goal (SDG) to ensure availability and sustainable management of water and sanitation for all. The SDG legitimizes certain water-society relations according to conventional understandings of water availability, water quality, water quantity, sustainable management and sanitation. Those elements not consistent with the mainstream definition of these concepts are delegitimized, ignored or targeted for intervention. If understood as hegemonic instruments of compliance, the UN water service ladder and the SDGs identify and elevate acceptable practices and technologies while labelling and disparaging unacceptable ones.

Analyzed critically, the hierarchical classification of water and sanitation practices by Western institutions is an example of Latour's two great divides created by the "moderns" $(1993,97)$. The first great divide, he explains, occurs when Westerners 
partition the natural world from the social world they live in through the invention and practice of Western science. The second great divide partitions the West from the rest, "moderns" from "premoderns," "us" from "them" and the present from the past (Figure 20) (ibid). Under this ideology or logic, Westerners ethnocentrically conflate what is correct/legitimate with what is produced in contemporary Western modernity, while separating and conflating the seemingly anachronic, non-Western world, with what is incorrect/illegitimate and premodern.

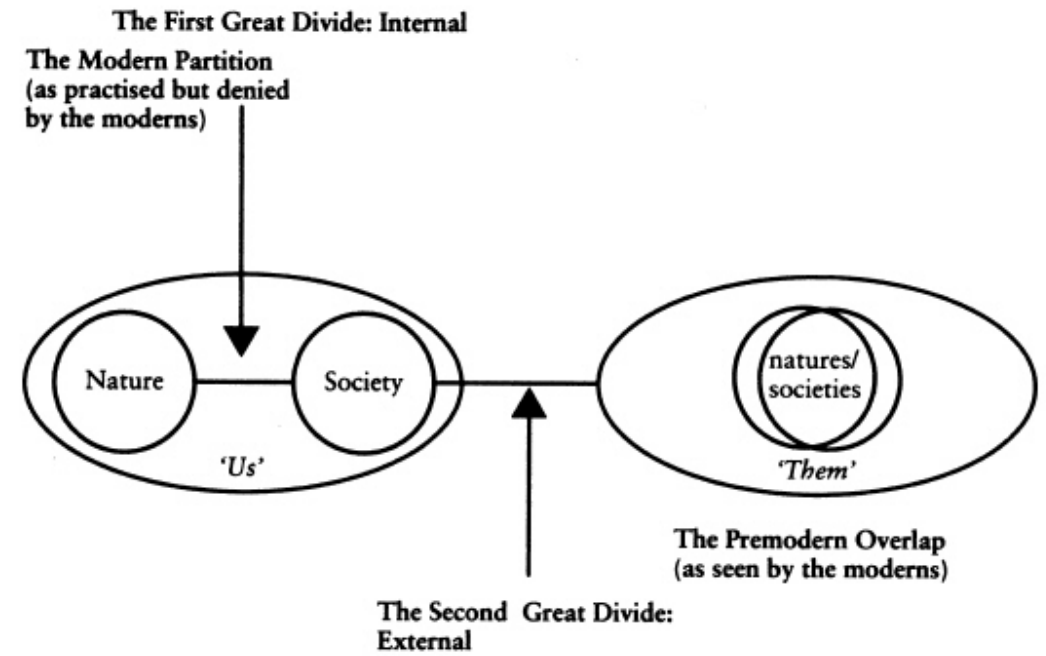

Figure 20. The two Great Divides

Source: We Have Never Been Modern (Latour 1993, 99)

In contrast to the conventional water management framework, Chapter Five and Six explored the Wayuu "non-conventional" water use and management practices and water knowledge system. These practices and ways of knowing have co-evolved with other aspects of a unique Wayuu way of life and identity as a pastoralist, peninsular, desert-dwelling people. Within a Wayuu ontological world, these hydrosocial relations also aim to ensure availability and sustainable management of water and sanitation for all the Wayuu people, according to Wayuu standards and definitions of the concepts. While not valued nor sought out (yet) by conventional water management, Wayuu water 
knowledge is an alternative to the future, the not yet, lying in latent form, "on the one hand capacity (power), and on the other, possibility (potential)," as stated by Santos' sociology of emergence $(2011,33)$.

Rather than imposing standardized development packages, the ecology of knowledges and intercultural translation (Santos 2011) encourages the dominant institutions and experts to admit their ignorance of certain realms of knowledge and be more receptive to guidance from those who have been historically subjugated, such as the Wayuu. This entails transferring power to the marginalized and recognizing the potential non-conventional alternatives have, not only to improve quality of life locally, but also preserve human life globally.

However, as described and analyzed in Chapter Six and throughout this dissertation, the emergence of a Wayuu water ontology into a legitimate alternative to conventional water governance is mired with obstacles. Critiques of integrating Indigenous knowledge and conventional environmental management point to the incommensurability of vastly different epistemologies and ontologies. What, if any, Wayuu knowledge would be useful for a Western water sector expert as climate change and unsustainable waterworks continue to constrain water provisioning on the Guajira Peninsula? If the supernatural relations, oneiric communication or moral principles that surround Wayuu water use and management are beyond the scope of Western science, then only the quantifiable actions labeled as unacceptable by the dominant water framework remain.

Furthermore, intercultural translation must contend with the politics and interests surrounding those called to represent each culture, the Indigenous and the Western 
scientific/managerial. At the global, regional and national scales, top-down bureaucratic relations are normalized that stifle bottom-up initiatives. Mandates such as the SDGs are virtually untouchable by, and non-negotiable with, local actors, such as Wayuu water users. The possibility of negotiation between decision-makers and beneficiaries is nearly impossible. Locally, La Guajira has gained the infamous distinction of being one of the most corrupt provinces in Colombia, its governing institutions blamed for illegally syphoning public funds and royalties destined to improve local living conditions for the alijuna and Wayuu inhabitants. One explanation for the disparities between urban and rural areas is the historical disdain, racism and abandonment of the rural Wayuu by the urban alijuna governors and populace. Overcoming these entrenched prejudices will not only take time but the equivalent of a paradigm shift, a cognitive revolution towards greater equality and acceptance.

Within the Wayuu society, local Wayuu representatives are not always the most suitable to serve as interlocutors. For various reasons they may not be willing or able to transmit the standards, priorities or aspirations of the Wayuu water users to the water sector institutions. Historically, bilingual leaders have been required for fluid communication to occur, yet in many cases the monolingual leaders are the ones who should serve as representatives. Among several of the Wayuu communities I conducted research in, the official or legal representative of the community did not live in the community, or even if he or she did, his or her affluence was far removed from the reality of the ordinary inhabitants, inhibiting empathy, camaraderie or solidarity.

In addition, familial or individual interests can divert or hamper assistance for the beneficiaries, and the transfer of large amounts of money has corrupted Wayuu leaders as 
well. For example, Javier Rojas Uliana is a Wayuu leader and legal representative of the Wayuu organization Shipia Wayuu who for the last ten years has led the reporting of Wayuu children deaths because of malnutrition. He has also accused the national, provincial and various municipal governments and agencies before the Inter-American Commission on Human Rights (IACHR) and the Colombian Constitutional Court for not fulfilling the preventive measures dictated by these judicial organisms (El Tiempo 2019). On March 29, 2019, Mr. Rojas was incarcerated for embezzlement of public funds (an estimated $\$ 294,000$ USD), breach of contract, and falsifying documentation related to a rural development project his organization led to benefit the Wayuu communities he represents (ibid).

As described in Chapter Seven, the general Wayuu populace has the most to gain and the most to lose when waterworks are to be installed in their communities. For this reason, and those detailed above, I have paid special attention to the voices of the ordinary Wayuu water users and the other-than-human Pulowi, rather than Wayuu leaders or Western water experts. The general Wayuu population is also the most knowledgeable of the social and natural milieus of their territory, retaining and passing on to the younger generations a wealth of tacit and explicit ways of knowing and being. Nevertheless, the knowledge produced from the base is the least visible, the least valued and the least accessible to the non-Wayuu resource managers and water experts. This dissertation is my attempt to make visible what has been historically invisibilized, and to incite reflection among the Wayuu and alijuna surrounding the right to water, its local value and alternative forms of governance. 


\section{REFERENCES}

Acheson, James. 1989. "Management of common property resources." In Economic Anthropology, edited by Stuart Plattner, 351-378. Stanford, CA: Stanford University Press.

Acheson, James M., and Bonnie J. McCay. 1987. The Question of the Commons: The culture and ecology of communal resources. Tucson: University of Arizona Press.

Acosta Medina, Amilkar. 2013. “Colombia: Escenario de las Desigualdades.” Tendencias 14 (1): 9-35.

Agrawal, Arun. 1998. Greener Pastures: Politics, markets, and community among a migrant pastoral people. New Delhi: Oxford University Press.

Agrawal, Arun. 2003. Sustainable Governance of Common-Pool Resources: Context, methods, and politics. Annual Review of Anthropology 32 (January): 243-262.

Agrawal, Arun. 2005. Environmentality: Technologies of government and the making of subjects. Durham: Duke University Press.

Allan, J. A. 2013. Handbook of Land and Water Grabs in Africa: Foreign direct investment and food and water security. 1st ed. Abingdon, United Kingdom; New York, NY: Routledge.

Anand, Nikhil. 2017. Hydraulic City: Water and the infrastructures of citizenship in Mumbai. Durham: Duke University Press.

Anderson, David. 2002. Eroding the Commons: The politics of ecology in Baringo, Kenya 1890s-1963. Oxford; Athens; Nairobi: Ohio University Press.

Anderson, Elizabeth P., Sue Jackson, Rebecca E. Tharme, Michael Douglas, Joseph E. Flotemersch, Margreet Zwarteveen, Chicu Lokgariwar, et al. 2019. "Understanding Rivers and their Social Relations: A critical step to advance environmental water management." WIREs Water. (6):1-21. DOI: 10.1002/wat2.1381.

Angulo, Roberto. 2011. Índice de Pobreza Multidimensional para Colombia. Index of Multidimensional Poverty for Colombia. Departamento Nacional de Planeación. https://www.ophi.org.uk/wp-content/uploads/OPHI-HDCA-SS11-Case-StudiesMPI-Mexico-Colombia-English-translation.pdf

Ardila, Gerardo. 1990. “Acercamiento a la Historia Prehispánica de La Guajira.” In La Guajira: De la memoria al porvenir una visión antropológica, edited by Gerardo Ardila, 59-80. Fondo FEN Colombia, Universidad Nacional de Colombia. 
Aschmann, Homer. 1960. "Indian Pastoralists of the Guajira Peninsula." Annals of the Association of American Geographers 50 (4): 408-418.

Assies, Willem, Gemma van der Haar, and A. J. Hoekema. 2000. The Challenge of Diversity: Indigenous peoples and reform of the state in Latin America. Amsterdam: Thela Thesis.

Baker, Lawrence. 2013. "Hegemonic Concepts and Water Governance from a ScientificEngineering Perspective." In Contemporary Water Governance in the Global South: Scarcity, marketization and participation, eds. Leila M. Harris, Jacqueline A. Goldin and Christopher Sneddon, 25-32. Abingdon, Oxon; New York, NY: Routledge.

Bakker, Karen. 2007. The "Commons" Versus the "Commodity": Alter-globalization, anti-privatization and the human right to water in the global south. Antipode 39 (3): 430-455.

Bakker, Karen. 2012a. Water Security: Research challenges and opportunities. Science 337 (6097): 914-915.

Bakker, Karen. 2012b. Water: Political, biopolitical, material. Social Studies of Science 42 (4): 616-623.

Ballesteros López, Judith. 2010. "Dinámicas de Identidad y Cultura en una Comunidad de Pescadores Wayuu: Caso Mmayapu en el Caribe Colombiano." Master's thesis, Universidad Nacional de Colombia - Sede Caribe.

Barber, Russell J., and Frances Berdan. 1998. The Emperor's Mirror: Understanding cultures through primary sources. Tucson: University of Arizona Press.

Barranquilla, José Agustín. 1946. Así Es La Guajira. Barranquilla: Emp. Litográfica.

Barth, Fredrik. 1961. Nomads of South-Persia. Boston: Little Brown.

Bassett, Thomas J., and Donald Crummey. 2003. African Savannas: Global narratives \& local knowledge of environmental change. Oxford; Portsmouth, NH: James Currey; Heinemann.

Becker, Marc. 2011. Pachakutik: Indigenous movements and electoral politics in Ecuador. Lanham, Md: Rowman \& Littlefield Publishers.

Benjaminsen, Tor A., Faustin P. Maganga, and Jumanne Moshi Abdallah. 2009. "The Kilosa Killings: Political ecology of a farmer-herder conflict in Tanzania." Development and Change 40 (3): 423-45.

Berkes, Fikret. 2012. Sacred Ecology. 3rd ed. New York: Routledge. 
Berkes, Fikret, Johan Colding, and Carl Folke. 2000. "Rediscovery of Traditional Ecological Knowledge as Adaptive Management.” Ecological Applications 10 (5): 1251-1262.

Berkes, Fikret, Johan Colding, and Carl Folke. 2003. Navigating Social-Ecological Systems: Building resilience for complexity and change. Cambridge, U.K.; New York: Cambridge University Press.

Bernard, H. R. 2006. Research Methods in Anthropology: Qualitative and quantitative approaches. 4th ed. Lanham, Md: AltaMira Press.

Bessire, Lucas, and David Bond. 2014. "Ontological Anthropology and the Deferral of Critique.” American Ethnologist 41 (3): 440-456.

Blasco, Lucía. 2019. "'La Guajira es una zona en Donde Colombia Refleja sus Miedos': Weildler Guerra, el indígena a quien le encomendaron gobernar una región en crisis.” $B B C$, February 03, 2019, World. https://www.bbc.com/mundo/noticiasamerica-latina-46863854.

Blaser, Mario. 2010. Storytelling Globalization from the Chaco and Beyond. Durham, NC: Duke University Press.

Blaser, Mario. 2009. "The Threat of the Yrmo: The political ontology of a sustainable hunting program.” American Anthropologist 111 (1): 10-20.

Blount, Ben G., and Ted L. Gragson. 1999. Ethnoecology: Knowledge, resources, and rights. Athens: University of Georgia Press.

Bodley, John H. 2011. Cultural Anthropology: Tribes, states, and the global system. 5th ed. Lanham, Md: AltaMira Press.

Boelens, Rutgerd. 2014. Cultural Politics and the Hydrosocial Cycle: Water, power and identity in the Andean Highlands. Geoforum 57: 234-247.

Bolinder, Gustaf. 1957. Indians on horseback. London: D. Dobson.

Bollig, Michael. 2006. Risk Management in a Hazardous Environment: A comparative study of two pastoral societies. New York: Springer.

Bollig, M., and C. Lesorogol. 2016. "The 'New Pastoral Commons' of Eastern and Southern Africa." International Journal of the Commons 10 (2): 665-687.

Brettes, Joseph de. 1898. "Chez les Indiens du Nord de la Colombie: Six ans d'exploration." Le Tour Du Mond IV: 433-479. 
Brodzinsky, Sibylla. 2015. "Colombia's Pipes to Nowhere: Villagers die of thirst as corruption stalls dam project." The Guardian, June 18, 2015, Food security. https://www.theguardian.com/global-development/2015/jun/18/colombia-waterdrought-rancheria-corruption.

Brown, Michael F. 2008. "Cultural relativism 2.0.” Current Anthropology 49 (3): 363383.

Budds, J., and F. Sultana. 2013. "Exploring Political Ecologies of Water and Development." Environment and Planning D: Society \& Space: 31: 275-279.

Butler, Judith. 1999. Gender Trouble: Feminism and the subversion of identity. New York: Routledge.

Butt, Bilal. 2015. "Herding by Mobile Phone: Technology, social networks and the 'transformation' of pastoral herding in East Africa." Human Ecology 43 (1): 1-14.

Caillon, Sophie, Georgina Cullman, Bas Verschuuren, and Eleanor J. Sterling. 2017. "Moving Beyond the Human-Nature Dichotomy Through Biocultural Approaches: Including ecological well-being in resilience indicators. Ecology and Society 22 (4): 27. https://doi.org/10.5751/ES-09746-220427

Cajete, Gregory. 1999. Native Science: Natural laws of interdependence. 1st ed. Santa Fe, N.M: Clear Light Publishers.

Candelier, Henri. 1893. Rio-hacha et les Indiens Goajires. Paris: Firmin-Didot.

Cano Correa, Claudia, María Clara van der Hammen Malo and Camilo Arbeláez Albornoz. 2010. Sembrar en Medio del Desierto: Ritual y agrobiodiversidad entre los Wayuu. Bogotá D.C., Colombia: Instituto Alexander von Humboldt, Tropenbos Internacional Colombia, Parque Nacional Natural Macuira de la UAESPNN.

Cano Pecharroman, Lidia. 2018. "Rights of Nature: Rivers that can stand in court." Resources 7(3): 1-14. doi:10.3390/resources7010013.

Carabali, A., M. L. Castellanos, D. Robles, A. Daza, F. Avella, A. Radillo, A. Oduber, et al. 2019. Lineamientos para el Ordenamiento Territorial Costero y Marino del Departamento de La Guajira desde la Diversidad Cultural, ed. Grupo Territorios Semiáridos del Caribe, Riohacha, Colombia: Universidad de La Guajira.

Cardoso, Fernando Henrique and Enzo Faletto. 1979. Dependency and Development in Latin America. Expanded and emended edition.University of California Press.

Casey, Nicolas. 2019. “They Survived Colonization and War, but Venezuela's Collapse was Too Much." New York Times, July 30, 2019, Americas. 
https://www.nytimes.com/2019/07/30/world/americas/venezuela-Indigenouswayuu.html

Castellanos, Juan de. 1955. Elegías de Varones Ilustres de Indias. Bogotá: Editorial $\mathrm{ABC}$.

Cepek, Michael. 2018. Life in Oil: Cofán survival in the petroleum fields of Amazonia. First edition. Austin, TX: University of Texas Press.

Cepek, Michael. 2011. "Foucault in the Forest: Questioning environmentality in Amazonia." American Ethnologist 38 (3): 501-515.

Chacín, Hilario. 2016. Asombros del Pueblo Wayuu. Cabimas, Venezuela: Fondo Editorial UNERMB.

Chandler, David. 2014. Resilience: The governance of complexity. Abingdon, Oxon; New York, NY: Routledge.

Charnley, Susan. 1996. "Pastoralism and the Demise of Communal Property in Tanzania.” Cultural Survival Quarterly 20 (1). https://www.culturalsurvival.org/publications/cultural-survivalquarterly/pastoralism-and-demise-communal-property-tanzania.

Chávez, Milciades. 1946. Mitos, Leyendas y Cuentos de La Guajira. Boletín De Arqueología 2 (4): 305-331.

Chief, Karletta, John J. Daigle, Kathy Lynn, and Kyle Powys Whyte. 2014. Indigenous Experiences in the U.S. with Climate Change and Environmental Stewardship in the Anthropocene. USDA Forest Service.

Clark, Nigel. 2014. "Geo-Politics and the Disaster of the Anthropocene." The Sociological Review (Keele) 62: 19-37.

Cleaver, Frances. 2006. "The Evolution of Community Water Governance in Uchira, Tanzania: The implications for equality of access, sustainability and effectiveness." Natural Resources Forum 30 (3): 207-218.

Clifford, James. 2013. Returns: Becoming Indigenous in the twenty-first century. Cambridge, Massachusetts: Harvard University Press.

Cochran, Patricia, Orville Huntington, Caleb Pungowiyi, Stanley Tom, F. Chapin, Henry Huntington, Nancy Maynard, and Sarah Trainor. 2013. "Indigenous Frameworks for Observing and Responding to Climate Change in Alaska." Climatic Change 120 (3): 557-567. 
Conklin, Beth A., and Laura R. Graham. 1995. "The Shifting Middle Ground: Amazonian Indians and eco-politics.” American Anthropologist 97 (4): 695-710.

CONtexto Ganadero. 2017. "Represa de El Cercado: ¿Nuevo elefante blanco de La Guajira?" CONtexto Ganadero2017.

Contraloría General de la Nación. 2017. Guajira Sin Solución de Agua a la Vista: Megaproyecto de represa del Río Ranchería sin utilidad alguna. Comunicado de Prensa no. 236. Bogotá, Colombia. https://www.contraloria.gov.co/contraloria/salade-prensa/boletines-de-prensa/boletines-prensa-2017//asset_publisher/y0hcpbxJNnDG/content/guajira-sin-solucion-de-agua-a-la-vistamegraproyecto-de-represa-del-rio-rancheria-sin-utilidad-alguna-y-sumantenimiento-es-costoso?inheritRedirect=false

Coppolillo, Peter B. 2000. "The Landscape Ecology of Pastoral Herding: Spatial analysis of land use and livestock production in East Africa." Human Ecology 28 (4): 527560.

Coppolillo, Peter B. 2001. "Central-Place Analysis and Modeling of Landscape-Scale Resource Use in an East African Agropastoral System. Landscape Ecology 16 (3): 205-219.

Corte Constitucional. 2017. Sentencia T302/2017. Acción De Tutela Para Proteger Los Derechos Fundamentales a La Salud, Al Agua Y a La Alimentación De Los Niños Y Niñas Del Pueblo Wayuu Del Departamento De La Guajira. República de Colombia. https://www.corteconstitucional.gov.co/relatoria/2017/t-302-17.htm

Crate, Susan Alexandra, Anthropological Association Meeting American, Applied Anthropology Meeting Society for, and Mark Nuttall. 2009. Anthropology and Climate Change: From Encounters to Actions. Walnut Creek, CA: Left Coast Press.

Dalby, Simon. 2009. Security and Environmental Change. Cambridge: Polity.

DANE. 2005. Censo Nacional 2005. República de Colombia: Departamento Administrativo Nacional de Estadística.

DANE. 2019. Pueblo Wayuu: Resultados del censo nacional de población y vivienda 2018. República de Colombia: Departamento Administrativo Nacional de Estadística.

DANE. 2019. Población Indígena de Colombia: Resultados del Censo Nacional de Población y Vivienda 2018. República de Colombia: Departamento Administrativo Nacional de Estadística. 
Daza Daza, Alcides R., Ciro A, Serna Mendoza, Alexis Carabalí Angola. 2018. "El Recurso Agua en las Comunidades Indígenas Wayuu de La Guajira Colombiana. Parte 2: Estudio Cualitativo de las Condiciones de Higiene, Aseo y Disponibilidad de Agua." Información Tecnológica 29 (6): 25-32.

Daza Villar, Vladimiro. 2002. Guajira, Memoria Visual. Riohacha: Banco de la República.

de Bont, Chris. 2016. "The Fluid Nature of Water Grabbing: The on-going contestation of water distribution between peasants and agribusinesses in Nduruma, Tanzania." Agriculture and Human Values 33 (3): 641-654.

de la Cadena, Marisol. 2000. Indigenous Mestizos: The politics of race and culture in Cuzco, Peru, 1919-1991. Durham, NC: Duke University Press.

de la Cadena, Marisol. 2010. "Indigenous Cosmopolitics in the Andes: Conceptual reflections beyond "politics'." Cultural Anthropology 25 (2): 334-370.

de la Cadena, Marisol. 2015. Earth Beings: Ecologies of practice across Andean worlds. Durham: Duke University Press.

Deloria, Vine. 1995. Red Earth, White Lies: Native Americans and the myth of scientific fact. New York: Scribner.

DNP. 2017. Panorámica Regional: Pobreza monetaria y multidimensional departamental: Necesidad y políticas públicas diferenciadas. República de Colombia: Departamento Nacional de Planeación. https://colaboracion.dnp.gov.co/CDT/Prensa/Publicaciones/Publicaci\%C3\%B3n\%20 Ipm\%20deptal.pdf

DPS/PMA. 2014. Informe del Estudio Piloto para el Análisis de la Vulnerabilidad a la inseguridad alimentaria y nutricional (VAM) en Poblaciones Indígenas (Etnia Wayuu - La Guajira). Departamento Nacional de Planeación y el Programa Mundial de Alimento Convenio de Cooperación No. 035 de 2013.

Dworkin, Daniel M. 1980. Rural Water Projects in Tanzania: Technical, social, and administrative issues. Washington, D.C: U.S. Agency for International Development.

Eira, Inger Marie Gaup, Christian Jaedicke, Ole Henrik Magga, Nancy G. Maynard, Dagrun Vikhamar-Schuler, and Svein D. Mathiesen. 2013. "Traditional Sámi Snow Terminology and Physical Snow Classification: Two ways of knowing." Cold Regions Science and Technology 85:117-130. 
El Tiempo. "Cárcel a Líder Wayúu que Denunció al Estado Colombiano Ante la CIDH." March 29, 2019. El Tiempo. Seguir Otras Ciudades.

https://www.eltiempo.com/colombia/otras-ciudades/capturado-lider-indigenawayuu-343426.

Elands, B. H. M., K. Vierikko, E. Andersson, L. K. Fischer, P. Concalves, D. Haase, I. Kowarik, et al. 2019. "Biocultural Diversity: A novel concept to assess humannature interrelations, nature conservation and stewardship in cities." Urban Forestry \& Urban Greening 40 (Spring): 29-34.

Eliade, Mircea. 1972. Shamanism: Archaic techniques of ecstasy. Princeton, N.J: Princeton University Press.

Erazo, Juliet S. 2013. Governing Indigenous Territories: Enacting sovereignty in the Ecuadorian Amazon. Durham: Duke University Press.

Erazo, Juliet S., and Christopher C. Jarrett. 2017. "Managing Alterity from Within: The ontological turn in anthropology and Indigenous efforts to shape shamanism." Journal of the Royal Anthropological Institute 24: 145-163.

Escobar, Arturo. 1995. Encountering Development: The making and unmaking of the third world. Princeton, N.J: Princeton University Press.

Escobar, Arturo. 2008. Territories of Difference: Place, movements, life, redes. Durham: Duke University Press.

Escobar, Arturo. 2012. Encountering Development: The making and unmaking of the third world. $2^{\text {nd }}$ Edition. Princeton and Oxford: Princeton University Press.

Escobar, Arturo. 2015. "Territorios de Diferencia: La ontología política de los 'derechos al territorio'." Cuadernos De Antropología Social (41): 25-38.

Escobar, Arturo. 2016. "Sentipensar con la Tierra: Las luchas territoriales y la dimensión ontológica de las Epistemologías del Sur." Revista De Antropología Iberoamericana 11 (1): 11-32.

Evans Pritchard, Edward Evan. 1969. The Nuer: A description of the modes of livelihood and political institutions of a Nilotic people. New York; Oxford: Oxford University Press.

Evans, Brad, and Julian Reid. 2014. Resilient Life: The art of living dangerously. Cambridge, UK; Malden, MA: Polity Press.

Evarist, Roman. 2016. Background Information on Mara Region. n.p. 
Fals Borda, Orlando. 1973. "Reflexiones Sobre la Aplicación del Método de EstudioAcción en Colombia.” Revista Mexicana De Sociología 35 (1): 49-62.

Fals Borda, Orlando. 2002. "El Tercer Mundo y la Reorientación de las Ciencias Contemporáneas.” Nueva Sociedad 107 (mayo/junio):169-181.

Fardon, Richard. 1992. "Postmodem Anthropology? Or, an Anthropology of Postmodemity?" In Postmodernism and the Social Sciences, edited by Joe Doherty, Elspeth Graham, and Mohammed H. Malek, 23-38. New York, NY: St. Martin's Press.

Faysse, Nicolas. 2006. "Troubles on the Way: An analysis of the challenges faced by multi-stakeholder platforms." Natural Resources Forum 30 (3): 219-229.

Ferguson, James. 1990. The Anti-Politics Machine: "Development," depoliticization, and bureaucratic power in Lesotho. Cambridge, England; New York: Cambridge University Press.

Fleisher, Michael L. 2000. Kuria Cattle Raiders: Violence and vigilantism on the Tanzania/Kenya frontier. Ann Arbor, MI: University of Michigan Press.

Folke, Carl. 2016. "Resilience.” In Oxford Research Encyclopedia of Environmental Science. USA: Oxford University Press.

Folke, C., L. Pritchard, F. Berkes, J. Colding, and U. Svedin. 2007. "The Problem of Fit Between Ecosystems and Institutions: Ten years later." Ecology and Society 12 (1): 30. http://www.ecologyandsociety.org/vol12/iss1/art30/

Foucault, Michel and Colin Gordon. 1980. Power/Knowledge: Selected interviews and other writings, 1972-1977. 1st American ed. ed. New York: Pantheon Books.

Foucault, Michel, Mauro Bertani, François Ewald, Alessandro Fontana, David Macey, and David Macey. 2003. Society Must be Defended: Lectures at the Collège de France, 1975-76. 1st ed. New York: Picador.

Frank, Billy, Zoltán Grossman, and Alan Parker. 2012. Asserting Native Resilience: Pacific rim Indigenous nations face the climate crisis. Corvalis, OR: Oregon State University Press.

Fratkin, Elliot. 1997. "Pastoralism: Governance and development issues." Annual Review of Anthropology 26: 235-261.

Fratkin, Elliot M., Kathleen A. Galvin, and Eric Abella Roth. 1994. African Pastoralist Systems: An integrated approach. Boulder, CO: L. Rienner Publishers. 
Fratkin, Elliot M., and Eric Abella Roth. 2005. As Pastoralists Settle: Social, health, and economic consequences of the pastoral sedentarization in Marsabit District, Kenya. New York: Kluwer Academic Publishers.

Freire, Paulo. 1970. Pedagogy of the Oppressed. New York: Herder and Herder.

Fundación Cerrejón. 2013a. Carpeta Reservorio de Jotomana. Fundación Cerrejón para el Progreso de La Guajira.

Fundación Cerrejón. 2013b. Hacia un Esquema de Sostenibilidad de Sistemas de Suministro de Agua Basados en Reservorios en la Alta Guajira: Caracterización sociocultural del territorio: Resumen ejecutivo. Fundación Cerrejón para el Progreso de La Guajira.

Fundación Cerrejón. 2013c. Hacia un Esquema de Sostenibilidad de Sistemas de Suministro de Agua Basados en Reservorios en la Alta Guajira: Caracterización sociocultural del territorio. Riohacha, Colombia: Fundación Cerrejón para el Progreso de La Guajira.

Fundación Cerrejón. 2013d. Plan de Reunión de Concertación: Con comunidades aledañas al proyecto de construcción del reservorio ubicado en el Arroyo Joutaipana. Fundación Cerrejón para el Progreso de La Guajira.

Fundación Cerrejón. 2013e. Reunión de Staff 28 agosto 2013. Fundación Cerrejón para el Progreso de La Guajira.

Fundación Cerrejón. 2019. Informe de Gestión 2018. Fundación Cerrejón para el Progreso de La Guajira.

Fundación Cerrejón and CINARA. 2013. Documento de Análisis de Alternativas para Potabilización del Agua de los Reservorios de la Gran Vía y Utaykalamana. Fundación Cerrejón para el Progreso de La Guajira; Instituto de Investigación y Desarrollo en Abastecimiento de Agua, Saneamiento Ambiental y Conservación del Recurso Hídrico, CINARA.

Galaty, John. 2014. “'Unused' Land and Unfulfilled Promises: Justifications for displacing communities in East Africa.” Nomadic Peoples 18 (1) (January): 80-93.

Galaty, John. 2016. "Reasserting the Commons: Pastoral contestations of private and state lands in East Africa." International Journal of the Commons 10 (2): 709-727.

Galaty, John, and Douglas L. Johnson. 1990. The World of Pastoralism: Herding systems in comparative perspective. New York; London: Guilford Press. 
Galeano, Eduardo. 1971. Las Venas Abiertas de América Latina. La Habana: Casa de las Américas.

García Hierro, Pedro, and Alexandre Surrallés. 2005. The Land Within: Indigenous territory and the perception of the environment. Copenhagen: IWGIA.

Graham, Laura R., and H. Glenn Penny. 2014. "Performing Indigeneity: Emergent Identity, Self-Determination, and Sovereignty." In Performing Indigeneity: Global Histories and Contemporary Experiences. Edited by Laura R Graham and H. Glenn Penny, 1-31. Lincoln; London: University of Nebraska Press.

Geere, Jo-Anne L., Paul R. Hunter, and Paul Jagals. 2010. "Domestic Water Carrying and its Implications for Health: A review and mixed methods pilot study in Limpopo Province, South Africa." Environmental Health 9 (52). doi: 10.1186/1476-069X-952.

GLOWS-FIU. 2012. Environmental Flows Recommendations for the Mara River, Kenya and Tanzania. Miami, FL: Global Water for Sustainability program (GLOWS).

Gobernación de La Guajira. 2011. Evaluación Social y Plan de Pueblos Indígenas: Para el proyecto "Construcción y sostenibilidad de once (11) reservorios y un (1) microacueducto, en comunidades indígenas de la Alta Guajira. Riohacha, Colombia: Gobernación de La Guajira.

Goldin, Jacqueline A., Christopher Sneddon, and Leila M. Harris. 2013. "Introduction: Interrogating hegemonic discourses in water governance." In Contemporary Water Governance in the Global South: Scarcity, marketization and participation., eds. Jacqueline A. Goldin, Christopher Sneddon and Leila M. Harris, 1-10. Abingdon, Oxon; New York, NY: Routledge.

Goldin, Jacqueline, Leila Harris, and Christopher Sneddon eds. 2013. Contemporary Water Governance in the Global South: Scarcity, marketization and participation. Abingdon, Oxon; New York, NY: Routledge.

Goldman, M. 2007. 'How 'Water For All!' Policy Became Hegemonic: The power of the World Bank and its transnational policy networks." Geoforum 38 (5): 786-800.

Goldman, Mara J., Meaghan Daly, and Eric J. Lovell. 2016. "Exploring Multiple Ontologies of Drought in Agro-Pastoral Regions of Northern Tanzania: A topological approach. Area 48 (1): 27-33.

Gomez, Edmund Terence, and Suzana Sawyer. 2012. The Politics of Resource Extraction: Indigenous peoples, multinational corporations, and the state. New York: Palgrave Macmillan, United Nations Research Institute for Social Development. 
Gonin, Alexis. 2015. "Shift in Herders' Territorialities from Regional to Local Scale: The political ecology of pastoral herding in Western Burkina Faso." Pastoralism: Research, Policy and Practice 5 (1): 1-12.

Gonzalez Bermudez, Jorge Luis. 2002. Etnoecologia Wayuu: Pautas de asentamientos y aprovechamiento del ecosistema en la Serrania de la Makuira, Alta Guajira, Colombia. Universidad de La Guajira.

Gorenflo, L. J., Suzanne Romaine, Russell A. Mittermeier, and Kristen WalkerPainemilla. 2012. "Co-Occurrence of Linguistic and Biological Diversity in Biodiversity Hotspots and High Biodiversity Wilderness Areas." Proceedings of the National Academy of Sciences of the United States of America 109 (21): 8032-8037.

Goulet, Jean-Guy. 1978. "Guajiro Social Organization and Religion (Volumes I and II).” $\mathrm{PhD}$ diss., Yale University.

Green, Lesley, ed. 2013. Contested Ecologies: Dialogues in the South on nature and knowledge. Cape Town, South Africa: HSRC Press.

Grove, Kevin. 2018. Resilience. Abingdon, Oxon; New York, NY: Routledge.

Guerra Curvelo, Weildler. 2002. La Disputa y la Palabra: La ley en la sociedad Wayuu. Bogotá: Ministerio de Cultura.

Guerra Curvelo, Weildler. 2007. "Las Marchantas y los Días.” Noticias 5 en Punto. http://noticiascincoenpunto.blogspot.com/2010/06/recordando-viejascolumnas.html\#more

Guerra Curvelo, Weildler. 2013. "Un Mirada Histórica y Etnográfica a la Cuenca del Río Ranchería.” Boletín Cultural y Bibliográfico XLVII (84): 66-93.

Guerra Curvelo, Weildler, and Luis Alonso Castaño Benjumea. 2015. El Mar Cimarrón: Conocimientos sobre el mar, la navegación y la pesca entre los Wayuu. Oranjestad, Aruba: Museo Arqueológico Nacional Aruba.

Gutiérrez de Pineda, Virginia. 1950. Organización Social en La Guajira. Prensas del Ministerio de Educación Nacional.

GWP. 2016. Agenda 2030, GWP in Action: 2015 annual report. Global Water Partnership.

Haraway, Donna Jeanne. 1989. Primate Visions: Gender, race, and nature in the world of modern science. New York: Routledge. 
Haraway, Donna Jeanne. 2008. When Species Meet. Minneapolis: University of Minnesota Press.

Hardin, Garret. 1968. “The Tragedy of the Commons.” Science 162 (3859): 1243-1248.

Harkin, Michael E. 2010. "Ethnohistory's Ethnohistory: Creating a Discipline from the Ground Up." Social Science History 34 (2): 113-128.

Heald, Suzette. 1991. "Tobacco, Time, and the Household Economy in Two Kenyan Societies: The Teso and the Kuria." Comparative Studies in Society and History 33 (01): 130-57.

Hernandez de Alba, Gregorio. 1936. Etnología Guajira. Bogotá: Editorial A.B.C.

Hernández Peña, Yolanda Teresa. 2010. “Ordenamiento Territorial y su Construcción Social en Colombia: ¿Un instrumento para el desarrollo sustentable?" Cuadernos De Geografía (19): 97-109.

Herskovits, Melville J. 1926. "The Cattle Complex in East Africa. American Anthropologist 28 (1): 230-272.

History Extra. 2019. “Why Do We Say 'White Elephant'?” History Extra. August 12, 2019. Victorian, https://www.historyextra.com/period/victorian/why-do-we-saywhite-elephant/.

Hodgson, Dorothy Louise. 2011. Being Maasai, Becoming Indigenous: Postcolonial politics in a neoliberal world. Bloomington, Ind: Indiana University Press.

Homewood, Katherine, Patricia Kristjanson, and Pippa Trench. 2009. Staying Maasai? Livelihoods, conservation, and development in East African rangelands. New York, NY: Springer.

Howard, Guy and Jamie Bartram. 2003. Domestic Water Quantity, Service Level and Health. Geneva, Switzerland: World Health Organization.

Hughes, Lotte. 2006. Moving the Maasai: A colonial misadventure. Basingstoke, England; New York; Oxford: Palgrave Macmillan in association with St. Antony's College.

Humanitarian Policy Group. 2009. Synthesis Paper April 2009: Pastoralism and climate change, enabling adaptive capacity. London: Overseas Development Institute.

Huysmans, Jef. 1998. "Security! What do You Mean? From concept to thick signifier." European Journal of International Relations 4 (2): 226-255. 
Igoe, Jim. 2004. Conservation and Globalization: A study of the national parks and Indigenous communities from East Africa to South Dakota. Belmont, CA, USA: Thomson/Wadsworth.

Iguarán, Agustín. 2019. “Contralor Reportó 1.193 Elefantes Blancos en el País.” El Heraldo. November 13, 2019, Magdalena. https://www.elheraldo.co/magdalena/contralor-reporto-1193-elefantes-blancos-en-elpais-680220.

INE. 2011. XIV Censo de Población y Vivienda 2011. República Bolivariana de Venezuela: Gerencia General de Estadísticas Demográficas, Instituto Nacional de Estadística.

IPCC. 2014. Climate Change 2014: Synthesis report. Contribution of working groups I, II and III to the fifth assessment report of the intergovernmental panel on climate change. Geneva, Switzerland: [Core Writing Team, R.K. Pachauri and L.A. Meyer (eds.)]. IPCC.

IPCC. 2018. "Summary for Policymakers." In Global Warming of $1.5^{\circ} \mathrm{C}$ : An IPCC special report on the impacts of global warming of $1.5^{\circ} \mathrm{C}$ above pre-industrial levels and related global greenhouse gas emission pathways, in the context of strengthening the global response to the threat of climate change, sustainable development, and efforts to eradicate poverty, eds. V. Masson-Delmotte, P. Zhai, H. O. Pörtner, D. Roberts, J. Skea, P. R. Shukla, A. Pirani, et al.

Issacs, Jorge. 1884. Estudio Sobre las Tribus Indígenas del Estado del Magdalena, Antes Provincia de Santa Marta. Anales De La Instrucción Pública 8.

Jackson, Jean E. 1995. "Culture, Genuine and Spurious: The Politics of Indianness in the Vaupés, Colombia." American Ethnologist 22 (1): 3-27.

Jackson, Jean E. and Kay B. Warren. 2002. Indigenous Movements, Self-Representation, and the State in Latin America. 1st ed. Austin: University of Texas Press.

Jaramillo, Pablo. 2014. Etnicidad y Victimización: Genealogías de la violencia y la indigenidad en el norte de Colombia. Primera edición. Bogotá: Universidad de los Andes, Facultad de Ciencias Sociales, Departamento de Antropología.

Jerez, Daniel. 2019. "Proyecto Busca Crear Registro de 'Elefantes Blancos' por Obras Inconclusas." Rcnradio. April 14, 2019, Política. https://www.rcnradio.com/politica/proyecto-busca-crear-registro-de-elefantesblancos-por-obras-inconclusas. 
Joint Monitoring Programme 2012. Progress on Drinking Water and Sanitation: 2012 update. New York: WHO/UNICEF Joint Monitoring Programme for Water Supply and Sanitation.

Joint Monitoring Programme 2015. Progress on Sanitation and Drinking Water: 2015 update and MDG assessment. New York: UNICEF and World Health Organization Joint Monitoring Programme for Water Supply and Sanitation.

Joint Monitoring Programme. 2017. Progress on Drinking Water, Sanitation and Hygiene: 2017 update and SDG baselines. Geneva: World Health Organization (WHO) and the United Nations Children's Fund (UNICEF).

Jusayú, Miguel Angel. 1975. Jukújalairrua Wayú: Relatos guajiros. Caracas: Universidad Católica Andrés Bello- Instituto de Investigaciones Históricas - Centro de Lenguas Indígenas - Editorial Arte.

Kaye-Zwiebel, E. 2014. “Kenyan Pastoralist Societies in Transition: Varying perceptions of the value of ecosystem services." Ecology and Society 19 (3) (September): 17. http://dx.doi.org/10.5751/ES-06753-190317

Kessler, Ilana. 2006. "What Went Right in Tanzania: How nation building and political culture have produced forty-four years of peace." Master's Thesis, Georgetown University.

Kohn, Eduardo. 2013. How Forests Think: Toward an anthropology beyond the human. Berkeley: University of California Press.

Komakech, Hans C. 2013. "Polycentrism and Pitfalls: The formation of water users forums in the Kikuletwa catchment, Tanzania." Water International 38 (3): 231-249.

Kosek, Jake. 2006. Understories: The political life of forests in northern New Mexico. Durham: Duke University Press.

Kottak, Conrad Phillip. 2015. Cultural Anthropology: Appreciating cultural diversity. Sixteenth edition. New York, NY: McGraw-Hill Education.

Kovach, Margaret. 2009. Indigenous Methodologies: Characteristics, conversations and contexts. Toronto: University of Toronto Press.

Krech, Shepard. 1999. The Ecological Indian: Myth and history. 1st ed. New York: W.W. Norton \& Company.

Kuethe, Allan J. 1970. "The Pacification Campaign on the Riohacha Frontier, 17721779." The Hispanic American Historical Review, 50 (3): 467-481. 
Kuhn, Thomas S. 1970. The Structure of Scientific Revolutions. 2nd ed., enlarged; Chicago: University of Chicago Press.

Laenui, Pō, Hayden Burgess, and TCP. 1990. "The World Council of Indigenous Peoples: An interview with Pōkā Laenui." The Contemporary Pacific 2 (2): 336-348.

Langeback, Carl, Andrea Cuellar, and Alejandro Dever. 1998. Medio Ambiente y Poblamiento en La Guajira: Investigaciones arqueológicas en el Ranchería Medio. Bogotá: Universidad de Los Andes, Departamento de Antropología.

Lankford, Bruce A. 2013. Water Security: Principles, perspectives, and practices. Abingdon, Oxon: Routledge.

Lansing, John Stephen. 1991. Priests and Programmers: Technologies of power in the engineered landscape of Bali. Princeton, N.J: Princeton University Press.

Latour, Bruno. 1993. We Have Never Been Modern. Cambridge, Mass: Harvard University Press.

Latour, Bruno. 2011. "From Multiculturalism to Multinaturalism: What rules of method for the new socio-scientific experiments?" Nature and Culture 6 (1) (April): 1-17.

Legum, Colin and Geoffrey Mmari, eds. 1995. Mwalimu: The influence of Nyerere. 1st Africa World Press ed. Trenton, N.J: Africa World Press.

Lertzman, David Adam. 2010. "Best of Two Worlds: Traditional ecological knowledge and Western science in ecosystem- based management." BC Journal of Ecosystems and Management 10 (3): 104-126.

Linton, Jamie. 2010. What is water? The history of a modern abstraction. Vancouver: UBC Press.

López Epieyu, Antonio. 1957. Los Dolores de una Raza. Maracaibo: Imprenta La Columna.

López-Hernández, Miguel Ángel. 2000. Encuentros en los Senderos de Abya Yala. Bogotá: Ministerio de Cultura de Colombia; Fondo Mixto de Promoción de la Cultura y las Artes de La Guajira.

Luilo, Gebhard. 2003. "Inadequacies in Water Legislation for Water Resources Management." Journal of Water and Environment Technology 1: 1-6.

Maganga, Faustin P. 2004. "Implications of Customary Norms and Laws for Implementing IWRM: Findings from Pangani and Rufiji basins, Tanzania." Physics and Chemistry of the Earth.Parts A/B/C 29 (15-18): 1335-1342. 
Maiero, Marina and Xiaomeng Shen. 2004. Commonalities Between Cultural and BioDiversity. Bonn: ZEF Bonn.

Maitima, Joseph, Robin S. Reid, Louis N. Gachimbi, Amos Majule, Herbert Lyaruu, Derek Pomery, Simon Mugatha, Stephen Mathai, and Sam Mugisha. 2004. Regional Synthesis Paper: The linkages between land use change, land degradation and biodiversity across East Africa. LUCID Working Paper Series 42: i,vi, 1-51.

Malley, Z. J. U., M. Taeb, T. Matsumoto, and H. Takeya. 2008. "Linking Perceived Land and Water Resources Degradation, Scarcity and Livelihood Conflicts in Southwestern Tanzania: Implications for sustainable rural livelihood." Environment Development and Sustainability 10 (3): 349-372.

Mallon, Florencia E. 2005. Courage Tastes of Blood: The Mapuche community of Nicolás Ailío and the Chilean state, 1906-2001. Durham, N.C: Duke University Press.

Mancuso, Alessandro. 2006. "Relaciones de Género entre los Wayuu: Estado de la investigación y nuevos campos de análisis.” Aguaita 13-14: 39-61.

Mann, Michael E. 2012. The Hockey Stick and the Climate Wars: Dispatches from the front lines. New York: Columbia University Press.

Massumi, Brian. 2009. "National Enterprise Emergency Steps Toward an Ecology of Powers." Theory, Culture \& Society 26 (6): 153-185.

Maybury Lewis, David. 2002. Indigenous Peoples, Ethnic Groups, and the State. 2nd ed. Boston: Allyn and Bacon.

Mbonile, M. J. 2005. "Migration and Intensification of Water Conflicts in the Pangani Basin, Tanzania." Habitat International 29 (1): 41-67.

Mehari, Abraham. 2009. Unchartered Innovation? Local reforms of national formal water management in the Mkoji sub-catchment, Tanzania." Physics and Chemistry of the Earth. Parts A/B/C 34 (4-5): 299-308.

Mehta. 2016. "Introduction to the Special Issue: Flows and Practices: The politics of integrated water resources management (IWRM) in Southern Africa." Water Alternatives 9 (3) (October): 389-411.

Mercado Epieyu, Rafael Segundo. 2017. "La Dimensión Pedagógica de la Palabra de los Wayuu: Relatos ancestrales y escritura. Master's thesis, Universidad de Antioquia, Facultad de Educación, Departamento de Posgrados. 
Mignolo, Walter. 2000. Local Histories/Global Designs: Coloniality, subaltern knowledges, and border thinking. Princeton, N.J: Princeton University Press.

Ministerio del Interior. 2010. Acta Protocolización Proceso de Consulta Previa Proyecto Reservorio Jotomana. República de Colombia: Ministerio del Interior y de Justicia.

Ministerio de Vivienda. 2018. "Guajira Azul Hace Parte de la Nueva Generación de Proyectos del Gobierno Nacional." Viceministerio de Agua y Saneamiento Básico, Sala de Prensa. http://www.minvivienda.gov.co/sala-deprensa/noticias/2018/octubre/guajira-azul-hace-parte-de-la-nueva-generacion-deproyectos-del-gobierno-nacional.

Molle, François, Peter P. Mollinga, and Ruth Meinzen-Dick. 2008. "Water, Politics and Development: Introducing water alternatives." Water Alternatives 1 (1): 1-6.

Mollinga. 2008. "Water, Politics and Development: Framing a political sociology of water resources management." Water Alternatives 1 (1): 7-23.

Montiel Fernández, Nemesio. 1974. Nociones Sobre los Guajiros Prehispánicos y su Procedencia. Caracas: América Indígena XXXIV.

Morales, Cindy. 2019. “Así Funciona el Único Centro de Atención al Migrante en Colombia." El Tiempo, June 10, 2019, Venezuela. https://www.eltiempo.com/mundo/venezuela/asi-funciona-el-unico-centro-deatencion-al-migrante-en-colombia-en-maicao-la-guajira-367770.

Mosse, David. 2005. Cultivating Development: An ethnography of aid policy and practice. London; Ann Arbor, MI: Pluto Press.

Motta Vargas, Ricardo. 2010. "El Derecho Humano al Agua en Colombia: Planes departamentales y proceso de privatización." Revista Republicana 8: 109-125.

Múnera Montes, L., M. Granados Castellanos, S. Teherán Sánchez, and J. Naranjo Vasco. 2014. "Bárbaros Hoscos: Historia de resistencia y conflicto en la explotación del carbón en La Guajira, Colombia." Opera (14): 47-69.

Muyungi, R. S. 2007. "Managing Land Use, Protecting Land and Mitigating Land Degradation: Tanzania case study." In Climate and Land Degradation, ed. R.S. Muyungi, 437-45. Springer Link.

Nadasdy, Paul. 1999. "The Politics of TEK: Power and the 'integration' of knowledge." Arctic Anthropology 36 (1/2): 1-18. 
Nadasdy, Paul. 2002. "'Property' and Aboriginal Land Claims in the Canadian Subarctic: Some theoretical considerations.” American Anthropologist 104 (1): 24761.

Nadasdy, Paul. 2003. Hunters and Bureaucrats: Power, knowledge, and aboriginal-state relations in the southwest Yukon. Vancouver: UBC Press.

Nadasdy, Paul. 2005. "Transcending the Debate Over the Ecologically Noble Indian: Indigenous peoples and environmentalism.” Ethnohistory 52 (2): 291-331.

Nadasdy, Paul. 2007. “Adaptive Co-Management and the Gospel of Resilience.” In Adaptive co-management collaboration, learning, and multi-level governance., eds. Armitage, Derek R., Fikret Berkes and Nancy Doubleday, 208-225. Vancouver: UBC Press.

Nájera, Milderd, Arnoldo Pimienta and María Iguarán. 2010. Documento de Caracterización Sociocultural de las Comunidades Wayuu Identificadas Dentro del Área de Influencia del Reservorio de Gran Vía - Bahía Portete. Fundación Cerrejón para el Progreso de La Guajira.

Nemoga, Gabriel R. 2016. "Diversidad Biocultural: Innovando en investigación para la conservación." Acta Biológica Colombiana 21 (1, Suppl. S): 311-319.

Neumann, Roderick P. 2004. "Moral and Discursive Geographies in the War for Biodiversity in Africa." Political Geography 23 (7): 813-837.

Neumann, Roderick P. 2005. Making Political Ecology. London; New York: Oxford University Press.

Nindi, Stephen Justice, Hanori Maliti, Samwel Bakari, Hamza Kija, and Mwita Machoke. 2014. "Conflicts Over Land and Water Resources in the Kilombero Valley Floodplain, Tanzania." African Study Monographs: 173-190.

Norman, E., G. Dunn, K. Bakker, D. Allen, and R. Cavalcanti de Albuquerque. 2013. "Water Security Assessment: Integrating governance and freshwater indicators." Water Resources Management 27 (2): 535-551.

Ochoa Romero, Claribel, and Alexis Carabalí Angola. 2002. Tras la Huella del Guanebucán. Riohacha: Programa de Investigación Arqueológica, Universidad de La Guajira.

O'Connor, T. G., and G. A. Kiker. 2004. "Collapse of the Mapungubwe Society: Vulnerability of pastoralism to increasing aridity." Climatic Change 66 (1-2): 49-66. 
Oliver, José R. 1990. Reflexiones Sobre el Posible Origen del Wayu (Guajiro). In La Guajira: De la memoria al porvenir, una visión antropológica, ed. Gerardo Ardila, 83-127. Bogotá: Universidad Nacional de Colombia.

Orwell, George. 1949. Nineteen Eighty-Four: A novel. 1st American ed. New York: Harcourt, Brace and Co.

Ostrom, Elinor. 1990. Governing the Commons: The evolution of institutions for collective action. Cambridge; New York: Cambridge University Press.

Pacini Hernandez, Deborah. 1984. Resource Development and Indigenous People: The El Cerrejón coal project in Guajira, Colombia. Cambridge, MA: Cultural Survival, Inc.

Padilla, Guillermo. 1996. "La Ley y los Pueblos Indígenas en Colombia.” Journal of Latin American Anthropology 1 (2): 78-97.

Pana Uriana, Glicerio. 1981. El Guajiro Arrepentido: Cuento histórico. Riohacha, Colombia: Tipografía Aarón.

Paz Ipuana, Ramón. 1972. Mitos, Leyendas y Cuentos Guajiros. Caracas: Instituto Nacional Agrario.

Paz Ipuana, Ramón. 2016a. Ale'eya. Tomo I: Cosmovisión Wayuu: Relatos Sagrados. Riohacha: Fondo Editorial Wayuu Araurayu.

Paz Ipuana, Ramón. 2016b. Ale'eya. Tomo II: Conceptos y Descripciones de la Cultura Wayuu. Riohacha: Fondo Editorial Wayuu Araurayu.

Perreault, Tom. 2008. "Custom and Contradiction: Rural water governance and the politics of usos y costumbres in Bolivia's irrigators' movement." Annals of the Association of American Geographers 98 (4): 834-854.

Perrin, Michel. 1980. "A Relatively Good Result: Western medicine among the Guajiro indians.” Social Science \& Medicine.Medical Anthropology 14B (4): 279-287.

Perrin, Michel. 1993. El Camino de los Indios Muertos: Mitos y símbolos Guajiros. Tercera edición. Monte Avila.

Pesquisa Javeriana. 2018. “El Planeta Pierde Terreno.” Pontificia Universidad Javeriana, June 15, 2018, Desertificación.

https://www.javeriana.edu.co/pesquisa/tag/desertificacion/.

Pierotti, Raymond John. 2010. Indigenous Knowledge, Ecology, and Evolutionary Biology. New York: Routledge. 
Pineda Giraldo, Roberto. 1950. Aspectos de la Magia en La Guajira. Bogotá: Instituto Etnológico Nacional.

Polanco, José Antonio. 1954. "Noticias Guajiras.” Boletín Indigenista Venezolano 2 (2): $55-60$.

Polo Acuña, José. 1999. "Los Wayuu y los Cosina: Dos caras diferentes a una misma moneda en la resistencia indígena en La Guajira, Siglo XVIII." Anuario Colombiano De Historia Social Y De La Cultura 26: 7-29.

Polo Acuña, José. 1998. "Aspectos Históricos de Riohacha Durante el Periodo Colonial.” Historia Caribe II (3): 33-49.

Polo Acuña, José. 2005. Etnicidad, Conflicto Social y Cultura Fronteriza en La Guajira (1700-1850). Universidad de los Andes, Facultad de Ciencias Sociales-Ceso; Observatorio del Caribe Colombiano; Ministerio de Cultura.

Posey, Darrell Addison, ed. 1999. Cultural and Spiritual Values of Biodiversity. Environment Programme United Nations. London: Intermediate Technology.

Povinelli, Elizabeth A. 2001. "Radical Worlds: The anthropology of incommensurability and inconceivability." Annual Review of Anthropology 30 (1): 319-334.

Povinelli, Elizabeth A. 2011. "Routes/Worlds.” E-flux Journal \#27 September.

Povinelli, Elizabeth A. 2016. Geontologies: A requiem to late liberalism. Durham: Duke University Press.

Prasser, Scott. 2007. "5. Overcoming the 'White Elephant' Syndrome in Big and Iconic Projects in the Public and Private Sectors." In Improving Implementation and Project Management. 47-67, Australian National University e-Press. http://epress.anu.edu.au/anzsog/imp/pdf/ch05.pdf

Pred, Allan Richard. 2004. The Past is Not Dead: Facts, fictions, and enduring racial stereotypes. Minneapolis: University of Minnesota Press.

Rajabu, K. R. M. 2005. "The Role of Participatory Problem Analysis in Performance Improvement and Sustainable Management of Rainwater Harvesting (RWH) Systems: A case study of Makanya village, Tanzania." Physics and Chemistry of the Earth 30 (11-16): 832-839.

Rappaport, Joanne. 2005. Intercultural Utopias: Public intellectuals, cultural experimentation, and ethnic pluralism in Colombia. Durham, N.C: Duke University Press. 
Redacción El Heraldo. 2014. "El de La Guajira Ha Sido un Abandono Histórico del Estado": Jorge Armando Otálora. El Heraldo, December 11, 2014, La Guajira. https://www.elheraldo.co/la-guajira/el-de-la-guajira-ha-sido-un-abandono-historicodel-estado-jorge-armando-otalora-177080.

Redacción La Guajira Hoy.com. 2020. "Guajira Azul invertirá 93 mil millones de pesos en agua potable y saneamiento básico." La Guajira Hoy, February 1, 2020, Departamento. https://laguajirahoy.com/2020/02/guajira-azul-invertira-93-milmillones-de-pesos-en-agua-potable-y-saneamiento-basico.html.

Reichel-Dolmatoff, Gerardo. 1951. Datos Histórico-Culturales sobre las Tribus de La Antigua Gobernación de Santa Marta. Bogotá: Banco de la República.

Reichel-Dolmatoff, Gerardo, and Alicia Dussán de Reichel-Dolmatoff. 1951. "Investigaciones Arqueológicas en el Departamento del Magdalena, Colombia 19461950." Boletín De Arqueología 3 (1-6).

República de Colombia 1991. Constitución Política de Colombia.

Rodgers, W. A., and K. M. Homewood. 1986. Cattle Dynamics in a Pastoralist Community in Ngorongoro, Tanzania, During the 1982-3 Drought." Agricultural Systems 22 (1): 33-51.

Riasco Yepes, Arnold Enrique, and Juán Guillermo Uriana. 2015. Plan Integral de Vida Comunidad Indígena Wayuu de Mayapo. Asociación Chevron-Ecopetrol, USAID, ASDI/VOCA, Promigas.

Roa-Garcia, Maria Cecilia, Patricia Urteaga-Crovetto, and Rocio Bustamante-Zenteno. 2015. "Water Laws in the Andes: A promising precedent for challenging neoliberalism." Geoforum 64: 270-280.

Robbins, Paul. 1998. "Authority and Environment: Institutional landscapes in Rajasthan, India. Annals of the Association of American Geographers 88 (3): 410-435.

Robbins, Paul. 2012. Political Ecology: A critical introduction. 2nd ed. Chichester, U.K.; Malden, Mass: J. Wiley \& Sons.

Robbins, Richard H. 2014. Global Problems and the Culture of Capitalism. 6th ed. Upper Saddle River, NJ: Pearson.

Rota, Antonio, and Silvia Sperandini. 2009. Livestock Thematic Papers: Tools for project design: Livestock and pastoralists. Rome: International Fund for Agricultural Development. 
Ruel, Malcolm. 2000. "The Kuria Homestead in Space and Time." Journal of Religion in Africa 30 (1): 62-85.

Saldaña, Johnny. 2013. The Coding Manual for Qualitative Researchers. 2nd ed. Los Angeles: SAGE.

Saler, Benson. 1986. "Los Wayu (Guajiro)" In Aborígenes de Venezuela., ed. Walter Coopens, 25-145. Caracas: Fundación La Salle de Ciencias Naturales, Instituto Caribe de Antropología y Sociología.

Salzman, James. 2006. "Thirst: A short history of drinking water." Yale Journal of Law \& the Humanities 18 (January): 94-121.

Sample, Ian. 2005. “The Father of Climate Change.” The Guardian, June 30, 2005, Environment.

https://www.theguardian.com/environment/2005/jun/30/climatechange. climatechangeenvironment 2

Santos, Boaventura de Sousa. 2011. "Epistemologías del Sur." Utopía Y Praxis Latinoamericana (54): 17-40.

Santos, Boaventura de Sousa. 2018. The End of the Cognitive Empire: The coming of age of epistemologies of the South. Durham: Duke University Press.

Sayer, R. A. 1992. Method in Social Science: A realist approach. 2nd ed. London; New York: Routledge.

Sayre, Nathan Freeman. 2017. The Politics of Scale: A history of rangeland science. Chicago: The University of Chicago Press.

Schwartz, Steven. "Aeolian Reconstructions: Wind Energy and Post-Extractive Futures in the Colombian Guajira." Paper presented at the Biannual Meeting of the Society for Latin American and Caribbean Anthropology, Santo Domingo, Dominican Republic, April 11-13, 2019.

Scott, C. A., F. J. Meza, R. G. Varady, H. Tiessen, J. McEvoy, G. M. Garfin, M. Wilder, L. M. Farfan, N. Pineda Pablos, and E. Montaña. 2013. "Water Security and Adaptive Management in the Arid Americas." Annals of the Association of American Geographers 103 (2): 280-289.

Scott, James C. 1998. Seeing Like a State: How certain schemes to improve the human condition have failed. New Haven: Yale University Press.

Scupin, Raymond. 2012. Cultural Anthropology: A global perspective. 8th ed. Upper Saddle River, N.J: Pearson/Prentice Hall. 
Semana Sostenible. 2019. "Energía Eólica: Un tema de alto voltaje para los Wayú." Semana Sostenible, October 21, 2019, Impacto.

https://sostenibilidad.semana.com/impacto/articulo/energia-eolica-un-tema-de-altovoltaje-para-los-wayu/47189

Sendalo, D. S. C. 2009. A Review of Land Tenure Policy Implications on Pastoralism in Tanzania. Dar es Salaam: Department of Livestock Research, Training and Extension; Ministry of Livestock Development and Fisheries.

Sherzer, Joel, and Greg Urban. 1991. Nation-States and Indians in Latin America. 1st ed. Austin: University of Texas Press.

Sillitoe, Paul. 2007. Local Science vs. Global Science: Approaches to Indigenous knowledge in international development. New York: Berghahn Books.

Simanca Pushaina, Estercilía. 2005. Manifiesta No Saber Firmar: Nacido 31 de diciembre. Editorial Antillas, Fondo mixto para la promoción de la cultura y las artes de La Guajira.

Simmons, Ellen, ed. 2013. Indigenous Earth: Praxis and transformation. Penticton, BC: Theytus Books.

Simmons, F. A. A. 1885. "An Exploration of the Goajiro Peninsula." Proceedings of the Royal Geographic Society of London 7: 781-796.

Siosi, Vicenta. 1992. "Esa Horrible Manera de Separarme de Ti." Woummainpa No 1. Gobernación de La Guajira.

Smith, Linda Tuhiwai. 2012. Decolonizing Methodologies: Research and Indigenous peoples. 2nd ed. London; New York: Zed Books: Distributed in the USA exclusively by Palgrave Macmillan.

Sneddon, Christopher. 2013. "Water, Governance and Hegemony." In Contemporary Water Governance in the Global South: Scarcity, marketization and participation, eds. Leila M. Harris, Jacqueline A. Goldin and Christopher Sneddon, 13-24. Abingdon, Oxon; New York, NY: Routledge.

Sokile, Charles S. 2004. "Local Water Rights and Local Water User Entities: The unsung heroines of water resource management in Tanzania." Physics and Chemistry of the Earth.Parts A/B/C 29 (15-18): 1349-1356.

Sowell, John. 2001. Desert Ecology: An introduction to life in the arid Southwest. Salt Lake City: University of Utah Press. 
St. Martin, K. 2006. “The Impact of 'Community' on Fisheries Management in the US Northeast.” Geoforum 37: 169-184.

Stein, C. 2011. "A Social Network Approach to Analyzing Water Governance: The case of the Mkindo catchment, Tanzania." Physics and Chemistry of the Earth.Parts $A / B / C 36$ (14-15): 1085-1092.

Stenning, Derrick J. 1959. Savannah Nomads: A study of the Wodaabe pastoral Fulani of Western Bornu province, Northern region, Nigeria. London: Published for the International African Institute by Oxford University Press.

Steward, Julian Haynes. 1963. Handbook of South American Indians, eds. Smithsonian Institution Bureau of American Ethnology Annual Report, United States Interdepartmental Committee on Scientific and Cultural Cooperation. New York: Cooper Square Publishers.

Stockholm International Water Institute. 2016. Issue Sheet: Water governance. UNDP Water Governance Facility.

Strauch, Ayron M., and Astier M. Almedom. 2011. "Traditional Water Resource Management and Water Quality in Rural Tanzania." Human Ecology 39 (1): 93-106.

Sultana, Farhana. 2013. "Water, Technology, and Development: Transformations of development technonatures in changing waterscapes." Environment and Planning D: Society \& Space 31 (2): 337-353.

Sutton, Mark Q., and Eugene N. Anderson. 2010. Introduction to Cultural Ecology. Vol. 2nd ed. Lanham, Md: AltaMira Press.

Swyngedouw, Erik. 2004. Social Power and the Urbanization of Water: Flows of power. Oxford; New York: Oxford University Press.

Swyngedouw, Erik. 2009. "The Political Economy and Political Ecology of the HydroSocial Cycle." Journal of Contemporary Water Research \& Education 142: 65-60.

Tauli-Corpuz, Victoria et. al. 2010. State of the World's Indigenous Peoples. United Nations Department of Public Information: Secretariat of the United Nations Permanent Forum on Indigenous Issues.

Thompson, M., and K. Homewood. 2002. "Entrepreneurs, Elites, and Exclusion in Maasailand: Trends in wildlife conservation and pastoralist development." Human Ecology 30 (1): 107-38. 
Tucker, Bram. 2013. "Cultural Ecology." In Theory in Social and Cultural Anthropology: An Encyclopedia, Vol. 1, edited by R. Jon McGee and Richard L. Warms, 142-147. Thousand Oaks, CA: SAGE.

Turner, Terence. 1995. “An Indigenous People's Struggle for Socially Equitable and Ecologically Sustainable Production: The Kayapo revolt against extractivism.” Journal of Latin American Anthropology 1 (1): 98-121.

Tylor, Edward Burnett. 1871. Primitive Culture: Researches into the development of mythology, philosophy, religion, art, and custom. 3rd ed. London: John Murray.

UN Periódico Digital. 2019. “El Cercado, ¿Nuevo Elefante Blanco en La Guajira?” August 21, 2019, Medio Ambiente. https://unperiodico.unal.edu.co/pages/detail/elcercado-nuevo-elefante-blanco-en-la-guajira/.

Unión Temporal Atlas. 2011. Atlas Ambiental del Departamento de La Guajira. Riohacha: MPX and Corpoguajira.

United Nations. "Sustainable Development Goals.” UN.org. https://www.un.org/sustainabledevelopment/sustainable-development-goals/ (accessed January 29, 2020).

United Nations. 2001. 31st Session of the General Conference. UNESCO Universal Declaration on Cultural Diversity. http://portal.unesco.org/en/ev.phpURL_ID=13179\&URL_DO=DO_TOPIC\&URL_SECTION=201.html

United Nations. 2008. United Nations Declaration on the Right of Indigenous Peoples. https://www.un.org/esa/socdev/unpfii/documents/DRIPS_en.pdf

United Nations. 2018. Sustainable Development Goal 6: Synthesis Report on Water and Sanitation. UN-Water. New York. United Nations Publications.

United Nations. 2019. Special Edition: Progress towards the sustainable development goals. United Nations Economic and Social Council.

https://sustainabledevelopment.un.org/content/documents/24978Report_of_the_SG_ on_SDG_Progress_2019.pdf

United States Dept of Agriculture. 1941. Climate and Man: Yearbook of agriculture. Washington, D.C: U.S. Govt. print. off.

Upton, Caroline. 2014. "The New Politics of Pastoralism: Identity, justice and global activism." Geoforum 54: 207-216.

Useche Melo, Claudia. 2012. Agua y Saneamiento Rural: Oportunidades para la participación comunitaria en Colombia. Banco Interamericano de Desarrollo. 
Van Koppen, Barbara, Tarimo, Andrew K. P. R., Aurelia van Eeden, Emmanuel Manzungu, and Philip Mathew Sumuni. 2016. "Winners and Losers of IWRM in Tanzania." Water Alternatives 9 (3): 588-607.

Van Maanen, John. 2011. Tales of the Field: On writing ethnography. 2nd ed. Chicago; London: University of Chicago Press.

Vásquez Cardozo, Socorro, and Hernán Darío Correa C. 1993. "Los Wayuu, Entre Juyá ("El que Llueve"), Mma ("la Tierra") y el Desarrollo Urbano Regional.” In Geografía Humana de Colombia, Nordeste Indígena Tomo II: Sierra Nevada de Santa Marta y las tierras adyacentes, los Wayuu, los Yuko-Yukpa, los Bari., ed. Carlos Alberto Uribe Tobón, 215-288. Santafé de Bogotá: Instituto Colombiano de Cultura Hispánica.

Vayda, Andrew P., and Bradley B. Walters. 1999. "Against Political Ecology." Human Ecology 27 (1): 167-179.

Vergara, Otto. 1990. “Los Wayuu, Hombres del Desierto.” In La Guajira de la Memoria al Porvenir: Una visión antropológica., ed. Gerardo Ardila, 139-161. Fondo FEN Colombia, Universidad Nacional de Colombia.

Vidal Parra, Sergi. 2019. "The Water Rights-Based Legal Mobilization of the Wayúu against the Cercado Dam: An Effective Avenue for Court-Centered Lawfare from Below?" Antípoda. Revista de Antropología y Arqueología 34: 45-68. https://doi.org/10.7440/antipoda34.2019. 03

Viveiros de Castro, Eduardo. 2004. "Perspectival Anthropology and the Method of Controlled Equivocation." Tipití: Journal of the Society for the Anthropology of Lowland South America 2 (1). http://digitalcommons.trinity.edu/tipiti/vol2/iss1/1

Wallerstein, Immanuel Maurice. 2004. World-Systems Analysis: An introduction. Durham: Duke University Press.

Walsh, Martin. 2012. "The Not-So-Great Ruaha and Hidden Histories of an Environmental Panic in Tanzania." Journal of Eastern African Studies 6 (2): 303335.

Warren, Jonathan W. 2001. Racial Revolutions: Antiracism and Indian resurgence in Brazil. Durham, NC: Duke University Press.

Watson, Lawrence Craig. 1968a. "The Inheritance of Livestock in Guajiro Society." Revista Antropológica 23: 3-17.

Watson, Lawrence Craig. 1968b. Guajiro Personality and Urbanization. Los Angeles: Latin American Center, University of California. 
Watson, Lawrence Craig. 1972. "Sexual Socialization in Guajiro Society." Ethnology 11 (2): $150-156$.

Watson-Franke, Maria Barbara. 1983. Now You are a Woman = Ahora eres una Mujer. Mexico, D.F: Ediciones Euroamericanas.

Watson-Franke, Maria Barbara. 1987. "Women and Property in Guajiro Society." Ethnos 52 (1): 229-245.

Waughray, Dominic. 2011. Water Security: The water-food-energy-climate nexus: The world economic forum water initiative. Washington, D.C: Island Press.

Weber, Max. 1958. The Protestant Ethic and the Spirit of Capitalism. Student's ed. New York: Scribner.

Weisiger, Marsha L. 2009. Dreaming of Sheep in Navajo Country. Seattle: University of Washington Press.

West, Paige. 2006. Conservation is Our Government Now: The politics of ecology in Papua New

Guinea. Durham: Duke University Press.

West, Paige. 2016. Dispossession and the Environment: Rhetoric and inequality in Papua New Guinea. New York: Columbia University Press.

Western, David, and Virginia Finch. 1986. "Cattle and Pastoralism: Survival and production in arid lands." Human Ecology 14 (1): 77-94.

Wiedman, Dennis. 1986. Ethnohistory: A Researcher's Guide. Williamsburg, VA: Dept. of Anthropology, College of William and Mary.

Wiedman, Dennis. 2010. "Globalizing the Chronicities of Modernity: Diabetes and the metabolic syndrome.” In Chronic Conditions, Fluid States., eds. Manderson, Lenore, Carolyn Smith-Moriss, 38-53. Rutgers University Press.

Wiedman, Dennis. 2012. "Native American Embodiment of the Chronicities of Modernity: Reservation Food, Diabetes and the Metabolic Syndrome among the Kiowa, Comanche and Apache." Medical Anthropology Quarterly 26(4):595-612.

Wilbert, Johannes. 1972. Survivors of El Dorado: Four Indian cultures of South America. New York: Praeger Publishers.

Wilbert, Johannes. 1976. "Kinsmen of Flesh and of Blood: A comment on possible socioeconomic Africanisms in Goajiro Indian culture." Afro-American Ethnohistory in Latin America and the Caribbean 1: 58-66. 
Wildcat, Daniel R. 2009. Red Alert! Saving the planet with Indigenous knowledge. Golden, CO: Fulcrum.

World Bank. 1992. AFTEN Working Paper No. 4: Integrated natural resource management. Environmental Division, Africa Technical Department, The World Bank.

World Bank. 2015. CO APL1: La Guajira water \& sanitation infrastructure and service management project (P096965). The World Bank.

World Bank. 2017a. Restructuring Paper: On a proposed project restructuring of the La Guajira water and sanitation infrastructure and service management project. The World Bank.

World Bank. 2017b. ¿Caminarías cinco horas para conseguir agua? Estos colombianos lo hacían casi a diario. September 26, 2017, Article.

https://www.bancomundial.org/es/news/feature/2017/09/26/caminarias-cinco-horaspara-conseguir-agua-estos-colombianos-lo-hacian-casi-a-diario

World Bank. 2018. La Guajira water \& sanitation infrastructure and service management project (P096965) (public disclosure copy). The World Bank.

World Bank. 2019. Improving Water Supply and Sanitation Services in La Guajira, Colombia. April 23, 2019, Results brief. https://www.worldbank.org/en/results/2019/04/23/improving-water-supply-andsanitation-services-in-la-guajira-colombia.

World Commission on Environment and Development. 1987. Our Common Future. Oxford: Oxford University Press.

World Health Organization. 1999. Toxic Cyanobacteria in Water: A guide to their public health consequences, monitoring and management, eds. Ingrid Chorus, Jamie Bartram. London; New York: E \& FN Spon.

Wurzinger, M., D. Ndumu, A. M. Okeyo, and J. Soelkner. 2008. "Lifestyle and Herding Practices of Bahima Pastoralists in Uganda." African Journal of Agricultural Research 3 (8): 542-548.

WWC. 2015. Bringing Water to Global Sustainability: World Water Council activities: 2014 annual report. Marseille, France: World Water Council.

Yates, Julian S., Leila M. Harris, and Nicole J. Wilson. 2017. "Multiple Ontologies of Water: Politics, conflict and implications for governance." Environment and Planning D: Society \& Space 35 (5): 797-815. 


\section{APPENDICES}

Appendix 1

Codebook Wayuu Hydrosocial Relations

\begin{tabular}{|c|c|}
\hline ALTERITY & Radical cultural difference, incommensurability \\
\hline FOOD SECURITY & Food-related topics not including AGRICULTURE \\
\hline HEALTH-WELLBEING & Health-related topics not including SHAMANISM \\
\hline SHAMANISM & Discussion of shamans and shamanism \\
\hline $\begin{array}{l}\text { INEQUALITY- } \\
\text { DISCRIMINATION }\end{array}$ & Discussion of inequality and discrimination \\
\hline INTERACTIONS & All types of interactions between different human groups \\
\hline $\begin{array}{l}\text { INTERACT-GOV- } \\
\text { PRI }\end{array}$ & $\begin{array}{l}\text { Interactions between government agencies and the private } \\
\text { sector }\end{array}$ \\
\hline $\begin{array}{l}\text { INTERACT- } \\
\text { LOCATIONS }\end{array}$ & Interactions between different communities or locations \\
\hline $\begin{array}{l}\text { INTERACT-NGO- } \\
\text { GOV }\end{array}$ & Interactions between NGOs and government agencies \\
\hline $\begin{array}{l}\text { INTERACT-NGO- } \\
\text { PRI }\end{array}$ & Interactions between NGOs and the private sector \\
\hline $\begin{array}{l}\text { INTERACT- } \\
\text { VENEZUELA }\end{array}$ & $\begin{array}{l}\text { Interactions between Wayuu and Venezuela or } \\
\text { Venezuelans }\end{array}$ \\
\hline $\begin{array}{l}\text { INTERACT- } \\
\text { WAYUU-ALIJUNA }\end{array}$ & Interactions between Wayuu and non-Wayuu (Alijuna) \\
\hline $\begin{array}{l}\text { INTERACT- } \\
\text { WAYUU-GOV }\end{array}$ & Interactions between the Wayuu and government agencies \\
\hline $\begin{array}{l}\text { INTERACT- } \\
\text { WAYUU-NGO }\end{array}$ & Interactions between the Wayuu and NGOs \\
\hline $\begin{array}{l}\text { INTERACT- } \\
\text { WAYUU-PRI }\end{array}$ & Interactions between the Wayuu and the private sector \\
\hline $\begin{array}{l}\text { INTERACT- } \\
\text { WAYUU-TOURIST }\end{array}$ & Interactions between the Wayuu and tourists \\
\hline $\begin{array}{l}\text { INTERACT- } \\
\text { WAYUU-WAYUU }\end{array}$ & Interactions among the Wayuu \\
\hline LIFE PLAN & Discussion of a Life Plan (document) \\
\hline RESILIENCE & $\begin{array}{l}\text { Includes different types of resilience or lack of resilience } \\
\text { (vulnerability) }\end{array}$ \\
\hline $\begin{array}{l}\text { RESILIENCE- } \\
\text { COMMUNITY }\end{array}$ & Resilience of entire community \\
\hline $\begin{array}{l}\text { RESILIENCE- } \\
\text { INDIVIDUAL }\end{array}$ & Resilience of an individual \\
\hline $\begin{array}{l}\text { RESILIENCE- } \\
\text { TRAINING }\end{array}$ & Training on resilience by NGO or government agency \\
\hline $\begin{array}{l}\text { RESILIENCE- } \\
\text { WAYUU }\end{array}$ & Resilience of the Wayuu society \\
\hline
\end{tabular}




\begin{tabular}{|c|c|}
\hline VULNERABILITY & Vulnerability of a person, a community or of the society \\
\hline RIGHTS & Includes different types of rights \\
\hline HUMAN-RIGHTS & Discussion of human rights \\
\hline $\begin{array}{l}\text { RIGHTS- } \\
\text { CONSTITUTIONAL }\end{array}$ & Discussion of constitutional rights \\
\hline $\begin{array}{l}\text { RIGHTS- } \\
\text { CUSTOMARY }\end{array}$ & Discussion of customary rights or Wayuu law \\
\hline $\begin{array}{l}\text { RIGHTS-TO- } \\
\text { WATER }\end{array}$ & Discussion of rights to water \\
\hline WATER-PERMIT & $\begin{array}{l}\text { Discussion of water permits (also formal water rights } \\
\text { given to people or companies) }\end{array}$ \\
\hline WATER COMPARISON & $\begin{array}{l}\text { Discussion comparing water between households, sectors, } \\
\text { communities or from past to present }\end{array}$ \\
\hline WATER SOURCES & Natural and manmade water sources, water services \\
\hline AQUIFER & Aquifer or underground water \\
\hline ARTISANAL WELL & $\begin{array}{l}\text { Locally made, dug well. Also called a casimba in Spanish } \\
\text { or ishi in Wayuunaiki }\end{array}$ \\
\hline DAM & $\begin{array}{l}\text { Refers to large dams, mainly the Cercado Dam in the } \\
\text { Lower Guajira }\end{array}$ \\
\hline $\begin{array}{l}\text { HOUSEHOLD } \\
\text { WATER } \\
\text { TREATMENT }\end{array}$ & $\begin{array}{l}\text { Local water treatment strategies or instruments, filtering, } \\
\text { etc. }\end{array}$ \\
\hline $\begin{array}{l}\text { NEIGHBOR } \\
\text { TREATED WATER }\end{array}$ & Using a neighbour's treated water \\
\hline $\begin{array}{l}\text { NEIGHBOR } \\
\text { UNTREATED } \\
\text { WATER }\end{array}$ & Using a neighbour's untreated water \\
\hline $\begin{array}{l}\text { PIPED TREATED } \\
\text { WATER }\end{array}$ & Discussion of piped treated water \\
\hline $\begin{array}{l}\text { PIPED } \\
\text { UNTREATED } \\
\text { WATER }\end{array}$ & Discussion of piped untreated water \\
\hline POND & $\begin{array}{l}\text { Use or discussion of a pond, pond water. Jagüey in } \\
\text { Spanish, Laa in Wayuunaiki }\end{array}$ \\
\hline RAIN & Discussion of rain, rainwater, rainwater harvesting \\
\hline RESERVOIR & $\begin{array}{l}\text { Larger than ponds, usually made by damming a seasonal } \\
\text { stream, built by engineers }\end{array}$ \\
\hline RIVER & Mainly refers to the Rancheria River \\
\hline $\begin{array}{l}\text { SEASONAL } \\
\text { STREAM }\end{array}$ & Discussion of streams, arroyos, in Spanish. \\
\hline $\begin{array}{l}\text { STORE-BOUGHT } \\
\text { WATER }\end{array}$ & $\begin{array}{l}\text { Discussion of jugs, bottles or bags of water bought in } \\
\text { stores }\end{array}$ \\
\hline $\begin{array}{l}\text { UNTREATED } \\
\text { WATER WELL }\end{array}$ & Drilled wells that provide untreated water \\
\hline
\end{tabular}




\begin{tabular}{|c|c|}
\hline $\begin{array}{l}\text { WATER CISTERN } \\
\text { TRUCK }\end{array}$ & Discussion of water cistern trucks that distribute water \\
\hline $\begin{array}{l}\text { WATER } \\
\text { CONTAINERS }\end{array}$ & $\begin{array}{l}\text { Various types of water containers, large, small, } \\
\text { traditional, modern }\end{array}$ \\
\hline WATER COSTS & Discussion of the cost of water \\
\hline $\begin{array}{l}\text { WATER } \\
\text { TREATMENT } \\
\text { PLANT }\end{array}$ & $\begin{array}{l}\text { Also includes aqueducts, purifying plants and } \\
\text { desalinization plants }\end{array}$ \\
\hline WATER-GOVERNANCE & Practices related to water governance \\
\hline $\begin{array}{l}\text { WATER-GOV- } \\
\text { FORMAL }\end{array}$ & Government or institutional water governance \\
\hline $\begin{array}{l}\text { WATER-GOV- } \\
\text { GLOBAL }\end{array}$ & Water governance by global institutions \\
\hline $\begin{array}{l}\text { WATER-GOV- } \\
\text { INSTITUTIONS }\end{array}$ & $\begin{array}{l}\text { laws, policies, rules, norms and customs by which } \\
\text { resources are governed }\end{array}$ \\
\hline $\begin{array}{l}\text { WATER-GOV- } \\
\text { LOCAL }\end{array}$ & $\begin{array}{l}\text { Water governance by local organizations, leaders and } \\
\text { users }\end{array}$ \\
\hline $\begin{array}{l}\text { WATER-GOV- } \\
\text { NATIONAL }\end{array}$ & Water governance by the national government \\
\hline WATER-GOV-ORG & Organizations that provide water governance services \\
\hline $\begin{array}{l}\text { WATER-GOV- } \\
\text { PRACTICES }\end{array}$ & $\begin{array}{l}\text { Processes and practices by which water is managed and } \\
\text { used by leaders and water users }\end{array}$ \\
\hline WATER-MEANING & $\begin{array}{l}\text { How water is perceived by different societies and } \\
\text { individuals }\end{array}$ \\
\hline WATER-PROBLEM & Issues related to the water problem in Wayuu territory \\
\hline $\begin{array}{l}\text { WATER- } \\
\text { PROBLEM-ACCESS }\end{array}$ & Accessibility to a water source \\
\hline $\begin{array}{l}\text { WATER- } \\
\text { PROBLEM- } \\
\text { CORRUPTION }\end{array}$ & Corruption related to water governance \\
\hline $\begin{array}{l}\text { WATER- } \\
\text { PROBLEM- } \\
\text { CULTURAL }\end{array}$ & Cultural beliefs or practices that affect water governance \\
\hline $\begin{array}{l}\text { WATER- } \\
\text { PROBLEM- } \\
\text { DEPENDENCY }\end{array}$ & $\begin{array}{l}\text { Becoming too dependent on external help for water } \\
\text { provision }\end{array}$ \\
\hline $\begin{array}{l}\text { WATER- } \\
\text { PROBLEM- } \\
\text { DISTRIBUTION }\end{array}$ & Water distribution problems \\
\hline $\begin{array}{l}\text { WATER- } \\
\text { PROBLEM- } \\
\text { DROUGHT }\end{array}$ & $\begin{array}{l}\text { Discussion of droughts, dry spells, insufficient rain, } \\
\text { aridity }\end{array}$ \\
\hline
\end{tabular}




\begin{tabular}{|c|c|}
\hline $\begin{array}{l}\text { WATER- } \\
\text { PROBLEM- } \\
\text { EDUCATIONAL }\end{array}$ & $\begin{array}{l}\text { Problems related to water use norm infringements } \\
\text { because of ignorance or disrespect }\end{array}$ \\
\hline $\begin{array}{l}\text { WATER- } \\
\text { PROBLEM- } \\
\text { ENVIRONMENT }\end{array}$ & Water problems because of environmental factors \\
\hline $\begin{array}{l}\text { WATER- } \\
\text { PROBLEM- } \\
\text { INSTITUTIONAL }\end{array}$ & $\begin{array}{l}\text { Bureaucratic factors or incompetence by formal } \\
\text { institutions, not CORRUPTION }\end{array}$ \\
\hline $\begin{array}{l}\text { WATER- } \\
\text { PROBLEM- } \\
\text { QUALITY }\end{array}$ & Problems relating to water quality \\
\hline $\begin{array}{l}\text { WATER- } \\
\text { PROBLEM- } \\
\text { QUANTITY }\end{array}$ & Problems relating to water quantity \\
\hline $\begin{array}{l}\text { WATER- } \\
\text { PROBLEM- } \\
\text { SANITATION }\end{array}$ & Problems relating to water contamination \\
\hline $\begin{array}{l}\text { WATER- } \\
\text { PROBLEM- } \\
\text { SUSTAINABILITY }\end{array}$ & Problems related to water sustainability \\
\hline WATER-USES & The various water uses \\
\hline $\begin{array}{l}\text { WATER-USE- } \\
\text { AGRICULTURE }\end{array}$ & For agricultural purposes \\
\hline $\begin{array}{l}\text { WATER-USE- } \\
\text { DOMESTIC }\end{array}$ & For domestic purposes \\
\hline $\begin{array}{l}\text { WATER-USE- } \\
\text { ECONOMIC }\end{array}$ & For economic purposes, the sale of water \\
\hline $\begin{array}{l}\text { WATER-USE- } \\
\text { INDUSTRIAL }\end{array}$ & For industrial purposes \\
\hline $\begin{array}{l}\text { WATER-USE- } \\
\text { PASTORALISM }\end{array}$ & Water consumed by livestock \\
\hline $\begin{array}{l}\text { WATER-USE- } \\
\text { RECREATIONAL }\end{array}$ & For recreational purposes \\
\hline $\begin{array}{l}\text { WATER-USE- } \\
\text { SPIRITUAL }\end{array}$ & For spiritual purposes \\
\hline WAYUU-CULTURE & Topics relating to Wayuu culture and society \\
\hline $\begin{array}{l}\text { ECONOMIC } \\
\text { ACTIVITIES }\end{array}$ & $\begin{array}{l}\text { Includes all economic activities, livelihoods subsistence } \\
\text { practices }\end{array}$ \\
\hline AGRICULTURE & Farming \\
\hline ARTS-CRAFTS & Weaving and other arts and crafts \\
\hline COMMERCE & Activities related to commerce, business, markets \\
\hline FISHING & Coastal, small-scale fishing \\
\hline
\end{tabular}




\begin{tabular}{|c|c|}
\hline $\begin{array}{l}\text { OTHER } \\
\text { ECONOMIC } \\
\text { ACTIVITY }\end{array}$ & Any other economic activity \\
\hline PASTORALISM & Livestock herding \\
\hline TOURISM & Related to tourism, not ARTS-CRAFTS \\
\hline WAGE-LABOR & Wage labour jobs \\
\hline EDUCATION & Discussion of formal education \\
\hline $\begin{array}{l}\text { WAYUU } \\
\text { TRADITIONS }\end{array}$ & Discussion of Wayuu traditions \\
\hline WAYUU-BELIEFS & $\begin{array}{l}\text { Discussion of Wayuu beliefs, cosmology, mythology, } \\
\text { cultural heroes }\end{array}$ \\
\hline WAYUU-HISTORY & Discussion of local or general Wayuu history \\
\hline $\begin{array}{l}\text { WAYUU- } \\
\text { LEADERSHIP }\end{array}$ & Discussion of Wayuu leadership and leaders \\
\hline $\begin{array}{l}\text { WAYUU-SOCIAL- } \\
\text { ORG }\end{array}$ & Wayuu social organization \\
\hline CLAN & Wayuu matrilineal clans \\
\hline HOUSEHOLD & Households \\
\hline SECTOR & Sectors of the town or community \\
\hline WAYUU-TEK & Wayuu traditional ecological knowledge \\
\hline $\begin{array}{l}\text { WAYUU- } \\
\text { TERRITORY }\end{array}$ & Wayuu territory \\
\hline
\end{tabular}


Appendix 2

Anonymous Data Sheet - Community of Mayapo

\begin{tabular}{|c|c|c|c|c|c|c|}
\hline Household & Clan & Sex & Age Group & $\begin{array}{c}\text { Household } \\
\text { count }\end{array}$ & Occupation & Occupation 2 \\
\hline 1 & Epinayu & Female & $15-30$ & 5 & Homemaker & Unassigned \\
\hline 2 & Sijona & Female & $51-70$ & 12 & Weaver & Unassigned \\
\hline 3 & Sijona & Female & $51-70$ & 5 & Weaver & Unassigned \\
\hline 4 & Sijona & Female & $51-70$ & 4 & Weaver & Unassigned \\
\hline 5 & Alijuna & Male & $51-70$ & 9 & Fisherman & Waiter \\
\hline 6 & Wouriyu & Male & $31-50$ & 6 & Fisherman & Herder \\
\hline 7 & Apushana & Female & $51-70$ & 4 & Teacher & Restaurant owner \\
\hline 8 & Epieyu & Female & $51-70$ & 3 & Weaver & Unassigned \\
\hline 9 & Sijona & Female & 71 and older & 6 & Weaver & Unassigned \\
\hline 10 & Epinayu & Male & $31-50$ & 5 & Fisherman & Farmer \\
\hline 11 & Wouriyu & Female & $51-70$ & 2 & Weaver & Unassigned \\
\hline 12 & Apushana & Male & $31-50$ & 4 & Security guard & Unassigned \\
\hline 13 & Sijona & Male & $51-70$ & 10 & Fisherman & Farmer \\
\hline 14 & Epieyu & Female & $51-70$ & 12 & Weaver & Unassigned \\
\hline 15 & Epinayu & Female & 71 and older & 3 & Weaver & Unassigned \\
\hline 16 & Ipuana & Male & 71 and older & 3 & $\begin{array}{l}\text { Indigenous } \\
\text { representative }\end{array}$ & Herder \\
\hline 17 & Epieyu & Female & $31-50$ & 7 & Homemaker & Unassigned \\
\hline 18 & Epinayu & Female & $31-50$ & 4 & Weaver & Unassigned \\
\hline 19 & Sijona & Male & $31-50$ & 5 & AUNAP & Unassigned \\
\hline 20 & Epieyu & Female & 71 and older & 5 & Weaver & Unassigned \\
\hline 21 & Epinayu & Female & $31-50$ & 7 & Weaver & Unassigned \\
\hline 22 & Sijona & Female & $51-70$ & 6 & Weaver & Unassigned \\
\hline 23 & Epieyu & Female & $31-50$ & 10 & Homemaker & Unassigned \\
\hline 24 & Jusayu & Female & 71 and older & 4 & Weaver & Unassigned \\
\hline 25 & Wouriyu & Male & $51-70$ & 2 & Fisherman & Farmer \\
\hline 26 & Uliana & Male & $31-50$ & 5 & $\begin{array}{l}\text { Fishing committee } \\
\text { president }\end{array}$ & Unassigned \\
\hline 27 & Epinayu & Male & $31-50$ & 6 & Fisherman & Unassigned \\
\hline 28 & Uliana & Male & 71 and older & 2 & Elder & Farmer \\
\hline 29 & Epieyu & Male & $31-50$ & 4 & Fisherman & Unassigned \\
\hline 30 & Epinayu & Female & $31-50$ & 6 & Weaver & Unassigned \\
\hline 31 & Wouriyu & Female & $15-30$ & 4 & Homemaker & Weaver \\
\hline 32 & Epinayu & Male & $31-50$ & 7 & Fisherman & Unassigned \\
\hline 33 & Wouriyu & Female & $15-30$ & 8 & Weaver & Unassigned \\
\hline 34 & Epieyu & Male & $51-70$ & 11 & Fisherman & Farmer \\
\hline 35 & Epinayu & Female & $31-50$ & 8 & Weaver & Unassigned \\
\hline 36 & Epieyu & Female & $51-70$ & 9 & Weaver & Unassigned \\
\hline 37 & Apushana & Female & $51-70$ & 14 & Teacher & Leader \\
\hline 38 & Alijuna & Male & $51-70$ & 10 & Security guard & Unassigned \\
\hline 39 & Ipuana & Female & $15-30$ & 4 & Homemaker & Unassigned \\
\hline 40 & Epieyu & Female & $51-70$ & 4 & Weaver & Unassigned \\
\hline 41 & Wouriyu & Female & $31-50$ & 5 & Weaver & Unassigned \\
\hline 42 & Sijona & Female & $31-50$ & 14 & Weaver & Waiter \\
\hline 43 & Epieyu & Female & $51-70$ & 4 & Homemaker & Unassigned \\
\hline
\end{tabular}




\begin{tabular}{|l|l|l|l|l|l|l|}
\hline 44 & Epinayu & Male & $51-70$ & 3 & Construction & Farmer \\
\hline 45 & Epinayu & Female & $31-50$ & 4 & Shaman & Weaver \\
\hline 46 & Epinayu & Female & $51-70$ & 4 & Homemaker & Unassigned \\
\hline 47 & Epinayu & Female & 71 and older & 3 & Healer & Weaver \\
\hline 48 & Epinayu & Male & $51-70$ & 3 & Fisherman & Herder \\
\hline 49 & Mestizo Wayuu & Male & $31-50$ & 3 & Construction & Unassigned \\
\hline 50 & Epinayu & Female & $51-70$ & 6 & Teacher & Weaver \\
\hline 51 & Pushaina & Male & $51-70$ & 7 & Fisherman & Construction \\
\hline 52 & Wouriyu & Female & $31-50$ & 9 & Weaver & Unassigned \\
\hline 53 & Epinayu & Female & $51-70$ & 9 & Weaver & Unassigned \\
\hline 54 & Epinayu & Female & $51-70$ & 4 & Weaver & Leader \\
\hline 55 & Mestizo Wayuu & Female & $15-30$ & 4 & Homemaker & Unassigned \\
\hline 56 & Ipuana & Female & $31-50$ & 4 & Weaver & Homemaker \\
\hline 57 & Mestizo Wayuu & Male & $31-50$ & 4 & Construction & Unassigned \\
\hline 58 & Apushana & Female & $31-50$ & 6 & Teacher & Weaver \\
\hline 59 & Epinayu & Female & $31-50$ & 7 & Weaver & Unassigned \\
\hline 60 & Ipuana & Female & $51-70$ & 7 & Weaver & Farmer \\
\hline
\end{tabular}

\begin{tabular}{|c|c|c|c|c|c|c|c|c|c|}
\hline Household & $\begin{array}{c}\text { Animal } \\
\text { count }\end{array}$ & Farm & $\begin{array}{c}\text { Piped } \\
\text { treated } \\
\text { water }\end{array}$ & $\begin{array}{c}\text { Piped } \\
\text { untreated } \\
\text { water }\end{array}$ & $\begin{array}{l}\text { Dug } \\
\text { well }\end{array}$ & Pond & Rainwater & $\begin{array}{c}\text { Neighbor } \\
\text { treated } \\
\text { water }\end{array}$ & $\begin{array}{c}\text { Neighbor } \\
\text { untreated } \\
\text { water }\end{array}$ \\
\hline 1 & 0 & No & No & Yes & No & No & Yes & Yes & No \\
\hline 2 & $11-50$ & Yes & No & No & Yes & Yes & Yes & No & No \\
\hline 3 & 0 & No & Yes & No & No & No & Yes & No & Yes \\
\hline 4 & $1-10$ & No & No & No & Yes & No & Yes & No & No \\
\hline 5 & 0 & No & No & No & No & No & No & No & No \\
\hline 6 & $1-10$ & Yes & No & Yes & No & Yes & Yes & Yes & No \\
\hline 7 & $11-50$ & No & Yes & Yes & No & No & Yes & No & No \\
\hline 8 & 0 & No & Yes & No & Yes & Yes & Yes & No & Yes \\
\hline 9 & $1-10$ & No & Yes & Yes & No & No & Yes & No & No \\
\hline 10 & $1-10$ & Yes & Yes & No & No & No & Yes & No & No \\
\hline 11 & $1-10$ & Yes & No & Yes & Yes & Yes & Yes & No & No \\
\hline 12 & 0 & No & No & No & No & No & Yes & No & No \\
\hline 13 & $11-50$ & Yes & No & No & No & Yes & Yes & No & No \\
\hline 14 & 0 & No & No & No & No & No & Yes & Yes & No \\
\hline 15 & 0 & Yes & No & No & No & No & Yes & No & Yes \\
\hline 16 & $11-50$ & Yes & Yes & No & No & Yes & Yes & No & No \\
\hline 17 & 0 & No & Yes & No & No & No & Yes & No & No \\
\hline 18 & 0 & Yes & No & No & Yes & Yes & Yes & No & No \\
\hline 19 & $11-50$ & No & No & No & No & Yes & Yes & No & No \\
\hline 20 & 0 & No & Yes & No & No & Yes & Yes & No & No \\
\hline 21 & 0 & No & Yes & No & No & No & No & No & No \\
\hline 22 & 0 & No & Yes & No & No & No & Yes & No & Yes \\
\hline 23 & 0 & No & Yes & No & No & No & Yes & No & No \\
\hline 24 & $1-10$ & Yes & No & Yes & No & No & Yes & Yes & No \\
\hline 25 & $11-50$ & Yes & No & Yes & Yes & Yes & Yes & Yes & No \\
\hline 26 & 0 & No & No & No & No & Yes & Yes & No & No \\
\hline 27 & 0 & No & Yes & No & No & No & Yes & No & No \\
\hline 28 & 0 & Yes & No & No & No & No & No & Yes & No \\
\hline 29 & 0 & No & Yes & Yes & No & No & Yes & No & No \\
\hline
\end{tabular}




\begin{tabular}{|c|c|c|c|c|c|c|c|c|c|}
\hline 30 & 0 & No & Yes & Yes & No & No & Yes & No & No \\
\hline 31 & 0 & No & No & No & No & No & Yes & No & No \\
\hline 32 & $1-10$ & No & No & No & Yes & No & Yes & No & No \\
\hline 33 & 0 & No & No & No & Yes & Yes & Yes & Yes & No \\
\hline 34 & $1-10$ & Yes & Yes & No & No & Yes & Yes & No & No \\
\hline 35 & $1-10$ & No & No & Yes & No & No & Yes & No & No \\
\hline 36 & 0 & No & No & No & No & No & Yes & Yes & Yes \\
\hline 37 & 0 & No & Yes & Yes & No & No & No & No & No \\
\hline 38 & 0 & No & Yes & No & No & No & Yes & No & No \\
\hline 39 & 0 & No & No & Yes & No & No & Yes & Yes & No \\
\hline 40 & 0 & No & Yes & Yes & No & No & Yes & No & No \\
\hline 41 & 0 & No & Yes & No & No & No & Yes & No & No \\
\hline 42 & $11-50$ & No & No & No & No & Yes & Yes & Yes & Yes \\
\hline 43 & $11-50$ & No & No & Yes & No & No & Yes & No & No \\
\hline 44 & 1-10 & Yes & Yes & Yes & No & Yes & Yes & No & No \\
\hline 45 & 0 & No & No & No & No & No & Yes & No & No \\
\hline 46 & $11-50$ & No & No & No & No & No & Yes & No & Yes \\
\hline 47 & $\begin{array}{c}\text { More } \\
\text { than } 50\end{array}$ & Yes & No & Yes & No & Yes & Yes & No & No \\
\hline 48 & $1-10$ & Yes & No & No & No & Yes & Yes & No & No \\
\hline 49 & 0 & No & No & No & No & Yes & Yes & No & Yes \\
\hline 50 & $\begin{array}{l}\text { More } \\
\text { than } 50\end{array}$ & No & No & No & No & No & Yes & No & No \\
\hline 51 & $11-50$ & No & No & No & Yes & Yes & Yes & Yes & No \\
\hline 52 & 0 & No & No & No & No & No & Yes & Yes & Yes \\
\hline 53 & $1-10$ & Yes & No & No & No & Yes & Yes & Yes & Yes \\
\hline 54 & $11-50$ & No & No & No & No & No & Yes & No & No \\
\hline 55 & 0 & No & Yes & No & No & Yes & Yes & No & No \\
\hline 56 & 1-10 & No & No & No & No & No & Yes & No & No \\
\hline 57 & 0 & No & Yes & No & No & Yes & Yes & No & No \\
\hline 58 & $1-10$ & No & No & Yes & No & No & No & No & No \\
\hline 59 & 0 & No & No & No & Yes & Yes & Yes & Yes & No \\
\hline 60 & $11-50$ & Yes & No & No & Yes & Yes & Yes & No & Yes \\
\hline
\end{tabular}

\begin{tabular}{|c|c|c|c|c|c|c|c|}
\hline Household & $\begin{array}{c}\text { Treated } \\
\text { water } \\
\text { tank }\end{array}$ & $\begin{array}{c}\text { Untreated } \\
\text { water } \\
\text { tank }\end{array}$ & $\begin{array}{c}\text { Water } \\
\text { cistern } \\
\text { truck }\end{array}$ & Wayuunaiki & $\begin{array}{c}\text { Date } \\
\text { Interviewed }\end{array}$ & Latitude & Longitude \\
\hline 1 & No & No & Yes & Yes & 9/11/2018 & $11^{\circ} \mathrm{XX}$ XX.XX"N & $72^{\circ} \mathrm{XX} \mathrm{X}^{\prime} \mathrm{XX} . \mathrm{XX} " \mathrm{~W}$ \\
\hline 2 & No & Yes & Yes & Yes & $9 / 27 / 2018$ & $11^{\circ} \mathrm{XX}$ XX.XX"N & $72^{\circ} \mathrm{XX}$ 'XX.XX"W \\
\hline 3 & No & No & Yes & Yes & $9 / 2 / 2018$ & $11^{\circ} \mathrm{XX}$ XX.XX"N & $72^{\circ} \mathrm{XX} \mathrm{X}^{\prime} \mathrm{XX} . \mathrm{XX} " \mathrm{~W}$ \\
\hline 4 & No & No & Yes & Yes & $10 / 2 / 2018$ & $11^{\circ} X X ' X X . X X " N$ & $72^{\circ} X X ' X X . X X " W$ \\
\hline 5 & No & No & Yes & No & $9 / 27 / 2018$ & $11^{\circ} \mathrm{XX}$ XX.XX"N & $72^{\circ} \mathrm{XX} \mathrm{X}^{\prime} \mathrm{XX} . \mathrm{XX} " \mathrm{~W}$ \\
\hline 6 & No & No & Yes & Yes & 9/18/2018 & $11^{\circ} \mathrm{XX}$ XX.XX"N & $72^{\circ} \mathrm{XX} \mathrm{XX}^{\prime} \mathrm{XXX} \mathrm{XX} \mathrm{W}$ \\
\hline 7 & No & No & Yes & No & $10 / 4 / 2018$ & $11^{\circ} X X^{\prime} X X . X X " N$ & $72^{\circ} \mathrm{XX}$ XX.XX"W \\
\hline 8 & No & No & Yes & Yes & $10 / 4 / 2018$ & $11^{\circ} X X ' X X . X X " N$ & $72^{\circ} X X ' X X . X X " W$ \\
\hline 9 & No & No & Yes & Yes & $10 / 1 / 2018$ & $11^{\circ} X X ' X X . X X " N$ & $72^{\circ} X X ' X X . X X " W$ \\
\hline 10 & No & No & Yes & Yes & $9 / 24 / 2018$ & $11^{\circ} \mathrm{XX}$ XX.XX"N & $72^{\circ} \mathrm{XX} \mathrm{XXX}^{\prime} \mathrm{XX}$ "W \\
\hline 11 & No & No & Yes & Yes & $10 / 2 / 2018$ & $11^{\circ} X X^{\prime} X X . X X " N$ & $72^{\circ} \mathrm{XX}$ XX.XX"W \\
\hline 12 & No & No & Yes & No & $9 / 26 / 2018$ & $11^{\circ} X X ' X X . X X " N$ & $72^{\circ} X X ' X X . X X " W$ \\
\hline 13 & No & No & Yes & No & $9 / 26 / 2018$ & $11^{\circ} X X^{\prime} X X . X X " N$ & $72^{\circ} \mathrm{XX}{ }^{\prime} \mathrm{XX} . \mathrm{XX} " \mathrm{~W}$ \\
\hline
\end{tabular}




\begin{tabular}{|c|c|c|c|c|c|c|c|}
\hline 14 & No & Yes & Yes & Yes & $9 / 24 / 2018$ & $11^{\circ} \mathrm{XX}$ 'XX.XX"N & $72^{\circ} X X^{\prime} X X . X X " W$ \\
\hline 15 & No & Yes & Yes & No & 9/6/2018 & $11^{\circ} X X^{\prime} X X . X X " N$ & $72^{\circ} X X^{\prime} X X . X X^{\prime \prime} W$ \\
\hline 16 & No & No & Yes & Yes & $8 / 17 / 2018$ & $11^{\circ} \mathrm{XX}$ 'XX.XX"N & $72^{\circ} X X^{\prime} X X . X X " W$ \\
\hline 17 & No & No & Yes & No & $9 / 6 / 2018$ & $11^{\circ} \mathrm{XX}{ }^{\prime} \mathrm{XX} . \mathrm{XX}$ "N & $72^{\circ} X X^{\prime} X X . X X " W$ \\
\hline 18 & No & Yes & Yes & No & $9 / 24 / 2018$ & $11^{\circ} X X ' X X . X X " N$ & $72^{\circ} X X^{\prime} X X . X X^{\prime \prime} W$ \\
\hline 19 & No & No & Yes & No & $9 / 19 / 2018$ & $11^{\circ} \mathrm{XX}{ }^{\prime} \mathrm{XX} . \mathrm{XX}{ }^{\prime \prime} \mathrm{N}$ & $72^{\circ} X X^{\prime} X X . X X " W$ \\
\hline 20 & No & No & Yes & Yes & $9 / 24 / 2018$ & $11^{\circ} X X ' X X . X X " N$ & $72^{\circ} X X^{\prime} X X . X X^{\prime \prime} W$ \\
\hline 21 & No & No & Yes & Yes & $9 / 24 / 2018$ & $11^{\circ} \mathrm{XX}$ XXXXX"N & $72^{\circ} X X^{\prime} X X . X X " W$ \\
\hline 22 & No & No & Yes & Yes & $9 / 19 / 2018$ & $11^{\circ} X X^{\prime} X X . X X " N$ & $72^{\circ} X X^{\prime} X X . X X^{\prime \prime} W$ \\
\hline 23 & No & Yes & Yes & Yes & $9 / 10 / 2018$ & $11^{\circ} X X^{\prime} X X . X X " N$ & $72^{\circ} X X^{\prime} X X . X X^{\prime \prime} W$ \\
\hline 24 & No & Yes & Yes & Yes & $10 / 3 / 2018$ & $11^{\circ} X X ' X X . X X " N$ & $72^{\circ} X X^{\prime} X X . X X " W$ \\
\hline 25 & No & Yes & Yes & Yes & $11 / 22 / 2018$ & $11^{\circ} X X ' X X . X X " N$ & $72^{\circ} X X^{\prime} X X . X X^{\prime \prime} W$ \\
\hline 26 & No & No & Yes & No & $9 / 4 / 2018$ & $11^{\circ} X X X^{\prime} X X . X X " N$ & $72^{\circ} X X^{\prime} X X . X X^{\prime \prime} W$ \\
\hline 27 & No & No & Yes & No & $9 / 19 / 2018$ & $11^{\circ} X X ' X X . X X " N$ & $72^{\circ} X X^{\prime} X X . X X^{\prime \prime} W$ \\
\hline 28 & No & No & Yes & Yes & $11 / 13 / 2018$ & $11^{\circ} X X X^{\prime} X X . X X " N$ & $72^{\circ} X X^{\prime} X X . X X^{\prime \prime} W$ \\
\hline 29 & No & No & Yes & Yes & $10 / 4 / 2018$ & $11^{\circ} X X ' X X . X X " N$ & $72^{\circ} X X^{\prime} X X . X X^{\prime \prime} W$ \\
\hline 30 & No & No & Yes & Yes & 9/19/2018 & $11^{\circ} X X X^{\prime} X X . X X " N$ & $72^{\circ} X X^{\prime} X X . X X^{\prime \prime} W$ \\
\hline 31 & No & No & Yes & No & $9 / 11 / 2018$ & $11^{\circ} \mathrm{XX} \mathrm{XXX}^{\prime} \mathrm{XX} " \mathrm{~N}$ & $72^{\circ} \mathrm{XX}{ }^{\prime} \mathrm{XX} . \mathrm{XX} \mathrm{X}^{\prime \prime}$ \\
\hline 32 & No & No & Yes & No & $9 / 5 / 2018$ & $11^{\circ} \mathrm{XX}$ XX.XX"N & $72^{\circ} X X^{\prime} X X . X X^{\prime \prime} W$ \\
\hline 33 & No & No & Yes & Yes & $9 / 26 / 2018$ & $11^{\circ} X X ' X X . X X " N$ & $72^{\circ} X X^{\prime} X X . X X^{\prime \prime} W$ \\
\hline 34 & No & No & Yes & Yes & $11 / 13 / 2018$ & $11^{\circ} X X ' X X . X X " N$ & $72^{\circ} X X^{\prime} X X . X X^{\prime \prime} W$ \\
\hline 35 & No & No & Yes & Yes & $10 / 1 / 2018$ & $11^{\circ} X X ' X X . X X " N$ & $72^{\circ} X X^{\prime} X X . X X^{\prime \prime} W$ \\
\hline 36 & No & No & Yes & Yes & $10 / 4 / 2018$ & $11^{\circ} \mathrm{XX} X X . X X^{\prime \prime} \mathrm{N}$ & $72^{\circ} X X^{\prime} X X . X X " W$ \\
\hline 37 & No & No & Yes & No & $10 / 3 / 2018$ & $11^{\circ} X X X^{\prime} X X . X X " N$ & $72^{\circ} X X^{\prime} X X . X X^{\prime \prime} W$ \\
\hline 38 & No & No & Yes & No & $9 / 11 / 2018$ & $11^{\circ} X X ' X X . X X " N$ & $72^{\circ} X X^{\prime} X X . X X^{\prime \prime} W$ \\
\hline 39 & No & Yes & Yes & No & $9 / 11 / 2018$ & $11^{\circ} X X ' X X . X X " N$ & $72^{\circ} X X^{\prime} X X . X X " W$ \\
\hline 40 & No & No & Yes & Yes & $9 / 11 / 2018$ & $11^{\circ} X X ' X X . X X " N$ & $72^{\circ} X X^{\prime} X X . X X^{\prime \prime} W$ \\
\hline 41 & No & No & Yes & Yes & $9 / 10 / 2018$ & $11^{\circ} X X ' X X . X X " N$ & $72^{\circ} X X^{\prime} X X . X X " W$ \\
\hline 42 & No & Yes & Yes & Yes & $10 / 1 / 2018$ & $11^{\circ} X X ' X X . X X " N$ & $72^{\circ} X X^{\prime} X X . X X^{\prime \prime} W$ \\
\hline 43 & No & Yes & No & Yes & $10 / 3 / 2018$ & $11^{\circ} X X ' X X . X X " N$ & $72^{\circ} X X^{\prime} X X . X X " W$ \\
\hline 44 & No & Yes & Yes & No & $11 / 29 / 2018$ & $11^{\circ} X X ' X X . X X " N$ & $72^{\circ} X X^{\prime} X X . X X^{\prime \prime} W$ \\
\hline 45 & Yes & No & Yes & Yes & $9 / 24 / 2018$ & $11^{\circ} X X ' X X . X X " N$ & $72^{\circ} X X^{\prime} X X . X X " W$ \\
\hline 46 & No & No & Yes & No & $9 / 9 / 2018$ & $11^{\circ} X X ' X X . X X " N$ & $72^{\circ} X X^{\prime} X X . X X^{\prime \prime} W$ \\
\hline 47 & No & No & Yes & Yes & $9 / 24 / 2018$ & $11^{\circ} X X ' X X . X X " N$ & $72^{\circ} X X^{\prime} X X . X X^{\prime \prime} W$ \\
\hline 48 & No & No & Yes & Yes & $11 / 20 / 2018$ & $11^{\circ} \mathrm{XX} \mathrm{XXX}^{\prime} \mathrm{XX} " \mathrm{~N}$ & $72^{\circ} \mathrm{XX}{ }^{\prime} \mathrm{XX} . \mathrm{XX} \mathrm{X}^{\prime \prime}$ \\
\hline 49 & No & Yes & Yes & No & $11 / 15 / 2018$ & $11^{\circ} \mathrm{XX}$ XX.XX"N & $72^{\circ} X X^{\prime} X X . X X^{\prime \prime} W$ \\
\hline 50 & No & No & Yes & No & $9 / 6 / 2018$ & $11^{\circ} X X ' X X . X X " N$ & $72^{\circ} X X^{\prime} X X . X X^{\prime \prime} W$ \\
\hline 51 & Yes & Yes & Yes & Yes & $9 / 16 / 2018$ & $11^{\circ} X X ' X X . X X " N$ & $72^{\circ} X X^{\prime} X X . X X " W$ \\
\hline 52 & No & Yes & Yes & Yes & $9 / 27 / 2018$ & $11^{\circ} X X ' X X . X X " N$ & $72^{\circ} X X^{\prime} X X . X X^{\prime \prime} W$ \\
\hline 53 & No & Yes & Yes & Yes & $9 / 27 / 2018$ & $11^{\circ} X X ' X X . X X " N$ & $72^{\circ} X X^{\prime} X X . X X^{\prime \prime} W$ \\
\hline 54 & No & Yes & Yes & No & $11 / 29 / 2018$ & $11^{\circ} X X ' X X . X X " N$ & $72^{\circ} X X^{\prime} X X . X X^{\prime \prime} W$ \\
\hline 55 & Yes & No & No & No & $10 / 17 / 2018$ & $11^{\circ} X X ' X X . X X " N$ & $72^{\circ} X X^{\prime} X X . X X " W$ \\
\hline 56 & No & Yes & Yes & No & $9 / 5 / 2018$ & $11^{\circ} X X ' X X . X X " N$ & $72^{\circ} X X^{\prime} X X . X X^{\prime \prime} W$ \\
\hline 57 & Yes & No & No & No & $10 / 17 / 2018$ & $11^{\circ} X X ' X X . X X " N$ & $72^{\circ} X X^{\prime} X X . X X^{\prime \prime} W$ \\
\hline 58 & No & No & Yes & No & $10 / 3 / 2018$ & $11^{\circ} X X ' X X . X X " N$ & $72^{\circ} X X^{\prime} X X . X X " W$ \\
\hline 59 & No & No & Yes & No & $11 / 14 / 2018$ & $11^{\circ} X X ' X X . X X " N$ & $72^{\circ} X X^{\prime} X X . X X^{\prime \prime} W$ \\
\hline 60 & No & No & Yes & Yes & $9 / 26 / 2018$ & $11^{\circ} \mathrm{XX} X X X . X X " \mathrm{~N}$ & $72^{\circ} X X ' X X . X X " W$ \\
\hline
\end{tabular}


Appendix 3a

IRB Approval 2015

\title{
INIDERA
}

Office of Research Integrity

Research Compliance, MARC̈ 270

\section{MEMORANDUM}

\author{
To: $\quad$ Dr. Juliet Erazo \\ CC: $\quad$ File \\ From: Maria Melendez-Vargas, MIIBA, IRB Coordinator WV \\ Date: June 9, 2015 \\ Protocol Title: 'David Robles' Field Site and Potential Dissertation Topic Exploration in \\ La Guajira, Colombia"
}

The Florida International University Office of Research Integiity has reviewed your research study for the use of human subjects and deemed it Exempt via the Exempt Review process.

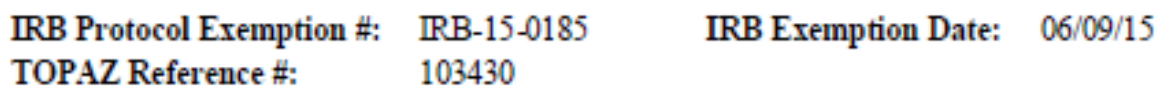

As a requirement of IRB Exemption you are required to:

1) Submit an Event Form and provide immediate notification of:

- Any additions or changes in the procedures involving human subjects.

- Every serious or unusual or unanticipated adverse event as well as problems with the rights or welfare of the human subjects.

2) Submit a Project Completion Report Form when the study is finished or discontinued.

Special Conditions: N/A

For further information, you may visit the $\mathbb{R B}$ website at $\underline{h t t p} / / /$ research.fiu.edu/irb.

MMV/em 
Appendix 3b

IRB Approval 2017

FIU

FLORIDA

INTERNATIONAL

Office of Research Integrity

UNIVERSITY

Research Compliance, MARC 414

\section{MEMORANDUM}

To:

CC:

From:

Date:

Protocol Title: "Indigenous Water Governance and Resilience on the Guajira Peninsula of Northem Colombia"

The Social and Behavioral Institutional Review Board of Florida International University has approved your study for the use of human subjects via the Expedited Review process. Your study was found to be in compliance with this institution's Federal Wide Assurance (00000060).
IRB Protocol Approval \#: $\quad$ RB-17-0034
IRB Approval Date: $\quad 02 / 08 / 17$
TOPAZ Reference \#:
105382
IRB Expiration Date: $02 / 08 / 18$

As a requirement of IRB Approval you are required to:

1) Submit an $\mathbb{R} B$ Amendment Form for all proposed additions or changes in the procedures involving human subjects. All additions and changes must be reviewed and approved by the $\mathbb{R B}$ prior to implementation.

2) Promptly submit an IRB Event Report Form for every serious or unusual or unanticipated adverse event, problems with the rights or welfare of the human subjects, and/or deviations from the approved protocol.

3) Utilize copies of the date stamped consent document(s) for obtaining consent from subjects (unless waived by the $\mathbb{R B}$ ). Signed consent documents must be retained for at least three years after the completion of the study.

4) Receive annual review and re-approval of your study prior to your IRB expiration date. Submit the $\mathbb{R B}$ Renewal Form at least 30 days in advance of the study's expiration date.

5) Submit an $\mathbb{R B}$ Project Completion Report Form when the study is finished or discontinued.

Special N/A

Conditions:

For further information, you may visit the IRB website at http://research.fiu.edu/irb. 
Appendix 3c

IRB Approval 2019

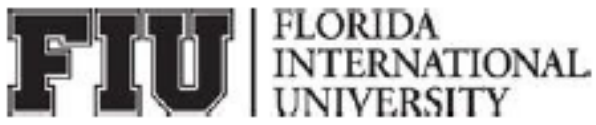

\author{
Office of Research Integrity \\ Research Compliance, MARC 414
}

\title{
MEMORANDUM
}

$\begin{array}{ll}\text { To: } & \text { Dr. Juliet Erazo } \\ \text { CC: } & \text { David Robles } \\ \text { From: } & \text { Maria Melendez-Vargas, MIBA, IRB Coordinator } \\ \text { Date: } & \text { January 23, } 2019 \\ \text { Protocol Title: } & \text { "Indigenous Water Governance and Resilience on the Guajira Peninsula of } \\ & \text { Northem Colombia" }\end{array}$

The Social and Behavioral Institutional Review Board of Florida International University has re-approved your study for the use of human subjects via the Expedited Review process. Your study was found to be in compliance with this institution's Federal Wide Assurance (00000060).

\section{IRB Protocol Approval \#: $\quad$ IRB-17-0034-CR02 IRB Approval Date: 01/22/19 \\ TOPAZ Reference \#: $\quad 105382 \quad$ IRB Expiration Date: $02 / 08 / 22$}

As a requirement of IRB Approval you are required to:

1) Submit an $\mathbb{R B}$ Amendment Form for all proposed additions or changes in the procedures involving human subjects. All additions and changes must be reviewed and approved by the $\mathbb{R} B$ prior to implementation.

2) Promptly submit an IRB Event Report Form for every serious or unusual or unanticipated adverse event, problems with the rights or welfare of the human subjects, and/or deviations from the approved protocol.

3) Utilize copies of the date stamped consent document(s) for obtaining consent from subjects (unless waived by the IRB). Signed consent documents must be retained for at least three years after the completion of the study.

4) Obtain continuing review and re-approval of the study prior to the IRB expiration date. Submit the $\mathbb{R B}$ Renewal Form at least 30 days in advance of the study's expiration date.

5) Submit an $\mathbb{R B}$ Project Completion Report Form when the study is finished or discontinued.

HIPAA Privacy Rule: N/A

Special Conditions: N/A

For further information, you may visit the $\mathbb{R B}$ website at $\underline{\mathrm{http}: / / \text { research.fiu.edu/irb. }}$

$\mathrm{MMV} / \mathrm{em}$ 
VITA

\title{
DAVID ALEXANDER ROBLES
}

\author{
Born, Bogotá, Colombia
}

EDUCATION

$2014-2020$

Ph.D. Candidate, Global and Sociocultural Studies

Florida International University

Miami, Florida

2005-2008

M.A., Cultural Anthropology

University of Kansas

Lawrence, Kansas

$1997-2000$

B.A., Anthropology

University of Kansas

Lawrence, Kansas

\section{PUBLICATIONS AND PRESENTATIONS}

"Non-conventional hydro-social relations, water security and inequality among the Wayuu of the Guajira Peninsula of Northern Colombia." Paper presented at the American Anthropological Association 2019 Annual Meeting, Vancouver, Canada, November 20, 2019.

"Human and other-than-human water relations and inequality among the Wayuu of the Guajira Peninsula." Paper presented at the 8th Annual SAGGSA Graduate Student Conference. Florida International University, Miami. March 1, 2019.

Robles Chávez, David. 2018. "The meaning of water and its governance on Wayuu territory, La Guajira, Colombia" In Diverse approximations towards the coastal and marine territorial ordering of the Department of La Guajira, edited by Grupo de Investigación Territorios Semiáridos del Caribe, pp. 27. Riohacha: University of La Guajira (ISBN 978-958-8942-85-8, in Spanish).

"A socio-ecological approach for the local construction of the coastal and marine territorial ordering in La Guajira," Paper presented at the I International Congress of Human and Social Sciences. Riohacha: University of La Guajira. Riohacha, Colombia (in Spanish). September 15, 2017.

"Pastoralist freshwater governance: Comparing the Wayuu of Colombia and the Kuria of East Africa." Paper presented at the International Congress for Conservation Biology. Cartagena, Colombia. July 26, 2017. 